\title{
JV TASK 129 - ADVANCED CONVERSION TEST - BULGARIAN LIGNITE
}

Final Report

(for the period May 1, 2008, through March 31, 2009)

Prepared for:

AAD Document Control

U.S. Department of Energy

National Energy Technology Laboratory

PO Box 10940, MS 921-107

Pittsburgh, PA 15236-0940

Cooperative Agreement: DE-FC26-98FT40321

Project Manager: Jenny Tennant

Prepared by:

Michael L. Swanson Everett A. Sondreal

Daniel A. Laudal Douglas R. Hajicek Ann K. Henderson Brandon M. Pavlish

Energy \& Environmental Research Center

University of North Dakota 15 North 23rd Street, Stop 9018

Grand Forks, ND 58202-9018 


\section{EERC DISCLAIMER}

LEGAL NOTICE This report was prepared by the Energy \& Environmental Research Center (EERC), an agency of the University of North Dakota, as an account of work sponsored by the Bulgarian Lignite Power Project and the U.S. Department of Energy National Energy Technology Laboratory. Because of the nature of the work performed, neither the EERC nor any of its employees makes any warranty, express or implied, or assumes any legal liability or responsibility for the accuracy, completeness, or usefulness of any information, apparatus, product, or process disclosed or represents that its use would not infringe privately owned rights. Reference herein to any specific commercial product, process, or service by trade name, trademark, manufacturer, or otherwise does not necessarily constitute or imply its endorsement or recommendation by the EERC.

\section{DOE DISCLAIMER}

This report was prepared as an account of work sponsored by an agency of the United States Government. Neither the United States Government, nor any agency thereof, nor any of their employees, makes any warranty, express or implied, or assumes any legal liability or responsibility for the accuracy, completeness, or usefulness of any information, apparatus, product, or process disclosed, or represents that its use would not infringe privately owned rights. Reference herein to any specific commercial product, process, or service by trade name, trademark, manufacturer, or otherwise does not necessarily constitute or imply its endorsement, recommendation, or favoring by the United States Government or any agency thereof. The views and opinions of authors expressed herein do not necessarily state or reflect those of the United States Government or any agency thereof.

This report is available to the public from the National Technical Information Service, U.S. Department of Commerce, 5285 Port Royal Road, Springfield, VA 22161; phone orders accepted at (703) 487-4650. 


\title{
JV TASK 129 - ADVANCED CONVERSION TESTING OF LOM BULGARIAN LIGNITES
}

\begin{abstract}
The objectives of this Energy \& Environmental Research Center (EERC) project were to evaluate Bulgarian lignite performance under both fluid-bed combustion and gasification conditions and provide a recommendation as to which technology would be the most technically feasible for the particular feedstock and also identify any potential operating issues (such as bed agglomeration, etc.) that may limit the applicability of a potential coal conversion technology.
\end{abstract}

Gasification tests were run at the EERC in the $100-400-\mathrm{kg} / \mathrm{hr}$ transport reactor development unit (TRDU) on a 50-tonne sample of lignite supplied by the Bulgarian Lignite Power Project. The quality of the test sample was inferior to any coal previously tested in this unit, containing $50 \%$ ash at $26.7 \%$ moisture and having a higher heating value of $5043 \mathrm{~kJ} / \mathrm{kg}$ after partial drying in preparation for testing. The tentative conclusion reached on the basis of tests in the TRDU is that oxygen-blown gasification of this high-ash Bulgarian lignite sample using the Kellogg, Brown, and Root (KBR) transport gasifier technology would not provide a syngas suitable for directly firing a gas turbine. After correcting for test conditions specific to the pilot-scale TRDU, including an unavoidably high heat loss and nitrogen dilution by transport air, the best-case heating value for oxygen-blown operation was estimated to be $3316 \mathrm{~kJ} / \mathrm{m}^{3}$ for a commercial KRB transport gasifier. This heating value is about $80 \%$ of the minimum required for firing a gas turbine. Removing $50 \%$ of the carbon dioxide from the syngas would increase the heating value to $4583 \mathrm{~kJ} / \mathrm{m}^{3}$, i.e., to about $110 \%$ of the minimum requirement, and $95 \%$ removal would provide a heating value of $7080 \mathrm{~kJ} / \mathrm{m}^{3}$. Supplemental firing of natural gas would also allow the integrated gasification combined cycle (IGCC) technology to be utilized without having to remove $\mathrm{CO}_{2}$. If removal of all nitrogen from the input gas streams such as the coal transport air were achieved, a heating value very close to that that needed to fire a gas turbine would be achieved; however, some operational issues associated with utilizing recycled syngas or carbon dioxide as the transport gas would also have to be resolved. Use of a coal with a quality similar to the core samples provided earlier in the test program would also improve the gasifier performance.

Low cold-gas efficiencies on the order of $20 \%$ calculated for oxygen-blown tests resulted in part from specific difficulties experienced in trying to operate the pilot-scale TRDU on this very high-ash lignite. These low levels of efficiency are not believed to be representative of what could be achieved in a commercial KRB transport gasifier.

Combustion tests were also performed in the EERC's circulating fluidized-bed combustor (CFBC) to evaluate this alternative technology for use of this fuel. It was demonstrated that thie fuel does have sufficient heating value to sustain combustion, even without coal drying; however, it will be challenging to economically extract sufficient energy for the generation of steam for electrical generation. The boiler efficiency for the dried coal was $73.5 \%$ at $85 \%$ sulfur capture (21.4\% moisture) compared to $55.3 \%$ at $85 \%$ sulfur capture (40\% moisture). Improved

boiler efficiencies for this coal will be possible operating a system more specifically designed to 
maximize heat extraction from the ash streams for this high-ash fuel. Drying of the coal to approximately $25 \%$ moisture probably would be recommended for either power system. Fuel moisture also has a large impact on fuel feedability. Pressurized gasifiers generally like drier fuels than systems operating at ambient pressures. The commercially recommended feedstock moisture for a pressurized transport reactor gasifier is $25 \%$ moisture. Maximum moisture content for a CFB system could be approximately $40 \%$ moisture as has been demonstrated on the Alstom CFB operating on Mississippi lignite.

A preliminary economic evaluation for $\mathrm{CO}_{2}$ was performed on the alternatives of 1) precombustion separation of $\mathrm{CO}_{2}$ in an IGCC using the KBR transport gasifier and 2) postcombustion $\mathrm{CO}_{2}$ capture using a $\mathrm{CFBC}$. It appears that the capture of $\mathrm{CO}_{2}$ from the highpressure IGCC precombustion system would be less costly than from the low-pressure postcombustion CFBC system by a factor of 1.5 , although the cost difference is not directly comparable because of the model input being limited to a higher coal quality than the Bulgarian lignite. While the decision to pursue precombustion removal of carbon dioxide has been technically proven with the Rectisol ${ }^{\circledR}$ and Selexol ${ }^{\mathrm{TM}}$ processes, General Electric and Siemens have not sold any gas turbine systems running on the high-hydrogen syngas. However, they have successfully demonstrated a gas turbine on syngases containing up to $95 \%$ hydrogen. The technological hurdles should not be too difficult given this experience in the gas turbine industry. 


\section{TABLE OF CONTENTS}

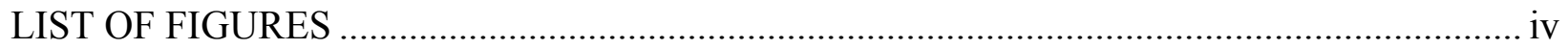

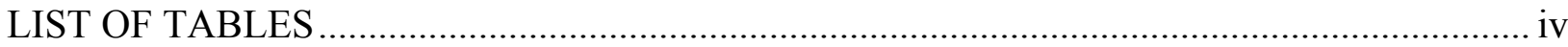

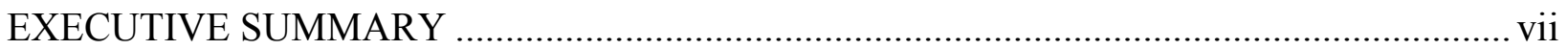

BACKGROUND FOR BULGARIAN LIGNITE CONVERSION TECHNOLOGY

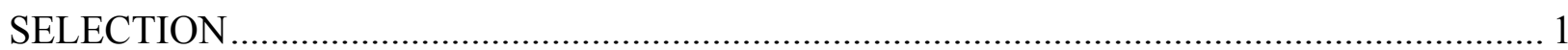

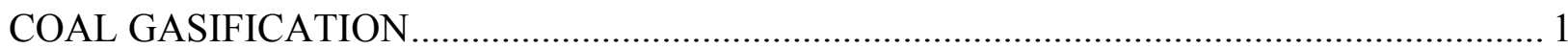

PROPERTIES OF LOW-RANK COALS AFFECTING THEIR UTILIZATION ......................... 3

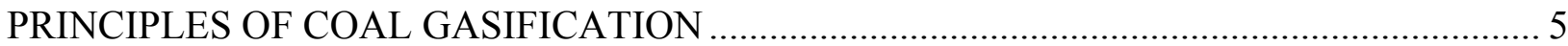

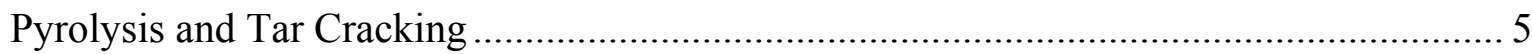

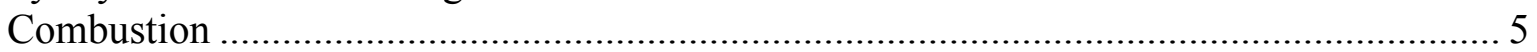

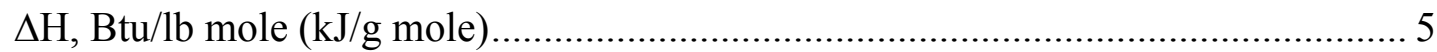

Steam Gasification ........................................................................................ 5

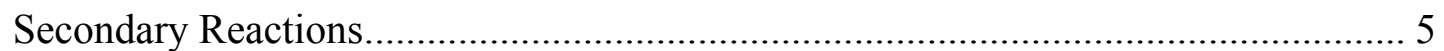

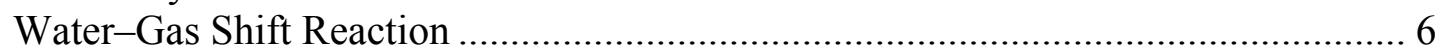

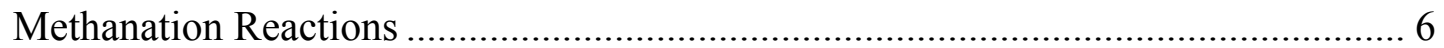

Equilibrium of the Carbon-Steam-Oxygen System ………………………………….... 6

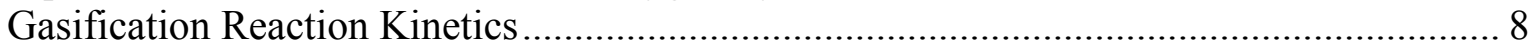

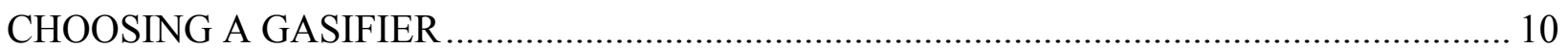

Slurry-Fed Entrained-Flow Gasifiers ........................................................................... 10

Dry Feed Entrained-Flow Gasifiers ……………………............................................. 14

Ash and Slag Behavior in High-Temperature Gasifiers................................................. 15

Dry-Ash Fixed-Bed Gasifiers................................................................................... 16

The British Gas Lurgi Fixed-Bed Gasifier .................................................................... 17

Fluidized-Bed Gasifiers: U-Gas, KRW, and HTW ………........................................ 18

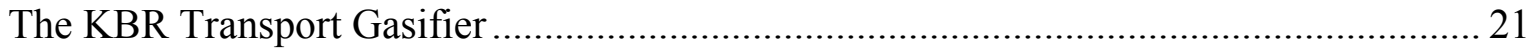

OVERALL PROJECT OBJECTIVES FOR EVALUATION OF BULGARIAN LIGNITE ......25

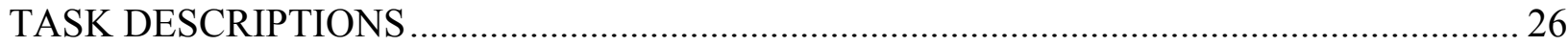

Task 1 - Detailed Characterization of the Bulgarian Lignite............................................... 26

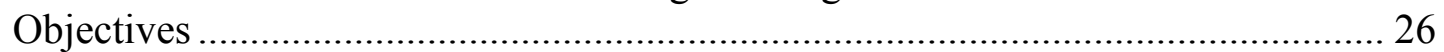

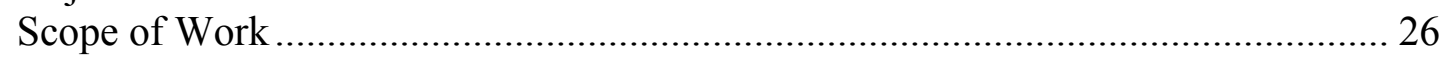

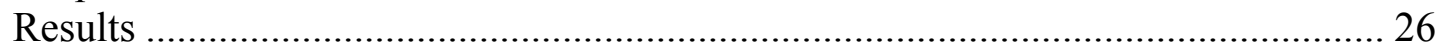

Summary and Conclusions for Task 1 .......................................................................... 31

Continued... 


\section{TABLE OF CONTENTS (continued)}

Task 2 - Bench-Scale Combustion Testing in the FBR ………….................................... 32

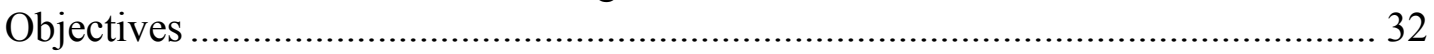

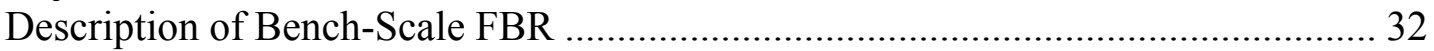

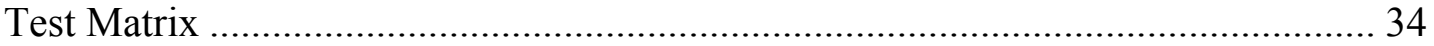

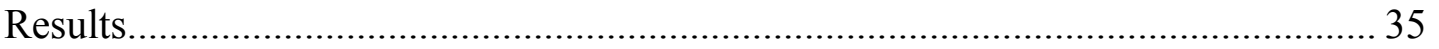

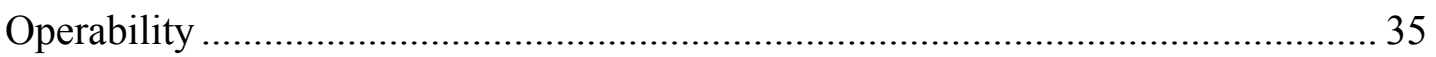

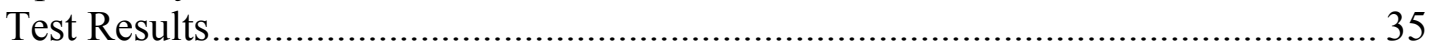

Summary and Conclusions for Task 2.............................................................. 40

Task 3 - Bench-Scale Fluid-Bed Gasification Testing ....................................................... 41

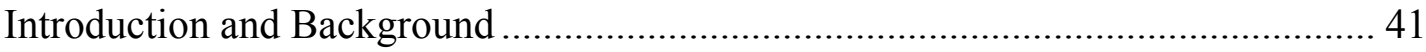

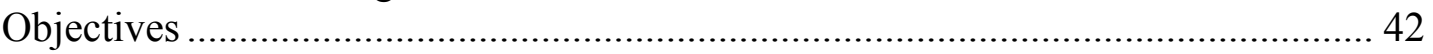

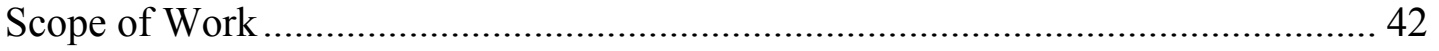

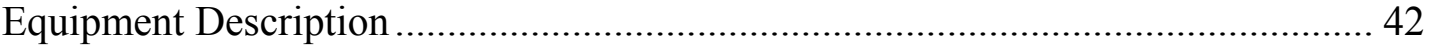

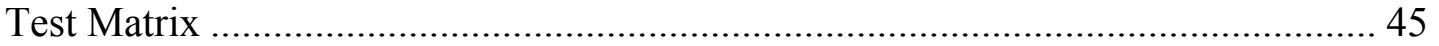

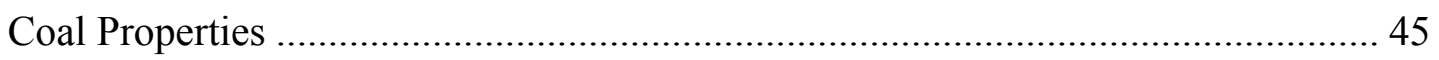

Operating Conditions ....................................................................................... 47

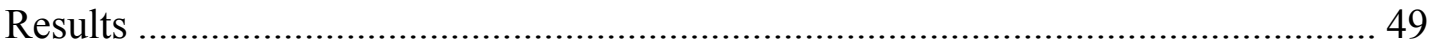

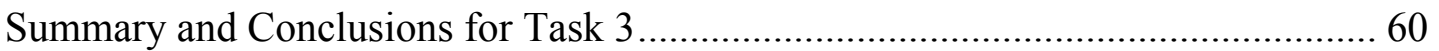

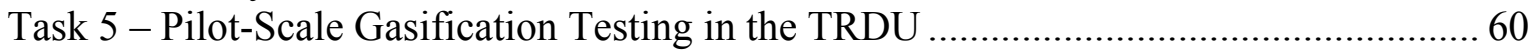

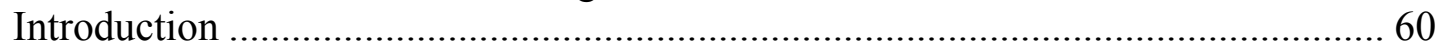

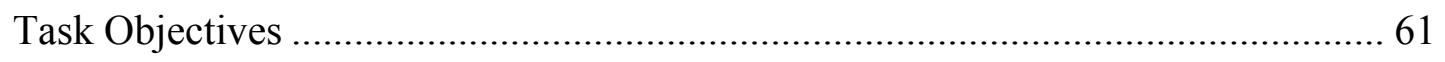

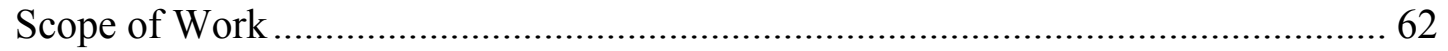

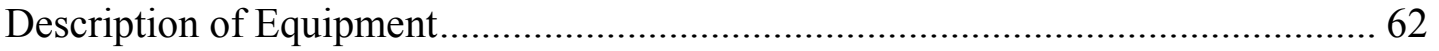

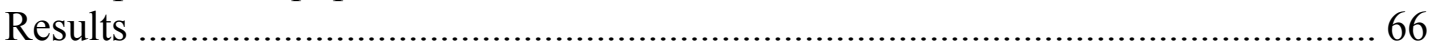

Summary and Conclusions for Task 5 ................................................................ 72

Recommendations Based on Task 5 Results ......................................................... 73

Task 4 - Pilot-Scale Combustion Testing in the CFBC ................................................ 73

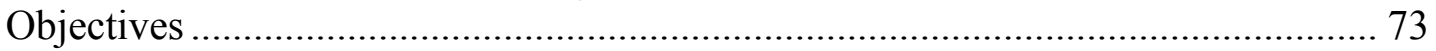

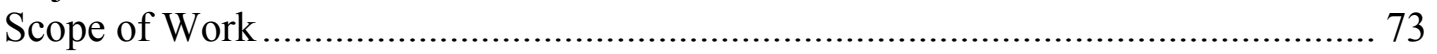

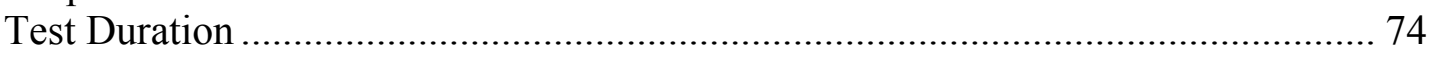

Fuel and Sorbent Sizing .................................................................................... 74

Operating Conditions...................................................................................... 74

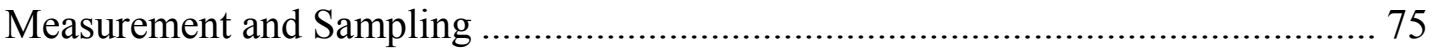

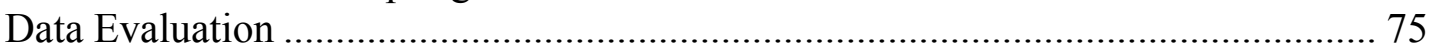

Description of the CFBC System ..................................................................... 75

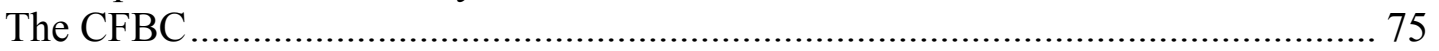

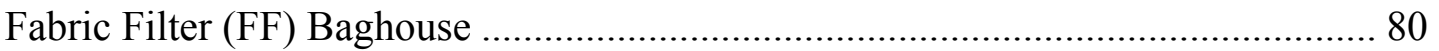

Niro Inc. Production Minor ${ }^{\mathrm{TM}}$ Spray Dryer, Model I …………………………........ 80

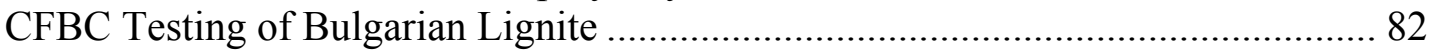

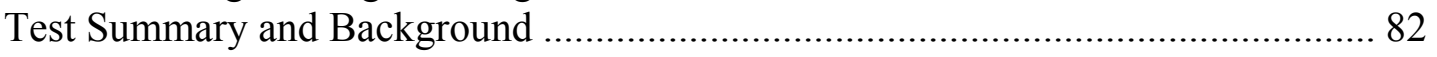

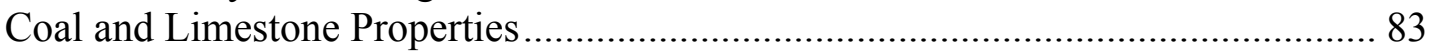

Continued... 


\section{TABLE OF CONTENTS (continued)}

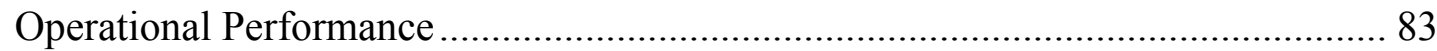

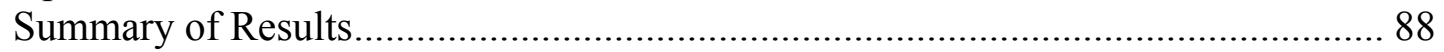

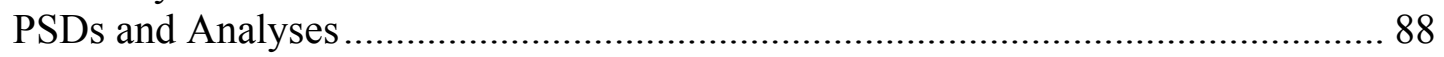

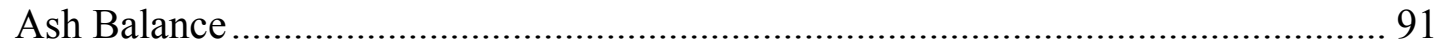

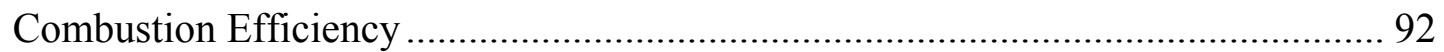

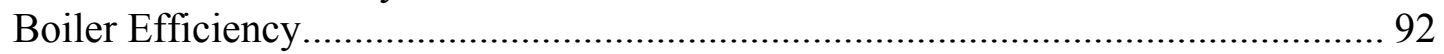

Pressure and Temperature Profiles ...................................................................... 95

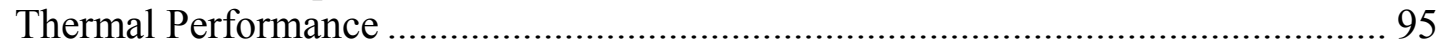

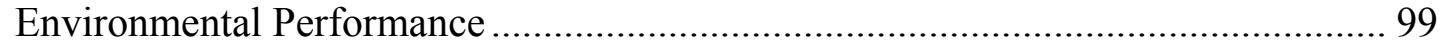

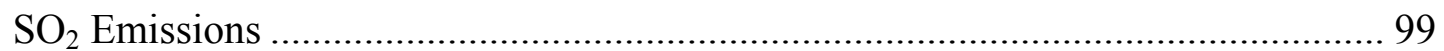

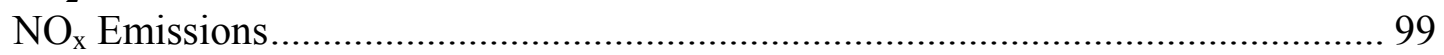

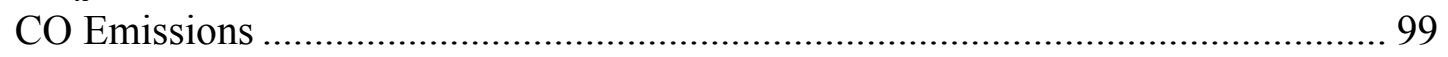

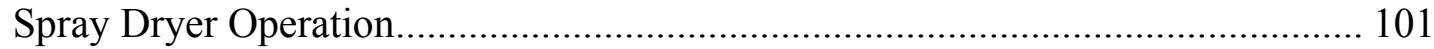

Agglomeration and Fouling................................................................................ 101

Trace Element and Volatile Organic Compound Emissions .................................... 101

Conclusions for Task 4 .................................................................................. 104

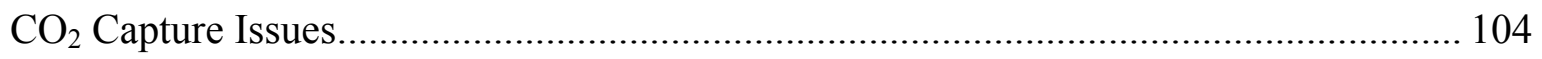

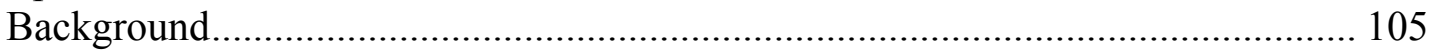

IGCC Design and Cost for a Changing Marketplace Requiring Carbon Capture... 108

$\mathrm{CO}_{2}$ CAPTURE COSTS FOR BURNING BULGARIAN LIGNITE....................................... 111

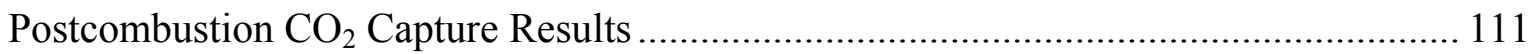

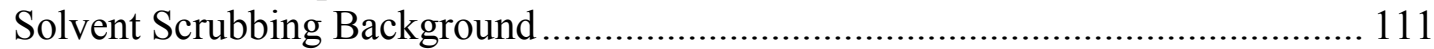

Other Commercial Solvents............................................................................... 113

Solvents under Development............................................................................ 114

Postcombustion Capture Model Results............................................................... 119

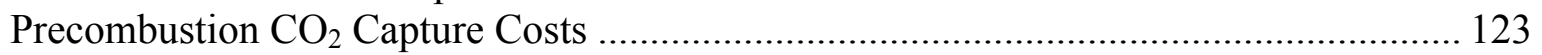

Precombustion Technology Background............................................................. 123

Precombustion Analysis Results ........................................................................ 126

Summary of $\mathrm{CO}_{2}$ Control Options for IGCC versus CFBC Power Plant Systems ............ 128

CONCLUSIONS REGARDING UTILIZATION OF BULGARIAN LIGNITE IN

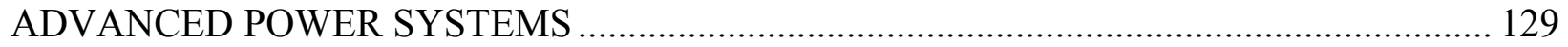

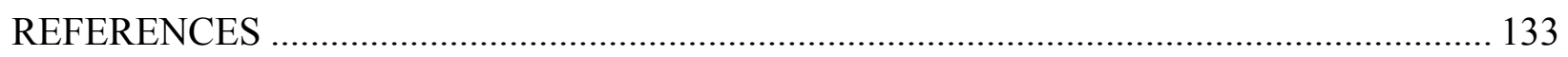

SUMMARY INFORMATION FROM THE BULGARIAN CLEAN COAL UTILIZATION TECHNOLOGY OPTIONS HANDBOOK …………………….............ppendix A 


\section{LIST OF FIGURES}

1 Effect of temperature on equilibrium gas composition................................................... 7

2 Effect of temperature and pressure on equilibrium gas composition.................................... 7

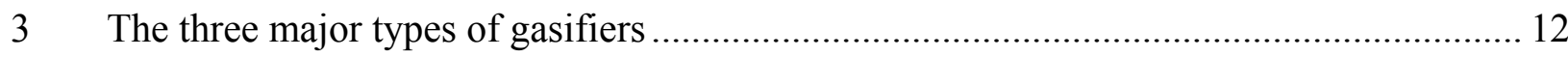

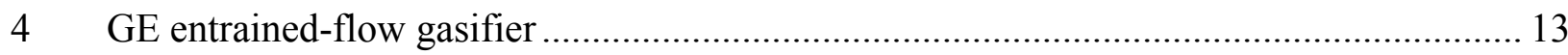

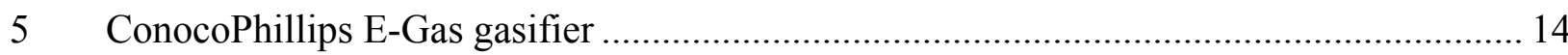

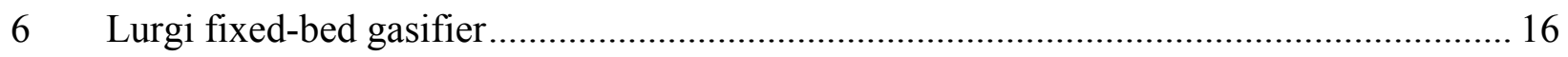

7 Generic schematic of a fluidized-bed gasifier representing the U-Gas, KRW,

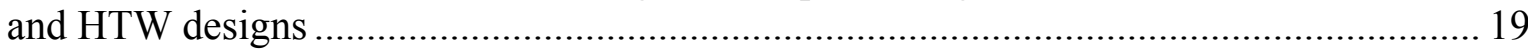

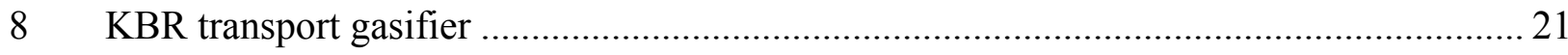

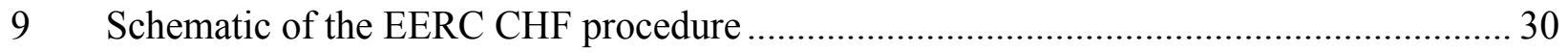

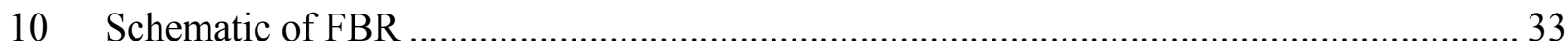

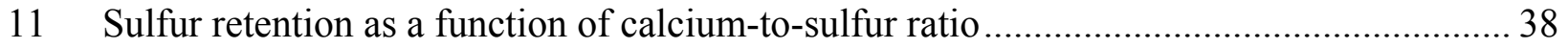

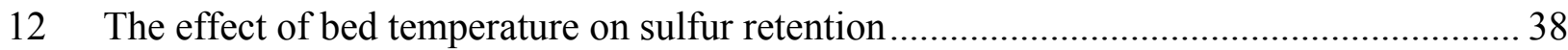

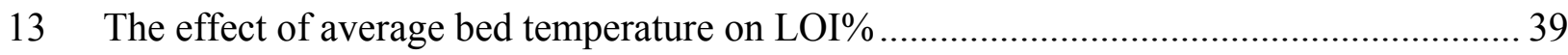

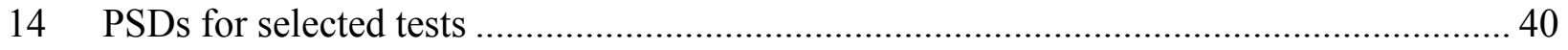

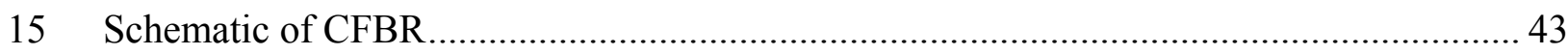

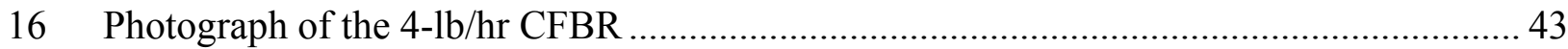

17 SEM morphology of CFBR bed material agglomeration samples..................................... 50

18 SEM morphology of CFBR bed material agglomeration samples..................................... 50

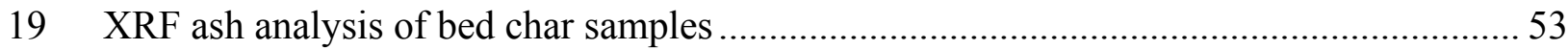

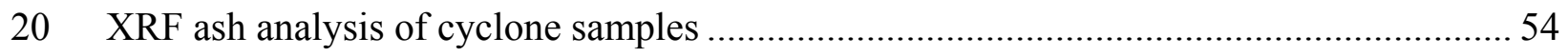

Continued... 


\section{LIST OF FIGURES (continued)}

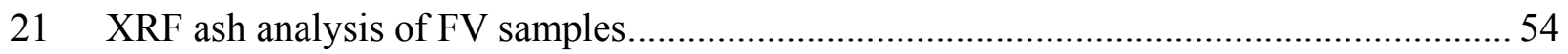

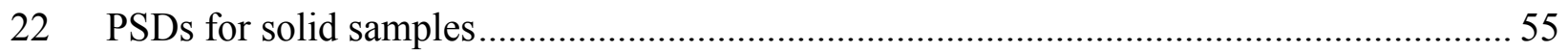

23 Arsenic and chromium concentration in solid samples..................................................56

24 Barium, manganese, and nickel concentrations in solid samples........................................ 56

25 Beryllium, cadmium, selenium, and silver concentrations in solid samples.......................57

26 Chlorine and lead concentrations in solid samples .......................................................5

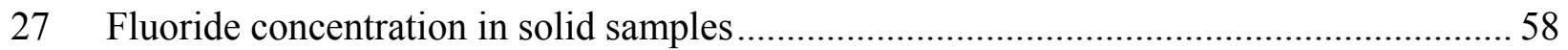

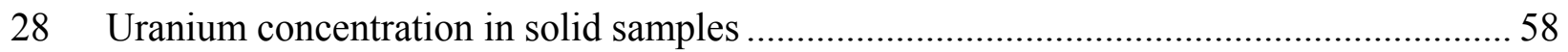

29 Product gas heating value and carbon conversion as a function of $\mathrm{O}_{2} / \mathrm{maf} \mathrm{coal}$................5 59

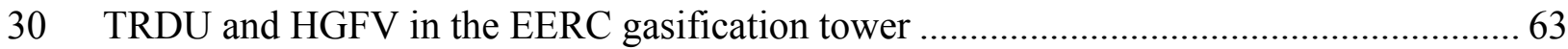

31 Schematic of the FV design with internal refractory, tube sheet, and shroud...................... 65

32 Plot of TRDU sample particle-size distributions for selected Bulgarian lignite samples ... 71

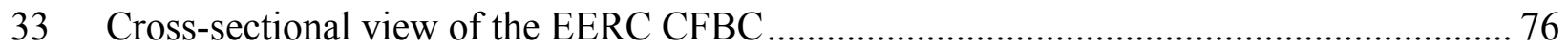

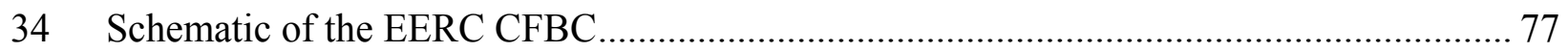

35 Schematic (not drawn to scale) of the Niro Inc. Production Minor Spray Dryer,

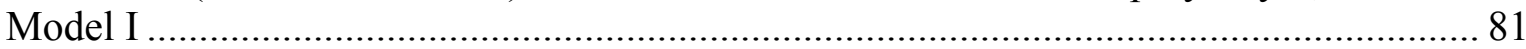

36 Size distribution of the Bulgarian coal and limestone for each sample .............................. 85

37 PSDs for each of the ash streams leaving the system..................................................... 91

38 Pressure profiles - pressure distribution across the height of the furnace .......................... 97

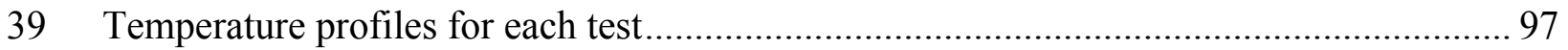

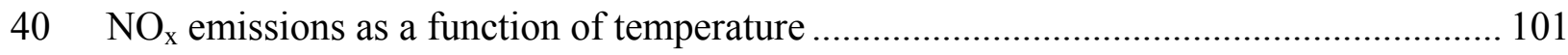

Continued... 


\section{LIST OF FIGURES (continued)}

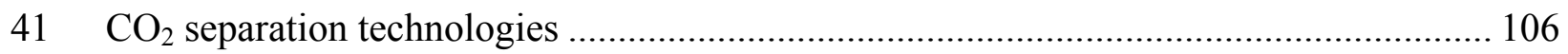

42 Schematic of an MEA absorption system for capturing $\mathrm{CO}_{2}$ from flue gas ..................... 113

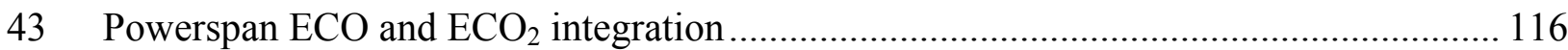

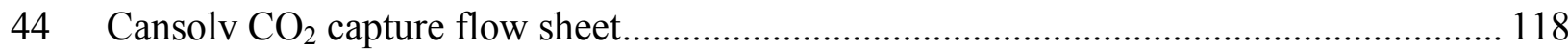

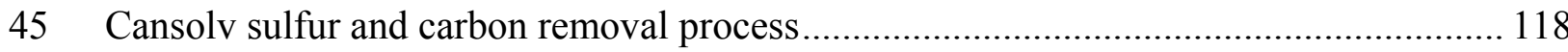

46 A summary of the $\mathrm{CO}_{2}$ capture costs for implementation on a Bulgarian lignite-fired combustion system .................................................................................... 122

47 A summary of the plant size required to maintain a $400-\mathrm{MWe}_{\mathrm{e}}$ output while increasing the $\mathrm{CO}_{2}$ capture rate ............................................................................. 122

48 Component breakdown for the costs associated with an $\mathrm{MEA} \mathrm{CO}_{2}$ capture system........ 123

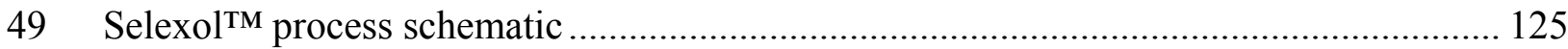

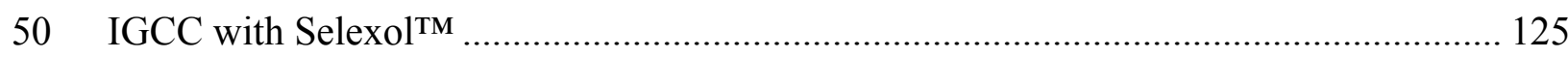

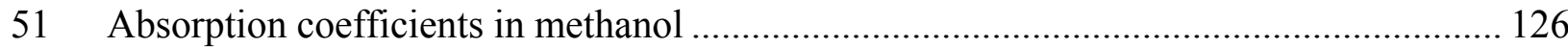

52 The breakdown of the IGCC + capture plant energy output and requirements ................ 127

53 The breakdown of the IGCC + capture plant energy output and requirements ................ 128

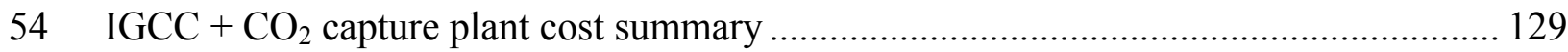




\section{LIST OF TABLES}

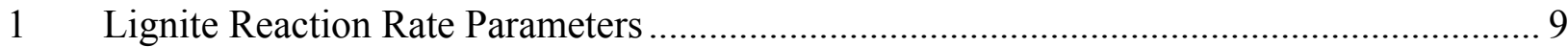

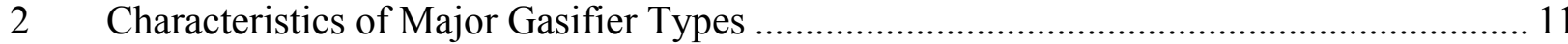

3 Representative Performance Parameters for the Transport Gasifier ................................... 23

4 Comparison of Coal Composite and Theoretical Blend C ............................................... 27

5 Comparison of Coal Composite and Theoretical Blend C Based on XRF Analysis .......... 28

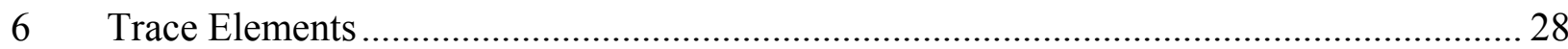

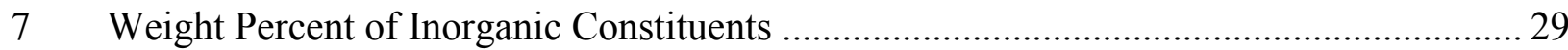

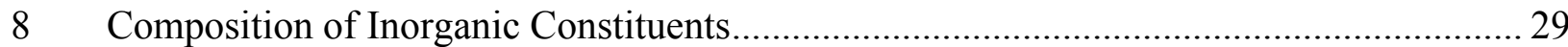

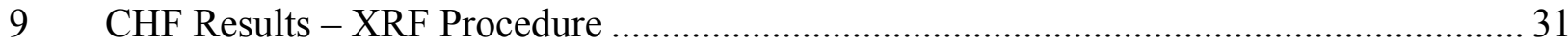

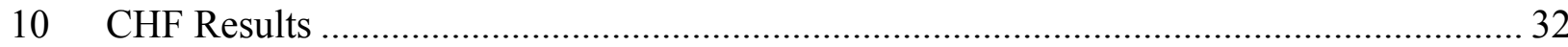

11 Summary of Process Data for FBR Test with Bulgarian Lignite.........................................36

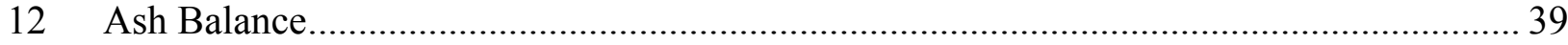

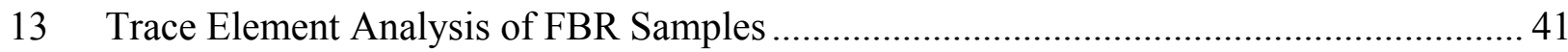

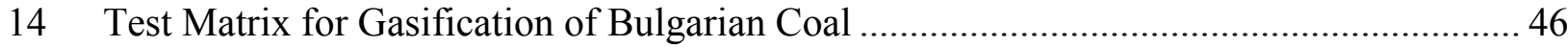

15 Proximate, Ultimate, and HHV for Coal Composite ....................................................... 46

16 XRF Ash Analysis for Coal Composite and Bulgarian Limestone......................................4 47

17 Composition of Tag Points from Figure 17 ................................................................. 51

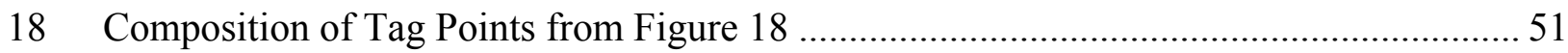

19 CFBR Operating Conditions ………………………................................................... 51

20 CFBR Product Gas Composition and Heating Value ………….......................................5 52

Continued... 


\section{LIST OF TABLES (continued)}

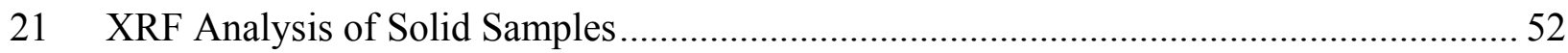

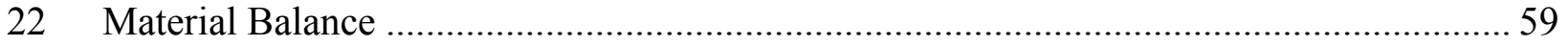

$23 \quad$ P83 Test Plan for Enomona Transport Reactor Integrated Gasification Test

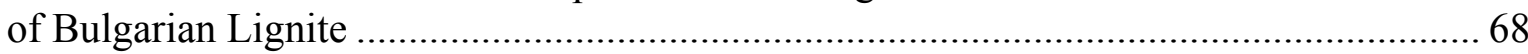

24 Proximate, Ultimate, HHV, and XRF Analysis Results for LOM Lignite .......................... 69

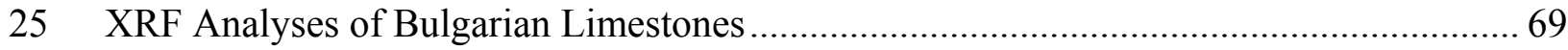

26 TRDU Operating Conditions for Oxygen-Blown Gasification Performance ……….......... 70

27 Actual and Corrected TRDU Product Gas Compositions for Air- and Oxygen-Blown Steady-State Tests.................................................................................. 70

28 Analyses of the Collected Samples from TRDU Testing on Bulgarian Lignite .................. 71

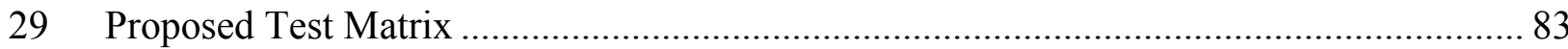

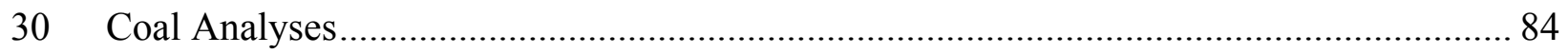

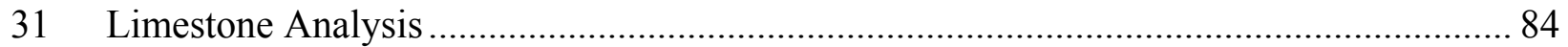

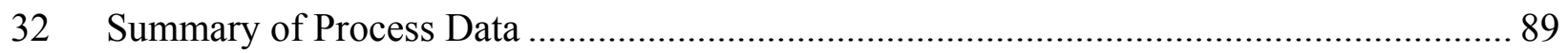

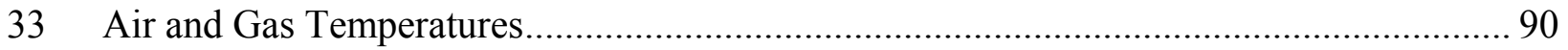

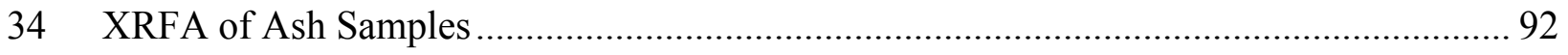

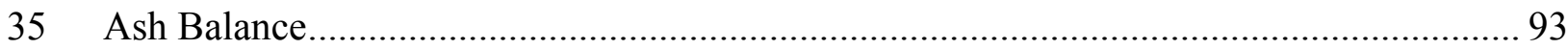

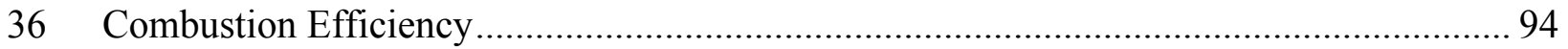

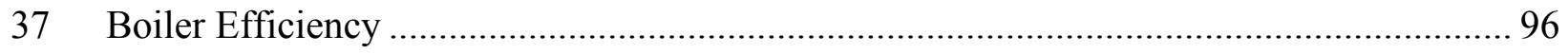

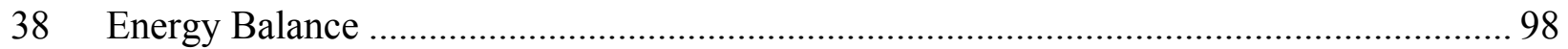

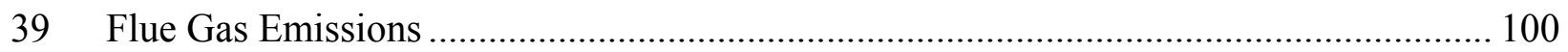

Continued... 


\section{LIST OF TABLES (continued)}

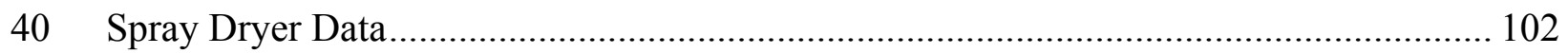

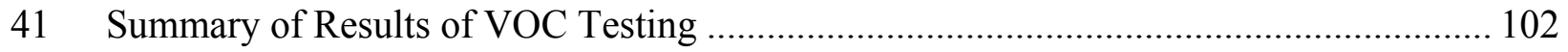

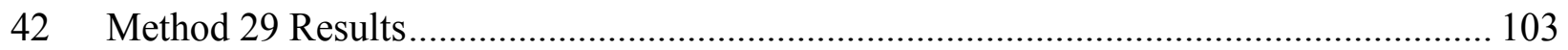

43 Trace Elements Analysis of CFBC Samples ............................................................... 103

44 Summary of IGCC Performance and Cost with and Without Carbon Capture................ 109

45 A Summary of the $\mathrm{CO}_{2}$ Capture Modeling for a Bulgarian Lignite-Fired

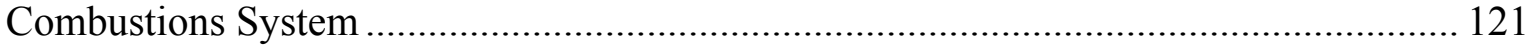

46 North Dakota Lignite Default Properties Used in the IECM Model Simulations ........... 127

47 Total Cost of an IGCC Plant Equipped with a Selexol Unit for $\mathrm{CO}_{2}$ Capture Based

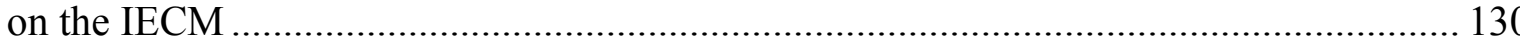




\section{JV TASK 129 - ADVANCED CONVERSION TESTING OF LOM BULGARIAN LIGNITES}

\section{EXECUTIVE SUMMARY}

The objective of the project was to evaluate Bulgarian lignite performance under both fluid-bed combustion and gasification conditions. The Energy \& Environmental Research Center (EERC) will provide a recommendation as to which technology would be the most technically feasible for this particular feedstock and also identify any potential operating issues (such as bed agglomeration, etc.) that may limit the applicability of a potential coal conversion technology. From the pilot-scale information, enough data would be generated so that a selected architecture and engineering firm could determine which conversion technology would have the best economics for this particular project.

Since the mine is not yet open and only core samples are likely to be available in the near future, the EERC proposed to conduct initial screening tests on its electrically heated bench-scale combustion and gasification systems. As the mine is opened and larger coal quantities become available, the EERC then proposes to conduct pilot-scale combustion and gasification testing where better heat and material balance information can be acquired. The EERC proposed a fivetask program as follows:

- Task 1 - Detailed Characterization of the Bulgarian Lignite

- Task 2 - Bench-Scale Combustion Testing in the Fluid-Bed Reactor

- Task 3 - Bench-Scale Gasification Testing in the Continuous Fluidized-Bed Reactor (CFBR)

- Task 5 - Pilot-Scale Gasification Testing in the Transport Reactor Development Unit (TRDU)

- Task 4 - Pilot-Scale Combustion Testing in the Circulating Fluid-Bed Combustor (CFBC)

Tasks 4 and/or 5 would only be conducted should promising results from Tasks 2 and 3 warrant further testing at the next scale. It was decided that Task 5 would be performed first and Task 4 would only be performed if Task 5 testing did not look promising.

Based on the data from Task 1, including x-ray fluorescence (XRF), computer-controlled scanning electron microscopy (CCSEM), and chemical fractionation analysis (CHF) analyses, this coal should perform well as a gasification fuel in the TRDU. That is, bed agglomeration and ash deposition would not be expected problems. Kalmanovitch ash viscosity modeling also shows that at the temperatures run in the TRDU, the ash viscosity would be in an acceptable range. 
Task 2 results showed that fuel fed well and burned well in the CFBR. There was no evidence of agglomeration in the bed material. The sulfur content of the coal was somewhat higher than expected, resulting in high-sulfur emissions. With no sorbent addition, sulfur retention was only $9 \%$ to $13 \%$ at an average bed temperature of $843^{\circ} \mathrm{C}\left(1550^{\circ} \mathrm{F}\right)$; at a bed temperature of $799^{\circ} \mathrm{C}\left(1470^{\circ} \mathrm{F}\right)$, sulfur retention was $17 \%$. Three different sulfur sorbents were used: the Bulgarian limestone supplied by the client, a Montana limestone, and a dolomite supplied by the EERC. All three were tested at similar conditions of coal feed, temperature, and excess air, although the Bulgarian limestone was only tested at a low $\mathrm{Ca} / \mathrm{S}$ ratio. The desired sulfur retention of $90 \%$ was achieved at a $\mathrm{Ca} / \mathrm{S}$ ratio of 2.7 and an average bed temperature of $801^{\circ} \mathrm{C}\left(1474^{\circ} \mathrm{F}\right)$. At the same $\mathrm{Ca} / \mathrm{S}$ ratio and a temperature of $843^{\circ} \mathrm{C}\left(1550^{\circ} \mathrm{F}\right)$, the sulfur retention was $82 \%$. At that temperature, a slight increase in sorbent feed rate could be expected to achieve $90 \%$ sulfur retention. It certainly appears that fluid-bed combustion of the Bulgarian lignite would be a viable utilization option.

Preliminary results from the Task 3 bench-scale gasification tests suggest that air-blown gasification is not likely to provide a syngas with a sufficient heating value for operating an integrated gasification combined-cycle (IGCC) system. However, enriched-air or oxygen-blown operation should provide the minimum heating value required to operate the gas turbine combined-cycle power plant.

Bed agglomeration that was observed is thought to be because of the accumulation of large clay particles that would eventually lead to portions of the bed defluidizing and to the development of localized hot spots in the bed. This will not be an issue for the high-velocity transport reactor system.

The lower carbon conversions obtained with the CFBR system should be higher since the cyclones on the transport reactor system recycle its char back to the gasifier until the carbon is either consumed by the partial oxidation reactions or is fine enough to pass through the cyclones. If the cyclone ash in the CFBR tests were recycled to extinction and the filter ash carbon were the only carbon loss, the carbon conversions would be above $98 \%$ for all of the tests.

Task 5 gasification tests were run at the EERC in the 100-400-kg/hr TRDU on a 50 -tonne sample of lignite supplied by the Bulgarian Lignite Power Project. The quality of the test sample was inferior to any coal previously tested in this unit, containing $50 \%$ ash at $26.7 \%$ moisture and having a higher heating value of $5043 \mathrm{~kJ} / \mathrm{kg}$ after partial drying in preparation for testing. The tentative conclusion reached on the basis of tests in the TRDU is that oxygen-blown gasification of this high-ash Bulgarian lignite sample using the KBR transport gasifier technology would not provide a syngas suitable for directly firing a gas turbine. After correcting for test conditions specific to the pilot-scale TRDU, including an unavoidably high heat loss and nitrogen dilution by transport air, the best-case heating value for oxygen-blown operation was estimated to be $3316 \mathrm{~kJ} / \mathrm{m}^{3}$ for a commercial KRB transport gasifier. This heating value is about $80 \%$ of the minimum required for firing a gas turbine. Removing $50 \%$ of the carbon dioxide from the syngas would increase the heating value to $4583 \mathrm{~kJ} / \mathrm{m}^{3}$, i.e., to about $110 \%$ of the minimum requirement, and $95 \%$ removal would provide a heating value of $7080 \mathrm{~kJ} / \mathrm{m}^{3}$. Supplemental firing of natural gas would also allow the IGCC technology to be utilized without having to remove $\mathrm{CO}_{2}$. If removal of all nitrogen from the input gas streams such as the coal transport air were achieved, a 
heating value very close to that needed to fire a gas turbine would be achieved; however, some operational issues associated with utilizing recycled syngas or carbon dioxide as the transport gas would also have to be resolved. Use of a coal with a quality similar to the core samples provided earlier in the test program would also improve the gasifier performance.

Low cold-gas efficiencies on the order of $20 \%$ calculated for oxygen-blown tests resulted in part from specific difficulties experienced in trying to operate the pilot-scale TRDU on this very high ash lignite. These low levels of efficiency are not believed to be representative of what could be achieved in a commercial KRB transport gasifier.

Because of the lower quality of the lignite supplied for testing in the TRDU and the marginal results obtained, it was decided with the concurrence of the Bulgarian Lignite Power Project that tests should be performed in the EERC's CFBC under Task 4 activities to evaluate this alternative technology for use of this fuel. It was demonstrated that this fuel does have sufficient heating value to sustain combustion, even without coal drying; however, it will be challenging to economically extract sufficient energy for the generation of steam for electrical generation. The boiler efficiency for the dried coal was $73.5 \%$ at $85 \%$ sulfur capture $(21.4 \%$ moisture) compared to $55.3 \%$ at $85 \%$ sulfur capture $(40 \%$ moisture). Improved boiler efficiencies for this coal will be possible operating a system more specifically designed to maximize heat extraction from the ash streams for this high-ash fuel. Drying of the coal to approximately $25 \%$ moisture probably would be recommended for either power system. Fuel moisture also has a large impact on fuel feedability. Pressurized gasifiers generally like drier fuels than systems operating at ambient pressures. The commercially recommended feedstock moisture for a pressurized transport reactor gasifier is $25 \%$. Maximum moisture content for a CFB system could be approximately $40 \%$ as has been demonstrated on the Alstom CFB operating on Mississippi lignite.

A separate ash-cleaning study to determine how much a nonwetting ash-cleaning system such as air jigging might remove is suggested especially if the cleaning technique can incorporate some coal drying also by utilizing a heat airstream. As discussed previously, every $\mathrm{kg}$ of fuel moisture removed results in a significantly higher improvement in a cycle efficiency than a comparable reduction in the ash content. In all likelihood, the removal or blending of coals just for the purpose of ash reduction is probably not worth the cost.

A preliminary economic evaluation on $\mathrm{CO}_{2}$ was performed on the alternatives of 1) precombustion separation of $\mathrm{CO}_{2}$ in an IGCC using the $\mathrm{KBR}$ transport gasifier and 2) postcombustion $\mathrm{CO}_{2}$ capture using a CFBC. It appears that the capture of $\mathrm{CO}_{2}$ from the highpressure IGCC precombustion system would be less costly than from the low-pressure postcombustion CFBC system by a factor of 1.5 , although the cost difference is not directly comparable because of the model input being limited to a higher coal quality than the Bulgarian lignite. While the decision to pursue precombustion removal of carbon dioxide has been technically proven with the Rectisol and Selexol processes, General Electric and Siemens have not sold any gas turbine systems running on the high-hydrogen syngas. However, they have successfully demonstrated a gas turbine on syngases containing up to $95 \%$ hydrogen. The technological hurdles should not be too difficult given this experience in the gas turbine industry. 
The only alternate technology that might make some sense, especially in the context of $\mathrm{CO}_{2}$ capture and sequestration, would be oxyfuel firing in a CFB, which is currently being demonstrated in a small Alstom pilot plant. However, commercial demonstration has not yet been contemplated. 


\section{JV TASK 129 - ADVANCED CONVERSION TESTING OF LOM BULGARIAN LIGNITES}

\section{BACKGROUND FOR BULGARIAN LIGNITE CONVERSION TECHNOLOGY SELECTION}

Previous data provided on the Bulgarian lignite indicated that ash content ranged between 19 to $21 \mathrm{wt} \%$ and moisture content ranged between 43 to $50 \mathrm{wt} \%$. This provides an as-received coal with a lower heating value that ranged between 1700 down to $1350 \mathrm{kcal} / \mathrm{kg}$ (3060 to $2430 \mathrm{Btu} / \mathrm{lb}$ ). Low-rank coals with high moisture contents and coals with high ash contents tend to favor the use of circulating fluid-bed combustors or gasifiers since the larger coal particle size is easier to feed to the fluid bed even when it has higher moisture. Some predrying of the lignite may be desirable; however, substantial drying of the coal would not be required. Since the fluid beds both operate at lower temperatures, the extra energy penalty associated with heating the high-ash material to the higher temperatures associated with pulverized coal-fired boilers or entrained-flow gasification systems rather than the lower fluid-bed temperatures can be significant. For this reason, the Energy \& Environmental Research Center (EERC) proposed to investigate the performance of the Bulgarian lignite under both fluid-bed combustion and fluidbed gasification scenarios. The following pages summarize the selection of fluid-bed conversion technology as the technology of choice.

\section{COAL GASIFICATION}

Coal gasification technologies will, in the future, play a central role in increasing the efficiency of electric power generation and in providing synthesis gas for the production of hydrogen, liquid fuels, chemicals, and carbon dioxide. Integrated gasification combined-cycle (IGCC) systems offer high efficiency, low emissions, and opportunities for $\mathrm{CO}_{2}$ separation and sequestration. Coproduction of hydrogen, synthetic natural gas (SNG), and liquid fuels from domestic coal will reduce dependency on oil and natural gas from foreign sources. Oxygenblown gasification and gas separation technologies are key to economically recovering $\mathrm{CO}_{2}$ from coal utilization for enhanced oil recovery (EOR) and sequestration. The noncaking and highly reactive properties of western lignite and subbituminous coals are generally very favorable for gasification, but problems associated with high moisture and a uniquely different inorganic content require that the technology be carefully chosen to match the fuel resource to achieve efficiency, reliability, and environmental compliance at reasonable cost. High-moisture coals can be more difficult to feed and can significantly reduce gasifier efficiency, particularly in slurryfed systems. However, high moisture content also increases mass flow in gas turbines and promotes the production of hydrogen by the water-gas shift reaction. The organically bound inorganic impurities, including sodium, calcium, and trace elements, affect ash deposition and emissions, but these constituents also catalyze gasification to improve carbon conversion at lower temperatures. The high base-to-acid ratio of the inorganic content in many low-rank coals affects the fusion and viscosity behavior of ash and slag, which impacts corrosion, deposition, and slag flow in high-temperature systems. The optimum choice of a gasifier for low-rank coals will depend on the end-use application as well as the properties of the coal. The temperature, 
pressure, and composition of the gas leaving the gasifier should match the requirements of the downstream gas cleaning and separation processes to minimize cost and efficiency penalties associated with gas cooling and compression. In particular, gasifier conditions will determine the selection of the optimum technology for separating $\mathrm{CO}_{2}$ at reasonable cost.

Without carbon capture and sequestration (CCS), currently offered IGCC systems for bituminous coal have been generally evaluated to represent a cost of electricity (COE) higher than that for a pulverized coal (pc)-fired plant. The cost margin for low-rank coals has generally been higher than that for bituminous coal, because most cost studies have been performed for slurry feed gasifiers that are not suitable for high-moisture coals. If CCS is required, IGCC systems with state-of-the-art $\mathrm{CO}_{2}$ capture are expected to be significantly less costly than pcfired plants equipped with amine scrubbers.

Gasification technologies incorporating $\mathrm{CO}_{2}$ separation and sequestration are the key to expanding the use of the world's vast coal reserves to provide high-efficiency power generation, liquid fuels, chemicals and, ultimately, hydrogen in response to growing energy demand, the need for regional energy security, and anticipated limits on carbon emissions to the atmosphere.

Low-rank coal reserves of 145 billion tons in the western United States together with an additional 325 billion tons in Europe, Asia, and Australia make up nearly half of the world's total coal reserves (1). The energy content of world coal reserves is more than twice that of currently proven oil reserves. The immense extent of U.S. coal reserves makes the development of clean coal technologies with near-zero emissions a goal of the highest priority, and the export of these technologies to coal-producing regions around the world offers an outstanding opportunity for U.S. companies.

Coal gasification produces clean synthesis gas (syngas, $\mathrm{CO}$, and $\mathrm{H}_{2}$ ) that can be used to produce electricity and a wide range of other end-use forms of energy with high efficiency and stringent environmental control. Hydrogen separated from coal-derived syngas will be the carbon-free fuel of the future for use in IGCC power systems and automotive fuel cells. The CO and $\mathrm{H}_{2}$ in syngas will be combined over catalysts to produce $\mathrm{SNG}$, diesel and jet fuel, and gasoline. The $\mathrm{CO}_{2}$ separated from syngas will be marketed for EOR or sequestered in other geological settings. Low-rank coal reserves found in oil-producing regions will provide both $\mathrm{CO}_{2}$ for EOR and hydrogen for refineries. Industries centered on coal gasification can and will play a substantial role in supplying the energy needs of the United States and other coal-producing regions in the coming century.

The properties of coals differ greatly, and it is essential to match the technology to the fuel resource to achieve efficiency, reliability, and environmental compliance at reasonable cost. The EERC is performing research on the effect of low-rank coal properties in gasification and gas separation processes and on geological or terrestrial sequestration of $\mathrm{CO}_{2}$, including its use for EOR and production of coalbed methane. This report reviews the effect of coal properties in different types of gasification and gas separation processes and focuses particular attention on the Kellogg, Brown, and Root (KBR) transport gasifier, which has unique advantages for lowrank coal. This gasifier was developed with the support of the U.S. Department of Energy (DOE) by the EERC, Southern Company, and KBR based on KBR's fluidized-bed catalytic cracking 
technology, first in tests on a 91-227-kg/hr (200-500-lb/hr) transport reactor development unit (TRDU) at the EERC and then in the $907-2721-\mathrm{kg} / \mathrm{hr}(1-3-\mathrm{ton} / \mathrm{hr})$ engineering-scale power systems development facility (PSDF) in Wilsonville, Alabama.

\section{PROPERTIES OF LOW-RANK COALS AFFECTING THEIR UTILIZATION}

The performance of low-rank coals in preparation, combustion, conversion, and gas cleanup/emission control processes is critically influenced by those properties that distinguish them from bituminous coals, and technologies developed primarily for bituminous coals often need to be modified to operate satisfactorily on low-rank fuels. Low-rank coals are unique in terms of their high moisture content, low heating value, high oxygen content, high reactivity, more alkaline inorganic content, and distinctive ash and slag behavior. Their organic structure consists of relatively small clusters of one to three aromatic/hydroaromatic rings connected by alkyl links, compared to a more condensed aromatic structure for bituminous coal. The $15 \%$ to $30 \%$ oxygen content of dry low-rank coal occurs as hydroxyl, ether, and carboxylate groups, which give low-rank coals a significant ion-exchange capacity that is lacking in bituminous coals. A significant portion of the inorganic content in low-rank coals occurs as ionexchangeable cations associated with carboxylates.

High moisture content acts as a diluent that lowers heating value and increases stack losses. It also adds to coal transportation cost. In conversion processes, coal moisture is a chemical reactant and a sensible heat load, and it adds to process wastewater. Predrying is required in some gasification processes. In slurry-fed gasifiers, the high moisture content of lowrank coals substantially reduces the energy content of the feed, increases oxygen requirement, and reduces efficiency. Moisture removed by thermal drying in a gas atmosphere tends to be reabsorbed when the coal is wetted, whereas moisture removed by hydrothermal drying in steam or hot water at pressure collapses the pore structure and limits reabsorption.

The friability of some low-rank coals causes excessive amounts of fines during crushing, handling, and processing. Also, the loss of moisture in drying processes or during storage results in cracking and crumbling of coal, which adds to dustiness.

Highly reactive low-rank coals react at higher rates and at lower temperatures than bituminous coals in combustion and conversion processes. Also, high reactivity at near-ambient temperatures results in significant oxidation during storage in air, which changes the processing behavior of the coal and increases the risk of spontaneous combustion.

Absence of plasticity when low-rank coals are heated avoids the agglomeration and plugging experienced with caking bituminous coals in some gasification systems. Also, their noncaking behavior allows low-rank coals to remain dispersed and to retain a highly reactive surface at high temperatures.

Carbon dioxide emissions in relation to heating value are higher for low-rank coals compared to competing fuels. On the basis of the lower heating value (product water remains vapor), bituminous coals emit approximately 1.7 times more $\mathrm{CO}_{2}$ than natural gas, whereas the 
emission ratio for low-rank coals ranges from about 1.8 to 2.1 depending on coal oxygen and moisture content.

Sulfur contents in low-rank coals fall in a broad range from about $0.2 \%$ to $5 \%$ (resulting in emissions of 0.14 to $3.6 \mathrm{~kg}(0.3$ to $8 \mathrm{lb}) \mathrm{SO}_{2} / \mathrm{MMBtu}$ assuming that all coal sulfur is emitted). For some low-rank coals, a significant fraction of the sulfur is retained in the combustion ash, depending on the ratio of $(\mathrm{Ca}+\mathrm{Na})$ to sulfur in the coal. In the United States, only Alaskan and Wyoming subbituminous coals at their lower range of sulfur content can consistently meet U.S. federal emission standards. For certain other low-rank coals having a high sulfur content and a low heating value, as for example some European brown coals, sulfur emissions and control requirements are greater than for competing fuels.

Ash-forming constituents in low-rank coals include 1) extraneous grains of clay, quartz, pyrite, calcite, and other discrete minerals; 2) ion-exchangeable cations that are chemically absorbed on coal carboxylate or clay; and 3) elements associated with coal moisture, including some sodium and sulfate. A fraction of the extraneous mineral content can be removed by conventional or fine coal-cleaning techniques such as washing, heavy-media separation, froth flotation, or oil agglomeration. Cleaning methods such as oil agglomeration that rely on surface effects are influenced by the hydrophilic properties of the low-rank coal particles. The cations absorbed on low-rank coal are removable only by washing with an acid or a solution capable of accomplishing ion exchange. Most low-rank coals also contain very low levels of chlorine, which affects the application of mercury control technologies.

Absorbed cations in low-rank coal include part of the aluminum, iron, calcium, magnesium, sodium, and trace elements in the coal. Organically associated ions tend to concentrate preferentially in the finer portion of fly ash, and they have unique effects on particulate collection and ash deposition. They can also have autocatalytic effects in combustion, gasification, and liquefaction, or they can inhibit or poison added catalysts. Sodium ions are readily volatilized at high temperatures in combustors and gasifiers and subsequently condense at lower temperatures to form finely divided fumes that are carried into downstream processing equipment unless removed in gas cleaning. Calcium ions in aqueous systems form insoluble scale that can plug equipment.

Ashes and slags from low-rank coal exhibit distinctive fusion, viscosity, and other phase properties in relation to their chemical and mineralogical composition. Ash fusion properties are not directly related to rank, but the ash chemistry controlling the relationship between fusion or viscosity and ash composition characteristically differs from that of bituminous coal owing to the greater amounts of alkali or alkaline-earth oxides in low-rank coals. Slag from some low-rank coals has a propensity to crystallize and experience rapid freezing when cooled. These slags have a low viscosity with a sharply defined temperature of critical viscosity. Low-viscosity slags can exhibit aggressive corrosive attacks on metal or refractory surfaces at high temperatures. Surface melts formed from silica, aluminosilicates, iron oxides, and mixed sulfides or sulfates in the presence of volatile alkalies are a major cause of ash deposition on high-temperature surfaces. Either total sodium or the soluble sodium content has historically been used as a measure of ashfouling tendency in U.S. low-rank coals. Volatile alkalies, and particularly hydroxides and 
chlorides, are a special concern in advanced power systems, requiring "alkali getters" in hot-gascleaning systems to protect gas turbine blades from deposition and corrosion.

\section{PRINCIPLES OF COAL GASIFICATION}

Most coal gasification processes employ fixed-bed, fluidized-bed, or entrained-flow reactor systems to react coal with air or oxygen and steam over a range of temperatures from $650^{\circ} \mathrm{C}\left(1202^{\circ} \mathrm{F}\right)$ for catalytic gasification to about $1500^{\circ} \mathrm{C}\left(2732^{\circ} \mathrm{F}\right)$ for entrained-flow gasifiers, variously resulting in dry, agglomerated, or slagging ash discharge. Hydrogasification alternatively reacts coal with hydrogen to produce methane, which is not discussed in this report. The goal of the gasification process is to convert the chemical energy present in the coal feedstock to chemical and possibly thermal energy present in the syngas stream. Typically, gasification processes can convert the solid feedstock to a gaseous form with efficiency between $70 \%$ and $80 \%$ on a cold-gas basis and can easily be over $90 \%$ on a warm-gas basis. Process pressures range from near atmospheric to $82 \mathrm{~atm}$ (1200 psig). The principal groups of reactions are pyrolysis, combustion, steam gasification, and secondary reactions among gaseous products and with carbon (2).

\section{Pyrolysis and Tar Cracking}

$$
\begin{gathered}
\text { Coal } \rightarrow \text { Char }+ \text { Tar, Light Oil, } \mathrm{H}_{2} \mathrm{O}, \mathrm{H}_{2}, \mathrm{CO}, \mathrm{CO}_{2} \text {, and } \mathrm{HC} \text { Gases } \\
\text { Tar, Light Oil } \rightarrow \mathrm{CH}_{4} \text { and Other HC Gases }+\mathrm{CO}+\mathrm{H}_{2}+\mathrm{CO}_{2}
\end{gathered}
$$

\section{Combustion}

$\Delta H, B t u / l b$ mole (kJ/g mole)

$$
\begin{gathered}
\mathrm{C}+\mathrm{O}_{2} \rightarrow \mathrm{CO}_{2}-169,300(-393.8) \\
\mathrm{C}+1 / 2 \mathrm{O}_{2} \rightarrow \mathrm{CO}-47,600(-110.7) \\
\mathrm{CO}+1 / 2 \mathrm{O}_{2} \rightarrow \mathrm{CO}_{2}-121,700(-283.1)
\end{gathered}
$$

\section{Steam Gasification}

$$
\mathrm{C}+\mathrm{H}_{2} \mathrm{O} \rightarrow \mathrm{CO}+\mathrm{H}_{2}+56,490(+131.4)
$$

\section{Secondary Reactions}

$$
\begin{gathered}
\mathrm{C}+\mathrm{CO}_{2} \rightarrow 2 \mathrm{CO}+74,200(+172.6) \\
\mathrm{H}_{2}+1 / 2 \mathrm{O}_{2} \rightarrow \mathrm{H}_{2} \mathrm{O}_{(\mathrm{g})}-104,000(-241.9) \\
\mathrm{C}+2 \mathrm{H}_{2} \mathrm{O}_{(\mathrm{g})} \rightarrow \mathrm{CO}_{2}+2 \mathrm{H}_{2}+38,780(+90.2)
\end{gathered}
$$




\section{Water-Gas Shift Reaction}

$$
\mathrm{CO}+\mathrm{H}_{2} \mathrm{O}_{(\mathrm{g})} \rightarrow \mathrm{CO}_{2}+\mathrm{H}_{2}-17,700(-41.2)
$$

\section{Methanation Reactions}

$$
\begin{gathered}
\mathrm{C}+2 \mathrm{H}_{2} \rightarrow \mathrm{CH}_{4}-32,200(-74.9) \\
\mathrm{CO}+3 \mathrm{H}_{2} \rightarrow \mathrm{CH}_{4}+\mathrm{H}_{2} \mathrm{O}-88,700(-206.3) \\
\mathrm{CO}+\mathrm{H}_{2} \rightarrow 1 / 2 \mathrm{CH}_{4}+1 / 2 \mathrm{CO}_{2}-53,200(-123.7)
\end{gathered}
$$

Note: (-) Exothermic

$(+)$ Endothermic

The primary products of gasification are $\mathrm{CO}, \mathrm{H}_{2}$, and $\mathrm{CH}_{4}$, along with some carbon dioxide and nitrogen when air is used as the oxidant. Coproducts may include tar, oil, phenol, char, hydrogen sulfide, carbonyl sulfide, ammonia, and hydrogen cyanide. Since the primary reactions involving pyrolysis and steam gasification are endothermic, heat must be provided either externally or by the combustion of carbon. Heat from combustion can also be supplied indirectly by recycling bed material to provide either sensible heat or chemical energy (e.g., the $\mathrm{CO}_{2}$ Acceptor process). The water-gas shift and methanation reactions are exothermic and contribute to the energy balance at lower temperatures and at low temperature and high pressure where $\mathrm{CH}_{4}$ is a principal product. The particular gas composition obtained from various types of gasifiers depends on the effects of temperature, pressure, flow patterns (e.g., concurrent versus countercurrent), fluid dynamic intensity, solid and gas residence times, and catalysis on chemical kinetics and equilibrium. Although the interactions of all of these effects are usually not completely understood, it is important to consider the general principles involved in choosing a gasifier for a particular application.

\section{Equilibrium of the Carbon-Steam-Oxygen System}

The effects of temperature on gas composition at equilibrium are presented in Figure 1 for a pressure of $20 \mathrm{~atm}$ (294 psia) and in Figure 2 comparing 1 versus $70 \mathrm{~atm}$ (14.7 versus $1029 \mathrm{psia})$. At $1 \mathrm{~atm}$ pressure, the equilibrium concentration of hydrogen in dry nitrogen-free syngas approaches $50 \%$ at $650^{\circ} \mathrm{C}\left(1202^{\circ} \mathrm{F}\right)$ and then drops with increasing temperature (Figure 2). At elevated pressures, the hydrogen concentration increases with increasing temperature. Above $1000^{\circ} \mathrm{C}\left(1832^{\circ} \mathrm{F}\right)$, hydrogen levels off at between $35 \%$ and $40 \%$ regardless of pressure. The concentration of $\mathrm{CO}$ increases along with temperature to exceed the concentration of $\mathrm{H}_{2}$ above a temperature level between $700^{\circ}$ to $900^{\circ} \mathrm{C}\left(1292^{\circ}\right.$ to $\left.1652^{\circ} \mathrm{F}\right)$ depending on pressure. At high temperatures above $1100^{\circ} \mathrm{C}\left(2012^{\circ} \mathrm{F}\right)$, representative of an entrained-flow gasifier, $\mathrm{CO}$ and $\mathrm{H}_{2}$ comprise $90 \%$ to $99 \%$ of the syngas at equilibrium (Figure 1), with the ratio of $\mathrm{CO} / \mathrm{H}_{2}$ increasing along with temperature from about 1.5 at $1100^{\circ} \mathrm{C}\left(2012^{\circ} \mathrm{F}\right)$ to 1.8 at $1500^{\circ} \mathrm{C}\left(2732^{\circ} \mathrm{F}\right)$. The equilibrium concentrations of $\mathrm{CO}_{2}$ and $\mathrm{H}_{2} \mathrm{O}$ decrease with 


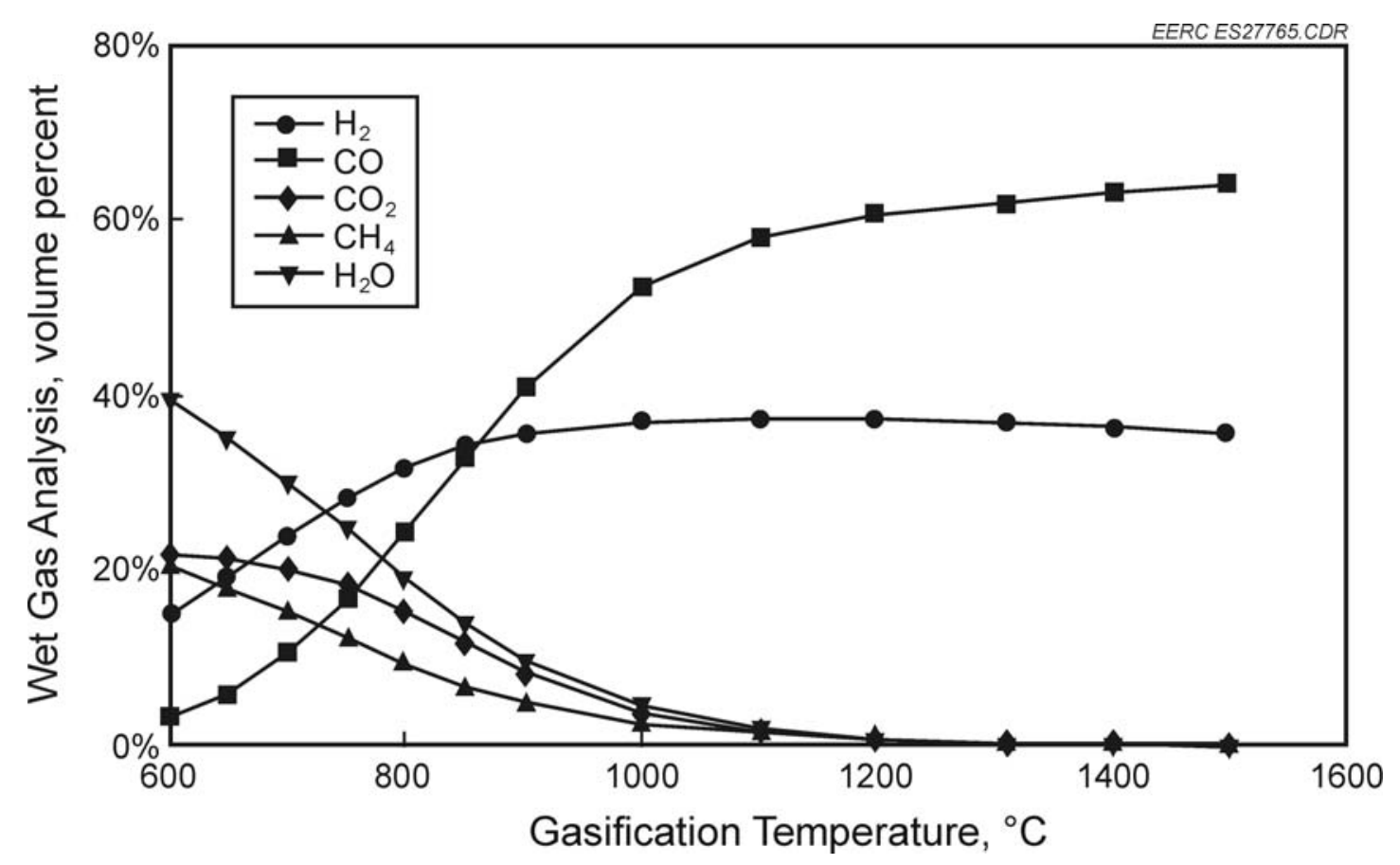

Figure 1. Effect of temperature on equilibrium gas composition.

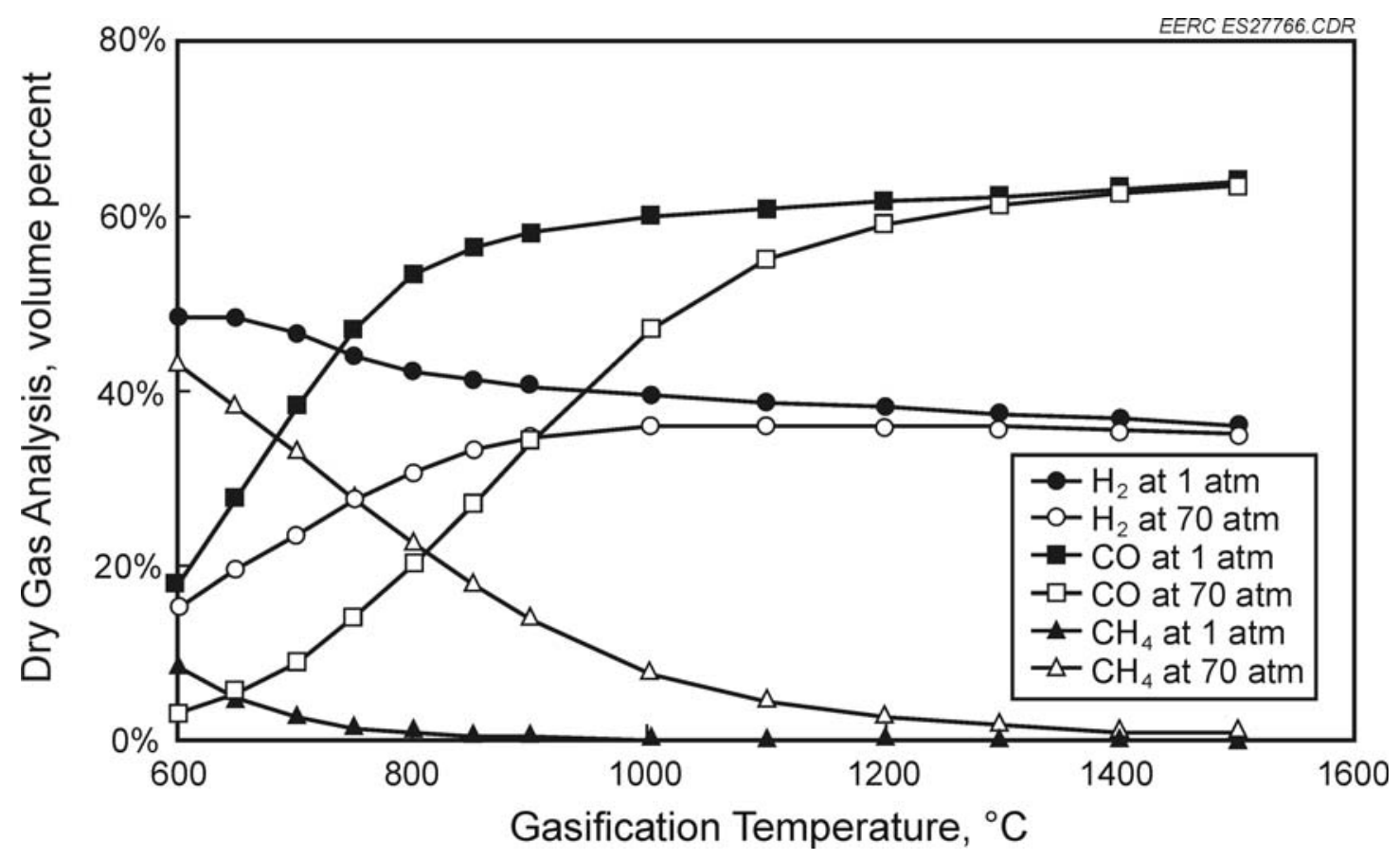

Figure 2. Effect of temperature and pressure on equilibrium gas composition. 
increasing temperature to reach negligible levels above $1100^{\circ} \mathrm{C}\left(2012^{\circ} \mathrm{F}\right)$ (Figure 1), indicating that the steam gasification and reverse water-gas shift reactions tend to approach completion at higher temperatures. The equilibrium curves presented here were calculated for the minimum amounts of steam and oxygen required to satisfy the energy balance and achieve 95\% carbon conversion. In practice, excess steam and oxygen will always be needed to drive the reaction kinetics and compensate for heat losses. Equilibrium calculations do not precisely predict gas compositions for different types of gasifiers, but they do reflect trends relating to differences in temperature and pressure. For example, low-temperature catalytic gasification processes operating in the range of $650^{\circ}$ to $750^{\circ} \mathrm{C}\left(1202^{\circ}\right.$ to $\left.1382^{\circ} \mathrm{F}\right)$ produce hydrogen at low pressure (3) and methane at high pressure (4). High-temperature entrained-flow gasifiers with exit gas temperatures in the range of $1040^{\circ}$ to $1430^{\circ} \mathrm{C}\left(1904^{\circ}\right.$ to $\left.2606^{\circ} \mathrm{F}\right)$ produce mainly $\mathrm{CO}$ and $\mathrm{H}_{2}$ at ratios generally between $1: 1$ and $2: 1$, along with $\mathrm{CO}_{2}$ in proportion to the amount of oxygen used to supply heat - which is greater for a slurry feed gasifier compared to a dry feed gasifier (5). Fixed-bed gasifiers with exit gas temperatures between $260^{\circ}$ and $540^{\circ} \mathrm{C}\left(500^{\circ}\right.$ and $\left.1004^{\circ} \mathrm{F}\right)$ and fluidized-bed gasifiers between $820^{\circ}$ and $1000^{\circ} \mathrm{C}\left(1508^{\circ}\right.$ and $\left.1832^{\circ} \mathrm{F}\right)$ produce syngas typically containing $3 \%$ to $5 \% \mathrm{CH}_{4}$ and ratios of $\mathrm{CO}$ to $\mathrm{H}_{2}$ governed by the effect of excess steam on the water-gas shift reaction (5).

\section{Gasification Reaction Kinetics}

Mass transfer and chemical reaction kinetics are the controlling factors determining the overall rate of gasification (2). Mass transfer is believed to be the dominant mechanism at temperatures above $1149^{\circ} \mathrm{C}\left(2100^{\circ} \mathrm{F}\right)$, where rates can be significantly improved by increasing the relative velocities of reactants and resulting mixing. Below $1149^{\circ} \mathrm{C}\left(2100^{\circ} \mathrm{F}\right)$, the mass action effect of reactants on chemical reaction kinetics will be more pronounced, although the effect of mixing will still be significant. An analysis of the controlling mechanisms must take into account that different reactions will predominate in different zones of a gasifier, which is illustrated by the defined zones for combustion, steam gasification, and pyrolysis/drying occurring from the bottom to the top of a fixed-bed gasifier, wherein coal is fed at the top and steam and oxygen are introduced at the bottom and pass counter currently upward through the descending bed of char.

The contributions of the different chemical reactions occurring in a gasifier can be illustrated by comparing the characteristic reaction rates for lignite shown in Table 1.

For the three heterogeneous gasification reactions between gas and carbon (Reactions 1-3 in Table 1), combustion is nearly seven orders of magnitude faster than steam gasification, and steam gasification, in turn, is about two orders faster than hydrogasification. The Boudouard reaction is slower still. In partial combustion (Reaction 1 in Table 1), the relative yield of CO versus $\mathrm{CO}_{2}$ increases along with temperature and the ratio of carbon to oxygen in the combustion zone of the gasifier (6). In a fixed-bed or fluidized-bed gasifier, where the residence time of solids is far greater than that of gas, combustion is confined to the region where oxygen is introduced, and oxygen is essentially absent outside this region. In a high-temperature entrainedflow gasifier, where the rate of reaction for carbon particles is controlled by heat and mass transfer and the residence times of both gas and carbon particles are on the order of seconds, some oxygen will be found throughout a substantial part of the reactor volume. 
Table 1. Lignite Reaction Rate Parameters ${ }^{\mathrm{a}}$

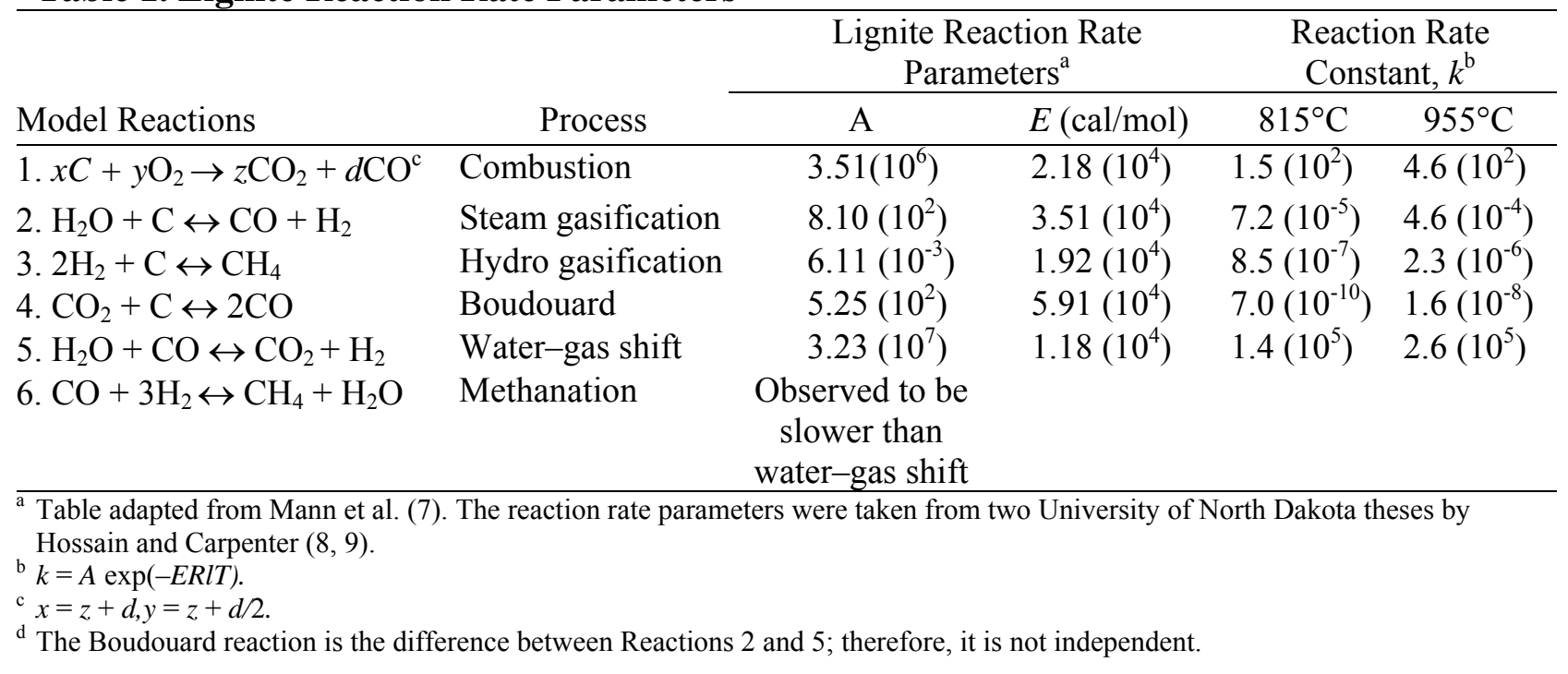

The rate of steam gasification for North Dakota lignite has been estimated to be proportional to the partial pressure of steam raised to the 0.63 power, total pressure to the -0.70 power, and $\left(\mathrm{CO} / \mathrm{CO}+\mathrm{CO}_{2}\right)^{-1.91}$, reflecting a relatively greater effect for an incremental increase in steam where steam is a small fraction of the total gas and an inhibiting effect due to the buildup of $\mathrm{CO}$ as a reaction product (7).

The homogeneous gas-phase Reactions 5 and 6 in Table 1 are carried out industrially using mixed metal oxide/sulfide catalysts to promote the water-gas shift conversion of $\mathrm{CO}$ to $\mathrm{H}_{2}$ at temperatures below $500^{\circ} \mathrm{C}\left(932^{\circ} \mathrm{F}\right)$ and nickel-based catalysts to accomplish methanation at temperatures below $300^{\circ} \mathrm{C}\left(572^{\circ} \mathrm{F}\right)$. Even without an added catalyst, the rate of the water-gas shift reaction is relatively rapid (Table 1), causing the gas composition exiting a fluidized-bed gasifier at between $820^{\circ}$ and $1000^{\circ} \mathrm{C}\left(1508^{\circ}\right.$ and $\left.1832^{\circ} \mathrm{F}\right)$ to approach the equilibrium concentration of hydrogen, which is higher when more steam is present and when the operating temperature is lower. For slurry-fed entrained-flow gasifiers operating at higher temperatures, the hydrogen content of the product gas will increase as the gas cools through a temperature range favorable for the forward reaction of $\mathrm{CO}$ and steam to produce $\mathrm{H}_{2}$. Table 1 does not include a reaction rate for methanation, but the rate can be inferred to be slower than that of the water-gas shift reaction from the fact that the concentration of $\mathrm{CH}_{4}$ exiting a gasifier at a moderately low temperature of $800^{\circ} \mathrm{C}\left(1472^{\circ} \mathrm{F}\right)$ does not begin to approach the relatively high equilibrium concentration of about $12 \%$ shown in Figure 1 . The concentration of $\mathrm{CH}_{4}$ can, however, approach its equilibrium value in a low-temperature catalytic gasifier operating with a long gas residence time of about 1 minute (e.g., the Exxon catalytic gasifier operated at $700^{\circ} \mathrm{C}$ $\left(1292^{\circ} \mathrm{F}\right.$ ) using $20 \% \mathrm{~K}_{2} \mathrm{CO}_{3}$ as a catalyst (4). 


\section{CHOOSING A GASIFIER}

The characteristics of the major gasifier types are summarized in Table 2, and temperature profiles are shown in Figure 3. Gasifiers are first categorized as entrained-flow, fixed-bed, or fluidized-bed systems and then further classified by their use of either dry or slurry coal feed and either dry-ash or slag discharge. The selection of an optimum design depends on the effect of coal properties on the operation of the gasifier and the desired gas exit conditions in relation to downstream process conditions. The temperature, pressure, and composition of the gas leaving the gasifier should match the requirements of the gas-cleaning and separation processes and enduse application to minimize cost and efficiency penalties associated with gas cooling, compression, and downstream processing.

The properties of low-rank coals that are most important in determining the choice of a gasifier are their high moisture content, their typically high calcium content, and highly variable sodium content. High moisture contents limit the use of slurry feed gasifiers, and high levels of sodium and calcium affect slag viscosity and the corrosion and deposition properties of the ash and slag, as well as enhance reactivity.

\section{Slurry-Fed Entrained-Flow Gasifiers}

The commercially available slurry-fed entrained-flow gasifiers are the General Electric (GE) and ConocoPhillips systems shown in Figures 4 and 5. In these high-throughput gasifiers, the coal slurry reacts with a concurrent flow of oxygen at peak temperatures up to $1649^{\circ} \mathrm{C}$ $\left(3000^{\circ} \mathrm{F}\right)$ or higher to produce syngas and molten slag in a residence time of seconds (see temperature profile in Figure 3). Hot product gas exiting at from $1038^{\circ}$ to $1482^{\circ} \mathrm{C}\left(1900^{\circ}\right.$ to $2700^{\circ} \mathrm{F}$ ) is either quenched or cooled in a radiant syngas cooling system. The advantage of these gasifiers for production of hydrogen or synthetic liquids is that they produce syngas having a relatively high $\mathrm{H}_{2} / \mathrm{CO}$ ratio and essentially no methane or other hydrocarbon products. Slurry feed ensures reliable high-pressure operation. These gasifiers also offer high carbon conversion, good turndown capability, tolerance for feeding caking coal, and minimum wastewater treatment requirements. The only solid waste is an inert, fritted, glassy slag. The disadvantages are a relatively high oxygen requirement, the high waste heat recovery duty, and very limited ability to use high-moisture coals.

The GE gasifier in Figure 4 is downfired and typically operates at 44.2-68 atm (650-1000 psi) with an exit gas composition of $36 \% \mathrm{H}_{2}, 47 \% \mathrm{CO}$, and $13 \% \mathrm{CO}_{2}$ (dry basis) at a temperature of $1260^{\circ}-1482^{\circ} \mathrm{C}\left(2300^{\circ}-2700^{\circ} \mathrm{F}\right)(5)$. The design is capable of gasifying essentially any carbonaceous material, but the dry-solids content in the feed slurry must approach $60 \%$ to achieve satisfactory oxygen demand, gas quality, and operating efficiency (9). The GE gasifier has been used extensively at full commercial scale, including U.S. operations on Appalachian bituminous coal in a chemical plant at Tennessee Eastman Chemical Company since 1983 and on bituminous coal and petcoke in a 250-MW IGCC Clean Coal demonstration project at Tampa Electric's Polk Power Station since 1996 (10). 
Table 2. Characteristics of Major Gasifier Types

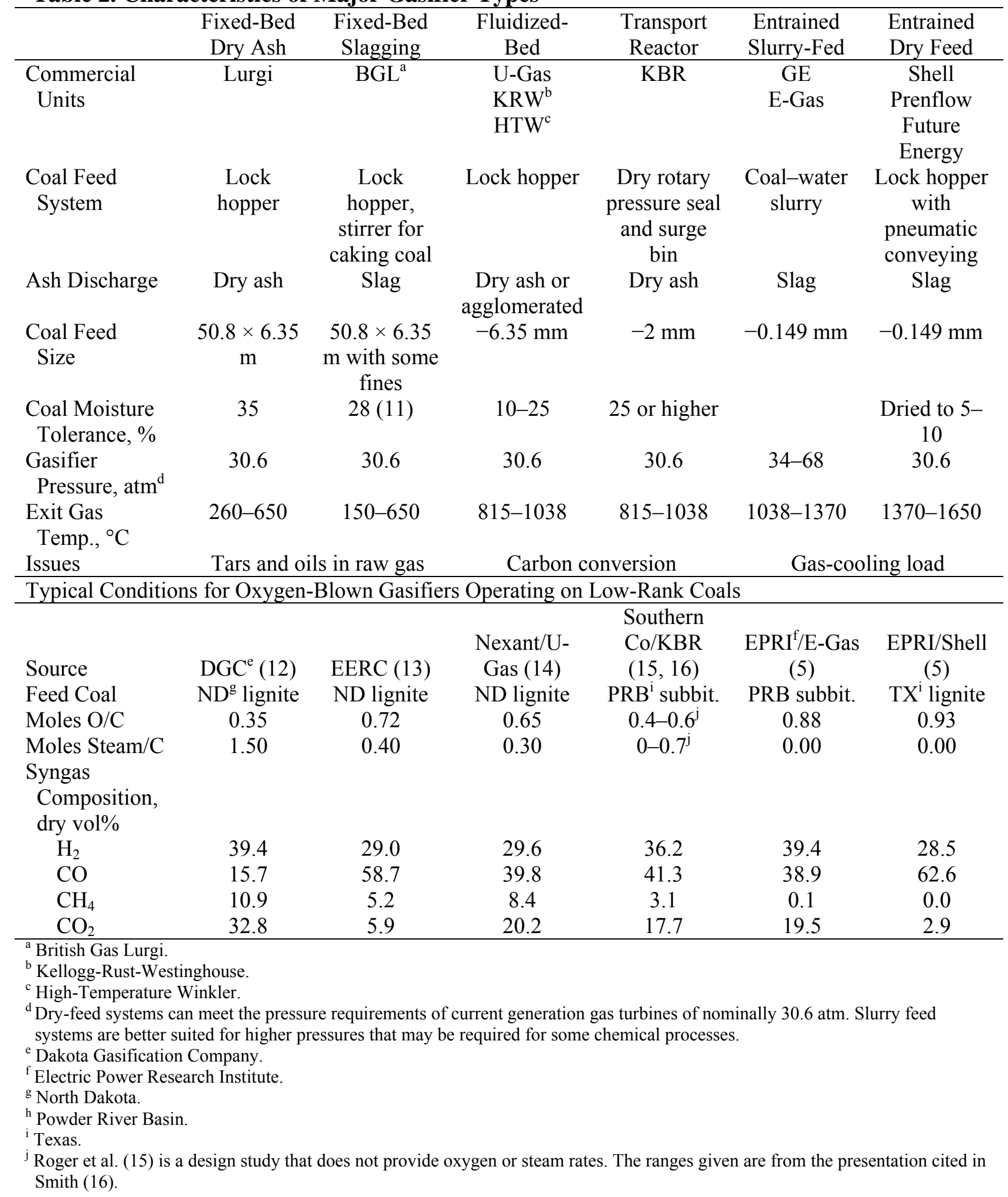



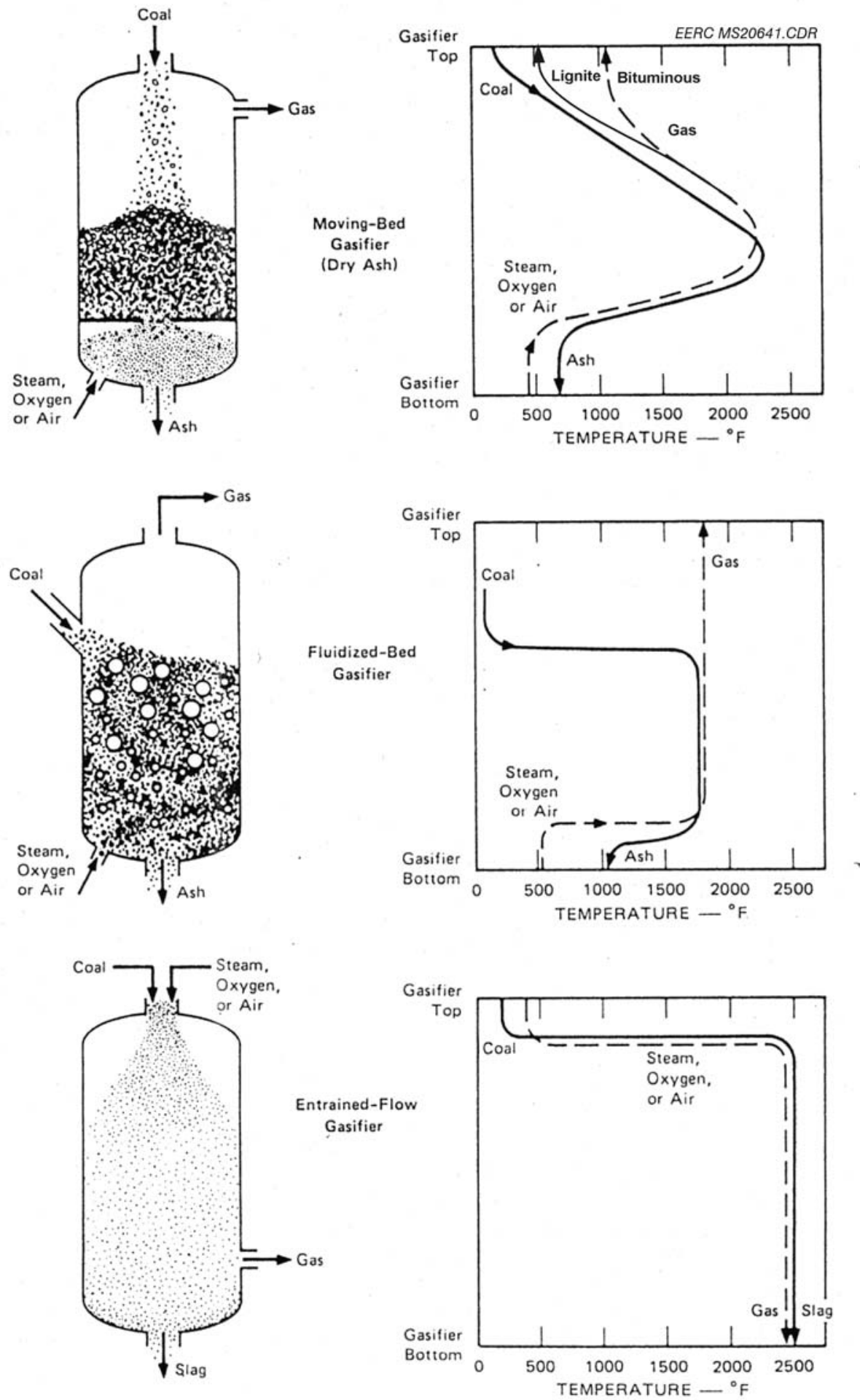

Figure 3. The three major types of gasifiers. 


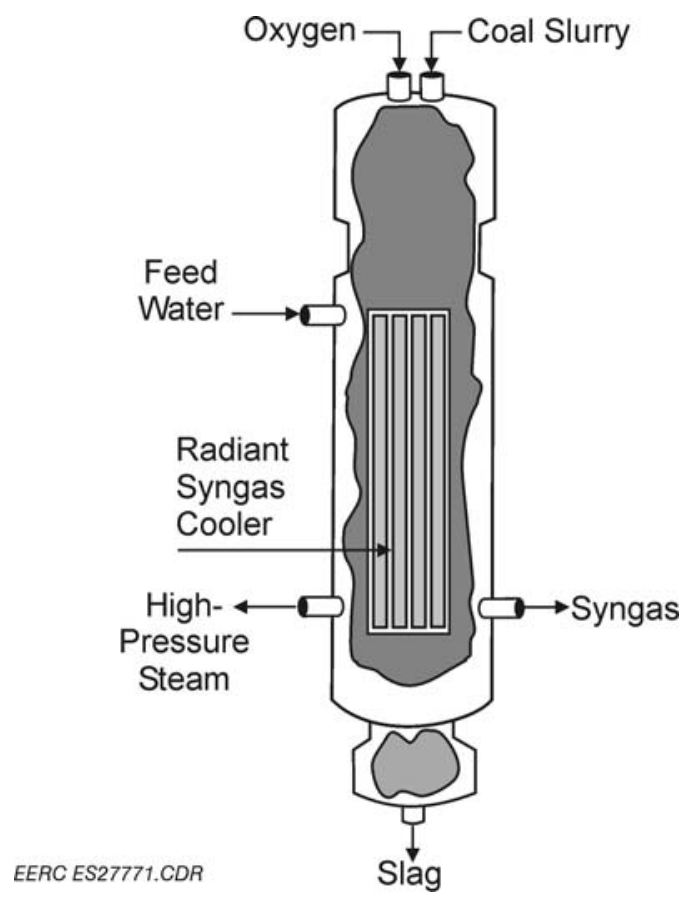

Figure 4. GE entrained-flow gasifier.

The ConocoPhillips E-Gas gasifier in Figure 5 differs from the GE design by being upward-fired and incorporating an integral second stage where $25 \%$ of the coal slurry is injected into the hot gas from the first stage to make use of latent heat to gasify additional coal and reduce the gas exit temperature to about $1038^{\circ} \mathrm{C}\left(1900^{\circ} \mathrm{F}\right)$. Unreacted char is separated from the product gas and recycled to achieve greater than $99 \%$ carbon conversion. The design has been tested on Appalachian and Illinois bituminous coals, Wyoming subbituminous coal, and Texas lignite (5). Because of the two-stage design, this gasifier has somewhat greater flexibility than the GE gasifier for operating on high-moisture coal. However, the E-Gas gasifier has a substantially greater oxygen requirement in relation to coal carbon for lignite than for bituminous coal (17) and a reduction in gas quality from $38 \% \mathrm{H}_{2}, 50 \% \mathrm{CO}$, and $9 \% \mathrm{CO}_{2}$ (dry basis) for bituminous coal to $38 \% \mathrm{H}_{2}, 33 \% \mathrm{CO}$, and $26 \% \mathrm{CO}_{2}$ for lignite (5). The gasifier has operated successfully on Illinois Basin bituminous coal and petroleum coke in a 262-MW IGCC Clean Coal demonstration project at the SG Solutions Wabash River Plant since 1995 (18), and it has been selected for the 500-600-MWe Excelsior Energy, Inc., IGCC project planned for Taconite, Minnesota, scheduled to be constructed starting in 2009 and to begin operating on PRB coal and petroleum coke in 2014 (19, Gasification Technology Conference, October 7, 2008).

In the short term, the technical limitations on the use of high-moisture low-rank coals in slurry-fed gasifiers can be remedied by blending with petroleum coke to achieve the required dry-solids concentration in the slurry. The longer-term solution would be to reduce the moisture of the feed coal by hydrothermal dewatering or thermal processing at temperatures above $240^{\circ} \mathrm{C}$ $\left(464^{\circ} \mathrm{F}\right)$ to collapse the coal structure, seal the micropores, and reduce the ability of the coal to reabsorb moisture. Low-temperature drying in hot gas is not effective owing to reabsorption of 


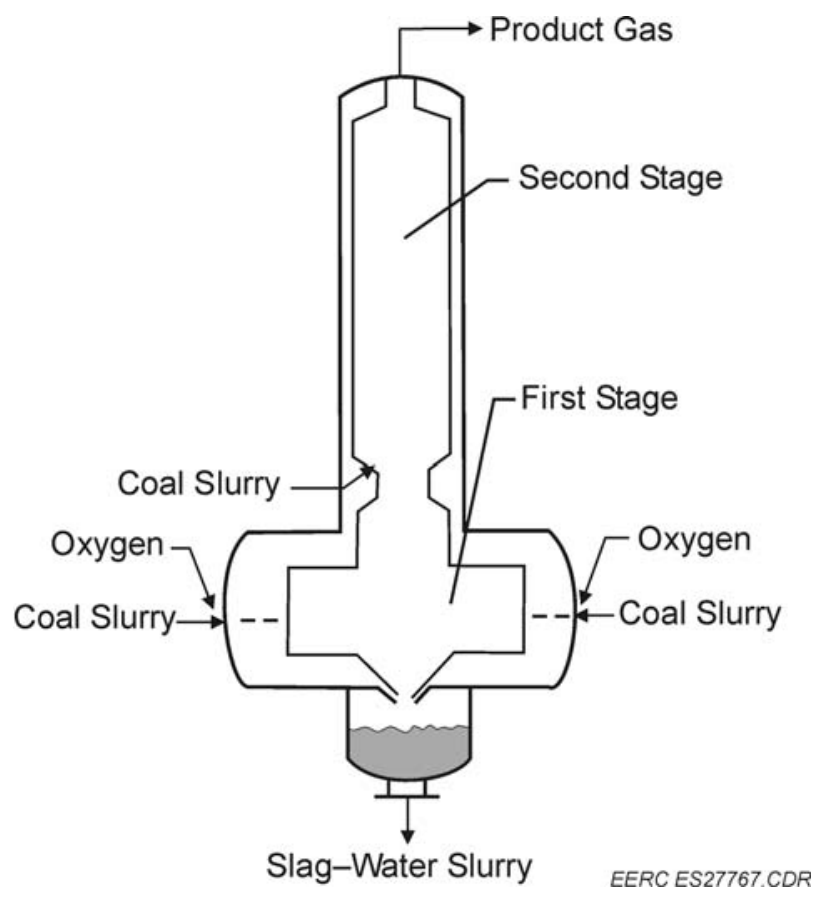

Figure 5. ConocoPhillips E-Gas gasifier.

moisture in the dried coal during slurry preparation. Hydrothermal dewatering of fine coal is accomplished in minutes at temperatures above $240^{\circ} \mathrm{C}\left(464^{\circ} \mathrm{F}\right)$ and at slightly above saturated steam pressure $(20,21)$. Excess water can be removed by centrifugation, filtration, hydroclones, and/or flashing to produce a slurry containing up to $60 \%$ dry solids. The wastewater produced can be used in the preparation of the slurry fed to the hydrothermal dewatering process. The drawback to high-temperature drying is cost, which has been estimated to be above $\$ 1 / \mathrm{kJ}$ of dried product-approximately doubling the cost of a low-rank coal feedstock (22). It may be possible to reduce the cost of high-temperature drying by integrating it with heat recovery from the gasification process, but process development would be required.

\section{Dry Feed Entrained-Flow Gasifiers}

In the Shell pressurized entrained-flow gasifier, dry pulverized coal is pneumatically fed to the burners of an upward-fired gasifier in a dense fluidized phase (5). Oxygen is added at the burners, along with steam, as required, to control the operating temperature. The typical operating pressure is $350-400 \mathrm{psi}$. The raw gas leaving the gasifier at $1371^{\circ}-1649^{\circ} \mathrm{C}\left(2500^{\circ}-\right.$ $3000^{\circ} \mathrm{F}$ ) contains a small amount of unburned carbon and about half the molten ash. The gas is partially cooled by quenching with cool recycle gas to solidify the molten ash before its removal as dry fly ash, and the hot gas is then further cooled in a syngas cooler.

Shell and Krupp Koppers cooperated in the development of the gasifier between 1974 and 1981. Since then, Shell Oil Company has pursued the development of the Shell gasifier, and Krupp Koppers has continued its own development of a similar technology called Prenflow. Future Energy $\mathrm{GmbH}$ also developed a similar gasifier design that was recently sold to Siemens. 
These gasifiers share many of the advantages of slurry-fed entrained-flow gasifiers, including a syngas having a relatively high $\mathrm{H}_{2} / \mathrm{CO}$ ratio and essentially no methane or other hydrocarbon products. They again offer high carbon conversion, good turndown capability, tolerance for feeding caking coal, and minimum wastewater treatment requirements. The unique advantage of the Shell gasifier and other dry feed technologies over slurry-fed gasifiers is their ability to gasify a wide variety of coals ranging from anthracite to brown coal. The Shell dry feed system incorporates drying pulverizers that are reported to handle all types of coal with essentially no design modifications (5). The disadvantages are, again, a relatively high oxygen requirement and the high waste heat recovery duty. The energy and material balances given for the Shell technology show similar oxygen requirements and product gas analysis (e.g., about $28 \% \mathrm{H}_{2}$, $62 \% \mathrm{CO}$, and $2 \%-3 \% \mathrm{CO}_{2}$ ) for either Illinois bituminous coal or Texas lignite (5). The Shell gasifier has operated successfully on a range of bituminous coals in a 253-MW IGCC plant in the Netherlands since 1998. The Prenflow gasifier has operated on bituminous coal and petroleum coke in a 298-MWe IGCC plant in Puertollano, Spain, since 1998. A 130-MWth Future Energy gasifier operated on German brown coal from 1984 to 1991 and thereafter on waste oil. Lowrank coals typically have to be dried to less than $10 \%$ to be fed to these systems.

\section{Ash and Slag Behavior in High-Temperature Gasifiers}

Generally, high-ash coals are not good candidates for slagging gasifiers as the high levels of ash place an extra-large heat load on the gasifier, since the ash not only has to be heated to the final gasifier temperature, but the ash also has to undergo a phase change as it is melted, requiring even more energy from the gasification process. Other problems associated with hightemperature slag produced by highly alkaline low-rank coals will be similar for all of the above entrained-flow gasifiers. In lower-temperature zones, similar ash deposition problems associated with high sodium content can be encountered in both entrained-flow and fluidized-bed gasifiers. The behavior of ash and slag in reducing environments has been investigated in the Coal Ash Behavior in Reducing Environments (CABRE) project at the EERC under the support of an industrial consortium (23). Algorithms were developed for estimating vapor, fine particulate, and ash deposition species from data on coal analyses and gas compositions in the gasifier. Gasifierspecific results and predictive models are proprietary to the sponsors, but the results that are available to the public indicate that different mechanisms control the behavior of the ash in the various temperature zones in a gasifier: 1) ash fusion and slag fluidity at high temperatures, 2) deposits of calcium aluminosilicates at high to intermediate temperatures, and 3) sintered ash deposits typically containing high concentrations of iron sulfides at lower temperatures. Coals with high concentrations of sodium and calcium have been found to produce strong ash deposits at high to intermediate temperatures, which reflects the well-established trend for pulverized-coal combustion systems operating on lignite. Slags from high-sodium low-rank coals typically have low viscosities suitable for maintaining slag flow, but some other low-rank coals produce ash with a high fusion temperature that is problematic in maintaining slag flow at desired operating temperatures. Slag from coals that contain high concentrations of both sodium and calcium exhibits a sharp drop in viscosity when heated just above its melting point. The resulting lowviscosity slag can corrode metal and refractory surfaces in high-temperature zones. At lower temperatures associated with ash deposition, eutectics formed from $\mathrm{Na}_{2} \mathrm{~S}, \mathrm{FeS}, \mathrm{Na}_{2} \mathrm{O}$, and $\mathrm{SiO}_{2}$ are believed to be the principal cause of ash sintering and deposition. Gas transport mechanisms that move volatile species from higher-temperature to lower-temperature zones serve to reduce 
the viscosity of eutectic melts and intensify sintering. Any volatile alkali species that remain in product gas after hot-gas cleaning can result in the corrosion of gas turbine blades. For all of these reasons, the ash and slag properties of low-rank coals, which can be very coal-specific, need to be carefully considered when the operating conditions of the gasifier are chosen.

\section{Dry-Ash Fixed-Bed Gasifiers}

The dry-ash fixed-bed Lurgi gasifier shown in Figure 6 was first commercially demonstrated in Germany in 1936 and has since been used worldwide on noncaking fuels, including major installations at SASOL in South Africa and the Dakota Gasification Great Plains Plant in North Dakota. Other fixed-bed designs include the Wellman-Galusha, the Riley-Morgan, the two-stage Woodall-Duckham, and a number of lesser used designs. All of these gasifiers use the temperature moderating effect of a high ratio of steam to oxygen to maintain the gasification temperature at the bottom of the bed below the fusion temperature of the ash. Clinker formation can be a problem for high-sodium low-rank coals if the temperature in the combustion zone approaches the initial deformation temperature of the ash. Low-rank coals are an ideal feedstock in that they are more reactive than bituminous coals at relatively low operating temperatures and are also noncaking. Lurgi gasifiers can be operated on either air or oxygen at pressures up to 450 psig. Because of their widespread application, including the lessons learned at the Dakota Gasification Plant operating on North Dakota lignite, gasifiers of this design represent a standard against which other designs can be compared (10). This plant was designed for zero liquid

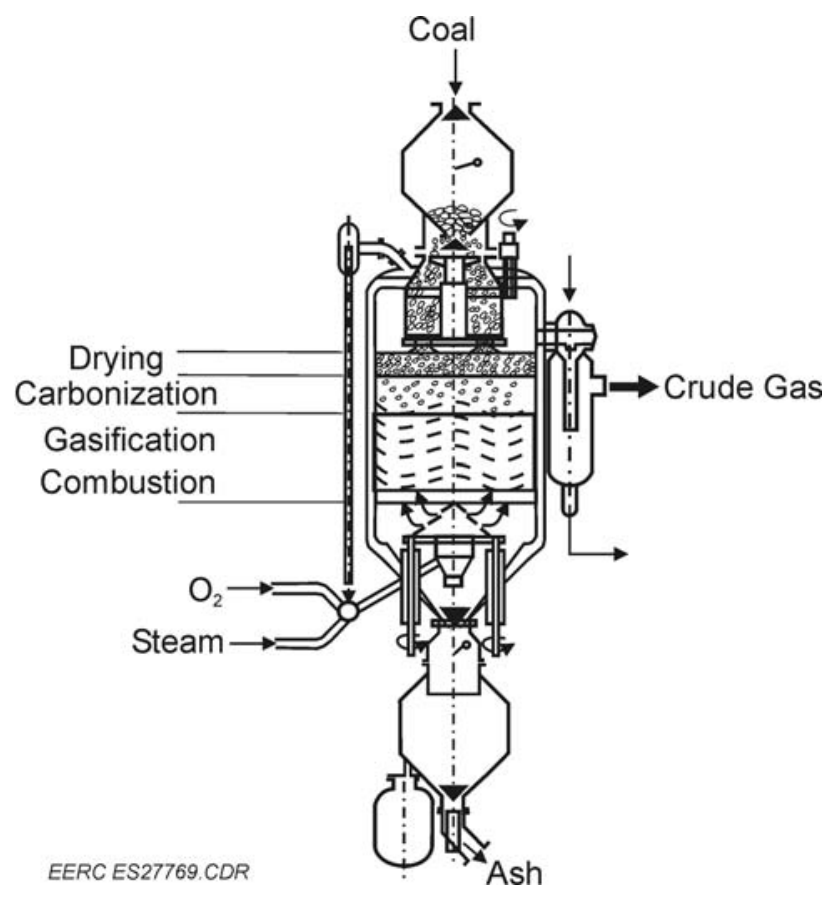

Figure 6. Lurgi fixed-bed gasifier. 
discharge by using treated gas liquor as the makeup to cooling towers, which has required ongoing attention to resolve problems of tower plugging and heat exchanger fouling.

Fixed-bed gasifiers have the inherent advantages of essentially complete carbon conversion, high thermal efficiency, and relatively low offgas temperature because of the countercurrent flow of fuel and gaseous reactants. A constant bed depth is maintained in the gasifier by adding coal at the top through a lock hopper and discharging ash through a grate at the bottom. Coal fed at the top is progressively heated and reacted as it moves down through drying, devolatilization, gasification, and oxidation zones as shown by the temperature profile in Figure 3. The air or oxygen and steam used as the gasification medium converts coal to synthesis gas $\left(\mathrm{CO}\right.$ and $\left.\mathrm{H}_{2}\right)$ by partial oxidation, steam gasification, and water-gas shift reactions. Coal feed size and friability are important considerations in maintaining gas flow and limiting coal dust carryover in the product gas, and the coal feed must be double-screened to remove fines and provide a minimum particle size of about $1 / 4$ inch. Highly friable coals that would crumble within the gasifier are not suitable feedstocks for fixed-bed gasifiers. The Lurgi dry-ash gasifier produces raw product gas with an analysis of $39 \% \mathrm{H}_{2}, 16 \% \mathrm{CO}, 31 \% \mathrm{CO}_{2}$, and $11 \% \mathrm{CH}_{4}$ (dry basis) and has an exit gas temperature of $316^{\circ} \mathrm{C}\left(600^{\circ} \mathrm{F}\right)$ operating on lignite containing $33 \%$ moisture (5).

The disadvantage of fixed-bed gasifiers is that the raw product gas contains all of the devolatilization products, including methane, water, hydrocarbons, and heavy tars. The processing steps required to condense and separate this tar, oil, and gas liquor add to the complexity and cost of a fixed-bed gasification system, compared to other gasification systems that break down volatile organics within the gasifier; however, the separated tar and oil also provide a source of potentially valuable by-products.

The creative use of a fixed-bed gasifier was indicated to be a potential least-cost IGCC option in a 1990 DOE study report on a broad range of systems (24). The favored system used predried coal as feed to a Lurgi gasifier to provide an exit gas temperature above $538^{\circ} \mathrm{C}\left(1000^{\circ} \mathrm{F}\right)$ that could be matched with a hot-gas cleaning system that incorporated a second fixed bed for tar cracking and desulfurization. This would, in principle, resolve the major disadvantage of a fixedbed gasifier, i.e., tar. The resulting product gas would be a good starting point for producing hydrogen if there were an on-site use for the relatively high yield of methane. The methane separated in the gas separation process could be subsequently reformed. A plant design based on the envisioned system would require process development.

\section{The British Gas Lurgi Fixed-Bed Gasifier}

Initial development of the BGL slagging fixed-bed gasifier was started by Lurgi and Ruhrgas in Germany in the early 1950s and continued at British Gas between 1955 and 1964 (5). British Gas operated two larger pilot plants of 272- and 453-tonne/day capacity between 1974 and 1990, supported in part by a consortium of U.S. companies led by Continental Oil. A parallel development was conducted in a smaller 18-tonne/day pilot plant by the U.S. Bureau of Mines and DOE at the Grand Forks Energy Technology Center (GFETC, which later became the EERC) between 1958 and 1983, focusing on hearth plate design and treatment of liquid effluents $(13,25,26)$. The research and development sponsored by DOE provides a support database on 
process effluents, by-products, and waste treatment methods. Allied Syngas Corporation is commercializing this technology in North America.

The principal differences between the slagging design and a dry-ash Lurgi gasifier are in the substitution of a slagging hearth and taphole for the ash grate and the fourfold reduction in steam flow per ton of coal which allows the oxidation zone of the gasifier to reach temperatures above the $1371^{\circ} \mathrm{C}\left(2500^{\circ} \mathrm{F}\right)$ required for slag tapping. The configuration of the BGL gasifier is similar to that of the Lurgi dry-ash gasifier shown in Figure 6, except for the slagging bottom. The slagging gasifier requires considerably more oxygen per pound of moisture and ash-free coal than the dry-ash Lurgi gasifier $\left(0.33\right.$ vs. $0.16 \mathrm{~kg}[0.72$ versus $0.35 \mathrm{lb}] \mathrm{O}_{2}$ for lignite $\left.[12,13]\right)$. The typical raw product gas analysis is similar for lignite and bituminous coal (ca. $32 \% \mathrm{H}_{2}, 55 \% \mathrm{CO}$, $3 \%-9 \% \mathrm{CO}_{2}$, and $5 \% \mathrm{CH}_{4}$, dry basis), and the gas exit temperature ranges from about $260^{\circ} \mathrm{C}$ $\left(500^{\circ} \mathrm{F}\right)$ for lignite to over $538^{\circ} \mathrm{C}\left(1000^{\circ} \mathrm{F}\right)$ for bituminous coal $(5,13)$. Because of the lower steam partial pressure, the slagging gasifier produces considerably less $\mathrm{H}_{2}$ and more $\mathrm{CO}$ compared to the dry-ash Lurgi, but less $\mathrm{CO}_{2}$. The advantages of the slagging gasifier are a higher thermal efficiency and a greatly reduced volume of gas liquor. Also, British Gas has demonstrated that tars and oils can be reinjected into the gasifier and recycled to extinction (11). The high-temperature slagging design is specifically recommended for bituminous coals that would not be suitable for the low-temperature, dry-ash Lurgi process because of their lower reactivity. However, the technology is applicable to all ranks of coal and other carbon fuels including petroleum coke and biomass. British Gas successfully pilot-tested all ranks of coal, including U.S. PRB subbituminous coal (11), and the GFETC (EERC) pilot plant was operated successfully on both lignite and subbituminous coal $(12,26)$. A 3.66-m (12-ft-)-diameter, 31.8-tonne/day BGL gasifier has operated commercially since 2000 at Scharze Pumpe in Germany on coal and waste materials to produce syngas for methanol synthesis $(11,27,28)$.

Potential problems in operating a slagging fixed-bed gasifier on low-rank coals would concern slag flow and corrosion of refractory materials, similar to the problems discussed previously for slagging entrained-flow gasifiers. In tests performed in the 18-tonne/day pilot plant at the EERC, operation on North Dakota lignite resulted in occurrences of interrupted slag flow and severe slag attack on refractory in the hearth zone when high-sodium and high-calcium lower-rank coals were fired (26). Various hearth plate materials in combination with different types of cooling coils and taphole inserts were tested. Erosion occurred on all of the refractory hearth plates that were not sufficiently cooled. Slag flow problems were resolved by designing a water-cooled metal hearth plate.

\section{Fluidized-Bed Gasifiers: U-Gas, KRW, and HTW}

The commercially available U-Gas, KRW, and HTW fluidized-bed gasifiers are represented by the generic schematic in Figure 7. The KBR transport gasifier differs significantly from these three designs and will be discussed separately. Fluidized-bed gasifiers operate by suspending coal in turbulent motion in an upward flow of steam and oxidant gas at gas velocities that typically range from about 1.5 to $6.1 \mathrm{~m} / \mathrm{sec}$ ( 5 to $20 \mathrm{ft} / \mathrm{sec}$ ). The resulting turbulence results in excellent gas-solid contact and high rates of heat and mass transfer while maintaining a relative constant gasifier temperature as shown by the temperature profile in Figure 3. Fluidized- 


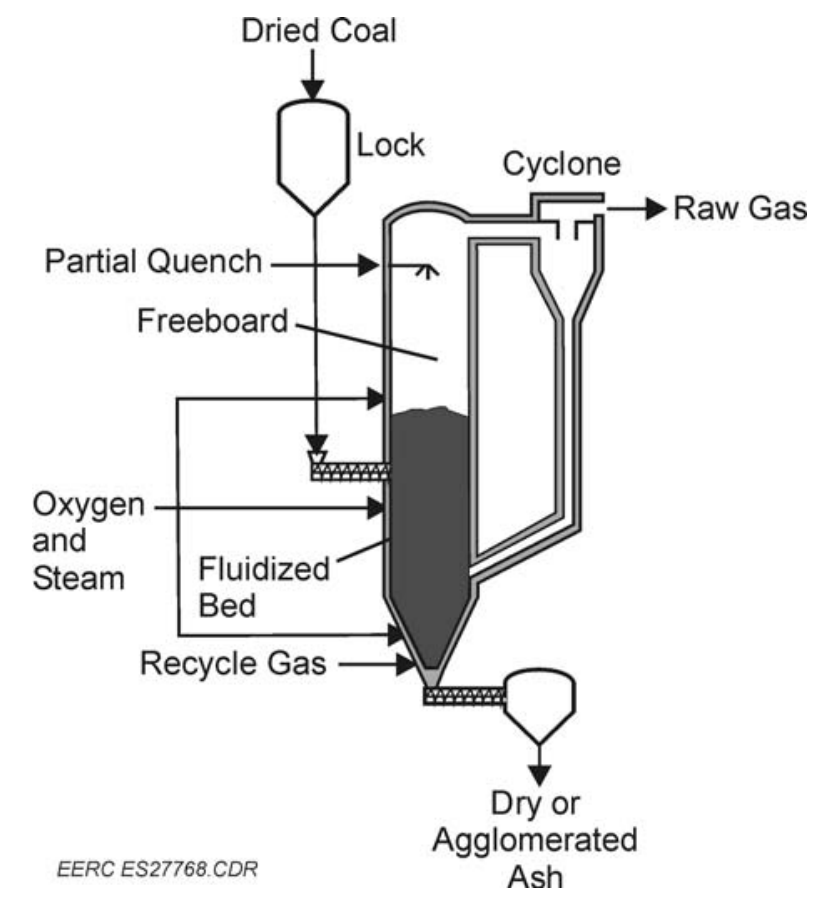

Figure 7. Generic schematic of a fluidized-bed gasifier representing the U-Gas, KRW, and HTW designs.

bed gasifiers have been designed for a wide range of operating conditions involving different temperatures, gas velocities, gaseous reactants, and bed materials. Two or more beds in series can be used to facilitate sequential reaction steps under optimum conditions. Advantages offered by various designs include flexibility to handle a wide range of caking and noncaking coals, low yields of tar and oil, and in-bed sulfur capture using limestone. Up to $90 \%$ sulfur removal can be accomplished in the bed at temperatures around $900^{\circ} \mathrm{C}\left(1625^{\circ} \mathrm{F}\right)$, where the limestone is substantially calcined. Disadvantages are carryover of coal fines and limited turndown capability because of the need to maintain fluidizing velocities. Special attention to design is required to deal with problems of agglomeration in the feeding of highly caking coals and ash deposition when high-sodium low-rank coals are used.

The U-Gas and KRW reactors employ a similar design concept to facilitate internal disengagement and recycle of char particles in a spouting bed, where the expanding diameter of the gasifier reduces the velocity so that larger unreacted char particles fall back into an internal solids recirculation pattern. All three fluidized-bed gasifiers, including the HTW, use external cyclones to separate char from the product gas for recycle back to the bottom of the gasifier.

The U-Gas process was developed by the Gas Technology Institute (GTI), formerly the Institute of Gas Technology (IGT), in the late 1970s and 1980s in tests on a 22.6-tonne/day pilot plant. The technology has been licensed to Enviropower in Finland for commercialization in Europe. Dried, crushed coal $(20 \%$ moisture, sized to $-6.35 \mathrm{~mm} \times 0)$ is fed into the bed through a lock hopper, and steam and oxygen or air are introduced in the bottom of the bed. Agglomerated ash is removed from the high-temperature zone at the bottom of the bed, which allows low- 
carbon ash to be removed from the high-carbon fluidized bed. The process is designed to operate at temperatures between $760^{\circ} \mathrm{C}$ and $982^{\circ} \mathrm{C}\left(1400^{\circ}\right.$ and $\left.1800^{\circ} \mathrm{F}\right)$ and up to $30 \mathrm{~atm}(29)$. The hightemperature agglomerating zone reportedly provides a higher carbon conversion (e.g., 95\%) with lower external char recycle than conventional fluidized-bed gasifiers. A recent 251-MWe IGCC design study on an oxygen-blown U-Gas gasifier operating on North Dakota lignite at $871^{\circ} \mathrm{C}$ $\left(1600^{\circ} \mathrm{F}\right)$ and $30.6 \mathrm{~atm}(450 \mathrm{psia})$ indicated an oxygen/carbon mole ratio of 0.65 moles and a steam/carbon ratio of 0.30 (14). The predicted dry product gas analysis was $30 \% \mathrm{H}_{2}, 40 \% \mathrm{CO}$, $20 \% \mathrm{CO}_{2}$, and $8 \% \mathrm{CH}_{4}$. Commercially operating U-Gas gasifiers include one 349-tonne/day (385-tonne/day) unit at IBIL Energy Systems, Ltd., in India that started in 2002 and eight 798-tonne/day units at the Shanghai Pacific Chemical Company, Ltd., in China operating since 1994 (30).

The KRW is similar to the U-Gas process in that it uses ash agglomeration to achieve high carbon conversion, which is important for processing low-reactivity bituminous coals. A key difference is that the KRW gasifier recycles product gas to control gas velocity and temperature. Westinghouse tested the KRW process in a small 27.2-tonne/day (30-t/d) pilot unit and the 181-tonne/day (200-t/d) Waltz Mill pilot plant between 1975 and 1988 (31, 32). Tests were run on single-stage and two-stage configurations in both air- and oxygen-blown modes for producing either low- or medium-heating value gas from coals of all ranks from lignite to bituminous. Coal feed is crushed to minus $1 / 4 \mathrm{in}$. and partially dried to reduce surface moisture. The single-stage process, designed for moderately caking coals and noncaking low-rank coals, uses a spouting bed wherein coal and recycled char fines are pneumatically injected through an axial feed tube in a high-velocity flow of transport gas into a converging stream of air or oxygen. The coal experiences rapid devolatilization and partial combustion in the inlet jet. Larger unreacted char particles fall back into an internal recirculation pattern of the spouting bed to undergo further gasification. Fines entrained out of the gasifier are separated in a cyclone and reinjected with the coal feed. Agglomerated ash is removed through a rotary valve at the bottom of the gasifier. The test gasifier operated at nominally $16.6 \mathrm{~atm}$ (230 psig) and at temperatures of $816^{\circ}$ to $1038^{\circ} \mathrm{C}$ $\left(1500^{\circ}\right.$ to $\left.1900^{\circ} \mathrm{F}\right)$.

An air-blown KRW gasifier together with a newly developed hot-gas-cleaning system was tested between 1998 and 2000 at the 107-MWe Piñon Pine IGCC Clean Coal Technology Demonstration project near Reno, Nevada (32). The hot-gas-cleaning system consisted of a zinc oxide/nickel oxide desulfurizer and regenerator followed by ceramic candle filters. The gasifier operated for short test periods on low-sulfur western bituminous coal from the Sufco Mine in Utah at nominally $922^{\circ} \mathrm{C}\left(1700^{\circ} \mathrm{F}\right)$ and $23.1 \mathrm{~atm}(325 \mathrm{psig})$. The typical dry flue gas analysis was $15 \% \mathrm{H}_{2}, 25 \% \mathrm{CO}, 6 \% \mathrm{CO}_{2}, 1.5 \% \mathrm{CH}_{4}$, and $51 \% \mathrm{~N}_{2}$. After 24 unsuccessful attempts to achieve sustained operation, testing was discontinued in August 2000, and the gasifier was mothballed. The DOE postproject assessment attributed failure in part to the decision to incorporate two new technologies in a single demonstration: the KRW gasifier and the hot-gas-cleaning system (32). Most of the start-up difficulties were caused by problems with the removal of fines from the hotgas filter system, rather than with the gasifier. The combined-cycle portion of the plant, including the GE turbine, heat recovery steam generator, and steam turbine/generator, operated reliably on natural gas. However, since integrated operation was not achieved, the gasifier could not be successfully demonstrated. 
The HTW process is an extension of the atmospheric Winkler fluidized-bed technology commercialized in the 1920s for German brown coal. Development work on an intermediatepressure (1.12 atm [150 psig]) HTW process was performed on a 31.8-tonne/day (35-t/d) pilot plant operated between 1978 and 1985 and on a 720-tonne/d unit supplying syngas to an existing methanol plant between 1986 and 1997 (5, 33, 34). Intermediate pressures minimize the production of methane in favor of $\mathrm{CO}$ and $\mathrm{H}_{2}$, which are desired for most syngas applications. Further development of the HTW process at higher pressures for IGCC applications has been carried out in a 170-tonne/day gasifier designed for 24.8 atm (350 psig) pressure using either air or oxygen. Dried coal crushed to minus $-6.35 \mathrm{~mm}$ is fed from pressurized lock hoppers by a variable-speed screw into the fluidized-bed operating at a superficial gas velocity of about $3.66 \mathrm{~m} / \mathrm{sec}(12 \mathrm{ft} / \mathrm{sec})$ and $760^{\circ}-816^{\circ} \mathrm{C}\left(1400^{\circ}-1500^{\circ} \mathrm{F}\right)$. Steam and oxidant are injected both at the bottom of the bed and also above the bed to raise the freeboard temperature to about $1038^{\circ} \mathrm{C}$ $\left(1900^{\circ} \mathrm{F}\right)$ to increase carbon conversion and reduce the yield of tar and oil. Coarse particles entrained in the exit gas are recovered in a primary cyclone and recycled through a dip leg. Carbon conversions of $96 \%$ have been reported for German brown coal. Ash deposition problems encountered at higher gasification temperatures have been controlled by the addition of limestone or dolomite to raise the fusion point of the lignitic-type ash in the German brown coal.

\section{The KBR Transport Gasifier}

The KBR transport gasifier shown in Figure 8 is a simple and robust design offering great flexibility for operating on a variety of coals in either air- or oxygen-blown modes to satisfy the requirements of both power and synfuels applications. It operates at considerably higher circulation rates, velocities, and riser densities than conventional circulating beds, resulting in higher throughput, better mixing, and increased heat, mass, and transfer rates. It is one of the

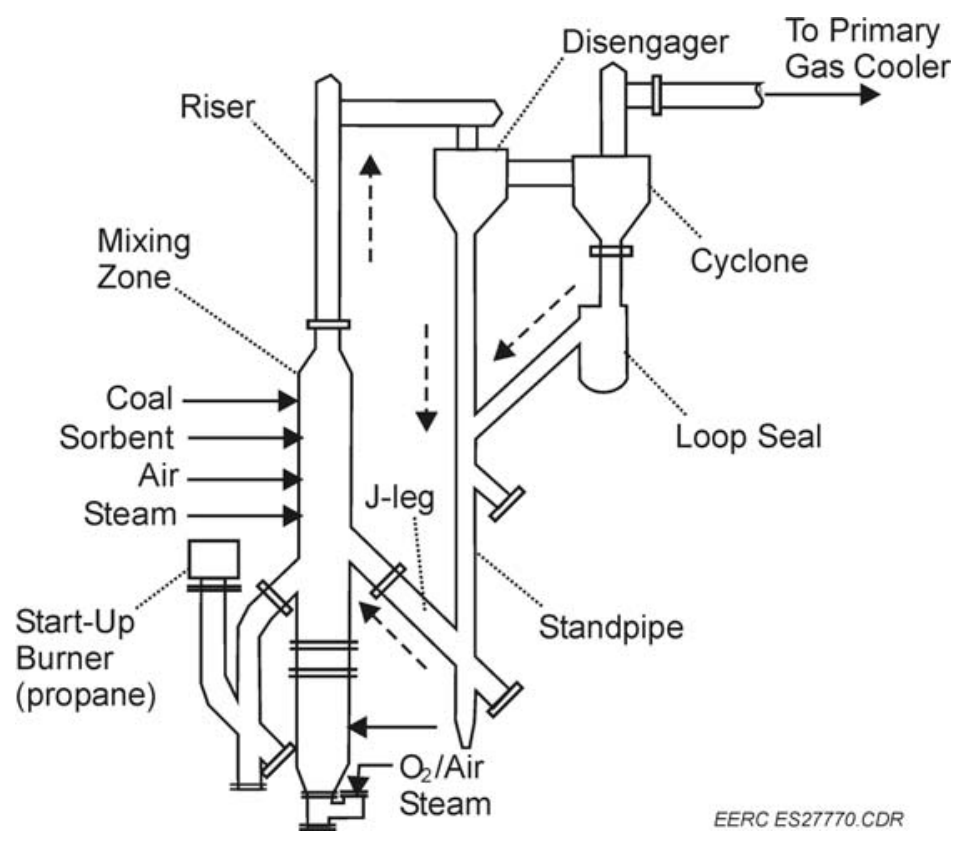

Figure 8. KBR transport gasifier. 
cornerstones of DOE's advanced power systems program to develop technology for producing electric power, hydrogen, and clean liquid fuels from coal with near-zero emissions. This gasifier has been developed with the support of DOE by the EERC, Southern Company, and KBR based on KBR's fluidized-bed catalytic cracking technology, first in tests on a 200-500-lb/hr (91-227-kg/hr) TRDU at the EERC and then in the 907-2721-kg/hr (1-3-ton/hr) engineeringscale PSDF in Wilsonville, Alabama. Both test units are designed for exit gas temperatures up to $1038^{\circ} \mathrm{C}\left(1900^{\circ} \mathrm{F}\right)$. Design pressures are $9.2 \mathrm{~atm}(120 \mathrm{psig})$ for the TRDU and $20.4 \mathrm{~atm}(285 \mathrm{psig})$ for the PSDF. The transport gasifier is unique among gasification technologies in its ability to use higher-moisture low-rank coals at lower temperatures that avoid ash deposition while still achieving good carbon conversion efficiency.

The reaction zone of the EERC transport gasifier in Figure 8 incorporates a larger-diameter mixing zone, followed by a smaller-diameter riser. A number of design modifications relating to mixing zone volume, feed locations, and coal or char residence times have been investigated on the TRDU to optimize performance (37). Normally, coal is fed near the top of the mixing zone, and air or oxygen and steam are introduced at the bottom. The entering oxidant is consumed essentially immediately by recirculating char to provide heat, and the feed coal is thereby allowed to devolatilize and react with steam in an almost oxygen-free environment. Gas residence time in the TRDU is 1 to 2 seconds for a riser velocity of about $9 \mathrm{~m} / \mathrm{sec}(30 \mathrm{ft} / \mathrm{sec})$, and char residence time in the mixing zone and riser is estimated to be about 45 seconds per pass based on cold-flow and tracer tests. Gas residence time in the PSDF is 3 to 4 seconds at about $25 \mathrm{ft} / \mathrm{sec}(7.6 \mathrm{~m} / \mathrm{sec})$ after modification to improve carbon conversion. Tar production is minimized by very rapid heating of coal in the mixing zone and tar cracking in the riser. Coal sulfur is partially captured as calcium sulfide by the calcium in the coal or added calcium sorbent. Char leaving the riser is separated from the raw product gas by a disengager and primary cyclone and recycled back to the mixing zone through a standpipe and nonmechanical "J-leg." Recycling results in high carbon conversion and sorbent utilization. Product gas and the fine char not captured in the cyclone are cooled to between $204^{\circ}$ and $427^{\circ} \mathrm{C}\left(400^{\circ}\right.$ and $\left.800^{\circ} \mathrm{F}\right)$, depending on filter material, before entering the candle-filter particulate control device (PCD).

The 2721-kg/hr (3-ton/hr) PSDF engineering test unit has verified the commercial potential of the KBR transport gasifier and has provided the design basis for Southern Company's cancelled Orlando, Florida, 285-MW IGCC demonstration project and the proposed 550-MW Kemper County IGCC project to be operated on Mississippi lignite. As of 2006, the PSDF had logged 8300 total hours of gasification run time on six different test coals, including PRB subbituminous coal; bituminous coals from Alabama, Utah, and Indiana; and two lignites from North Dakota (36). PRB coal has been the primary test fuel, with 6841 hours of run time. Tests on lignite alone, or on lignite in conjunction with some run time on PRB coal, total 1528 hours. Additional tests on lignite are scheduled in late 2006. The unit has operated on both air and oxygen, with 1722 hours of oxygen-blown operation including all ranks of coal.

The TRDU at the EERC, which provided proof of concept for building the PSDF and continues to provide test data on design modifications and a broader range of test fuels, has operated for a total of 2850 hours in both air- and oxygen-blown modes on 16 different fuels including U.S. lignite, subbituminous, and bituminous coals; Australian brown coal; petroleum 
coke; and wood residue (hog fuel) (37-43). Tests performed on the TRDU have also demonstrated removal of mercury from syngas on treated activated carbon $(39,40)$.

Table 3 presents typical performance parameters for the transport gasifier. The gasifier is capable of achieving acceptable carbon conversions for different coals by operating over a range of temperatures from $843^{\circ}$ to $1038^{\circ} \mathrm{C}\left(1550^{\circ}\right.$ to $\left.1900^{\circ} \mathrm{F}\right)$ to accommodate both the ash-fouling properties of reactive high-sodium lignite at low operating temperatures and the less reactive properties of bituminous coals at high operating temperatures. Wet coal containing up to $45 \%$ total moisture (inherent and surface) was successfully fed to the PSDF by raising the mill

Table 3. Representative Performance Parameters for the Transport Gasifier

\begin{tabular}{|c|c|c|c|c|}
\hline & Data Source & ND Lignite & Subbituminous & Bituminous \\
\hline Temperature in Mixing Zone, ${ }^{\circ} \mathrm{F}$ & TRDU data & & 954 & $982-1038$ \\
\hline Low Sodium & & 843 & & \\
\hline High Sodium & & 899 & & \\
\hline Carbon Conversion, $\%$ & PSDF (37) & 95 & 95 & 90 \\
\hline $\begin{array}{l}\text { Corrected Gas Heating Values (LHV), } \\
\mathrm{kJ} / \mathrm{m}^{3}\end{array}$ & PSDF (37) & & & \\
\hline Air Blown & & $2,236-4,471$ & $3,912-5,589$ & $2,980-5,216$ \\
\hline Oxygen-Blown & & $3,726-10,060$ & $7,825-11,178$ & $8,197-10,805$ \\
\hline Dry Syngas Analysis, vol\% & PSDF (15) & & & \\
\hline \multicolumn{5}{|l|}{ Air-Blown } \\
\hline $\mathrm{CH}_{4}$ & & & $2.2 \%$ & \\
\hline $\mathrm{CO}$ & & & $23.9 \%$ & \\
\hline $\mathrm{CO}_{2}$ & & & $7.2 \%$ & \\
\hline $\mathrm{H}_{2}$ & & & $12.1 \%$ & \\
\hline $\mathrm{H}_{2} \mathrm{~S}$ & & & $0.04 \%$ & \\
\hline $\mathrm{N}_{2}$ & & & $54.3 \%$ & \\
\hline $\mathrm{NH}_{3}$ & & & $0.16 \%$ & \\
\hline \multicolumn{5}{|l|}{ Oxygen-Blown } \\
\hline $\mathrm{CH}_{4}$ & & & $3.1 \%$ & \\
\hline $\mathrm{CO}$ & & & $41.3 \%$ & \\
\hline $\mathrm{CO}_{2}$ & & & $17.7 \%$ & \\
\hline $\mathrm{H}_{2}$ & & & $36.2 \%$ & \\
\hline $\mathrm{H}_{2} \mathrm{~S}$ & & & $0.11 \%$ & \\
\hline $\mathrm{N}_{2}$ & & & $1.3 \%$ & \\
\hline $\mathrm{NH}_{3}$ & & & $0.32 \%$ & \\
\hline
\end{tabular}


temperature $6^{\circ} \mathrm{C}\left(10^{\circ} \mathrm{F}\right)$ above the dew point so that no condensation occurred to plug the coal feed system (44). Ash problems encountered in the PSDF when operating on high-sodium lignite were caused by the reaction of sodium with the silica sand bed material; deposition problems were alleviated by substituting coarse PRB ash for sand as bed material and operating at a slightly reduced temperature (45). Operation on high sodium lignite at higher operating temperatures has been possible with the addition of an additive to react with the sodium to prevent the formation of low-melting euthetics. Selected midrange values of carbon conversion in the PSDF have been higher for subbituminous coal and lignite (94\%-96\%) than for bituminous coals $(87 \%-91 \%)$, comparing those tests showing a smaller range of variation and presumably more stable operations (36). The range of gas heating values observed for PRB coal is in the range of about $3912-5589 \mathrm{~kJ} / \mathrm{m}^{3}(105-150 \mathrm{Btu} / \mathrm{scf})$ for air-blown operation and $7825-11,178 \mathrm{~kJ} / \mathrm{m}^{3}(210-300 \mathrm{Btu} / \mathrm{scf})$ for oxygen-blown operations, reported on the basis of lower heating value (LHV) after correcting for excess dilution with nitrogen purge gas and higher heat loss in the PSDF compared to a full-scale gasifier (36). The gas heating value increases with the percent oxygen in the oxidizing gas, whereas gas heating value decreases and carbon conversion increases along with an increasing oxygen/maf coal ratio $(37,46)$. Air-blown gas heating values higher than the $4285 \mathrm{~kJ} / \mathrm{m}^{3}(115 \mathrm{Btu} / \mathrm{scf})$ specified for a gas turbine have been achieved for all coal ranks. Gas quality from an oxygen-blown transport gasifier is well suited for either power production integrated with carbon sequestration or synfuels production. The syngas analysis for oxygen-blown gasification of PRB coal in Table 1 indicates a relatively high ratio of $\mathrm{H}_{2}$ to $\mathrm{CO}$ and moderate $\mathrm{CH}_{4}\left(36 \%, 41 \%\right.$, and $3 \%$ respectively). The high $\mathrm{H}_{2}$ concentration reflects both the low operating temperature (e.g., $954^{\circ} \mathrm{C}\left[1750^{\circ} \mathrm{F}\right]$ ) and the excess steam required to moderate the reactor temperature in oxygen-blown operation. Syngas having higher hydrogen content requires less shift conversion before separating carbon dioxide for sequestration, which can be an advantage for the transport gasifier over entrained-flow gasifiers that operate at higher temperatures or the slagging fixed-bed gasifier that operates with minimum steam. The gas analysis for air-blown operation in Table 3 reflects dilution with nitrogen from air and a higher ratio of $\mathrm{CO}$ to $\mathrm{H}_{2}$.

Studies are ongoing to better understand the contribution of different reactions in the transport gasifier. Computational fluid dynamics (CFD) modeling (47) and chemical engineering residence-time-distribution calculations at the EERC have achieved only limited success in matching laboratory measurements of reaction rates and operating data from the TRDU or PSDF, suggesting that rates and resulting product distributions in the gasifier are strongly affected by the fluid dynamic regime in ways that are not adequately understood or tested in laboratory experiments. A laboratory study on the partial oxidation and steam gasification of lignite and bituminous coal chars and petcoke performed in support of TRDU modeling indicated that 1) the ratio of $\mathrm{CO}$ to $\mathrm{CO}_{2}$ obtained from partial oxidation of char in a bench-scale fluidized bed (representing the mixing zone of the TRDU) varied widely but tended to increase along with both temperature and the ratio of $\mathrm{C}$ to $\mathrm{O}_{2}$ fed into the bed and 2) the rate of steam gasification for lignite char was an order of magnitude or more greater than that for bituminous coal char, which was, in turn, an order of magnitude greater than that for petcoke $(7,16)$. Sampling at five levels in the riser of the TRDU when lignite was tested showed a two-thirds reduction in volatile matter and close to $50 \%$ reduction in fixed carbon in particulate samples between the exit from the mixing zone and the top of the riser and a large increase in $\mathrm{CO}$ and $\mathrm{CH}_{4}$ in the gas, from a fraction of a percent up to the $2 \%-5 \%$ outlet values for $\mathrm{CH}_{4}$, indicating that substantial pyrolysis, 
steam gasification, and water-gas shift reactions were all occurring in the 1-2-second gas residence time in the riser $(37,43)$. Sulfur capture on limestone has been observed to be close to the equilibrium values predicted for calcination and the reaction of calcium oxide with hydrogen sulfide (48). Overall, modeling and observations based on operating data and the literature suggest 1) rapid pyrolysis of coal and cracking of tar account for a substantial part of the product yield and distribution; 2) the product gas composition is near equilibrium for the water-gas shift reaction at the gasifier outlet, indicating higher yields of $\mathrm{H}_{2}$ in relation to $\mathrm{CO}$ at lower operating temperatures (e.g., for low-rank coals); 3) the ratio of $\mathrm{CO}$ to $\mathrm{CO}_{2}$ from partial oxidation in the mixing zone will be higher at higher operating temperature (e.g., for bituminous coal), and the ratio will be higher under conditions where a larger amount of carbon is recycled back to the combustion zone (determined by the carbon content of the bed and the bed recycle rate); and 4) partial oxidation accounts for the largest fraction of char conversion, with steam gasification contributing significantly for low-rank coal char but only slightly for bituminous coal char or petcoke.

\section{OVERALL PROJECT OBJECTIVES FOR EVALUATION OF BULGARIAN LIGNITE}

The EERC evaluated the Bulgarian lignite performance under both fluid-bed combustion and gasification conditions. The EERC provided a recommendation as to which technology would be the most technically feasible for this particular feedstock and also identified any potential operating issues (such as bed agglomeration, etc.) that may limit the applicability of a potential coal conversion technology. From the pilot-scale information, enough data were generated so that a selected architecture and engineering firm could determine which conversion technology would have the best economics for this particular project.

Since the mine was not yet open and only core samples were likely to be available in the near future, the EERC proposed to conduct initial screening tests on its electrically heated benchscale combustion and gasification systems. As the mine opens and larger coal quantities become available, the EERC proposed to conduct pilot-scale combustion and gasification testing where better heat and material balance information can be acquired. The EERC proposed a five-task program that included the following:

- Task 1 - Detailed Characterization of the Bulgarian Lignite

- Task 2 - Bench-Scale Combustion Testing in the Fluid-Bed Reactor

- Task 3 - Bench-Scale Gasification Testing in the Continuous Fluidized-Bed Reactor (CFBR)

- Task 5 - Pilot-Scale Gasification Testing in the Transport Reactor Demonstration Unit (TRDU)

- Task 4 - Pilot-Scale Combustion Testing in the Circulating Fluid-Bed Combustor (CFBC) 
Tasks 4 and/or 5 would only be conducted should promising results from Tasks 2 and 3 warranted further testing at the next scale. It was decided to perform Task 5 first and only conduct Task 4 testing if Task 5 testing did not look promising.

\section{TASK DESCRIPTIONS}

\section{Task 1 - Detailed Characterization of the Bulgarian Lignite}

\section{Objectives}

The objective of this task was to analyze the coal with enough detail to allow the prediction of potential operating problems in fluid-bed systems. This task will require approximately $2 \mathrm{~kg}$ of coal for extensive analysis of the coal to determine its suitability as a feedstock for the fluid-bed conversion processes. Issues that can present some problems for feedstocks in a fluid bed include the presence of significant amounts of alkali such as sodium or potassium, which can cause bed agglomeration and deposition issues in the boiler/gasifier. Other issues include the presence of various mineral species such as illite and other lower-meltingtemperature alkali aluminosilicate eutectics. In addition, the presence of various trace metals can cause certain emission problems, and their presence in the coal should be determined.

\section{Scope of Work}

This task was budgeted to analyze two distinct core samples utilizing both standard ASTM International (ASTM) methods for proximate, ultimate, and heating value, and advanced methods including computer-controlled scanning electron microscopy (CCSEM), chemical fractionation, $\mathrm{x}$-ray diffraction (XRD), and $\mathrm{x}$-ray fluorescence (XRF) to determine both the mineral and bulk ash chemistry of the coal.

\section{Results}

Difficulties were initially experienced in crushing core samples to a size of $-2 \mathrm{~mm}$ $(-10$ mesh) in preparation for analysis because the high moisture and stickiness of the clay in the ash caused plugging of the smaller screens in the bench-scale crusher. At the as-received moisture, the clay in the coal ash balls up like a potter's clay. Because of these coal-preparation difficulties, the fuel was air-dried to approximately $25 \%$ moisture prior to crushing and was sized at $-6 \mathrm{~mm}$ rather than the usual $-2 \mathrm{~mm}(-10 \mathrm{mesh})$. This lower moisture is consistent with the moisture levels of coals tested in the Wilsonville, Alabama, transport reactor with its coal dryer. This moisture content is also consistent with previous testing in which good fuel flow through narrow piping in the feed auger systems in both the CFBR and the FBR has been achieved in the past. Future testing in the TRDU was projected to involve half of the tests at $20 \%-25 \%$ moisture and the other half at as-received moisture.

Previous analysis identified Blend $\mathrm{C}$ as a promising blend. This blend was taken from Drill Core T3, excluding the layer of clay and detritus-polluted lignite between Seams I-A4 and I-A3. The fuel used during bench-scale testing was a composite of Blend C taken from Drill Core T3 
and the whole of Cores T1, T2, and T4. Table 4 compares proximate-ultimate analysis and heating value of the coal composite and the theoretical Blend $\mathrm{C}$. In order to make a relevant comparison, the coal composite and Blend $\mathrm{C}$ are shown on both an as-received and a moisturefree basis. In the moisture-free proximate analysis, the volatile matter contents are essentially identical, but the coal composite has higher fixed carbon and lower ash contents, resulting in a higher heating value. The ultimate analysis shows a similar trend with a higher carbon and lower ash content in the coal composite.

Overall, the composite sample and Blend $\mathrm{C}$ are comparable, with a difference in their moisture free heating values of only $328 \mathrm{~kJ} / \mathrm{kg}(12,180 \mathrm{vs} .11,852 \mathrm{~kJ} / \mathrm{kg} ; 5239 \mathrm{vs} .5098 \mathrm{Btu} / \mathrm{lb})$. Based on their moisture free analyses, these samples have the lowest heating values of any fuel that has been tested in the TRDU to date and will help define how low the quality of the fuel can be to successfully operate a transport reactor gasification system.

Table 5 shows no significant differences in the XRF ash analyses of the coal composite and Blend $\mathrm{C}$. The XRF analysis indicates that the fuel is low in sodium and potassium, which potentially are major factors causing bed agglomeration. The only constituent that might present some agglomeration issues is the iron.

Table 4. Comparison of Coal Composite and Theoretical Blend C

\begin{tabular}{lcccc}
\hline & $\begin{array}{c}\text { Coal } \\
\text { Composite, as } \\
\text { tested partially } \\
\text { dried }\end{array}$ & $\begin{array}{c}\text { Coal } \\
\text { Composite, } \\
\text { moisture-free }\end{array}$ & $\begin{array}{c}\text { Blend C, } \\
\text { as-received }\end{array}$ & $\begin{array}{c}\text { Blend C, } \\
\text { moisture-free }\end{array}$ \\
\hline Proximate Analysis, wt\% & & & & \\
Moisture & 22.90 & $\mathrm{NA}^{1}$ & 39.27 & $\mathrm{NA}$ \\
$\quad$ Volatile Matter & 23.46 & 30.44 & 18.49 & 30.96 \\
Fixed Carbon & 16.15 & 20.92 & 10.65 & 17.98 \\
Ash & 37.49 & 48.64 & 31.60 & 51.06 \\
\hline Ultimate Analysis, wt\% & & & & \\
Hydrogen & 5.12 & 3.34 & 6.76 & 3.98 \\
Carbon & 25.48 & 33.06 & 17.33 & 29.20 \\
Nitrogen & 0.59 & 0.76 & 0.40 & 0.67 \\
Sulfur & 0.94 & 1.21 & 0.38 & 0.63 \\
Oxygen & 30.38 & 12.99 & 43.54 & 14.47 \\
Ash & 37.49 & 48.64 & 31.60 & 51.06 \\
\hline Higher Heating Value, $\mathrm{kJ} / \mathrm{kg}$ & & & & \\
Measured kJ & 9,387 & 12,180 & 7,021 & 11,561 \\
Calc. Calorific Value & 10,863 & 14,100 & 8,060 & 13,248 \\
\hline
\end{tabular}

${ }^{1}$ Not applicable. 
Table 5. Comparison of Coal Composite and Theoretical Blend C Based on XRF Analysis, wt \% of ash

\begin{tabular}{lcc}
\hline $\mathrm{wt} \%$ & Coal Composite & Blend C \\
\hline $\mathrm{SiO}_{2}$ & 52.80 & 53.97 \\
$\mathrm{Al}_{2} \mathrm{O}_{3}$ & 27.30 & 26.17 \\
$\mathrm{Fe}_{2} \mathrm{O}_{3}$ & 7.06 & 7.06 \\
$\mathrm{TiO}_{2}$ & 0.68 & 0.70 \\
$\mathrm{P}_{2} \mathrm{O}_{5}$ & 0.17 & 0.15 \\
$\mathrm{CaO}$ & 4.10 & 4.50 \\
$\mathrm{MgO}$ & 1.98 & 1.89 \\
$\mathrm{Na}$ & 0.17 & 0.28 \\
$\mathrm{~K}_{2} \mathrm{O}$ & 1.47 & 1.38 \\
$\mathrm{SO}_{3}$ & 4.14 & 3.83 \\
\hline
\end{tabular}

Table 6 compares trace element analysis found in the coal composite to other types of lignite coals. Mercury, selenium, and arsenic are all very comparable for the coal composite and the U.S. lignites. However, the arsenic and selenium are about twice the concentration in the coal composite as compared to the Bulgarian lignite, while mercury is about half in the coal composite.

Size and composition of mineral grains in coal can be determined by CCSEM, a program used in conjunction with an SEM and microprobe system and a mineral characterization program. The Noran Voyager system, which is used at the EERC and many other institutions,

Table 6. Trace Elements

\begin{tabular}{lcccc}
\hline & Coal Composite & $\begin{array}{c}\text { Bulgarian Lignite } \\
(49)\end{array}$ & $\begin{array}{c}\text { TX Lignite } \\
(49)\end{array}$ & $\begin{array}{c}\text { ND Lignite } \\
(49)\end{array}$ \\
\hline Concentration, $\mu \mathrm{g} / \mathrm{g}$ & & & & \\
Antimony & $<0.3$ & 1.3 & $<0.3-1.9$ & $0.1-4.5$ \\
Arsenic & 23.4 & 12 & $<0.1-31$ & $0.70-110$ \\
Barium & 257 & 16 & $2-1820$ & $\mathrm{~N} / \mathrm{A}$ \\
Beryllium & 1.62 & $\mathrm{~N} / \mathrm{A}^{2}$ & $<0.1-9.9$ & $0.08-14$ \\
Cadmium & 0.25 & 1.9 & $0.1-3.0$ & $0.06-2.7$ \\
Chlorine & 51 & $\mathrm{~N} / \mathrm{A}$ & $100-1300$ & $100-1300$ \\
Chromium & 78.2 & 31 & $2.0-87$ & $0.25-43$ \\
Fluoride & 188 & $\mathrm{~N} / \mathrm{A}$ & $\mathrm{N} / \mathrm{A}$ & $15-1300$ \\
Lead & 13.5 & $\mathrm{~N} / \mathrm{A}$ & $0.3-32$ & $1.4-17$ \\
Manganese & 130 & $\mathrm{~N} / \mathrm{A}$ & $1-1075$ & $7.3-660$ \\
Mercury & 0.127 & 0.25 & $<0.1-1.5$ & $0.01-12$ \\
Nickel & 42.1 & $\mathrm{~N} / \mathrm{A}$ & $0.8-79$ & $0.52-84$ \\
Selenium & 1.31 & 0.63 & $0.5-18$ & $0.10-3.4$ \\
Silver & 0.14 & $\mathrm{~N} / \mathrm{A}$ & $\mathrm{N} / \mathrm{A}$ & $\mathrm{N} / \mathrm{A}$ \\
Uranium & 4.28 & 4 & $0.4-6.2$ & $0.21-13$ \\
\hline 'Notavilium & & & &
\end{tabular}

${ }^{1}$ Not available. 
characterizes inorganic components in samples of coal, char, and inorganic combustion products. The CCSEM system uses a computer to control the operation of the SEM in order to determine the size, quantity, distribution, and association of coal and mineral grains and other particulate matter. The CCSEM system analyzes for $\mathrm{Na}, \mathrm{Mg}, \mathrm{Al}, \mathrm{Si}, \mathrm{P}, \mathrm{S}, \mathrm{Cl}, \mathrm{K}, \mathrm{Ca}, \mathrm{Fe}, \mathrm{Ba}$, and Ti. These elemental data are used in a mineral classification program to group the different mineral or inorganic phases according to molar ratios that correspond best with known mineral or amorphous species. Size distributions are also tabulated.

The results of the CCSEM analysis are shown in Tables 7 and 8 . The most abundant of the mineral groups is iron aluminosilicate at $72.5 \mathrm{wt} \%$, roughly half of which is not organically associated within the coal matrix. Nearly $80 \mathrm{wt} \%$ of the particles analyzed ranged from 46 to $300 \mu \mathrm{m}$, the largest range of particles tested. These larger particles are more likely to stay within

Table 7. Weight Percent of Inorganic Constituents

\begin{tabular}{lcc}
\hline Mineral & $\mathrm{wt} \%$ & \% Excluded \\
\hline Quartz & 2.3 & 82.3 \\
Montmorillonite & 0.3 & 94.9 \\
K Al-Silicate & 0.2 & 69.0 \\
Fe Al-Silicate & 72.5 & 52.8 \\
Mixed Al-Silicate & 5.1 & 26.4 \\
Pyrrhotite & 0.4 & 46.9 \\
Oxidized Pyrrhotite & 0.2 & 7.9 \\
Gypsum & 0.5 & 43.5 \\
Gypsum/Al-Silicate & 4.6 & 27.1 \\
Si-Rich & 0.6 & 59.4 \\
Na Al-Silicate & 0.1 & 9.8 \\
Unclassified & 13.2 & 40.4 \\
\hline
\end{tabular}

Table 8. Composition of Inorganic Constituents

\begin{tabular}{lcccccccccccc}
\hline Mineral wt\% & $\mathrm{Si}$ & $\mathrm{Al}$ & $\mathrm{Fe}$ & $\mathrm{Ti}$ & $\mathrm{P}$ & $\mathrm{Ca}$ & $\mathrm{Mg}$ & $\mathrm{Na}$ & $\mathrm{K}$ & $\mathrm{S}$ & $\mathrm{Ba}$ & $\mathrm{Cl}$ \\
\hline Quartz & 95.5 & 0.8 & 1.3 & 0.2 & 0.2 & 0.4 & 0.2 & 0.1 & 0.4 & 0.2 & 0.5 & 0.1 \\
Montmorillonite & 57.2 & 32.0 & 3.1 & 0.1 & 0.1 & 2.5 & 1.7 & 0.4 & 1.7 & 1.1 & 0.0 & 0.1 \\
K Al-Silicate & 52.8 & 21.0 & 3.1 & 0.5 & 0.2 & 1.5 & 0.6 & 0.4 & 18.3 & 0.8 & 0.6 & 0.2 \\
Fe Al-Silicate & 52.4 & 25.3 & 11.9 & 0.8 & 0.2 & 2.6 & 1.4 & 0.3 & 3.2 & 1.3 & 0.6 & 0.2 \\
Mixed Al-Silicate & 50.9 & 25.6 & 8.6 & 0.9 & 0.3 & 5.0 & 1.3 & 0.3 & 4.1 & 2.2 & 0.7 & 0.2 \\
Pyrrhotite & 1.9 & 1.1 & 49.8 & 0.1 & 0.0 & 2.1 & 0.2 & 0.2 & 0.2 & 44.2 & 0.1 & 0.1 \\
Oxidized Pyrrhotite & 3.4 & 1.6 & 71.0 & 1.2 & 0.1 & 3.1 & 0.5 & 0.5 & 0.2 & 18.0 & 0.2 & 0.1 \\
Gypsum & 3.3 & 1.8 & 2.4 & 0.1 & 0.0 & 52.9 & 0.2 & 0.1 & 0.3 & 38.1 & 0.4 & 0.4 \\
Gypsum/Al-Silicate & 38.9 & 19.8 & 9.3 & 0.6 & 0.2 & 15.5 & 1.5 & 0.3 & 2.3 & 10.6 & 0.6 & 0.2 \\
Si-Rich & 72.9 & 10.7 & 7.7 & 0.6 & 0.2 & 2.1 & 1.4 & 0.2 & 2.3 & 1.0 & 0.6 & 0.2 \\
Na Al-Silicate & 70.1 & 18.1 & 1.2 & 0.3 & 0.2 & 1.5 & 0.0 & 7.3 & 0.3 & 0.3 & 0.4 & 0.3 \\
Unclassified & 44.7 & 20.7 & 15.4 & 1.3 & 0.2 & 5.8 & 1.4 & 0.4 & 4.7 & 4.0 & 1.3 & 0.2 \\
\hline
\end{tabular}


the bed and not leave the reactor with the finer coal ash. Over $13 \mathrm{wt} \%$ of the inorganic constituents are unclassified, meaning there is no mineral grouping in the program that matched their elemental composition. However, Table 8 shows that the unclassified particles are very similar in composition to the iron aluminosilicate.

Chemical fractionation (CHF) is used to quantitatively determine the modes of occurrence of the inorganic elements in coal, based on the extractability of the elements in solutions of water, 1 molar ammonium acetate, and 1 molar hydrochloric acid. This type of analysis is especially important for low-rank coals or biomass fuels that can have significant quantities of organically bound elements which are ionically dispersed within the organic matrix of the fuel and are essentially invisible to SEM and mineralogical techniques. The flow diagram shown in Figure 9 illustrates the technique. A 75 -gram sample of $-45 \mu \mathrm{m}$ ( -325 -mesh) vacuum-dried coal is stirred with $160 \mathrm{~mL}$ of deionized water to extract water-soluble minerals such as sodium chloride. After being stirred for 24 hours at room temperature, the water-coal mixture is filtered. The filtered coal is dried, and a portion is removed to be tested by XRF to determine the percent of each element remaining. The residues are then mixed with $160 \mathrm{~mL}$ of 1 molar ammonium acetate $\left(\mathrm{NH}_{4} \mathrm{OAc}\right)$ and stirred at $70^{\circ} \mathrm{C}$ for 24 hours to extract the elements associated with the coal as ion-exchangeable cations present primarily as the salts of organic acids. The ammonium acetate extractions are performed two more times to effect complete removal of the ionexchangeable cations. After the third ammonium acetate extraction, a sample of the dried residue is analyzed by XRF. The remaining residue of the ammonium acetate extractions is then stirred with 1 molar hydrochloric acid $(\mathrm{HCl})$ at $70^{\circ} \mathrm{C}$ for 24 hours to remove the elements held in coordination complexes within the organic structure of the coal, as well as acid-soluble minerals

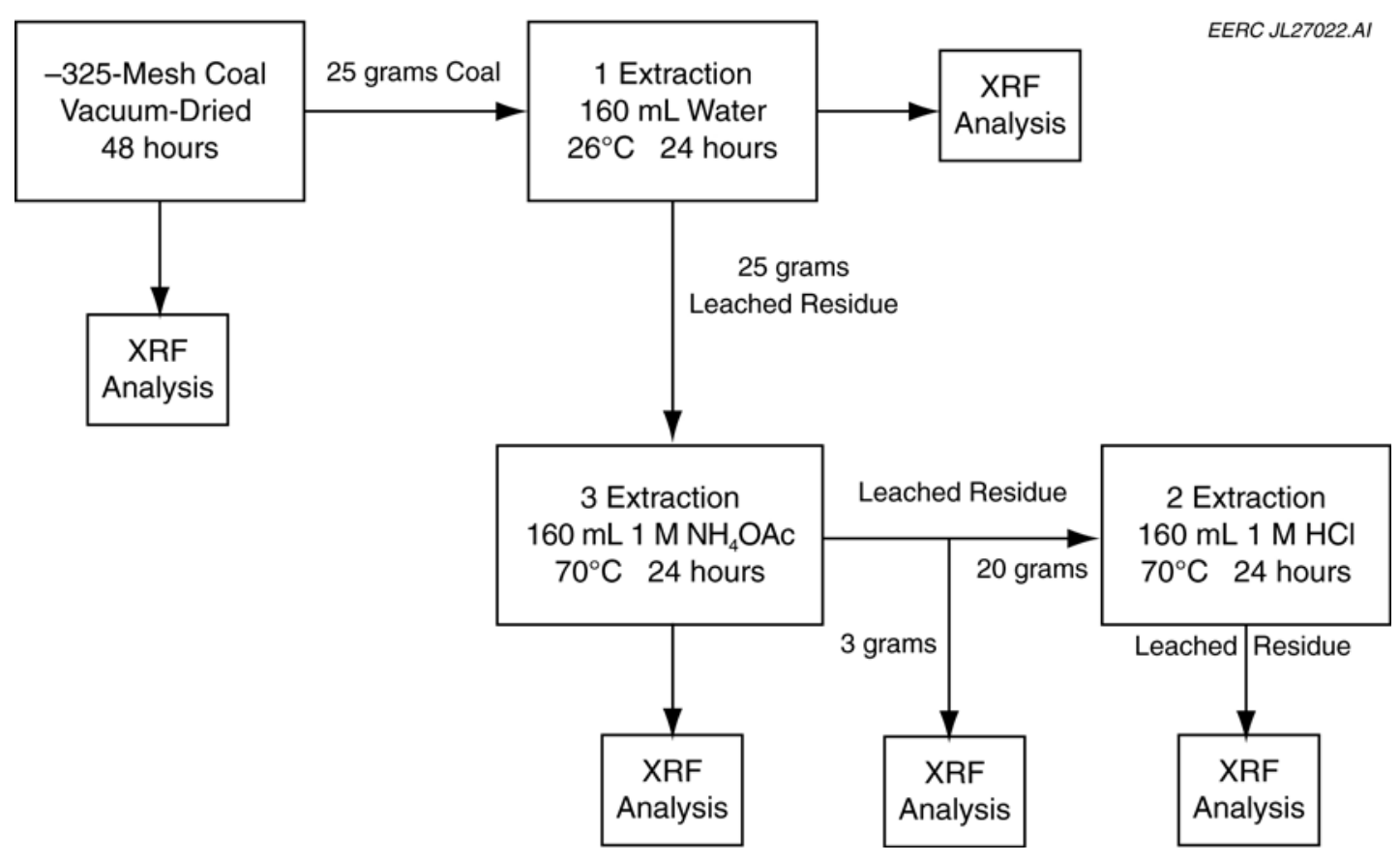

Figure 9. Schematic of the EERC CHF procedure. 
such as carbonates, oxides, and sulfates. The residue is then analyzed by XRF. The hydrochloric acid extraction is repeated once. The elements remaining in the coal after the CHF extractions are determined by difference. The nonextractable elements are associated in the coal as silicates, aluminosilicates, sulfides, and insoluble oxides.

Table 9 displays the XRF results after each step in the CHF procedure, and Table 10 lists how much of the oxides each extraction removed from the coal. A CHF analysis showing that a major fraction of the sodium is removed by either water or ammonium acetate would indicate that the coal has a significant potential for ash fouling and slagging. Calcium is a lesser concern than the more volatile sodium. In the current CHF analysis for this coal, two-thirds of the calcium was either water-soluble or removed by ion exchange. Most of the remaining calcium was removed by acid extraction, possibly suggesting the presence of calcium carbonate that would contribute to sulfur retention in the gasifier. For sodium, only $19 \%$ was water-soluble, and none was removed by either ion exchange or acid extraction. Almost all of the potassium remained in the final residue after acid extraction. Results for sodium and potassium indicate that these elements are largely not either soluble or ion-exchangeable but are likely present in aluminosilicate clay minerals that would not be a cause of serious ash fouling. Ion exchange removed $27 \%$ of the magnesium and acid extraction another $28 \%$. All of the silicon and titanium and most of the alumina were not extracted and remained in the acid-leached residue at the end of the procedure as expected. None of the sulfur remained in the residue at the end.

\section{Summary and Conclusions for Task 1}

Based on the data from the XRF, CCSEM, and CHF analyses, this coal should perform well as a gasification fuel in the TRDU; that is, bed agglomeration and ash deposition would not be expected problems. Kalmanovitch ash viscosity modeling also shows that at the temperatures run in the TRDU, the ash viscosity would be in an acceptable range.

Table 9. CHF Results - XRF Procedure

\begin{tabular}{lcrcr}
\hline $\mathrm{wt} \%$ & Unleached & Water & $\mathrm{NH}_{4} \mathrm{OAc}$ & $\mathrm{HCl}$ \\
\hline $\mathrm{SiO}_{2}$ & 52.79 & 53.73 & 56.94 & 63.58 \\
$\mathrm{Al}_{2} \mathrm{O}_{3}$ & 27.32 & 28.07 & 30.00 & 28.31 \\
$\mathrm{Fe}_{2} \mathrm{O}_{3}$ & 7.06 & 6.96 & 7.24 & 4.34 \\
$\mathrm{TiO}_{2}$ & 0.68 & 0.69 & 0.72 & 0.81 \\
$\mathrm{P}_{2} \mathrm{O}_{5}$ & 0.17 & 0.17 & 0.17 & 0.12 \\
$\mathrm{CaO}$ & 4.15 & 3.58 & 1.29 & 0.21 \\
$\mathrm{MgO}$ & 1.98 & 1.83 & 1.34 & 0.83 \\
$\mathrm{Na} 2 \mathrm{O}$ & 0.17 & 0.14 & 0.15 & 0.20 \\
$\mathrm{~K}_{2} \mathrm{O}$ & 1.47 & 1.47 & 1.52 & 1.57 \\
$\mathrm{SO}$ & 4.14 & 3.30 & 0.59 & 0.00 \\
$\mathrm{BaO}$ & 0.06 & 0.06 & 0.05 & 0.03 \\
\hline$\%$ Ash & 47.31 & 47.65 & 46.38 & 42.94 \\
\hline
\end{tabular}


Table 10. CHF Results

\begin{tabular}{lcccc}
$\begin{array}{c}\text { wt } \% \text { Removed } \\
\text { by Water }\end{array}$ & $\begin{array}{c}\mathrm{wt} \% \text { Removed } \\
\text { by } \mathrm{NH}_{4} \mathrm{OAc}\end{array}$ & $\begin{array}{c}\mathrm{wt} \% \text { Removed } \\
\text { by HCl }\end{array}$ & $\begin{array}{c}\mathrm{wt} \% \\
\text { Remaining }\end{array}$ \\
\hline $\mathrm{SiO}_{2}$ & 0 & 0 & 0 & 100 \\
$\mathrm{Al}_{2} \mathrm{O}_{3}$ & 0 & 0 & 14 & 86 \\
$\mathrm{Fe}_{2} \mathrm{O}_{3}$ & 1 & 0 & 45 & 54 \\
$\mathrm{TiO}_{2}$ & 0 & 0 & 0 & 100 \\
$\mathrm{P}_{2} \mathrm{O}_{5}$ & 0 & 5 & 30 & 65 \\
$\mathrm{CaO}$ & 13 & 57 & 26 & 4 \\
$\mathrm{MgO}$ & 7 & 27 & 28 & 38 \\
$\mathrm{Na}$ & 19 & 0 & 0 & 81 \\
$\mathrm{~K}_{2} \mathrm{O}$ & 0 & 0 & 4 & 96 \\
$\mathrm{SO}_{3}$ & 20 & 66 & 14 & 0 \\
$\mathrm{BaO}$ & 6 & 21 & 35 & 38 \\
\hline
\end{tabular}

\section{Task 2 - Bench-Scale Combustion Testing in the FBR}

\section{Objectives}

The goal of this project task was to demonstrate the performance of the Bulgarian lignite in a fluidized-bed combustion unit. This testing determined material balance, gas emission, and operating data under the range of operating conditions typical for a fluidized-bed combustion (FBC) system. This test also indicated whether the ash constituents would result in bed agglomeration or superheater region deposition. In order to meet the goals of the project, the following objectives were set:

1. Perform continuous feed steady-state combustion testing with the Bulgarian lignite.

2. Determine gaseous emissions such as $\mathrm{SO}_{2}, \mathrm{NO}_{\mathrm{x}}, \mathrm{N}_{2} \mathrm{O}, \mathrm{CO}$, and hydrocarbon emissions as a function of various operating conditions such as bed temperature, excess air, and $\mathrm{Ca} / \mathrm{S}$ ratio.

3. Analyze the residual samples to determine if any ash or other components will present any operational issues for a CFB system.

\section{Description of Bench-Scale FBR}

The bench-scale FBR at the EERC simulates the bed chemistry, ash interactions, and emissions of a fluidized-bed combustor under closely controlled conditions. This reactor is used for sorbent characterization, gaseous emissions including trace elements, agglomeration, and hotgas cleanup testing in a cost-effective manner over a wide range of operational conditions. The $139.7-\mathrm{cm}(55-\mathrm{in}$.)-tall reactor is constructed of 7.62-cm (3-in.) Schedule 80 Haynes 556 pipe and is externally heated with three ceramic heaters. A heated cyclone collects the ash and bed material that is carried out of the reactor. The preheated fluidizing gas can be a mixture of air and 
nitrogen or just air. Preheated gas at temperatures of up to $760^{\circ} \mathrm{C}\left(1400^{\circ} \mathrm{F}\right)$ are supplied at the bottom of the reactor through a 2.54-cm (1-in.) Schedule 40 pipe. The fluidizing gas is supplied at sufficiently high velocities to prevent the sized bed material from dropping out during operation.

The fluidizing gas enters the main section of the FBR reactor through a conical transition. This conical section was designed without a distributor plate to facilitate quick removal and quenching of the bed material after completion of a test. Bed material can be sampled or collected using a lock hopper system located at the bottom of the reactor. Figure 10 is a side view schematic of the reactor and cyclone.

Temperatures in the reactor are measured at ten heights above the conical transition section. Thermocouples are also located at the gas inlet and the cyclone exit. A flue gas sampling port is located in the stack.

External heaters are used for heating and maintaining the reactor and hot cyclone at temperatures of up to $1093^{\circ} \mathrm{C}\left(2000^{\circ} \mathrm{F}\right)$. The external ceramic heaters on the gas preheater and the reactor itself are rated at 10.8 and $10.05 \mathrm{~kW}$, respectively, with an upper temperature limit of $1204^{\circ} \mathrm{C}\left(2200^{\circ} \mathrm{F}\right)$. This type of heating system provides very good control of the reactor temperature. The use of electric heaters provides the capability to match the fuel feed rate to the amount of bed material in the reactor. In a full-scale system, the bed is deep relative compared to that in the FBR. Therefore, to keep the coal feed rate-to-bed inventory similar between benchand full-scale systems, the coal feed rate in the FBR is kept low relative to full-scale systems,

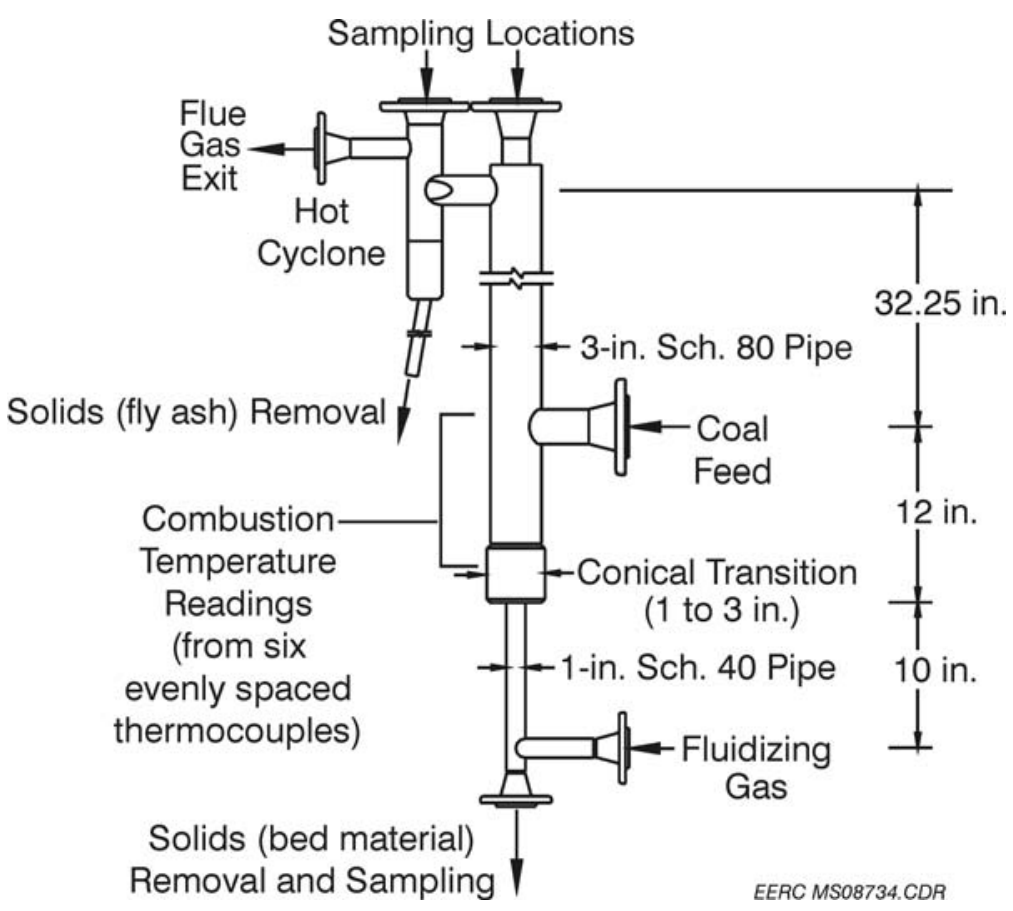

Figure 10. Schematic of FBR. 
compared on a fuel-feed-rate-per-bed-cross-sectional-area basis. Therefore, additional heat is required to maintain the desired temperature. The high heat losses through the reactor walls inherent to small-scale systems also require either good insulation or reactor heating. The utilization of the external heaters allows the effects of high heat losses that occur at this smallscale to be minimized; however, these heaters also make an accurate heat balance around the reactor difficult to measure. An in-bed cooling coil can be used to remove excess heat from the high-temperature dense bed region, allowing for higher fuel feed rates and providing a more uniform overall temperature distribution. The use of both air and nitrogen as fluidizing gas allows excess air and gas velocity to be matched to any design condition.

Dry coal and sorbent are premixed in the desired ratio. Two identical hoppers allow for coal hopper refills without an interruption in coal feed. Fuel feed from each hopper is metered with separate augers that feed into a common water-cooled auger which, in turn, carries the material into the reactor. A bed material hopper empties directly into the common auger, without flow control. Each hopper is maintained at a pressure slightly higher than that in the reactor during operation. At the bottom of each hopper is an Excelor sight tube; in addition, both hoppers are equipped with sensors to alert the operator when the hoppers are empty and need to be refilled.

A data acquisition and control system is used to monitor and record all critical pressures, temperatures, flow rates, and emissions. The critical data include the gas flow rates, bed static pressure and differential pressures across the bed and cyclone, and eight different internal reactor temperatures. The air and nitrogen flow rates are controlled automatically to flow rate set points. The three ceramic heaters on the reactor may be controlled manually to a given heater temperature or controlled automatically to maintain a desired gas temperature in each zone. Ports for alkali sampling probes or, alternatively, solids-sampling or gas-sampling probes are located at the top of the reactor and the top of the cyclone.

\section{Test Matrix}

The purpose of this test matrix was to determine the combustion characteristics of the fuel and establish a sorbent feed rate sufficient to achieve $90 \%$ sulfur capture. Tests were performed at nominally $25 \%$ excess air and a superficial gas velocity of $0.91 \mathrm{~m} / \mathrm{s}(3 \mathrm{ft} / \mathrm{sec})$ at five different average bed temperatures: $788^{\circ}, 816^{\circ}, 843^{\circ}, 871^{\circ}$, and $899^{\circ} \mathrm{C}\left(1450^{\circ}, 1500^{\circ}, 1550^{\circ}, 1600^{\circ}\right.$, and $1650^{\circ} \mathrm{F}$ ). Velocity is controlled by the amount of fluidizing air added to the reactor, as well as the temperature. Excess air is a function of airflow rate and coal feed rate. Temperature is partially dependent on coal feed rate but can be adjusted in the FBR with the ceramic heaters encasing the reactor and cyclone. Because these parameters are interrelated, the operator must sometimes choose between a target velocity or a target excess air level. Tests were performed with and without limestone at $\mathrm{Ca} / \mathrm{S}$ mole ratios between 0 and 3 . 


\section{Results}

\section{Operability}

The FBC was operated over 3 consecutive days, but coal feed was stopped and the unit kept hot with the ceramic heaters overnight. The coal was fed without difficulty, and there was no evidence of agglomeration during operation. There was trouble with plugging in the cyclone and in the piping between the reactor and the cyclone. When this happened, the reactor pressure would increase, and coal would stop feeding. The reactor temperature dropped off until the plug was cleared and coal feed reestablished, sometimes as quickly as 2 or 3 minutes, sometimes as long as 15 minutes. Throughout the first day of testing, these plugging incidents became more frequent; at the end of testing for the day, the heaters were turned off and the bed material drained so the cyclone could be thoroughly cleaned in the morning.

The next day, the cyclone was cleaned and the unit restarted. A smaller-sized bed material was used, so that the operating velocity and coal feed rate could be reduced, in an effort to minimize the potential for cyclone inlet plugging. This was quite effective for one day, but by the end of the third day of testing (the second day of smaller bed size and lower velocity), plugging again became more frequent.

Because of the high ash content of the coal, bed inventory increased over time, as evidenced by an increase in differential pressure across the bed. Periodically, some bed material would be drained from the bottom of the reactor, in an effort to maintain a fairly consistent bed depth. Most of the ash was captured in the cyclone and collected in a pot. The pot was removed and cyclone ash samples collected at the end of each test period.

\section{Test Results}

Critical operating data were collected every 30 seconds for the duration of testing. At the conclusion of testing, the data for each steady-state test period were isolated and the averages and standard deviations calculated. Operating parameters are shown in Table 11. Emissions are shown in either percent $\left(\mathrm{O}_{2}, \mathrm{CO}_{2}\right)$ or ppm $\left(\mathrm{CO}, \mathrm{NO}_{\mathrm{x}}, \mathrm{SO}_{2}\right)$. Because the moisture is removed from the flue gas before the gas goes to the analyzers, the emission values shown are on a dry basis. The moisture content of the flue gas for these tests is calculated to be about $16 \%$. The emissions are also expressed on an equivalent-oxygen basis (at $6 \% \mathrm{O}_{2}$ ) and as a function of heat input in $\mathrm{mg} / \mathrm{Nm}^{3}$.

Three test periods were completed the first day: $788^{\circ} \mathrm{C}\left(1450^{\circ} \mathrm{F}\right)$ with no sorbent, $843^{\circ} \mathrm{C}$ $\left(1550^{\circ} \mathrm{F}\right)$ with no sorbent, and $843^{\circ} \mathrm{C}\left(1550^{\circ} \mathrm{F}\right)$ with Bulgarian sorbent. Sorbent was premixed and fed with the coal at the desired add rate. As expected, the sulfur retention with no sorbent addition was minimal; more surprising was the fact that the addition of sorbent, at a planned calcium-to-sulfur ratio $(\mathrm{Ca} / \mathrm{S})$ of 2 , had little effect on sulfur capture, $17 \%$ compared to about $8 \%$ without limestone. The sulfur content of the coal used during this test was considerably higher than that shown in the analysis available at the time of the run $(0.94 \%$ compared to $0.35 \%)$, so the actual $\mathrm{Ca} / \mathrm{S}$ ratio was considerably lower than expected. Based on the analysis of the actual coal burned, the $\mathrm{Ca} / \mathrm{S}$ ratio for the first limestone test was about 0.7 . 
Table 11. Summary of Process Data for FBR Test with Bulgarian Lignite

\begin{tabular}{|c|c|c|c|c|c|c|c|c|c|c|c|}
\hline & Test 1 & Test 2 & Test 3 & Test 4 & Test 5 & Test 6 & Test 7 & Test 8 & Test 9 & Test 10 & Test 11 \\
\hline Coal Feed Rate, $\mathrm{g} / \mathrm{hr}$ & 1616.2 & 1552.7 & 1600.2 & 1121.4 & 1088.4 & 1174.2 & 1058.9 & 1192.2 & 1154.4 & 1200.6 & 1095.6 \\
\hline Sorbent Feed Rate, $\mathrm{g} / \mathrm{hr}$ & 0.0 & 0.0 & 38.8 & 0.0 & 64.7 & 106.0 & 130.6 & 147.1 & 94.1 & 97.8 & 89.3 \\
\hline Sorbent & None & Bulgarian & Bulgarian & None & Bulgarian & Montana & $\mathrm{PRD}^{1}$ & PRD & PRD & PRD & PRD \\
\hline Zone 1 Temp., ${ }^{\circ} \mathrm{C}$ & 799 & 844 & 852 & 847 & 846 & 840 & 846 & 801 & 824 & 904 & 870 \\
\hline Total Air, slpm & 77.3 & 77.3 & 77.0 & 56.1 & 56.1 & 56.1 & 56.1 & 56.1 & 56.1 & 55.8 & 56.1 \\
\hline $\mathrm{FG}^{2} \mathrm{SGV},{ }^{3} \mathrm{~m} / \mathrm{sec}$ & 1.1 & 1.2 & 1.2 & 0.85 & 0.85 & 0.85 & 0.85 & 0.83 & 0.85 & 0.91 & 0.88 \\
\hline $\mathrm{O}_{2}, \%$ & 4.91 & 4.73 & 4.18 & 4.97 & 5.38 & 4.54 & 4.65 & 4.26 & 4.99 & 4.47 & 4.69 \\
\hline Excess Air & 29.1 & 27.7 & 23.8 & 29.8 & 33.5 & 26.9 & 28.0 & 25.0 & 30.6 & 26.7 & 28.1 \\
\hline $\mathrm{CO}_{2}$ Content, $\%$ & 14.0 & 14.2 & 14.6 & 13.7 & 13.7 & 15.0 & 15.0 & 15.7 & 14.4 & 15.2 & 14.7 \\
\hline $\mathrm{CO}_{2}$ Content, ${ }^{1 \%}$ & 15.6 & 15.7 & 15.6 & 15.4 & 15.8 & 16.4 & 16.6 & 16.9 & 16.2 & 16.6 & 16.2 \\
\hline CO Content, ppm & 1954 & 1764 & 1310 & 1034 & 310 & 747 & 420 & 635 & 258 & 161 & 288 \\
\hline CO Content, ${ }^{4}$ ppm & 2186 & 1951 & 1403 & 1161 & 357 & 817 & 462 & 682 & 290 & 175 & 318 \\
\hline $\mathrm{CO}$ Emission, $\mathrm{mg} / \mathrm{Nm}^{3}$ & 2733 & 2439 & 1754 & 1451 & 446 & 1021 & 578 & 853 & 363 & 219 & 398 \\
\hline $\mathrm{NO}_{\mathrm{x}}$ Content, ppm & 275 & 274 & 295 & 249 & 291 & 299 & 323 & 346 & 367 & 384 & 323 \\
\hline $\mathrm{NO}_{\mathrm{x}}$ Content, ${ }^{4} \mathrm{ppm}$ & 307 & 303 & 316 & 280 & 335 & 327 & 356 & 372 & 413 & 418 & 356 \\
\hline $\mathrm{NO}_{\mathrm{x}}$ Emission, $\mathrm{mg} / \mathrm{Nm}^{3}$ & 630 & 622 & 649 & 575 & 688 & 672 & 731 & 764 & 848 & 858 & 731 \\
\hline $\mathrm{SO}_{2}$ Content, ppm & 1619 & 1814 & 1677 & 1664 & 856 & 334 & 373 & 206 & 455 & 898 & 634 \\
\hline $\mathrm{SO}_{2}$ Content, ${ }^{4} \mathrm{ppm}$ & 1811 & 2006 & 1795 & 1869 & 987 & 365 & 411 & 222 & 512 & 978 & 700 \\
\hline $\mathrm{SO}_{2}$ Emission, $\mathrm{mg} / \mathrm{Nm}^{3}$ & 5174 & 5731 & 5129 & 5340 & 2820 & 1043 & 1174 & 634 & 1463 & 2794 & 2000 \\
\hline $\mathrm{SO}_{2}$ Retention, $\%$ & 17.4 & 8.9 & 17.5 & 12.7 & 54.8 & 84.0 & 82.1 & 90.5 & 77.2 & 57.4 & 68.8 \\
\hline $\mathrm{Ca} / \mathrm{S}, 1 \mathrm{~s}^{5}$ & 0.00 & 0.00 & 0.74 & 0.00 & 1.81 & 2.85 & 2.74 & 2.74 & 1.81 & 1.81 & 1.81 \\
\hline Calcium Utilization, ls & NA & NA & 23.8 & NA & 30.3 & 29.4 & 30.0 & 33.1 & 42.7 & 31.7 & 38.1 \\
\hline
\end{tabular}


As described above, the second day of testing began with new bed material and a lower velocity. The $843^{\circ} \mathrm{C}\left(1550^{\circ} \mathrm{F}\right)$ test without limestone was repeated to establish a baseline at the new velocity. When limestone was added for the next test, it was at a rate almost double that of the first limestone test, which resulted in a sulfur retention rate of about $55 \%$, at a $\mathrm{Ca} / \mathrm{S}$ ratio of 1.8 .

Prior EERC experience using a variety of sulfur sorbents indicates that there is great variability in the sulfur capture ability of different sorbents. In an effort to improve sulfur capture performance, a Montana limestone was used for the next test at the same $\mathrm{Ca} / \mathrm{S}$ ratio and temperature as the previous test. Sulfur retention improved from $54 \%$ to $84 \%$. A third sorbent, a dolomite, was used for the next test, again at the same $\mathrm{Ca} / \mathrm{S}$ ratio and temperature. This resulted in $82 \%$ sulfur retention. The performance of dolomite was similar to that of the Montana limestone, and dolomite was used for the remaining tests.

The relationship between $\mathrm{Ca} / \mathrm{S}$ ratio and sulfur retention is clearly shown in Figure 11. At a bed temperature of $843^{\circ} \mathrm{C}\left(1550^{\circ} \mathrm{F}\right)$, sulfur retention increased from around $10 \%$ with no sorbent addition to about $83 \%$ with a $\mathrm{Ca} / \mathrm{S}$ ratio of 2.7 . At a lower temperature, the trend is the same, but the sulfur retention is higher, from $17 \%$ with no sorbent to almost $91 \%$ with a $\mathrm{Ca} / \mathrm{S}$ ratio of 2.7. Figure 12 also shows the effect of temperature on sulfur retention. At both levels of sorbent addition, sulfur retention was greatest at lower temperature and decreased at temperatures greater than $843^{\circ} \mathrm{C}\left(1550^{\circ} \mathrm{F}\right)$. This is consistent with results from previous work at the EERC during FBC tests with low-rank coals.

The only set of conditions that achieved the desired $90 \%$ sulfur retention was an average bed temperature of $799^{\circ} \mathrm{C}\left(1470^{\circ} \mathrm{F}\right)$ and a $\mathrm{Ca} / \mathrm{S}$ ratio of 2.7 using dolomite as the sorbent. It is possible that $90 \%$ retention could have been achieved at a slightly lower $\mathrm{Ca} / \mathrm{S}$ ratio at a lower temperature; the tradeoff is poor combustion efficiency and increased $\mathrm{CO}$ emissions. Combustion efficiency is estimated for these tests by performing a loss-on-ignition (LOI) test on the cyclone ash and is shown as a function of bed temperature in Figure 13. LOI includes both carbon and carbonate in the ash, so actual carbon values could be lower for tests with limestone feed. The blue symbols in Figure 13 represent carbon content for three test periods. Test 4 had no limestone addition; Test 5 had a low rate of addition of Bulgarian limestone. Test 8, with a much higher add rate of dolomite, showed a much bigger difference between total LOI and carbon content, with the difference predominantly carbonate.

The ash balance for the test is shown in Table 12. The sorbent weight is adjusted to reflect the weight of reactants, $\left(\mathrm{CaSO}_{4}\right)$ and does not include the $\mathrm{CO}_{2}$ in the limestone, which is quickly driven off during calcination and treated as a gas rather than as a solids input. The outputs are cyclone ash, removed at the end of each test period, and baghouse ash. The baghouse was left online for the entire run and emptied at the end of the last day of testing. The baghouse ash output shown in Table 12 is the total mass of ash removed, divided by the total number of hours of coal feed. Typically, ash balance closures are poor on a small-scale unit, but the closure for these tests was quite good, generally ranging from $86 \%$ to $121 \%$. The lowest closure was $69 \%$, for Test 1. An increase in bed differential pressure over the course of the test indicates that material was accumulating in the bed, rather than exiting the cyclone. 


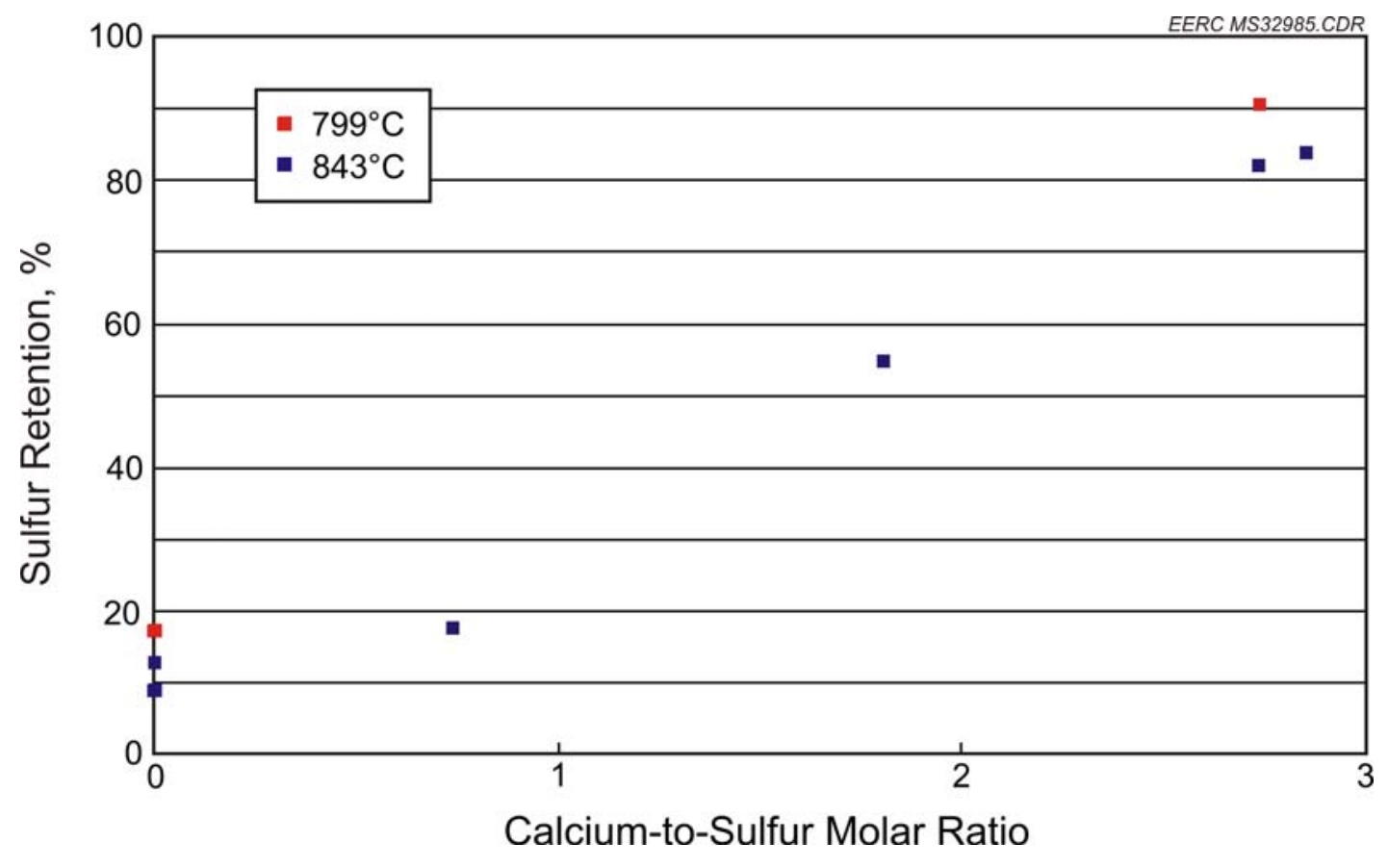

Figure 11. Sulfur retention as a function of calcium-to-sulfur ratio.

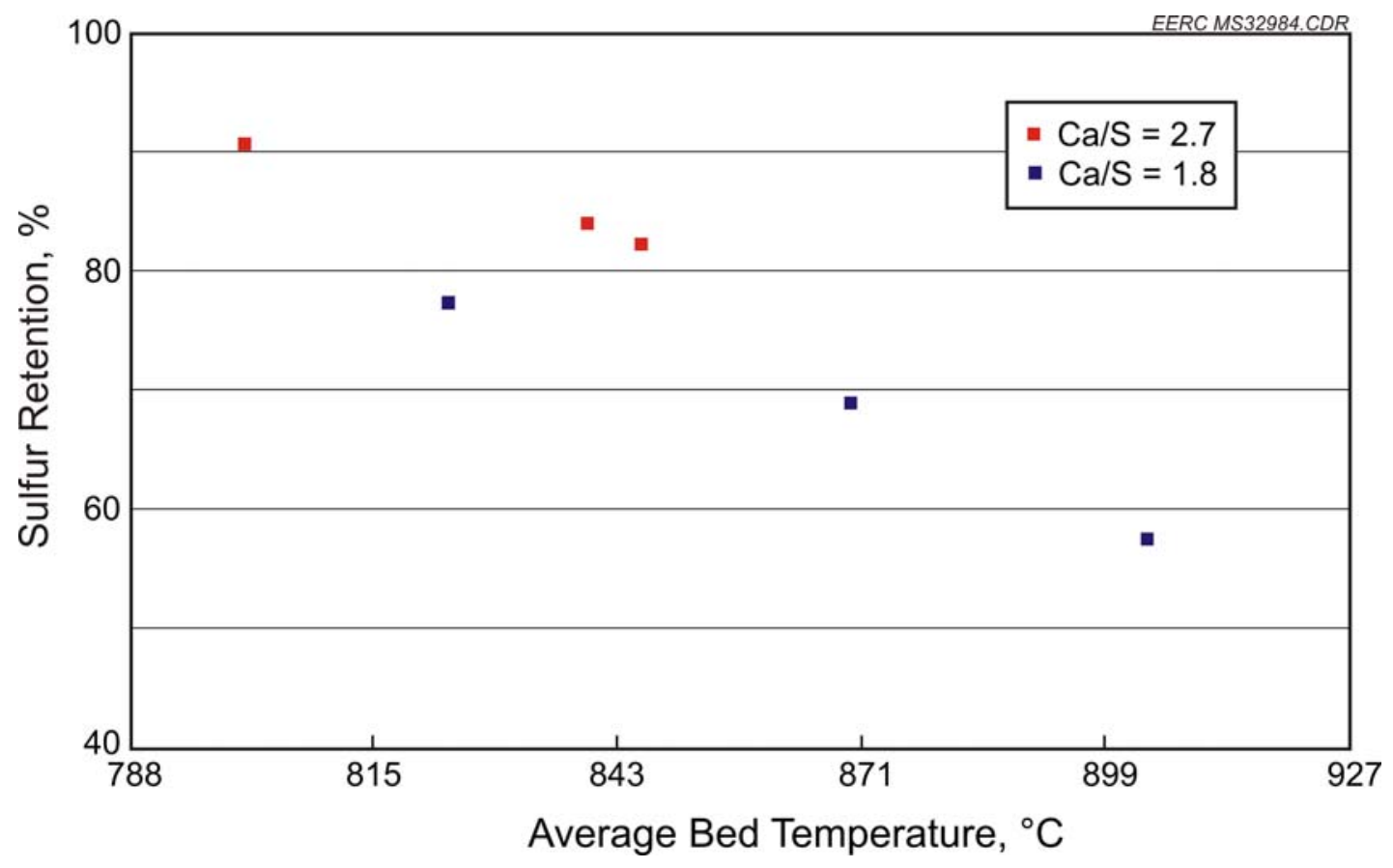

Figure 12. The effect of bed temperature on sulfur retention. 


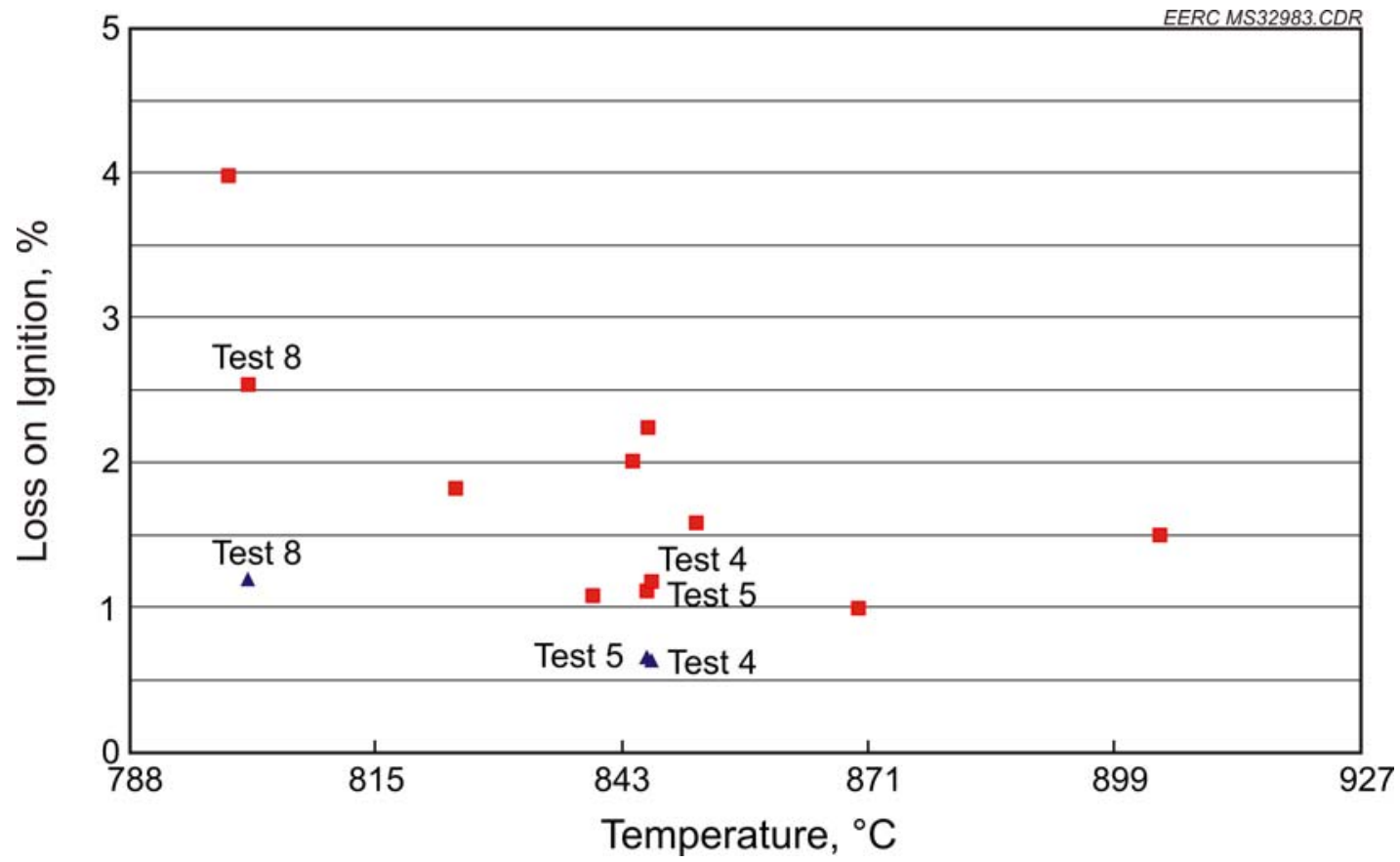

Figure 13. The effect of average bed temperature on LOI\%.

Table 12. Ash Balance

\begin{tabular}{|c|c|c|c|c|c|c|c|c|c|c|c|}
\hline & Test 1 & Test 2 & Test 3 & Test 4 & Test 5 & Test 6 & Test 7 & Test 8 & Test 9 & Test 10 & Test 11 \\
\hline \multicolumn{12}{|l|}{ Input, $\mathrm{g} / \mathrm{hr}$} \\
\hline $\begin{array}{l}\text { Coal Ash } \\
\text { Limestone: } 1\end{array}$ & 605.9 & 582.1 & 599.9 & 420.4 & 408.1 & 440.2 & 397.0 & 447.0 & 432.8 & 450.1 & 410.8 \\
\hline $\mathrm{CaO}$ & 0.0 & 0.0 & 14.8 & 0.0 & 22.6 & 0.0 & 0.0 & 0.0 & 0.0 & 24.4 & 20.2 \\
\hline $\mathrm{CaSO}_{4}$ & 0.0 & 0.0 & 4.6 & 0.0 & 9.8 & 0.0 & 0.0 & 0.0 & 0.0 & 11.3 & 12.4 \\
\hline Inerts & 0.0 & 0.0 & 0.0 & 0.0 & 0.0 & 0.0 & 0.0 & 0.0 & 0.0 & 0.0 & 0.0 \\
\hline Total Solids In & 605.9 & 582.1 & 619.3 & 420.4 & 440.4 & 440.2 & 397.0 & 447.0 & 432.8 & 485.8 & 443.4 \\
\hline \multicolumn{12}{|l|}{ Output, $\mathrm{g} / \mathrm{hr}$} \\
\hline Baghouse Ash & 55.1 & 55.1 & 55.1 & 55.1 & 55.1 & 55.1 & 55.1 & 55.1 & 55.1 & 55.1 & 55.1 \\
\hline Cyclone Ash & 364.0 & 447.6 & 598.7 & 337.7 & 375.6 & 456.3 & 425.0 & 437.1 & 445.1 & 447.7 & 393.1 \\
\hline Total Solids Out & 419.1 & 502.7 & 653.8 & 392.8 & 430.7 & 511.4 & 480.1 & 492.2 & 500.2 & 502.8 & 448.2 \\
\hline Closure, \% & 69.2 & 86.4 & 105.6 & 93.4 & 97.8 & 116.2 & 120.9 & 110.1 & 115.6 & 103.5 & 101.1 \\
\hline
\end{tabular}

\footnotetext{
${ }^{1} \mathrm{The} \mathrm{CaO}$ and $\mathrm{CaSO}_{4}$ mass inp uts are included to express sorb ent equivalent mass inputs.
} 
Particle-size distributions (PSD) for samples of bed material, cyclone ash, and filter ash from selected tests are shown in Figure 14. Filter particles ranged from 1-120 $\mu \mathrm{m}$ with a $\mathrm{d}_{50}$ of $10-15 \mu \mathrm{m}$. Cyclone particles had a maximum size of greater than $1100 \mu \mathrm{m}$ and a $\mathrm{d}_{50}$ of roughly $300 \mu \mathrm{m}$. Bed material particles ranged from $200 \mu \mathrm{m}$ to greater than $1100 \mu \mathrm{m}$ with a $\mathrm{d}_{50}$ of approximately $700 \mu \mathrm{m}$. The larger filter and cyclone particle sizes during Test 8 are most likely due to plugging of the cyclone.

The same samples, excluding the filter samples, were also tested for trace elements. The results of this analysis are shown in Table 13. The Test 8 cyclone sample had chlorine and fluoride concentrations that were more than three times greater than in any other sample, possibly due to the lower reactor temperature during this test. Antimony concentration was significantly higher in the bed material sample. Manganese was lowest in the bed material sample, suggesting that this metal is more volatile and is vaporized into the finer ash fractions that are collected in the back end.

\section{Summary and Conclusions for Task 2}

This fuel fed well and burned well in the FBR. There was no evidence of agglomeration in the bed material. The sulfur content of the coal was somewhat higher than expected, resulting in high-sulfur emissions. With no sorbent addition, sulfur retention was only $9 \%$ to $13 \%$ at an average bed temperature of $843^{\circ} \mathrm{C}\left(1550^{\circ} \mathrm{F}\right)$; at a bed temperature of $799^{\circ} \mathrm{C}\left(1470^{\circ} \mathrm{F}\right)$, sulfur retention was $17 \%$.

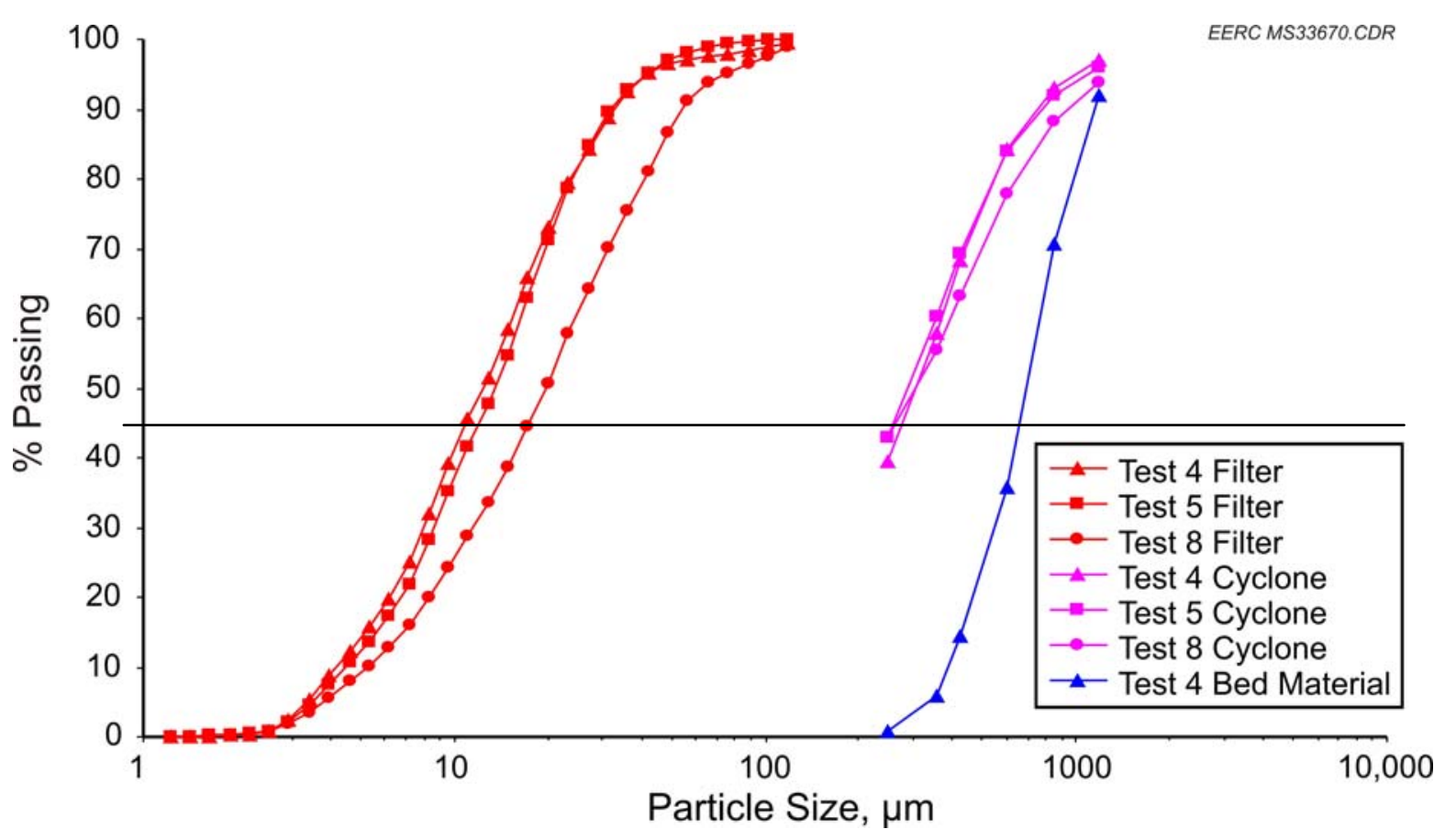

Figure 14. PSDs for selected tests. 
Table 13. Trace Element Analysis of FBR Samples

\begin{tabular}{lccccc}
\hline & $\begin{array}{c}\text { Test } 4 \\
\text { Cyclone }\end{array}$ & $\begin{array}{c}\text { Test } 5 \\
\text { Cyclone }\end{array}$ & $\begin{array}{c}\text { Test } 8 \\
\text { Cyclone }\end{array}$ & $\begin{array}{c}\text { Test 4 Bed } \\
\text { Material }\end{array}$ & $\begin{array}{c}\text { Composite } \\
\text { Baghouse Ash }\end{array}$ \\
\hline Concentration, $\mu \mathrm{g} / \mathrm{g}$ & & & & & \\
Antimony & 3.5 & 3 & 1.4 & 6.22 & 2.5 \\
Arsenic & 30.8 & 31.6 & 32.8 & 32.9 & 86.5 \\
Barium & 318 & 350 & 360 & 79.2 & 556 \\
Beryllium & 1.8 & 2.2 & 2.4 & 0.59 & 2.88 \\
Cadmium & 0.29 & 0.37 & 0.39 & 0.2 & 0.70 \\
Chlorine & 23 & 27 & 97 & 19 & 800 \\
Chromium & 429 & 384 & 180 & 530 & 281 \\
Fluorine & 247 & 283 & 913 & 125 & 554 \\
Lead & 15 & 16.2 & 21.5 & 4.3 & 24.2 \\
Manganese & 180 & 250 & 220 & 73 & 270 \\
Mercury & 0.0070 & 0.0079 & 0.0079 & 0.0072 & 1.23 \\
Nickel & 208 & 185 & 99.9 & 268 & 191 \\
Selenium & 0.97 & 1.2 & 2.2 & 0.72 & 17.2 \\
Silver & $<0.2$ & 0.2 & $<0.2$ & $<0.2$ & 0.29 \\
Uranium & 4.59 & 5.26 & 5.76 & 1.27 & 5.17 \\
\hline
\end{tabular}

Three different sulfur sorbents were used: the Bulgarian limestone supplied by the client, a Montana limestone, and a dolomite supplied by the EERC. All three were tested at similar conditions of coal feed, temperature, and excess air, although the Bulgarian limestone was only tested at a low $\mathrm{Ca} / \mathrm{S}$ ratio. The desired sulfur retention of $90 \%$ was achieved at a $\mathrm{Ca} / \mathrm{S}$ ratio of 2.7 and an average bed temperature of $801^{\circ} \mathrm{C}\left(1474^{\circ} \mathrm{F}\right)$. At the same $\mathrm{Ca} / \mathrm{S}$ ratio and a temperature of $843^{\circ} \mathrm{C}\left(1550^{\circ} \mathrm{F}\right)$, the sulfur retention was $82 \%$. At that temperature, a slight increase in sorbent feed rate could be expected to achieve $90 \%$ sulfur retention. It certainly appears that fluid-bed combustion of the Bulgarian lignite would be a viable utilization option.

\section{Task 3 - Bench-Scale Fluid-Bed Gasification Testing}

\section{Introduction and Background}

The potential for gasification systems to produce power more efficiently and with lower emissions than other power generation technologies has been well demonstrated over a wide range of fuel and gasifier types. The gasifier for a high-reactivity feedstock such as lignite was selected to be a fluid-bed gasifier since low-rank coals tend to have a high reactivity that will lend itself to a high carbon conversion and good fuel gas heating values at the lower operating temperatures consistent with a fluid-bed gasifier. Since fluid-bed gasifiers operate with a larger feedstock PSD, it is not necessary to size the lignite down to a fine-size PC as required by entrained-flow gasifiers. Other factors influencing the choice of fluid-bed versus entrainedtype gasifiers for coal include the amount of moisture in the feedstock and the amount of ash in the coal. High-ash coals tend to favor fluid-bed gasifiers, since the ash does not have to be heated and melted (with the associated heat for the phase change), as compared to the fluid-bed gasifier, which just heats the ash up to the bed temperature (which is substantially lower). In addition, high-moisture coals need to be dried (to less than $10 \mathrm{wt} \%$ water) before being fed to the 
entrained-flow gasifier, while fluid-bed gasifiers can handle moisture contents up to $40 \mathrm{wt} \%$ or possibly even higher.

The EERC at the University of North Dakota has more than 20 years of experience in gasification research at the laboratory, bench, and pilot scale.

\section{Objectives}

The objective of the Bulgarian Lignite Power Project (BLPP) portion of the gasification tests were to gasify the Bulgarian lignite in a small fluid-bed gasifier to obtain operating data including material balances on the conversion of the lignite to a useful syngas. This test generated 16 different steady-state test periods looking at the effects of operating temperature, reactor velocity, and oxidant/fuel ratio on the fuel gas heating value; carbon conversion; and the emissions of various syngas constituents and pollutants. In addition, these tests identified ash agglomeration and deposition that might occur with this particular lignite ash, which could be detrimental to the successful operation of the fluid-bed gasifier.

\section{Scope of Work}

This project utilized the existing bench-scale CFBR to gasify the lignite provided by the BLPP. Approximately $220 \mathrm{~kg}(480 \mathrm{lb})$ of a representative sample was provided, and approximately $30 \mathrm{~kg}(68 \mathrm{lb})$ of a locally selected calcium-based sorbent was provided for conducting the in-bed sulfur capture. The lignite moisture was reported to be $50 \mathrm{wt} \%$, which was air-dried to some extent in order to improve its feeding characteristics in the CFBR feed system. Steam was added back into the fluidizing gases to achieve the desired level of water vapor in the fuel gas. This budget assumed 5 full days of operation, generating 15 different steady-state test periods along with time for the prerun setup, including fuel preparation, system heatup and shutdown, and postrun maintenance. Parameters to be investigated during these tests included operating temperature in the gasifier, reactor velocity (or residence time), and the oxidant-to-fuel ratio. Operating parameters to be measured included an overall material balance including fuel gas composition, carbon conversion, and various pollutant emissions such as $\mathrm{H}_{2} \mathrm{~S}, \mathrm{NH}_{3}, \mathrm{HCl}$, etc., that might require additional control. The production of any tar was also determined, although detailed analysis of any tar for specific organic compounds was not conducted. In addition, analysis of any by-products and waste streams was completed to determine their potential for landfilling or their utilization in various by-products such as cement. Factors affecting the disposal potential for these residual streams include PSD, ash composition, and residual carbon content.

\section{Equipment Description}

\section{CFBR}

Figure 15 shows the $1.82-\mathrm{kg} / \mathrm{hr}(4-\mathrm{lb} / \mathrm{hr})$ CFBR used for gasification tests. Figure 16 is a photograph of the fluid-bed reactor system. The unit was originally designed as a pyrolysis unit for a DOE mild gasification program but has since been used for gasification and pyrolysis on a variety of projects. Gases used for fluidization are mixed in a gas manifold. Bottled gases, 


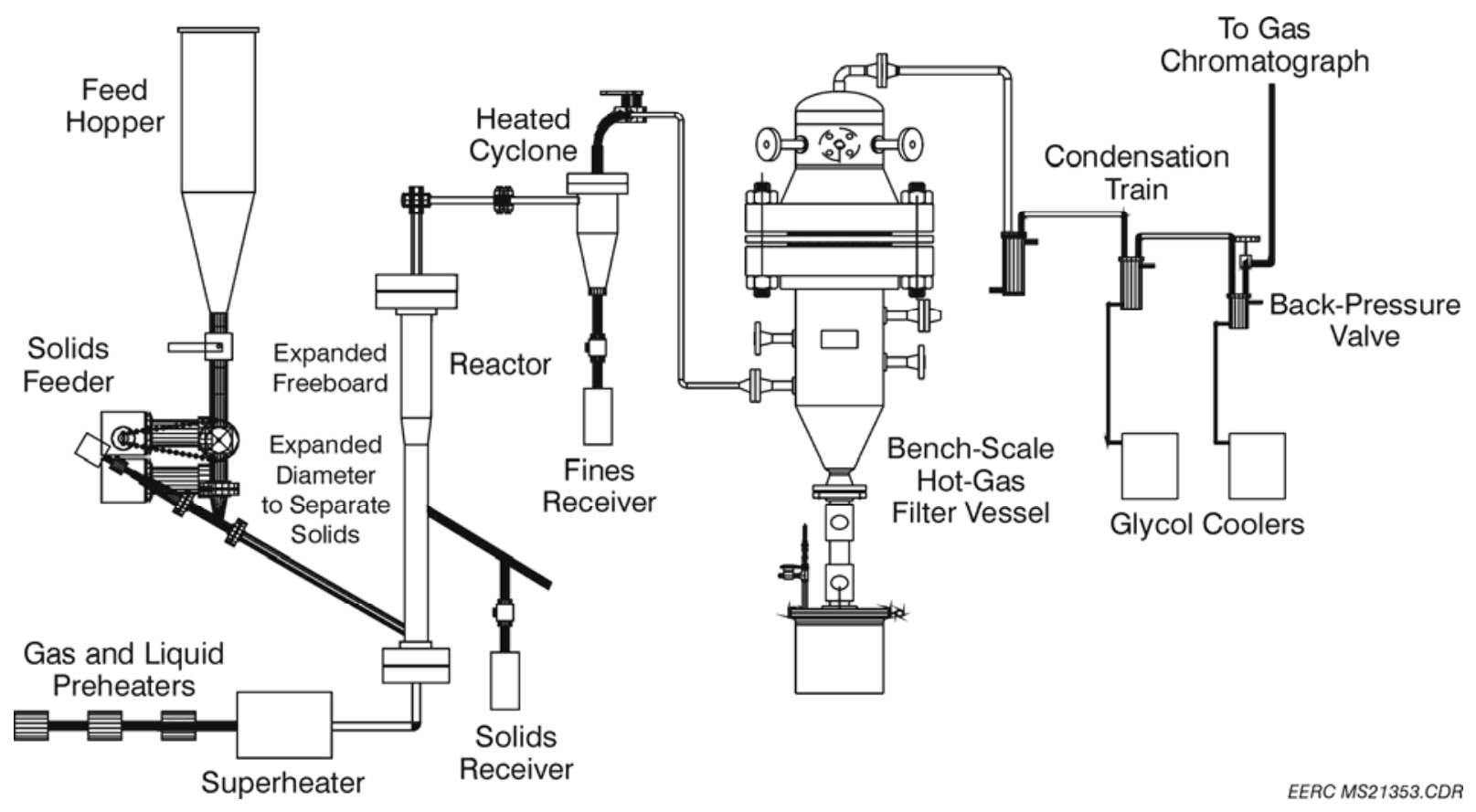

Figure 15. Schematic of CFBR.

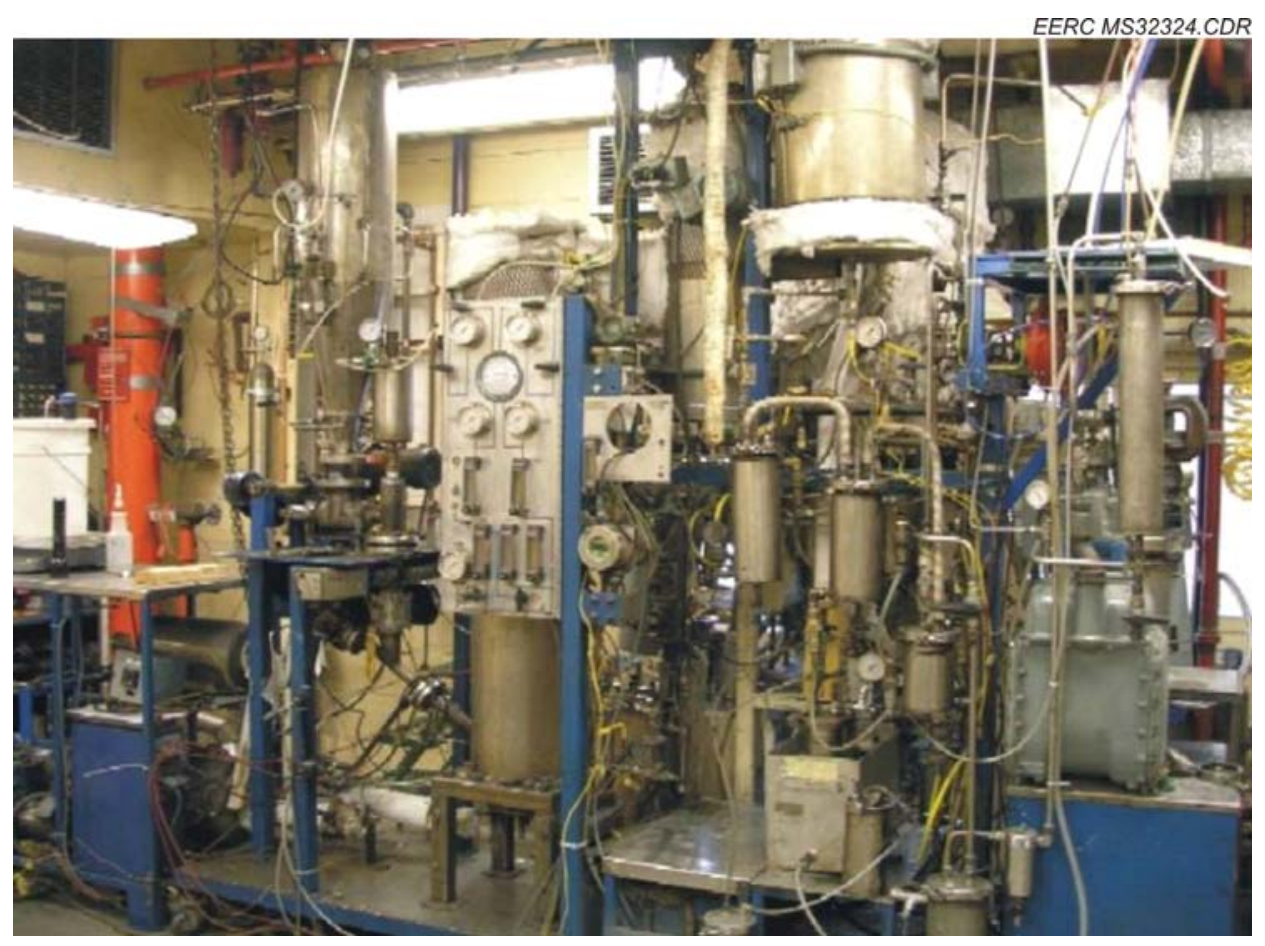

Figure 16. Photograph of the $4-1 \mathrm{~b} / \mathrm{hr}$ CFBR. 
including hydrogen, house nitrogen, house air, and any liquid desired (such as water), are first preheated, then mixed and heated to temperatures around $400^{\circ}$ to $500^{\circ} \mathrm{C}$ in a superheater $(6.1 \mathrm{~m}$ of $0.95-\mathrm{cm}$. tubing coiled into a $45.7-\mathrm{cm}$ ceramic fiber heater). Two bottled gases in combination with both house air or house nitrogen and a liquid can be used at the present time. A MAXIMATOR ${ }^{\circledR}$ gas booster is utilized as a recycle syngas compressor to allow syngas to be recycled to the bottom of the gasifier to allow the fluidization velocity to be set independently of the oxidant and steam flow rates without having to dilute the syngas with inert nitrogen.

The reactor is constructed of $316 \mathrm{H}$ stainless steel Schedule 80 pipe. The first (bottom) section is made of 7.62-cm (3-in.) pipe and is $83.8 \mathrm{~cm}$ (33 in.) in length. The next (top) reactor section is made of $10.2-\mathrm{cm}$ (4-in.) pipe, $47.6 \mathrm{~cm}$ (18.75 in.) in length. The two sections are connected with a $316 \mathrm{H}$ weld reducer. The unit was designed such that the top of the fluid bed lies $83.8 \mathrm{~cm}$ (33 in.) above the coal injection point. A solids offtake leg at the top of the bed is the primary means of solids removal from the reactor. A ball valve facilitates collection of the product while the system is operating. The reactor currently has two ceramic fiber heaters to maintain the vessel's temperature and eliminate hot spots. Using external heaters allows the evaluation of internal and external heating methods for process development and scale-up. The utilization of the external heaters allows the effects of high heat losses that occur at this small scale to be minimized; however, these heaters also make obtaining an accurate heat balance around the reactor difficult to measure. The reactor is capable of operation at a maximum of $11.7 \mathrm{bar}(155 \mathrm{psig})$ and $845^{\circ} \mathrm{C}\left(1550^{\circ} \mathrm{F}\right)$.

A 7.62-cm (3-in.)-diameter cyclone is used for solids removal from the gas stream. A ball valve allows the changing of the solids catch pot while the system is operating. The cyclone is heated with a ceramic fiber heater capable of operating at a temperature of $845^{\circ} \mathrm{C}\left(1550^{\circ} \mathrm{F}\right)$. Different-sized heated vessels ranging from $5.08-\mathrm{cm}(2-\mathrm{in}$.) inside diameter (i.d.) to $12.7-\mathrm{cm}$ (5-in.) i.d. and lengths from 25.4 to $61.0 \mathrm{~cm}$ (10 in. to $24 \mathrm{in}$.) are available for utilizing various sorbents in a packed-bed mode for conducting contaminate removal (i.e., sulfur, trace metals, etc.) or catalyst testing (i.e., gas shifting). A new circulating fluid-bed reactor for bulk desulfurization has recently been constructed and is currently being integrated with this gasification system. Six 10.2-cm (4-in.)-diameter vessels are used to remove all condensables from the gas stream. The first condenser pot is indirectly cooled by water and typically cools the gas stream from $300^{\circ} \mathrm{C}\left(570^{\circ} \mathrm{F}\right)$ to $95^{\circ} \mathrm{C}\left(200^{\circ} \mathrm{F}\right)$. The next two condensers, also indirect, are glycol-cooled. The last three are water-cooled. The exit gas temperature is typically $10^{\circ} \mathrm{C}\left(50^{\circ} \mathrm{F}\right)$. A glass wool filter is used to capture aerosols passed through the condenser system.

Not shown in the schematic is a product gas recycle loop. A portion of the gas is taken off between the condensation train and back-pressure control valve, passed through a booster pump to increase the pressure, and fed back to the bottom of the reactor. Using recycled syngas instead of nitrogen as fluidizing gas results in a higher heating value product gas, because of the reduction in nitrogen. Recycled syngas is used for pressure tap purges, as well, so that during oxygen-blown operation, the only nitrogen entering the system is from backpulsing the FV and pressuring the coal hopper and cyclone pots during filling and emptying, respectively.

A Genesis software package is used for process control and data acquisition. Two transmitters measure pressure drop across the bed, and thermocouples throughout the unit 
measure temperature. Temperature and pressure readings are recorded every 30 seconds, and these data are directly transferred to spreadsheets. Online continuous emission monitors for $\mathrm{H}_{2}$, $\mathrm{CO}, \mathrm{CH}_{4}, \mathrm{CO}_{2}$, and $\mathrm{H}_{2} \mathrm{~S}$ together with online Foxboro and Yokogawa process gas chromatographs are utilized for measuring gas compositions. If desired, the gas composition of the coal-derived gas stream can be adjusted slightly by adding bottled gas to the gas stream entering the reactor.

\section{Bench-Scale Hot-Gas Filter Vessel (HGFV)}

The design and construction of a bench-scale filter vessel (FV) that could be used in conjunction with the CFBR (for gasification/pyrolysis) was built to test hot-gas candle filters for their ability to obtain high-temperature, high-pressure operational data on various filter elements. This vessel is designed to handle all of the gas flow from the CFBR at its nominal design conditions. The vessel is $25.4-\mathrm{cm}$ (10-in.) i.d. and $152.4 \mathrm{~cm}$ (60 in.) long (including cone, vessel, and cap) and can handle a gas flow up to $850 \mathrm{slpm}(30 \mathrm{scfm})$ at $845^{\circ} \mathrm{C}\left(1550^{\circ} \mathrm{F}\right)$ and $11.3 \mathrm{bar}$ (150 psig). The tube sheet is interchangeable to handle different-sized filters. The filters are sealed in the tube sheet by a bolted metal plate and Nextel ${ }^{\text {TM }}$ fiber gaskets which counteract the upward force imparted across the candle filter by the filter's differential pressure. The vessel is sized such that it could handle three candle filters up to $45.7 \mathrm{~cm}$ (18 in.) long with a $6.03-\mathrm{cm}$ (2.375-in.) outside diameter. This would provide candle space of $9.78 \mathrm{~cm}(3.85 \mathrm{in}$.) centerline to centerline and enable filter face velocities as low as $1.27 \mathrm{~cm} / \mathrm{sec}(2.5 \mathrm{ft} / \mathrm{min})$ to be tested in the CFBR. Higher face velocities would be achieved by using shorter candles or higher gas flow rates. Ports are added in the FV for allowing temperature and pressure measurements to be obtained. The ash letdown station consists of two high-temperature valves that act as lock hoppers to isolate the ash hopper from the FV.

The nitrogen backpulse system is constructed from existing materials utilized from a previous hot-gas filter test system. The backpulse system is designed to supply a minimum of three candle volumes per pulse for the longest candle filters and even higher volumes for the shorter candle filters. The length and volume of nitrogen displaced into the vessel is controlled by the regulated pressure (up to 42.4 bar) of the cold-nitrogen reservoir and the solenoid valves used to control the timing of the cold-gas pulse, which displaces the hot nitrogen into the FV. An electrically heated $1.27-\mathrm{cm}(1 / 2-$ in. $)$ pipe is used to connect the CFBR to the HGFV.

\section{Test Matrix}

This program will examine gasification performance under both air-blown and oxygenblown operation. Temperature, moisture-to-coal ratio, and $\mathrm{O}_{2}$-to-coal ratio were varied in both air-blown and oxygen-blown mode. Temperature is controlled with a combination of coal feed rate, air flow rate, and ceramic heater control. The test matrix is shown in Table 14.

\section{Coal Properties}

The fuel analyses for the coal are shown in Table 15 . The coal was sized to $-6 \mathrm{~mm}$, and premixed with Bulgarian limestone at a ratio of 11 grams of limestone per pound of coal. XRF 
Table 14. Test Matrix for Gasification of Bulgarian Coal

\begin{tabular}{lcccc}
\hline $\begin{array}{l}\text { Test } \\
\text { Number }\end{array}$ & $\begin{array}{c}\text { Bed Temperature, } \\
{ }^{\circ} \mathrm{C}\end{array}$ & $\begin{array}{c}\text { Steam Flow, } \\
\mathrm{g} / \mathrm{hr}\end{array}$ & $\begin{array}{c}\text { Air Flow, } \\
\text { slpm }\end{array}$ & $\begin{array}{c}\text { Oxygen Flow, } \\
\text { slpm }\end{array}$ \\
\hline 1 & 750 & 454 & 53.3 & 0 \\
2 & 750 & 908 & 74.1 & 0 \\
3 & 800 & 454 & 53.3 & 0 \\
4 & 800 & 908 & 74.1 & 0 \\
5 & 850 & 454 & 53.3 & 0 \\
6 & 850 & 908 & 74.1 & 0 \\
7 & 750 & 1452 & 0 & 15.6 \\
8 & 750 & 1816 & 0 & 19.8 \\
9 & 800 & 1452 & 0 & 15.6 \\
10 & 800 & 1816 & 0 & 19.8 \\
11 & 850 & 1452 & 0 & 15.6 \\
12 & 850 & 1816 & 0 & 19.8 \\
\hline
\end{tabular}

Table 15. Proximate, Ultimate, and $\mathrm{HHV}^{1}$ for

Coal Composite

Proximate, as run, $\mathrm{wt} \%$

Moisture

Volatile Matter

23.46

Fixed Carbon

16.15

Ash

37.49

Ultimate, as run, $\mathrm{wt} \%$

Carbon

25.48

Hydrogen

5.12

Nitrogen

1.59

Sulfur

0.94

Oxygen

30.38

Ash

$\mathrm{HHV}, \mathrm{kJ} / \mathrm{kg}$

As Run, kJ/kg

9387

$\mathrm{MF}^{2} \mathrm{~kJ} / \mathrm{kg}$

12180

${ }^{1}$ Higher heating value.

2 Moisture-free. 
ash analyses for the coal and Bulgarian limestone are shown in Table 16. Silica sand was used as the start-up bed material.

\section{Operating Conditions}

Test periods for this fuel were scheduled to be 8 hours long, including a period for changing conditions and reaching steady state. At the end of each test period, the FV was backpulsed, and the pot emptied so that a sample could be collected. The cyclone pot was emptied every hour, and a sample collected at the end of the steady-state period. Quench pots were also drained hourly; the liquids were collected in a single container for the duration of the test period and sampled at the end.

The air-blown tests were completed first, starting at the lowest temperature $\left(750^{\circ} \mathrm{C}\right)$. The coal fed very well, although the high ash content did result in a gradual increase in solids inventory, as evidenced by an increase in differential pressure across the bed. After about 4 hours of coal feed, there was a plug in the bottom of the reactor where coal enters the unit.

Bed temperatures increased, indicating a loss in coal feed; a dramatic temperature spike in the bottom of the reactor suggested agglomeration. The test was stopped; the unit was depressurized so that the bed material could be removed and examined. Bed material can be removed from the unit, but the drain point is about $76.2 \mathrm{~cm}$ (30 inches) above the distributor plate. As a result, only smaller-sized particles can be drained from the reactor bed during operation. When agglomeration occurs, the bottom flange must be removed from the reactor to empty the reactor. Large, hard agglomerates were found in the bed material.

The unit was started up again using bauxite instead of silica sand for start-up. Experience at the EERC shows that a bauxite bed is less prone to agglomeration problems than silica. Bauxite is less dense than sand and has different fluidization characteristics, so more bauxite was required to achieve the same bed depth. When coal was started, steam and air flow rates were increased for Test 2, and the syngas recycle rate was increased to maintain a higher fluidization

Table 16. XRF Ash Analysis for Coal Composite and Bulgarian Limestone

\begin{tabular}{lcc}
\hline & Coal Composite, wt $\%$ & Bulgarian Limestone, wt \% \\
\hline $\mathrm{SiO}_{2}$ & 52.8 & 18.3 \\
$\mathrm{Al}_{2} \mathrm{O}_{3}$ & 27.3 & 2.6 \\
$\mathrm{Fe}_{2} \mathrm{O}_{3}$ & 7.06 & 0.34 \\
$\mathrm{TiO}_{2}$ & 0.68 & 0.15 \\
$\mathrm{P}_{2} \mathrm{O}_{5}$ & 0.17 & 0.15 \\
$\mathrm{CaO}$ & 4.2 & 76.3 \\
$\mathrm{MgO}$ & 1.98 & 1.8 \\
$\mathrm{Na}_{2} \mathrm{O}$ & 0.17 & 0 \\
$\mathrm{~K}_{2} \mathrm{O}$ & 1.47 & 0.26 \\
$\mathrm{SO}_{3}$ & 4.15 & 0.13 \\
\hline
\end{tabular}


velocity in the reactor. The unit lined out quickly and ran well for about 3.5 hours, when temperatures indicated poor fluidization. A temperature spike at the bottom indicated agglomeration, so once again, the unit was shut down and bed material was removed.

The ash analysis of this coal showed relatively small amounts of alkaline components (sodium and potassium). It was not expected that agglomeration would be a problem, based on the analysis. Examination of the bed material removed from the bottom of the reactor, compared to the coal being fed, indicated that the coal contained large particles of ash that were not breaking down in the reactor. They were too large to be carried out of the bed, or even as high as the bed material drain port, so they accumulated in the bed as fresh coal entered the system. It was decided to screen the feed coal to remove the larger ash particles. For the remaining tests, the coal was screened to $<1.7 \mathrm{~mm}$ ( $-12 \mathrm{mesh})$. The same ratio of limestone to coal was used.

Test 3, at $800^{\circ} \mathrm{C}$ and low steam and air flow rates, ran well for about 4 hours, then experienced periodic loss of coal feed. The test conditions continued for 7 hours, at which time steam and air flow rates were increased for Test 4 . Recycled syngas was reduced to maintain the same fluidizing velocity, and the external heaters were turned down to maintain the temperature. After 7 hours, the heaters were increased to bring the bed temperature up to $850^{\circ} \mathrm{C}$, at the higher rate of steam and air addition (Test 6 in Table 14). The order of the tests was changed to minimize transition times between tests, by changing as few parameters as possible. Again, the test was uneventful.

The last air-blown test was run at $850^{\circ} \mathrm{C}$ and low steam and air flow rates, with increased recycled syngas to maintain velocity. Almost immediately, the temperature distribution indicated poor fluidization. The recycled syngas enters the reactor through a tube that comes up in the middle of the distributor plate so that the combustible gas does not contact oxygen until it reaches the reactor. Changing the ratio of steam/air to syngas can affect the fluidization pattern in the reactor. Because we had been feeding coal for over 20 hours, it is possible that we were also seeing a buildup of larger ash particles, which would adversely affect fluidization. There were several times during these tests that coal feed was lost, and the pressure tap at the bottom of the reactor plugged off occasionally, further indicating poor fluidization at the bottom of the bed. After 4 hours, a temperature spike indicated bed agglomeration.

The unit was started again on silica sand. Since the agglomeration episodes seemed to be more of a fluidization issue than a chemical issue, it was decided to use the material that had the better fluidization characteristics. The next set of tests was performed in oxygen-blown mode. Because much less oxygen than air is required, both the steam and recycled syngas flows are increased to maintain the same fluidizing velocity as the previous tests. The first oxygen test, Test 7 , was at $750^{\circ} \mathrm{C}$ and low rates of $\mathrm{O}_{2}$ and steam. The temperature distribution in the bed suggested excellent fluidization for the first 3 hours of coal feed; after that, the fluidization was still good, but the temperature in the bottom of the reactor dropped off a little. Transitioning to Test $8,750^{\circ} \mathrm{C}$ and higher steam and $\mathrm{O}_{2}$ rates, resulted in a very uniform temperature distribution across the bed. For Test 9 , the steam and $\mathrm{O}_{2}$ flows were kept high, and the bed temperature was increased to $800^{\circ} \mathrm{C}$. It was difficult to achieve the desired temperature in the reactor during this test, and the test period was cut short when a coal feed plug resulted in a system upset. After draining some bed material and reducing the steam and $\mathrm{O}_{2}$ flow rates, the average bed 
temperature lined out closer to $800^{\circ} \mathrm{C}$ for Test 10 . However, after only 3.5 hours at this condition, the bed agglomerated again.

Sand was again used as the start-up bed material. Because the low-steam, low-oxygen tests, with a higher proportion of recycled syngas as fluidizing gas, seem to cause more problems than the high-steam, high-oxygen tests, Test 11 was run at $850^{\circ} \mathrm{C}, 1816 \mathrm{~g} / \mathrm{hr}$ steam and $19.8 \mathrm{slpm}(42 \mathrm{scfh}) \mathrm{O}_{2}$, and Test 12 was run at $1452 \mathrm{~g} / \mathrm{hr}$ steam and $15.6 \mathrm{slpm}(33 \mathrm{scfh}) \mathrm{O}_{2}$.

Figures 17 and 18 and Tables 17 and 18 show the results of SEM morphologies performed on the bed material agglomeration samples. This was done to determine the cause of the agglomeration problems. Figures 17 and 18 have various tag points where a compositional analysis was done. These compositional analyses are summarized in Tables 17 and 18. The tag points of most interest are those at the boundaries of the bed material particles such as Points 5 and 8 in Figure 17. It seems that the agglomeration problems were caused by iron and potassium silicate clays melting and binding the particles together.

\section{Results}

The CFBR includes a data acquisition and control system that saves operating data every 30 seconds. These data include reactor temperatures, steam, air, oxygen and nitrogen flow rates, calculated fluidizing velocity, differential pressure across the bed, differential pressure across the $\mathrm{FV}$, and product gas composition. Table 19 shows the main steady-state operating conditions in the CFBR during each test period.

The product gas composition was measured using a Yokogawa gas chromatograph, sampling and analyzing a point sample of gas every 10 minutes. A steady-state test period begins when the gas composition has lined out. Table 20 shows the results of the most common components and the corresponding heating value. The product gas produced during oxygenblown tests has a higher hydrogen concentration and heating value than tests performed during air-blown mode. The LHVs measured with the air-blown tests suggest that some oxygen enrichment may be necessary for fuel gas heating values to be sufficient to sustainably operate an advanced aero-derivative gas turbine. This heating value has been reported to be above $4471 \mathrm{~kJ} / \mathrm{m}^{3}(120 \mathrm{Btu} / \mathrm{scf})$ by GE, although heating values as low as $4099 \mathrm{~kJ} / \mathrm{m}^{3}$ (110 Btu/scf) are possible.

Solid samples were submitted for XRF analysis; the results are shown in Table 21. The data are also represented graphically in Figures 19-21. Tests 9 and 12 show significantly higher levels of silica for all three sampling locations because of the fact that silica sand was used as the bed material for these tests, while bauxite was used for Tests 3 and 4.

PSD of the solid samples was also determined. The results are shown in Figure 22. FV particles ranged from $1-90 \mu \mathrm{m}$ with a $\mathrm{d}_{50}$ of roughly $6 \mu \mathrm{m}$. Cyclone particles had a maximum size of approximately $1000 \mu \mathrm{m}$ and a $\mathrm{d}_{50}$ of $105 \mu \mathrm{m}$. Bed char particles had a maximum size over $1000 \mu \mathrm{m}$ and $\mathrm{a} \mathrm{d}_{50}$ of roughly $600 \mu \mathrm{m}$. Each of the four test periods sampled produced comparable PSDs for the three sampling locations. 


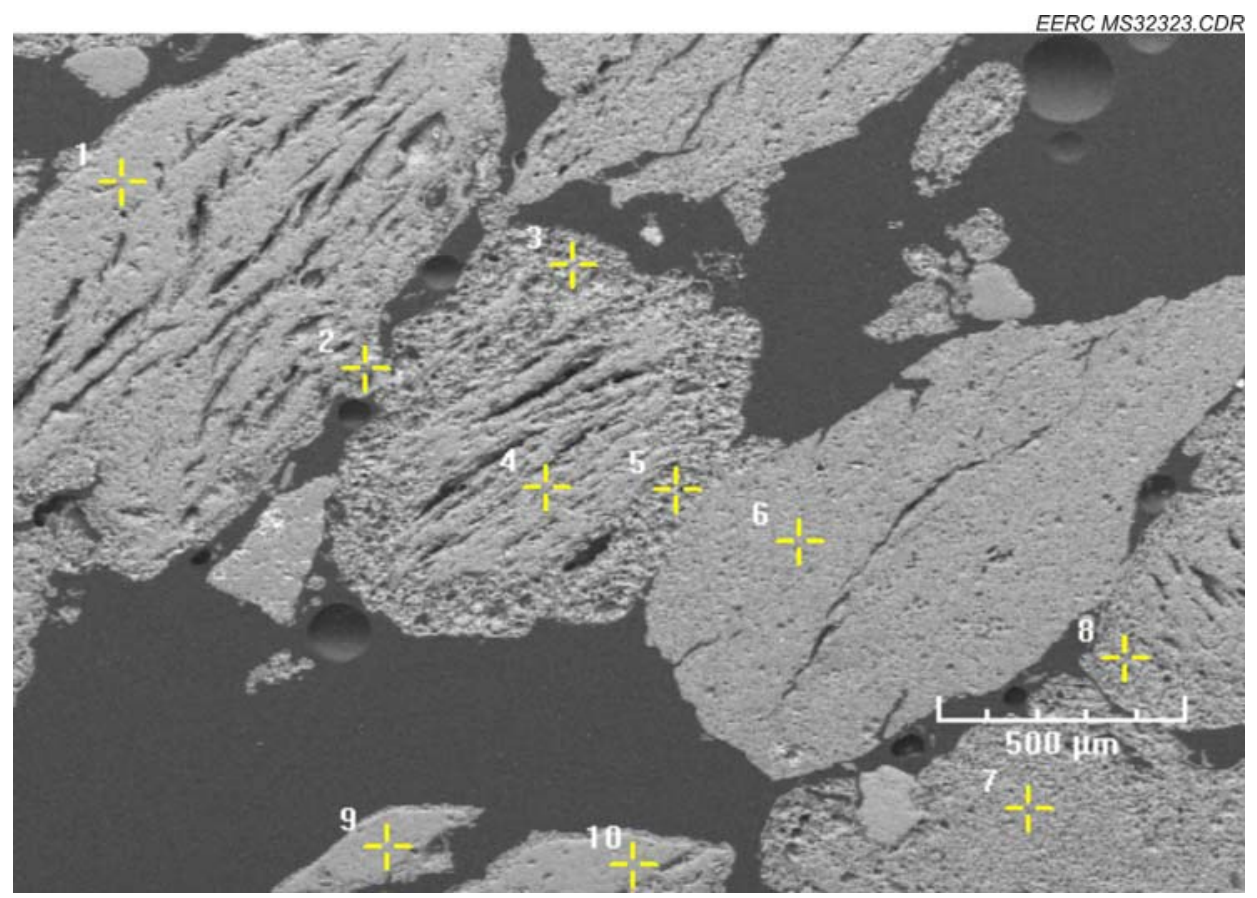

Figure 17. SEM morphology of CFBR bed material agglomeration samples.

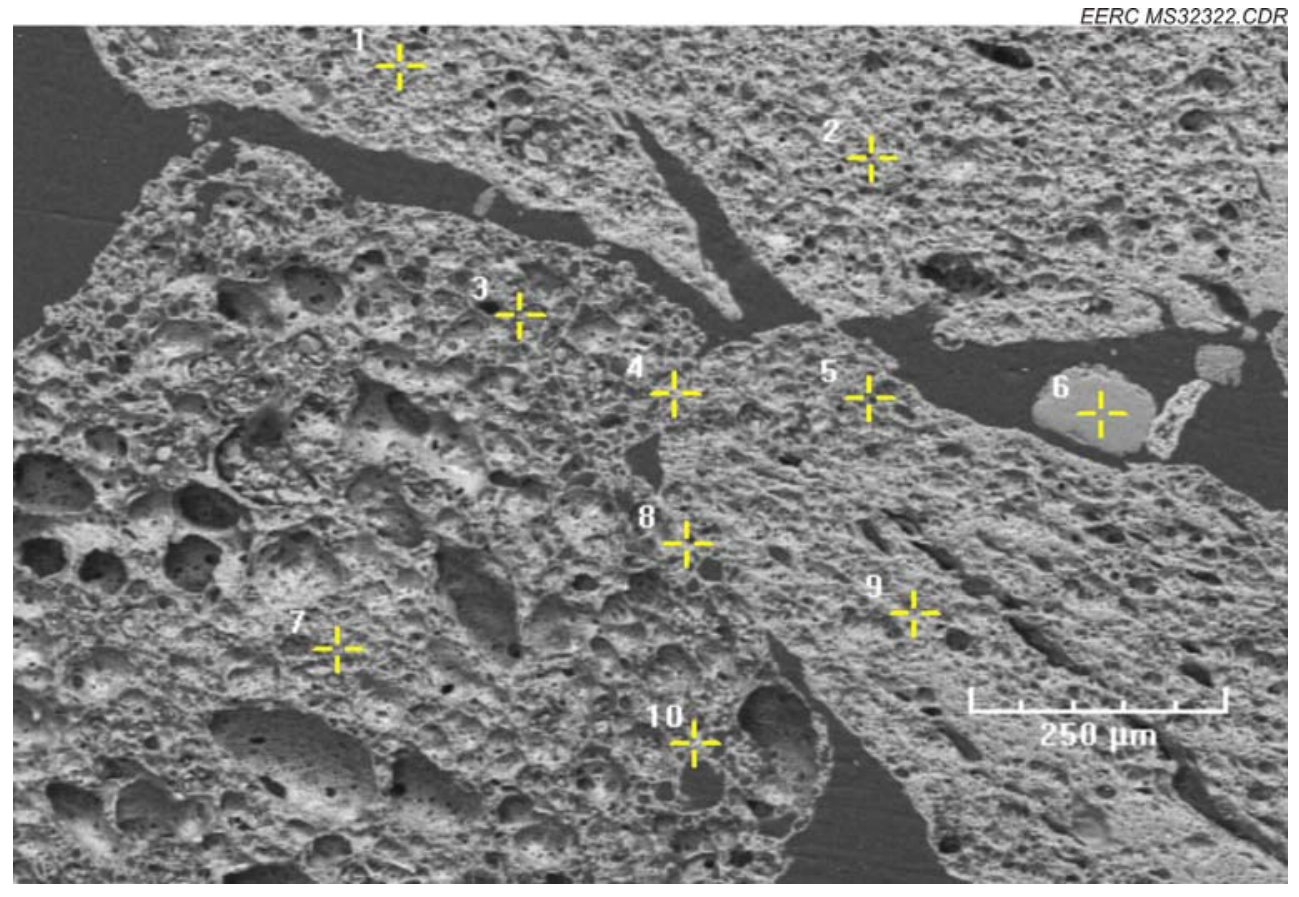

Figure 18. SEM morphology of CFBR bed material agglomeration samples. 
Table 17. Composition of Tag Points from Figure 17

\begin{tabular}{lclllllll}
\hline Tag & $\mathrm{Mg}$ & $\mathrm{Al}$ & $\mathrm{Si}$ & $\mathrm{Cl}$ & $\mathrm{K}$ & $\mathrm{Ca}$ & $\mathrm{Ti}$ & $\mathrm{Fe}$ \\
\hline 1 & $1.21 \%$ & $26.56 \%$ & $59.86 \%$ & $0.00 \%$ & $4.05 \%$ & $0.94 \%$ & $0.88 \%$ & $6.50 \%$ \\
2 & $0.24 \%$ & $8.76 \%$ & $79.73 \%$ & $0.00 \%$ & $5.56 \%$ & $0.66 \%$ & $0.55 \%$ & $3.57 \%$ \\
3 & $1.07 \%$ & $25.37 \%$ & $60.24 \%$ & $0.00 \%$ & $4.92 \%$ & $0.68 \%$ & $0.26 \%$ & $6.81 \%$ \\
4 & $1.48 \%$ & $24.44 \%$ & $56.42 \%$ & $0.00 \%$ & $6.27 \%$ & $0.98 \%$ & $1.17 \%$ & $9.15 \%$ \\
5 & $0.00 \%$ & $6.67 \%$ & $7.55 \%$ & $0.00 \%$ & $6.01 \%$ & $2.91 \%$ & $4.22 \%$ & $71.90 \%$ \\
6 & $0.69 \%$ & $25.82 \%$ & $61.45 \%$ & $0.00 \%$ & $4.04 \%$ & $1.61 \%$ & $0.94 \%$ & $5.11 \%$ \\
7 & $0.83 \%$ & $23.43 \%$ & $62.67 \%$ & $0.06 \%$ & $4.98 \%$ & $0.64 \%$ & $0.93 \%$ & $6.46 \%$ \\
8 & $0.98 \%$ & $25.85 \%$ & $54.79 \%$ & $0.00 \%$ & $4.75 \%$ & $1.87 \%$ & $0.91 \%$ & $10.79 \%$ \\
9 & $1.03 \%$ & $26.91 \%$ & $59.81 \%$ & $0.00 \%$ & $3.11 \%$ & $1.60 \%$ & $0.51 \%$ & $7.02 \%$ \\
10 & $0.94 \%$ & $27.04 \%$ & $60.88 \%$ & $0.03 \%$ & $2.95 \%$ & $0.98 \%$ & $0.38 \%$ & $6.79 \%$ \\
\hline
\end{tabular}

Table 18. Composition of Tag Points from Figure 18

\begin{tabular}{lcccccccc}
\hline Tag & $\mathrm{Mg}$ & $\mathrm{Al}$ & $\mathrm{Si}$ & $\mathrm{P}$ & $\mathrm{K}$ & $\mathrm{Ca}$ & $\mathrm{Ti}$ & $\mathrm{Fe}$ \\
\hline 1 & $1.85 \%$ & $23.84 \%$ & $61.24 \%$ & $0.00 \%$ & $3.60 \%$ & $0.82 \%$ & $0.51 \%$ & $8.14 \%$ \\
2 & $1.20 \%$ & $21.60 \%$ & $60.05 \%$ & $0.25 \%$ & $7.17 \%$ & $1.84 \%$ & $0.92 \%$ & $6.91 \%$ \\
3 & $0.88 \%$ & $22.81 \%$ & $63.30 \%$ & $0.97 \%$ & $4.40 \%$ & $0.84 \%$ & $0.55 \%$ & $5.78 \%$ \\
4 & $2.26 \%$ & $28.00 \%$ & $49.90 \%$ & $0.19 \%$ & $3.28 \%$ & $3.17 \%$ & $0.44 \%$ & $12.56 \%$ \\
5 & $0.19 \%$ & $24.42 \%$ & $51.48 \%$ & $0.00 \%$ & $4.58 \%$ & $2.84 \%$ & $1.05 \%$ & $13.21 \%$ \\
6 & $0.00 \%$ & $0.03 \%$ & $94.63 \%$ & $0.51 \%$ & $4.38 \%$ & $0.00 \%$ & $0.01 \%$ & $0.34 \%$ \\
7 & $1.35 \%$ & $27.85 \%$ & $56.07 \%$ & $0.00 \%$ & $2.63 \%$ & $0.55 \%$ & $0.41 \%$ & $11.13 \%$ \\
8 & $0.55 \%$ & $26.49 \%$ & $47.93 \%$ & $0.30 \%$ & $2.92 \%$ & $2.33 \%$ & $1.00 \%$ & $13.30 \%$ \\
9 & $1.25 \%$ & $27.24 \%$ & $58.13 \%$ & $0.44 \%$ & $4.36 \%$ & $1.48 \%$ & $0.38 \%$ & $6.66 \%$ \\
10 & $1.19 \%$ & $25.94 \%$ & $61.19 \%$ & $1.41 \%$ & $3.93 \%$ & $0.64 \%$ & $0.42 \%$ & $5.05 \%$ \\
\hline
\end{tabular}

Table 19. CFBR Operating Conditions

\begin{tabular}{|c|c|c|c|c|c|c|}
\hline $\begin{array}{l}\text { Test } \\
\text { Number }\end{array}$ & $\begin{array}{c}\text { Average Bed } \\
\text { Temperature, } \\
{ }^{\circ} \mathrm{C} \\
\end{array}$ & $\begin{array}{l}\text { Steam } \\
\text { Flow, } \\
\mathrm{g} / \mathrm{hr}\end{array}$ & $\begin{array}{c}\text { Air Flow } \\
\text { Rate, } \\
\text { slpm }\end{array}$ & $\begin{array}{c}\text { Oxygen } \\
\text { Flow } \\
\text { Rate, } \\
\text { slpm } \\
\end{array}$ & $\begin{array}{l}\text { Coal } \\
\text { Feed } \\
\text { Rate, } \\
\mathrm{kg} / \mathrm{hr}\end{array}$ & $\begin{array}{r}\mathrm{SGV}, \\
\mathrm{m} / \mathrm{s}\end{array}$ \\
\hline 1 & 755 & 475 & 56.6 & 0.0 & 2.31 & 0.236 \\
\hline 2 & 747 & 914 & 70.3 & 0.0 & 2.68 & 0.241 \\
\hline 3 & 792 & 469 & 52.4 & 0.0 & 2.04 & 0.242 \\
\hline 4 & 795 & 907 & 75.5 & 0.0 & 2.39 & 0.237 \\
\hline 5 & 842 & 911 & 72.7 & 0.0 & 2.43 & 0.227 \\
\hline 6 & 828 & 488 & 51.9 & 0.0 & 2.16 & 0.221 \\
\hline 7 & 748 & 1468 & 0.0 & 15.6 & 2.47 & 0.242 \\
\hline 8 & 745 & 1833 & 0.0 & 19.8 & 2.52 & 0.241 \\
\hline 9 & 792 & 1826 & 0.0 & 19.8 & 2.55 & 0.235 \\
\hline 10 & 792 & 1483 & 0.0 & 15.6 & 2.28 & 0.234 \\
\hline 11 & 846 & 1838 & 0.0 & 19.8 & 2.50 & 0.249 \\
\hline 12 & 833 & 1551 & 0.0 & 15.6 & 2.43 & 0.244 \\
\hline
\end{tabular}


Table 20. CFBR Product Gas Composition and Heating Value

\begin{tabular}{lccccccc}
\hline Test & $\mathrm{H}_{2}, \%$ & $\mathrm{CH}_{4}, \%$ & $\mathrm{CO}, \%$ & $\mathrm{CO}_{2}, \%$ & $\mathrm{~N}_{2}, \%$ & $\mathrm{H}_{2} \mathrm{~S}, \mathrm{ppm}$ & $\mathrm{HV}, \mathrm{kJ} / \mathrm{m}^{3}$ \\
\hline 1 & 8.2 & 2.2 & 7.3 & 17.2 & 65.58 & 1584 & 2682 \\
2 & 7.8 & 1.5 & 5.1 & 18.2 & 66.36 & 1302 & 2124 \\
3 & 5.9 & 1.1 & 6.4 & 16.9 & 69.23 & 835 & 1900 \\
4 & 5.7 & 0.5 & 4.2 & 18.0 & 71.15 & 1923 & 1379 \\
5 & 7.9 & 0.5 & 6.2 & 17.4 & 67.29 & 1881 & 1900 \\
6 & 7.8 & 0.9 & 8.8 & 16.0 & 65.89 & 1833 & 2347 \\
7 & 9.3 & 4.1 & 11.0 & 52.2 & 23.60 & 3699 & 3987 \\
8 & 8.7 & 3.8 & 9.9 & 63.7 & 13.66 & 6406 & 3689 \\
9 & 11.4 & 4.0 & 13.9 & 65.3 & 4.50 & 7306 & 4546 \\
10 & 11.4 & 4.5 & 16.3 & 62.5 & 4.76 & 7146 & 5030 \\
11 & 15.4 & 4.0 & 22.3 & 55.1 & 3.87 & 4717 & 6036 \\
12 & 16.9 & 4.9 & 25.1 & 50.4 & 3.67 & 5948 & 6893 \\
\hline
\end{tabular}

Table 21. XRF Analysis of Solid Samples

\begin{tabular}{|c|c|c|c|c|}
\hline & $\begin{array}{l}\text { Bed Char } \\
\text { Test } 3\end{array}$ & $\begin{array}{c}\text { Bed Char } \\
\text { Test } 4\end{array}$ & $\begin{array}{c}\text { Bed Char } \\
\text { Test } 9\end{array}$ & $\begin{array}{c}\text { Bed Char } \\
\text { Test } 12\end{array}$ \\
\hline \multicolumn{5}{|c|}{ Bed Char, wt $\%$} \\
\hline $\mathrm{SiO}_{2}$ & 40.8 & 44.1 & 58.9 & 64.2 \\
\hline $\mathrm{Al}_{2} \mathrm{O}_{3}$ & 49.3 & 43.0 & 27.3 & 23.3 \\
\hline $\mathrm{Fe}_{2} \mathrm{O}_{3}$ & 3.44 & 5.01 & 5.71 & 4.88 \\
\hline $\mathrm{TiO}_{2}$ & 1.26 & 1.04 & 0.64 & 0.53 \\
\hline $\mathrm{P}_{2} \mathrm{O}_{5}$ & 0.15 & 0.15 & 0.16 & 0.15 \\
\hline $\mathrm{CaO}$ & 3.4 & 4.0 & 3.6 & 3.7 \\
\hline $\mathrm{MgO}$ & 0.62 & 1.19 & 1.71 & 1.54 \\
\hline $\mathrm{Na}_{2} \mathrm{O}$ & 0.00 & 0.07 & 0.20 & 0.17 \\
\hline $\mathrm{K}_{2} \mathrm{O}$ & 0.78 & 1.18 & 1.49 & 1.26 \\
\hline \multirow[t]{2}{*}{$\mathrm{SO}_{3}$} & 0.26 & 0.29 & 0.33 & 0.28 \\
\hline & Cyclone Test 3 & Cyclone Test 4 & Cyclone Test 9 & Cyclone Test 12 \\
\hline \multicolumn{5}{|c|}{ Cyclone, wt\% } \\
\hline $\mathrm{SiO}_{2}$ & 47.0 & 49.9 & 53.5 & 57.8 \\
\hline $\mathrm{Al}_{2} \mathrm{O}_{3}$ & 33.6 & 29.9 & 26.8 & 23.8 \\
\hline $\mathrm{Fe}_{2} \mathrm{O}_{3}$ & 6.40 & 6.68 & 6.74 & 6.32 \\
\hline $\mathrm{TiO}_{2}$ & 0.86 & 0.74 & 0.65 & 0.55 \\
\hline $\mathrm{P}_{2} \mathrm{O}_{5}$ & 0.17 & 0.17 & 0.17 & 0.16 \\
\hline $\mathrm{CaO}$ & 6.2 & 6.7 & 6.3 & 5.9 \\
\hline $\mathrm{MgO}$ & 1.69 & 1.88 & 1.92 & 1.76 \\
\hline $\mathrm{Na}_{2} \mathrm{O}$ & 0.11 & 0.13 & 0.14 & 0.15 \\
\hline $\mathrm{K}_{2} \mathrm{O}$ & 1.26 & 1.34 & 1.41 & 1.26 \\
\hline $\mathrm{SO}_{3}$ & 2.69 & 2.58 & 2.49 & 2.33 \\
\hline
\end{tabular}

Continued ... 
Table 21. XRF Analysis of Solid Samples (continued)

\begin{tabular}{lcccc}
\hline & FV Test 3 & FV Test 4 & FV Test 9 & FV Test 12 \\
\hline $\mathrm{FV}, \mathrm{wt} \%$ & & & & \\
$\mathrm{SiO}_{2}$ & 30.2 & 41.8 & 49.8 & 50.4 \\
$\mathrm{Al}_{2} \mathrm{O}_{3}$ & 50.1 & 32.8 & 23.8 & 23.2 \\
$\mathrm{Fe}_{2} \mathrm{O}_{3}$ & 4.34 & 6.45 & 6.85 & 7.26 \\
$\mathrm{TiO}_{2}$ & 1.98 & 1.12 & 0.65 & 0.65 \\
$\mathrm{P}_{2} \mathrm{O}_{5}$ & 0.22 & 0.20 & 0.19 & 0.19 \\
$\mathrm{CaO}$ & 7.1 & 10.7 & 11.0 & 11.3 \\
$\mathrm{MgO}$ & 0.98 & 1.81 & 1.97 & 2.09 \\
$\mathrm{Na}_{2} \mathrm{O}$ & 0.27 & 0.18 & 0.22 & 0.21 \\
$\mathrm{~K}_{2} \mathrm{O}$ & 0.63 & 0.95 & 1.22 & 1.24 \\
$\mathrm{SO}_{3}$ & 4.13 & 4.00 & 4.31 & 3.43 \\
\hline
\end{tabular}

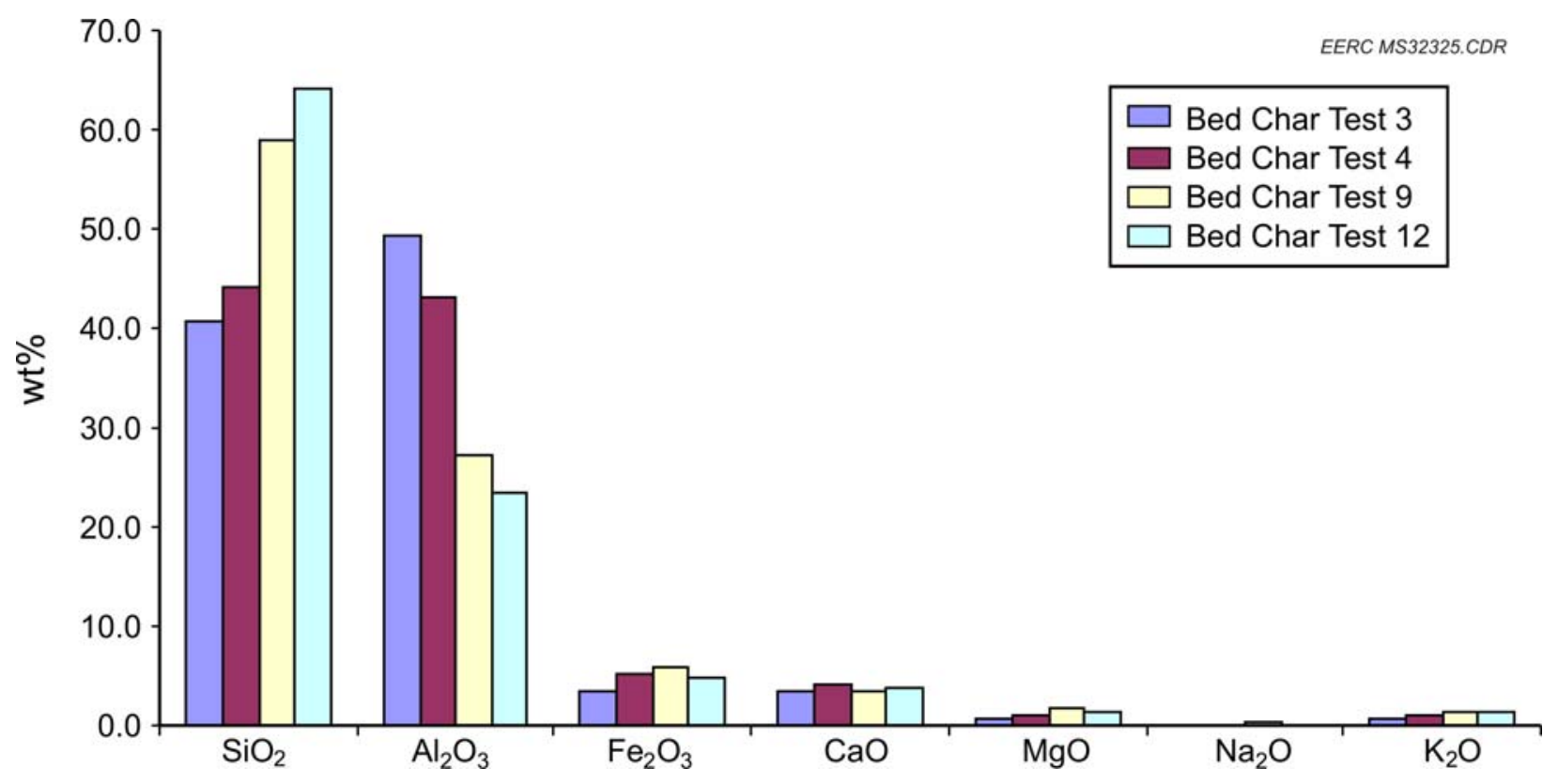

Figure 19. XRF ash analysis of bed char samples. 


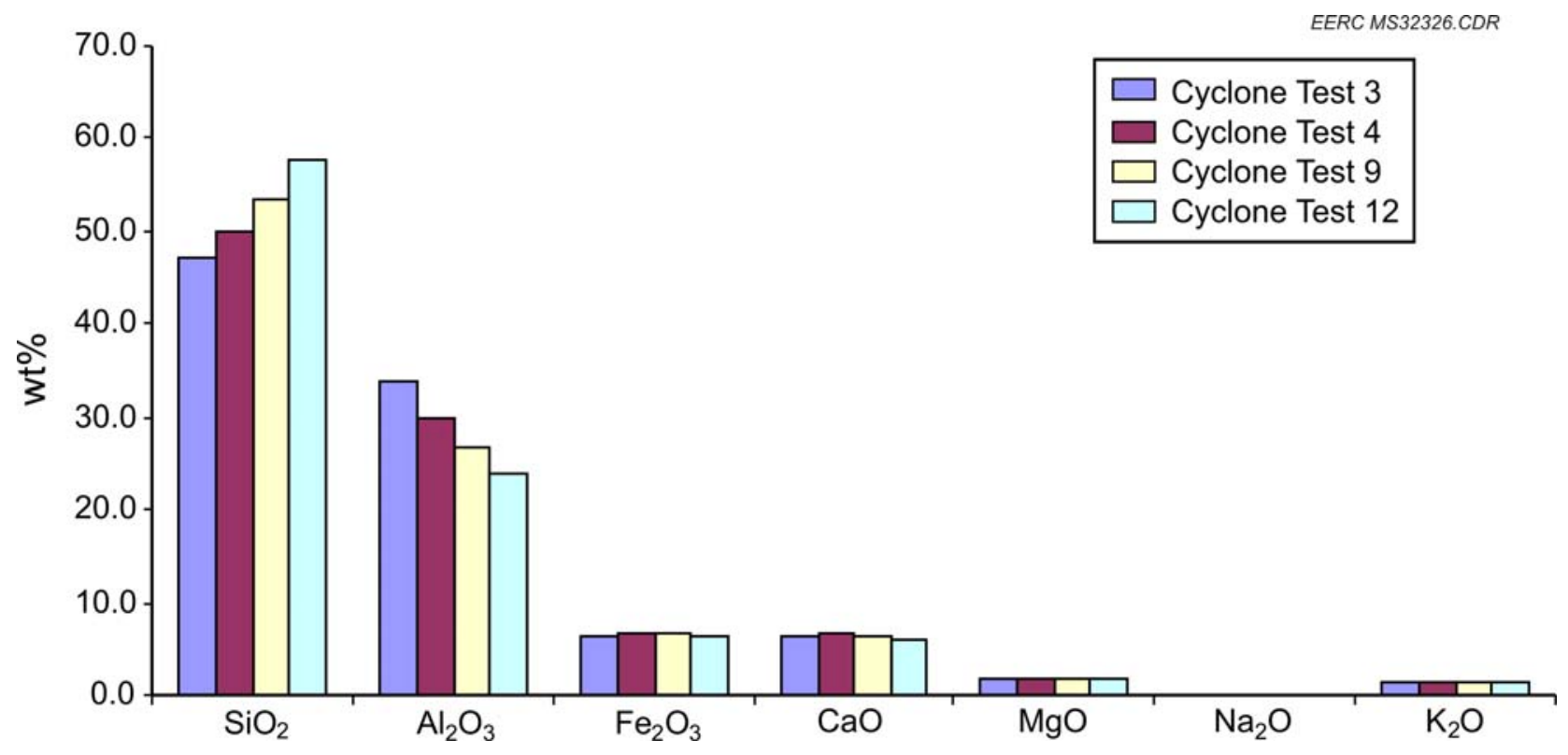

Figure 20. XRF ash analysis of cyclone samples.

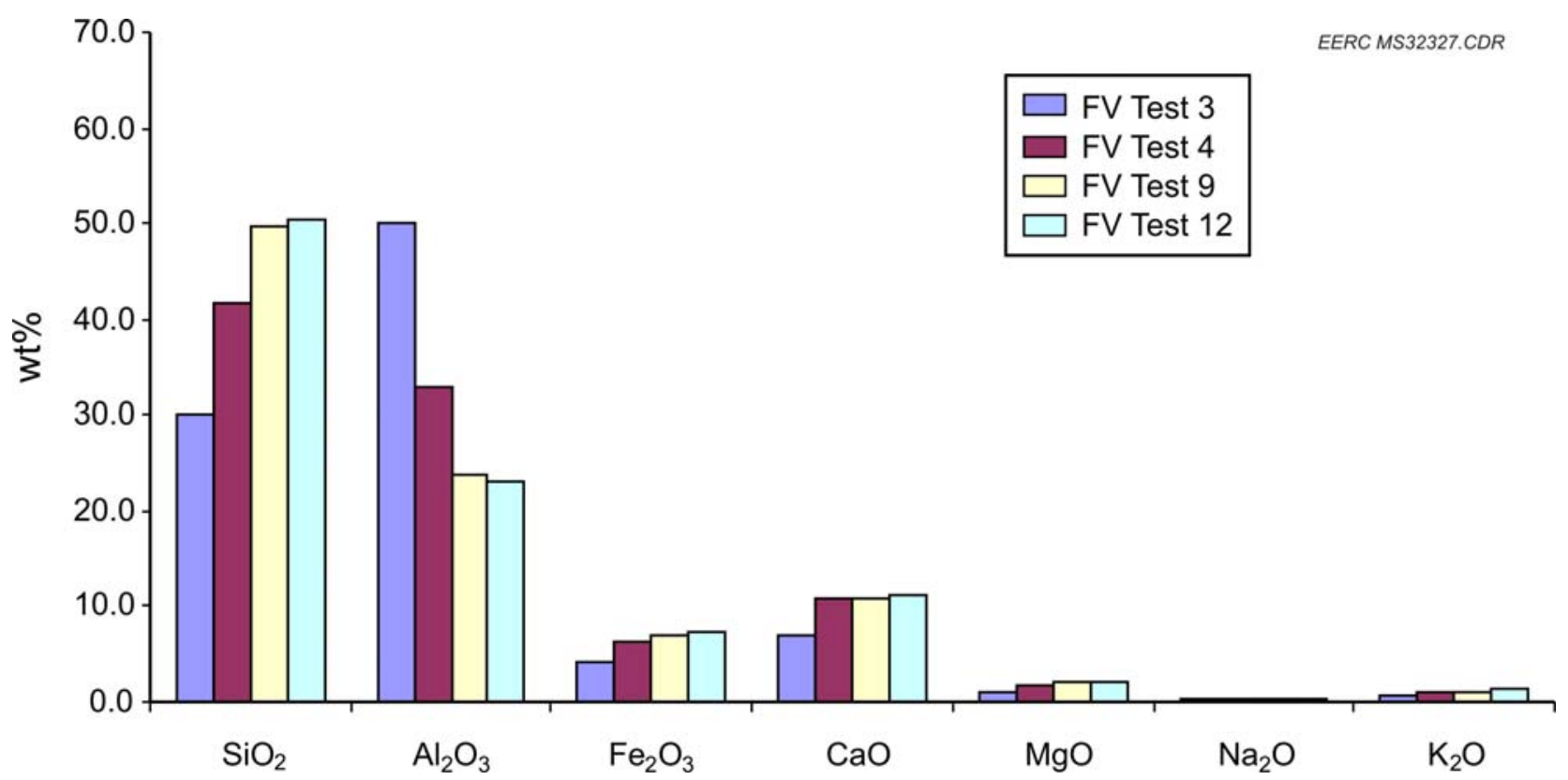

Figure 21. XRF ash analysis of FV samples. 


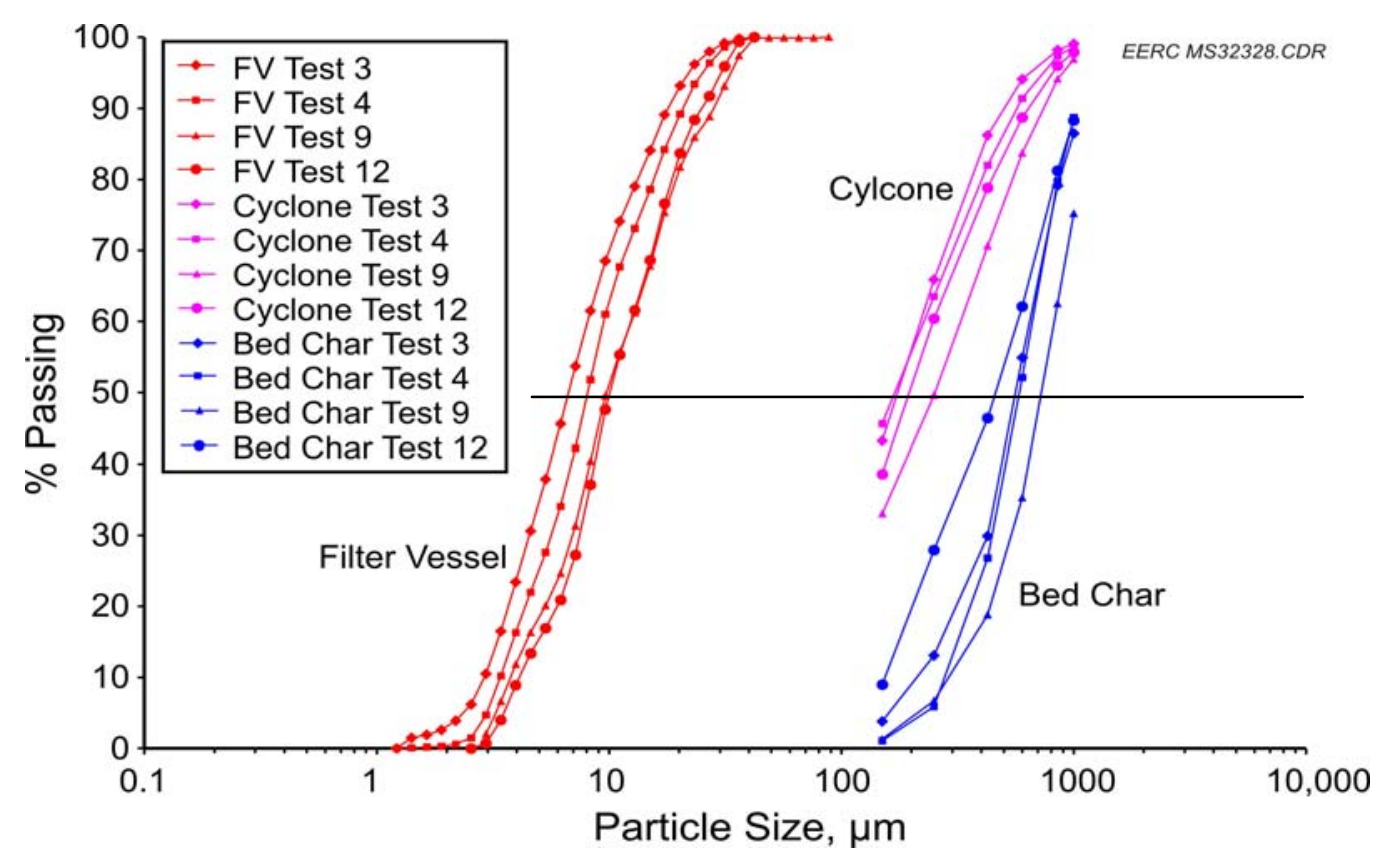

Figure 22. PSDs for solid samples.

Figures 23-28 show the results of trace elements analysis on the solid samples from the CFBR. The figures show that the majority of each of the trace metals accumulates in the FV. Chromium and lead are the exceptions, as their concentration is more equally spread over the sampling locations. Antimony concentration was less than $0.5 \mu \mathrm{g} / \mathrm{g}$ for all samples except the FV sample from Test $12(2.4 \mu \mathrm{g} / \mathrm{g})$. Mercury typically exits the system in vapor phase resulting in essentially zero accumulation in the solid samples. Manganese concentration was lowest in the bed material and highest in the FV, again indicating higher volatility for this metal result in concentration in the finer ash fractions.

Figure 29 shows a plot of the product gas heating value and carbon conversion as a function of $\mathrm{O}_{2} / \mathrm{maf}$ coal ratio. During air-blown operation, there is a clear trend of decreasing heating value with increasing $\mathrm{O}_{2} / \mathrm{maf}$ coal ratio. There seems to be the same trend during oxygen-blown operation, but the data are much more scattered. Carbon conversion data appears to have the opposite trend: increasing conversion with increasing $\mathrm{O}_{2} / \mathrm{maf}$ coal ratio which agrees with previous testing. As more oxygen is fed to the reactor and the gasifier operates closer to stoichiometric, more carbon is converted into $\mathrm{CO}_{2}$, thereby decreasing the syngas heating value.

Table 22 shows the material balance data from the tests. Some discrepancies in the closure are because of accumulation or entrainment losses from the FBR itself. No solids were added or removed from the bed itself during the testing. 


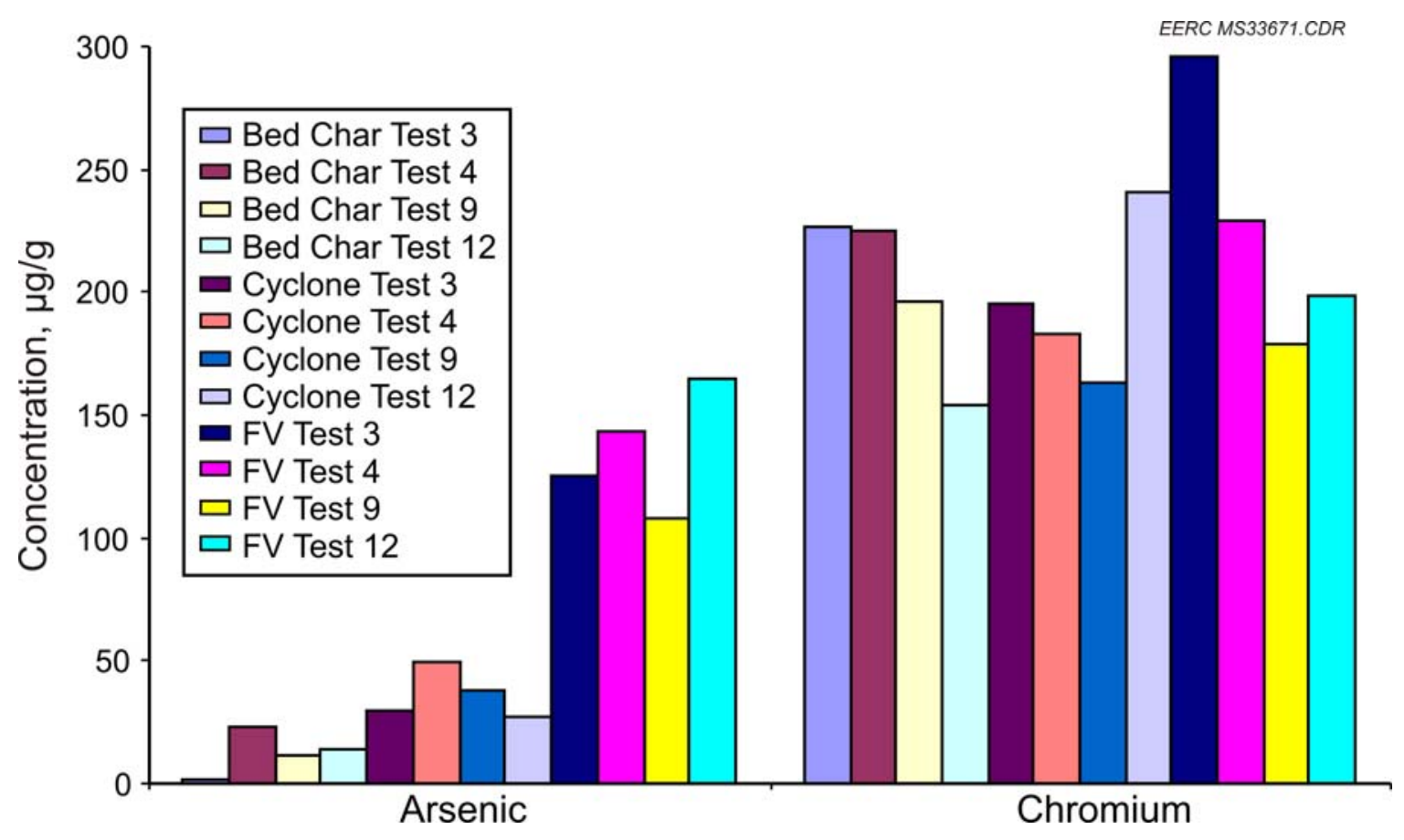

Figure 23. Arsenic and chromium concentration in solid samples.

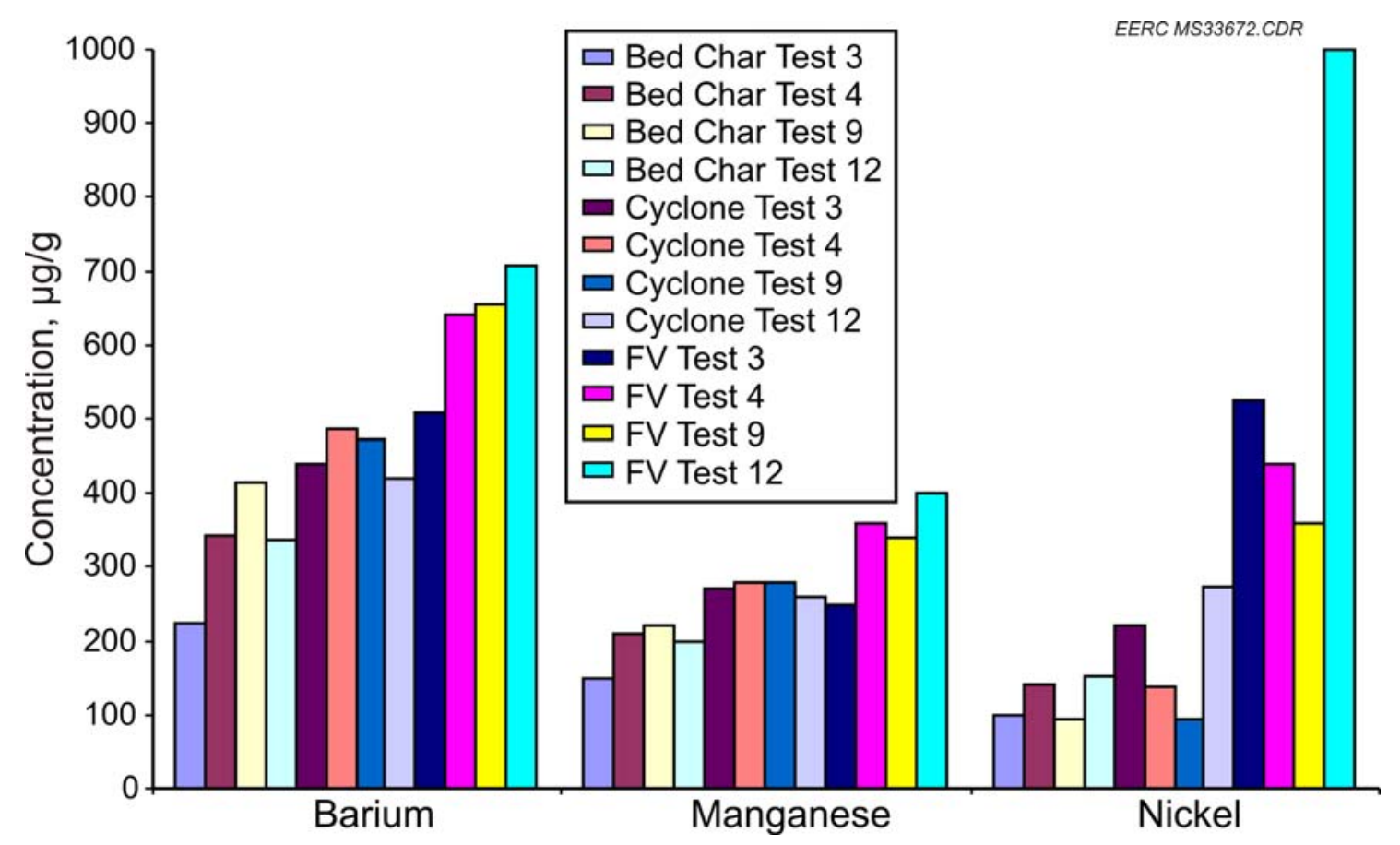

Figure 24. Barium, manganese, and nickel concentrations in solid samples. 


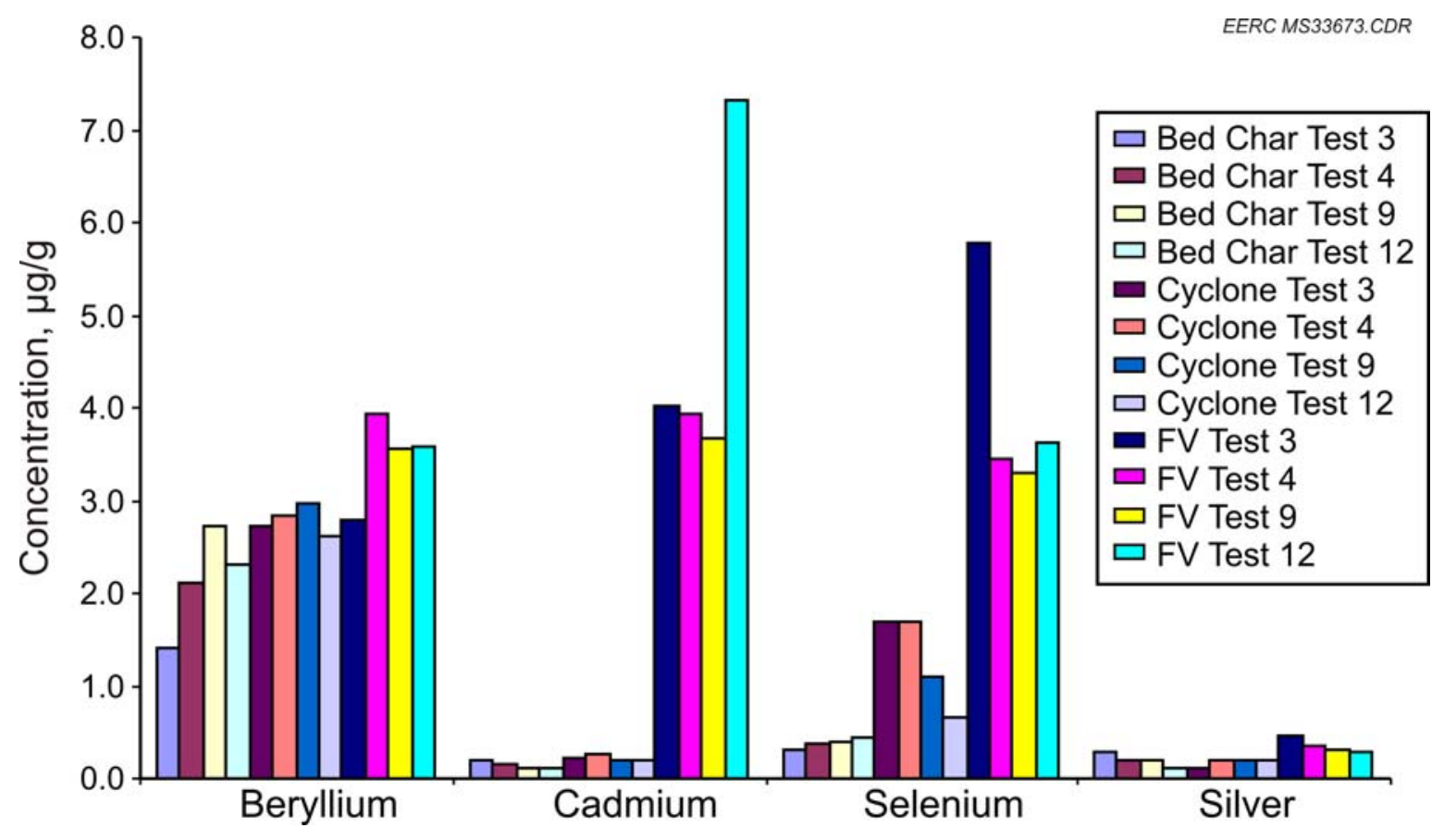

Figure 25. Beryllium, cadmium, selenium, and silver concentrations in solid samples.

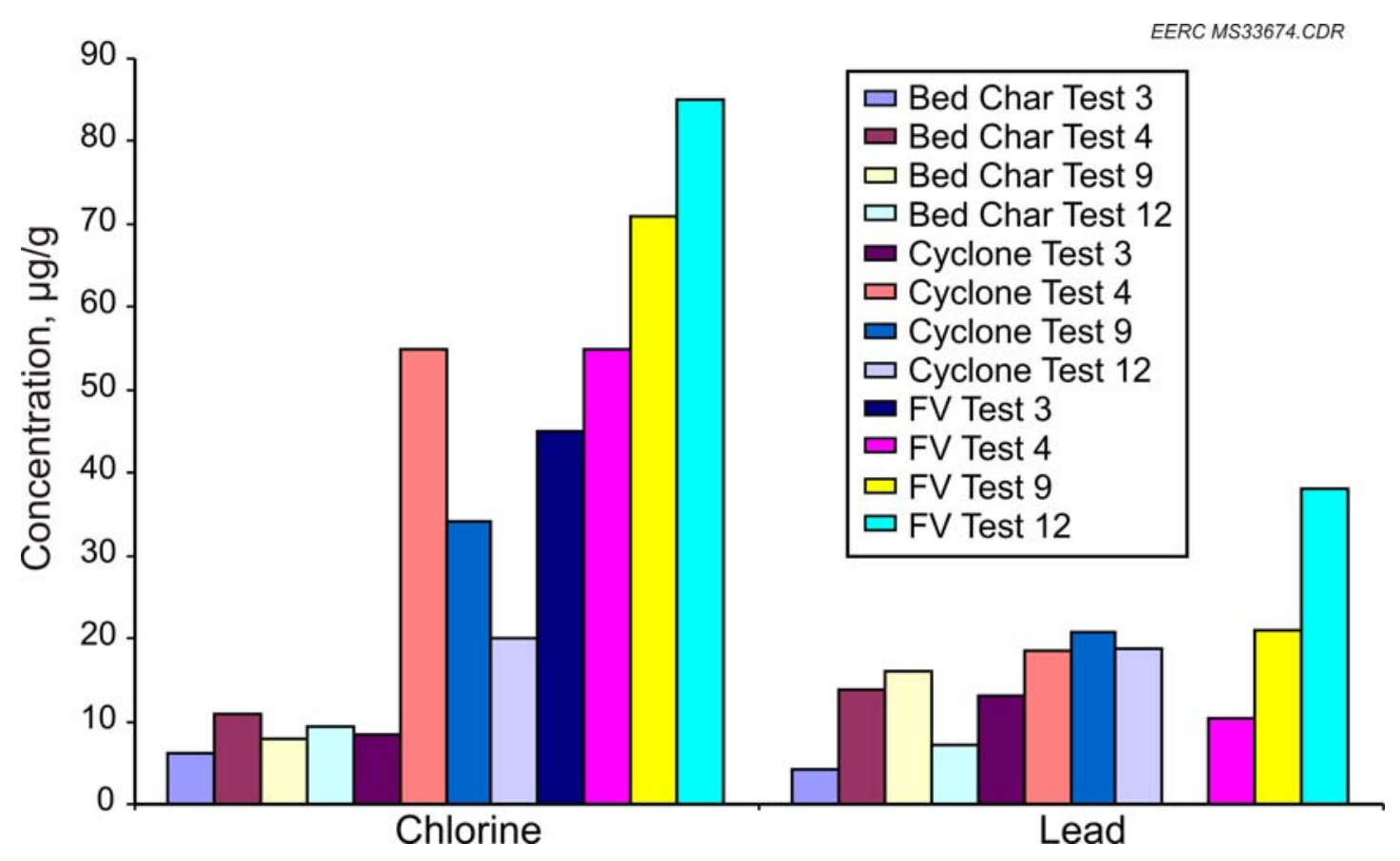

Figure 26. Chlorine and lead concentrations in solid samples. 


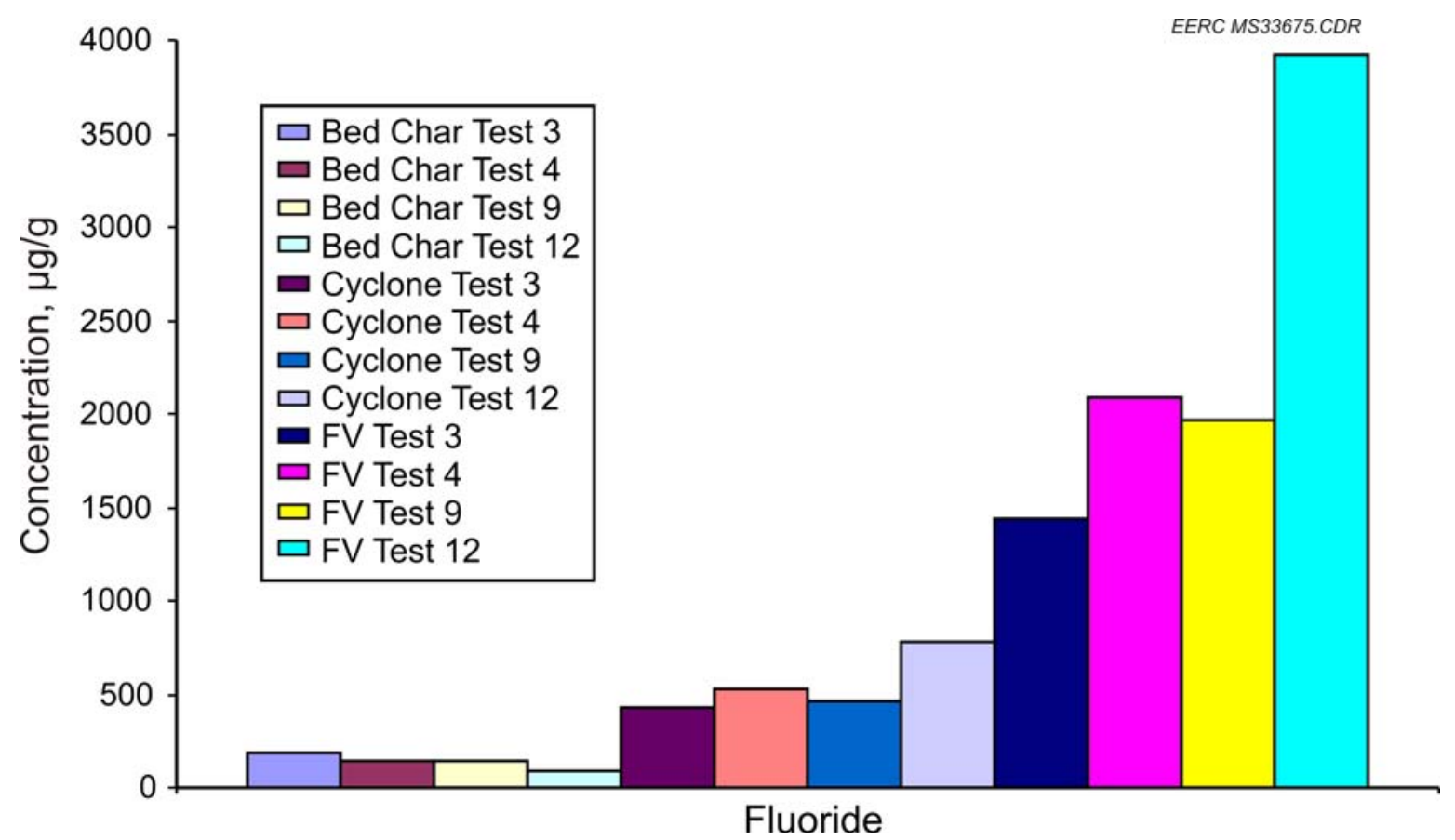

Figure 27. Fluoride concentration in solid samples.

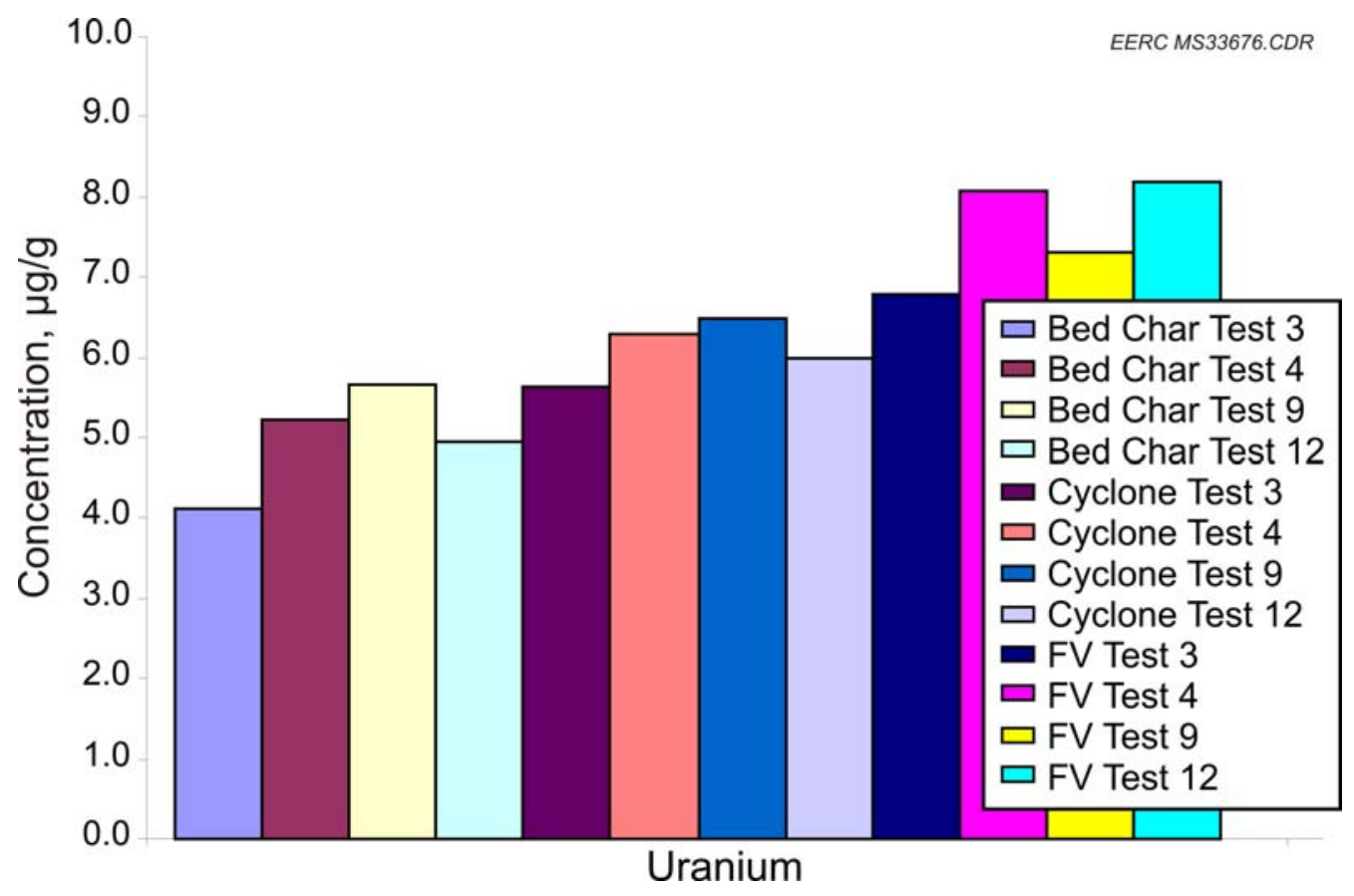

Figure 28. Uranium concentration in solid samples. 


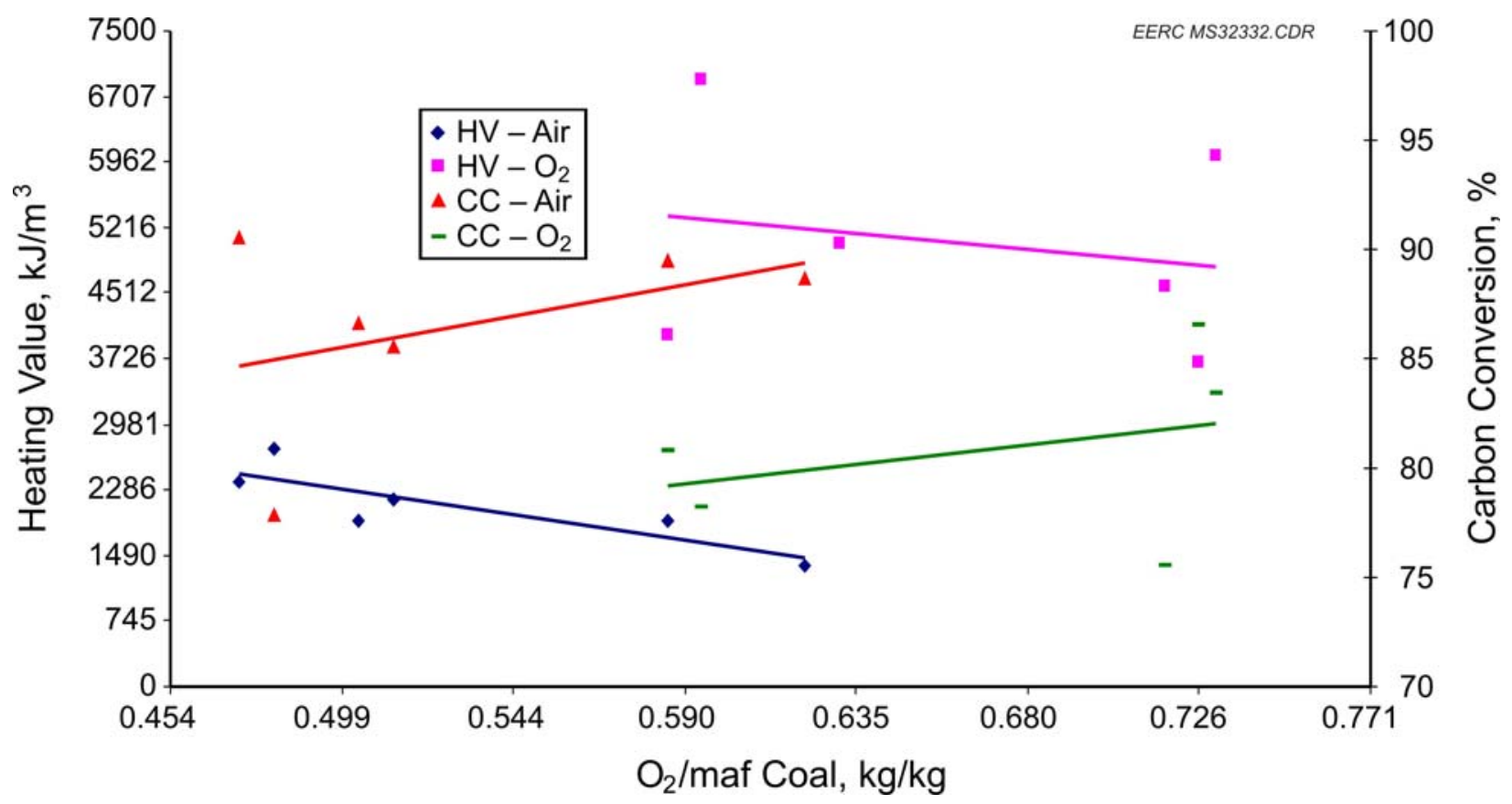

Figure 29. Product gas heating value and carbon conversion as a function of $\mathrm{O}_{2} / \mathrm{maf}$ coal.

Table 22. Material Balance

\begin{tabular}{|c|c|c|c|c|c|c|c|c|c|}
\hline & \multirow[b]{2}{*}{$\begin{array}{c}\text { Coal } \\
\text { Feed, } \\
\mathrm{g} / \mathrm{hr}\end{array}$} & \multirow[b]{2}{*}{$\begin{array}{c}\text { Steam, } \\
\mathrm{g} / \mathrm{hr}\end{array}$} & \multirow[b]{2}{*}{$\begin{array}{c}\text { Cyclone, } \\
\mathrm{g} / \mathrm{hr}\end{array}$} & \multirow[b]{2}{*}{$\begin{array}{c}\text { Cyclone } \\
\text { LOI }\end{array}$} & \multirow[b]{2}{*}{$\begin{array}{l}\mathrm{FV}, \\
\mathrm{g} / \mathrm{hr}\end{array}$} & \multirow[b]{2}{*}{$\begin{array}{l}\text { FV } \\
\text { LOI }\end{array}$} & \multicolumn{2}{|r|}{ Solid and } & \multirow[b]{2}{*}{$\begin{array}{c}\text { Solid Carbon } \\
\text { Conversion, } \\
\%\end{array}$} \\
\hline & & & & & & & $\begin{array}{l}\text { Quench } \\
\text { Water, } \\
\text { g/hr }\end{array}$ & $\begin{array}{c}\text { Liquid } \\
\text { Closure, } \\
\%\end{array}$ & \\
\hline 1 & 2306 & 475 & 552 & 10.3 & 34.5 & 18.1 & 1072 & 67.6 & 77.9 \\
\hline 2 & 2683 & 914 & 572 & 16.9 & 33.1 & 8.0 & 1681 & 71.0 & 85.5 \\
\hline 3 & 2038 & 469 & 580 & 10.3 & 32.2 & 7.4 & 1108 & 77.5 & 86.6 \\
\hline 4 & 2384 & 907 & 711 & 8.6 & 23.9 & 5.5 & 1770 & 84.8 & 88.7 \\
\hline 5 & 2433 & 911 & 610 & 7.4 & 19.8 & 4.9 & 1607 & 74.5 & 89.5 \\
\hline 6 & 2161 & 488 & 522 & 8.5 & 22.4 & 8.8 & 1129 & 71.4 & 90.5 \\
\hline 7 & 2470 & 1468 & 996 & 10.6 & 28.4 & 10.4 & 2255 & 91.4 & 80.8 \\
\hline 8 & 2520 & 1833 & 1060 & 16.2 & 31.3 & 12.7 & 2555 & 91.2 & 86.5 \\
\hline 9 & 2551 & 1826 & 1049 & 14.6 & 28.0 & 8.6 & 2715 & 94.4 & 75.5 \\
\hline 10 & 2284 & 1483 & $\mathrm{NA}^{1}$ & NA & NA & NA & 2492 & NA & NA \\
\hline 11 & 2497 & 1838 & 1123 & 8.3 & 86.4 & 9.4 & 2607 & 95.8 & 83.4 \\
\hline 12 & 2429 & 1551 & 1123 & 11.1 & 36.5 & 13.3 & 2429 & 98.7 & 78.2 \\
\hline
\end{tabular}

${ }^{1}$ Not available. 


\section{Summary and Conclusions for Task 3}

Preliminary results from the bench-scale gasification tests suggest that air-blown gasification is not likely to provide a syngas with a sufficient heating value for operating an IGCC system. However, enriched-air or oxygen-blown operation should provide the minimum heating value required to operate the gas turbine combined cycle.

Bed agglomeration that was observed is thought to be because of the accumulation of large clay particles that would eventually lead to portions of the bed defluidizing and to the development of localized hot spots in the bed. This will not be an issue for the high velocity transport reactor system.

The lower carbon conversions obtained with the CFBR system should be higher since the cyclones on the transport reactor system recycle its char back to the gasifier until the carbon is either consumed by the partial oxidation reactions or is fine enough to pass through the cyclones. If the cyclone ash in the CFBR tests were recycled to extinction and the filter ash carbon were the only carbon loss, the carbon conversions would be above $98 \%$ for all of the tests.

\section{Task 5 - Pilot-Scale Gasification Testing in the TRDU}

\section{Introduction}

One of the technologies being developed for advanced electric power-generating systems is an IGCC that converts coal to a combustible gas, cleans the gas of pollutants, and combusts the gas in a gas turbine to generate electricity. The hot exhaust from the gas turbine is used to generate steam to produce more electricity from a steam turbine cycle. The utilization of advanced hot-gas particulate and sulfur control technologies together with the combined power generation cycles makes IGCC one of the cleanest and most efficient ways available to generate electric power from coal. One of the strategic objectives of the DOE IGCC research and development program is to develop and demonstrate advanced gasifiers and second-generation IGCC systems. Another objective is to develop advanced hot-gas cleanup and trace contaminant control technologies that will enable high cycle efficiencies to be achieved, especially with higher-moisture feedstocks.

Specific DOE program goals for baseload IGCC systems include achieving net electric system efficiency of greater than $52 \%$, particulate matter and $\mathrm{NO}_{\mathrm{x}}$ emissions at one-tenth of New Source Performance Standards (NSPS), 5\% of NSPS for $\mathrm{SO}_{2}$, exceeding 1990 Clean Air Act Amendment levels for air toxic emissions, and achieving a capital cost of less than US $\$ 1500 / \mathrm{kW}$. One of the more recent gasification concepts to be investigated is that of the transport reactor gasifier, which functions as a CFB gasifier while operating in the pneumatic transport regime of solid particle flow. This gasifier concept provides excellent solid-gas contacting of relatively small particles to promote high gasification rates and the highest coal throughput per unit cross-sectional area of any other gasifier, thereby reducing the capital cost of the gasification island. 
A total of 25 test campaigns have been completed to date at the EERC on the TRDU, with over 2500 hours of operation on coal with several different fuels. These fuels have ranged from a less reactive petroleum coke and bituminous coals to the more reactive subbituminous and lignite coals. Operating temperatures varied from $815^{\circ}$ to $1093^{\circ} \mathrm{C}\left(1500^{\circ}\right.$ to $\left.2000^{\circ} \mathrm{F}\right)$, depending on the fuel reactivity and the fuel ash's propensity to agglomerate. The TRDU has been operated in both air- and oxygen-blown mode on most of these fuels. Operation on the more reactive western coals has displayed higher carbon conversions and product gas heating values, even when operating at lower reactor temperatures than comparable bituminous coal tests. The more reactive lower-rank fuels had higher carbon conversions and corrected dry product gas heating values than the higher-rank bituminous coals. The bituminous coals were operated at higher oxygen/coal ratios than the lower-rank coals since they tended to be operated at higher reactor temperatures in order to achieve the same level of steam gasification (bituminous fuels have a $\mathrm{HHV}$, so less fuel feed is required to achieve the same heat input to the TRDU). For all fuels, carbon conversion increased and corrected dry product gas heating value decreased with increasing oxygen/coal ratio.

Oxygen-blown operation requires the addition of considerable excess steam to maintain the reactor temperatures below the temperature where ash deposition and agglomeration of the circulating ash material become a problem. Test results indicate that oxygen-blown operation provides a slightly higher carbon conversion at comparable oxygen/coal ratios. The corrected dry product gas heating for the oxygen-blown test has a significantly HHV than air-blown operation ( 7080 to $8570 \mathrm{~kJ} / \mathrm{m}^{3}$ as compared to 3350 to $4840 \mathrm{~kJ} / \mathrm{m}^{3}$ ). An evaluation of the wet fuel gas heating values shows that oxygen-blown gasifiers have marginally increased HHVs entering the gas turbine combustor compared to the air-blown case. This small difference is due to the high volume of steam addition needed in the oxygen-blown system to prevent circulating bed material from agglomerating and forming deposits in the reactor wall.

\section{Task Objectives}

The objective of the Bulgarian lignite test in the advanced high-temperature, high-pressure transport gasification program at the EERC is to demonstrate acceptable hydrodynamic and gasification performance under a variety of operating conditions. This 200 -hour gasification test would allow steady-state heat and material balance information to be obtained, which will enable the syngas composition (heating value and carbon conversion) to be determined as a function of oxygen-to-coal and steam-to-coal ratios. Testing under both air-blown and oxygen-blown operating conditions would be conducted. A secondary objective of the program is to demonstrate acceptable performance of hot-gas filter elements on the hot dust-laden fuel gas stream coming from the pilot-scale TRDU system prior to long-term demonstration tests. The goal of hot-gas particulate control is not simply to meet current NSPS with respect to particulate emissions, but also to protect high-efficiency gas turbines adequately and control particulate emissions to sufficiently low levels to meet more stringent regulatory requirements anticipated in the future. 


\section{Scope of Work}

\section{0-hour Coal Gasification Test}

The EERC is proposing to complete one 200-hour coal gasification test. The objectives of this test would be to test the Bulgarian lignite in a pilot-scale transport reactor gasification system similar to the commercial gasification system being designed for Mississippi lignite. The BLPP participants will provide 50 tonnes of the Bulgarian lignite which would need approximately 4.75 tonnes of locally available calcium-based sorbent or the EERC could provide a limestone for use as a sulfur control additive. Prior to the performance of the 200-hr test, EERC personnel will prepare, in consultation with the BLPP sponsors and the DOE National Energy Technology Laboratory Performance Monitor, a detailed test plan. The test plan will include a discussion of the test purpose/goals; a description of the gasification parameters to be tested, with a description of the TRDU and FV operating conditions; and a list of specific data to be collected, success criteria established, and sampling and analytical support required for this test. The primary test variables are expected to be oxygen/carbon ratio, gasification temperature, steam/carbon ratio, and fuel properties such as moisture and PSD. Several activities will occur in support of the gasification test. The nature of the ash, including deposits and agglomerates (if any), from each test will be investigated using advanced analytical techniques. Solid wastes will also be evaluated to determine if any combination of fuel and operating condition results in hazardous wastes.

\section{Description of Equipment}

\section{Advanced Transport Reactor}

The TRDU has an operating gas temperature of up to $980^{\circ} \mathrm{C}\left(1800^{\circ} \mathrm{F}\right)$, a nominal gas flow rate of $9.9 \mathrm{Nm}^{3} / \mathrm{min}$. (350 scfm), and an operating pressure of approximately $9.3 \mathrm{bar}(120 \mathrm{psig})$. The TRDU system can be divided into three sections: the coal feed section, the TRDU, and the product recovery section. The TRDU proper, as shown in Figure 30, consists of a riser reactor with an expanded mixing zone at the bottom, a disengager, primary cyclone, standpipe, and dipleg. The standpipe collects solids from the disengager and is connected to the mixing section of the riser by an L-valve transfer line which utilizes steam to move the solids back to the mixing zone. Additional solids are collected by the primary cyclone into the dipleg that returns these solids into the standpipe through a seal pot. All of the components in the system are refractorylined and designed mechanically for 11.3 bar (150 psig) and an internal temperature of $1090^{\circ} \mathrm{C}$ $\left(2000^{\circ} \mathrm{F}\right)$.

For oxygen-blown operation, the TRDU loop seal was modified to allow more solids circulation through the mixing zone. Higher solids circulation rates will dissipate more of the heat release in the mixing zone. The loop seal was changed from a J-leg to an L-valve configuration which allowed the length of the mixing zone to be increased substantially for increased solids residence time. In addition, the diameters of the standpipe, dipleg, and L-valve return legs were increased to reduce the amount of wall friction and gas bubble holdup caused by the small inside diameters of these sections. Another modification was to install a seal pot on the 


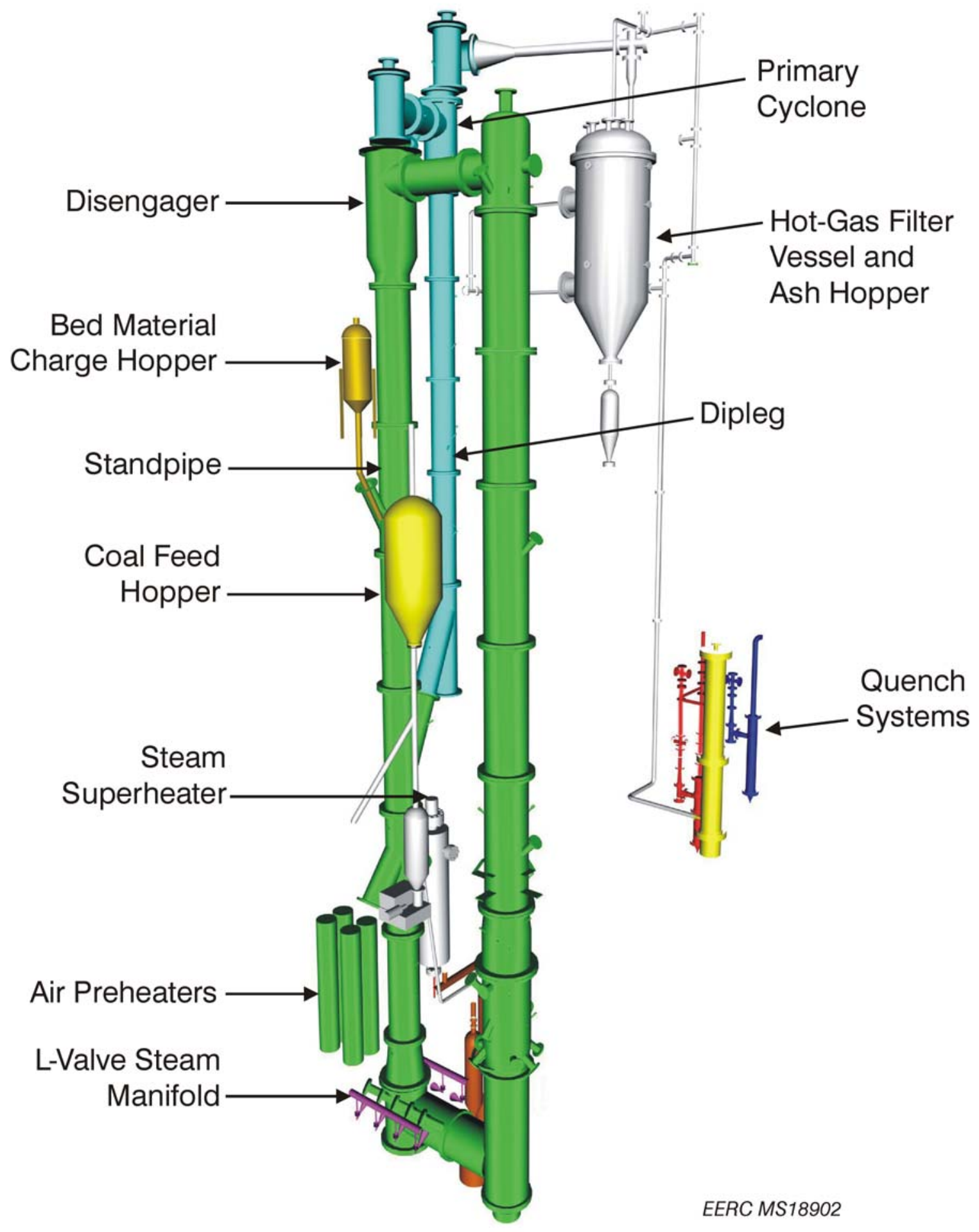

Figure 30. TRDU and HGFV in the EERC gasification tower. 
bottom of the dipleg to allow the bed material height in the standpipe to be operated independently of the level in the dipleg without having the primary cyclone performance spoiled by gas bypassing up the dipleg when the solids level dropped below the dipleg solids return point.

The premixed coal and limestone feed can be admitted to the transport reactor through three separate nozzles, which are at varying elevations. Two of these nozzles are located near the top of the mixing zone (gasification), and the remaining one is near the bottom of the mixing zone (combustion). During operation of the TRDU, feed is admitted through one predetermined nozzle at a time. The coal feed is measured by an rpm-controlled metering auger. Oxidant is fed to the reactor through two pairs of nozzles at varying elevations within the mixing zone. For the combustion mode of operation, additional nozzles are provided in the riser for feeding secondary air. Hot solids from the standpipe are circulated into the mixing zone where they come into contact with the nitrogen and the steam being injected into the J-leg. This feature enables spent char to contact steam prior to the fresh coal feed. This staged gasification process is expected to enhance the process efficiency. Gasification or combustion and desulfurization reactions arecarried out in the riser as coal, sorbent, and oxidant (with steam for gasification) flow up the reactor. The solids circulation into the mixing zone is controlled by the solids level in the standpipe.

The riser, disengager, standpipe, and cyclones are equipped with several internal and skin thermocouples. Nitrogen-purged pressure taps are also provided to record differential pressure across the riser, disengager, dipleg, and cyclones. The data acquisition and control system scans the data points every one-half second and saves the process data every 30 seconds. The bulk of entrained solids leaving the riser is separated from the gas stream in the disengager and circulated back to the riser via the standpipe. A solids stream is withdrawn from the standpipe via an auger to maintain the system's solids inventory. Gas exiting the disengager enters a primary cyclone. Gas exiting this cyclone enters a jacketed-pipe heat exchanger before entering the HGFV. The cleaned gases leaving the HGFV can either be depressurized and the hot fuel gas directly combusted in a thermal oxidizer or the fuel gas can enter a quench system before being depressurized and vented to the thermal oxidizer or a flare.

The quench system uses a sieve tower and two direct-contact water scrubbers to act as heat sinks and remove impurities. The condensed liquid is separated from the gas stream in a cyclone that also serves as a reservoir. Liquid is pumped either to a shell-and-tube heat exchanger for reinjection into the scrubber or down to the product receiver barrels.

\section{Hot-Gas Filter Vessel HGFV}

A schematic of the HGFV design is given in Figure 31. This vessel is designed to handle all of the gas flow from the TRDU at its expected operating conditions. The vessel is approximately $4.7 \mathrm{~m}$ (15.4 ft.) long with a $1.21-\mathrm{m}$ (4-ft.) inner diameter (i.d.) and is designed to handle gas flows of approximately $9.9 \mathrm{Nm} / \mathrm{min}(350 \mathrm{scfm})$ at up to $815^{\circ} \mathrm{C}\left(1500^{\circ} \mathrm{F}\right)$ and 150 psig. The refractory has a $0.71-\mathrm{m}(2.33-\mathrm{ft}$.) i.d. with a shroud diameter of approximately $0.559 \mathrm{~m}(1.83 \mathrm{ft}$.). The vessel is sized such that it could handle candle filters up to $1.5 \mathrm{~m}$ long 


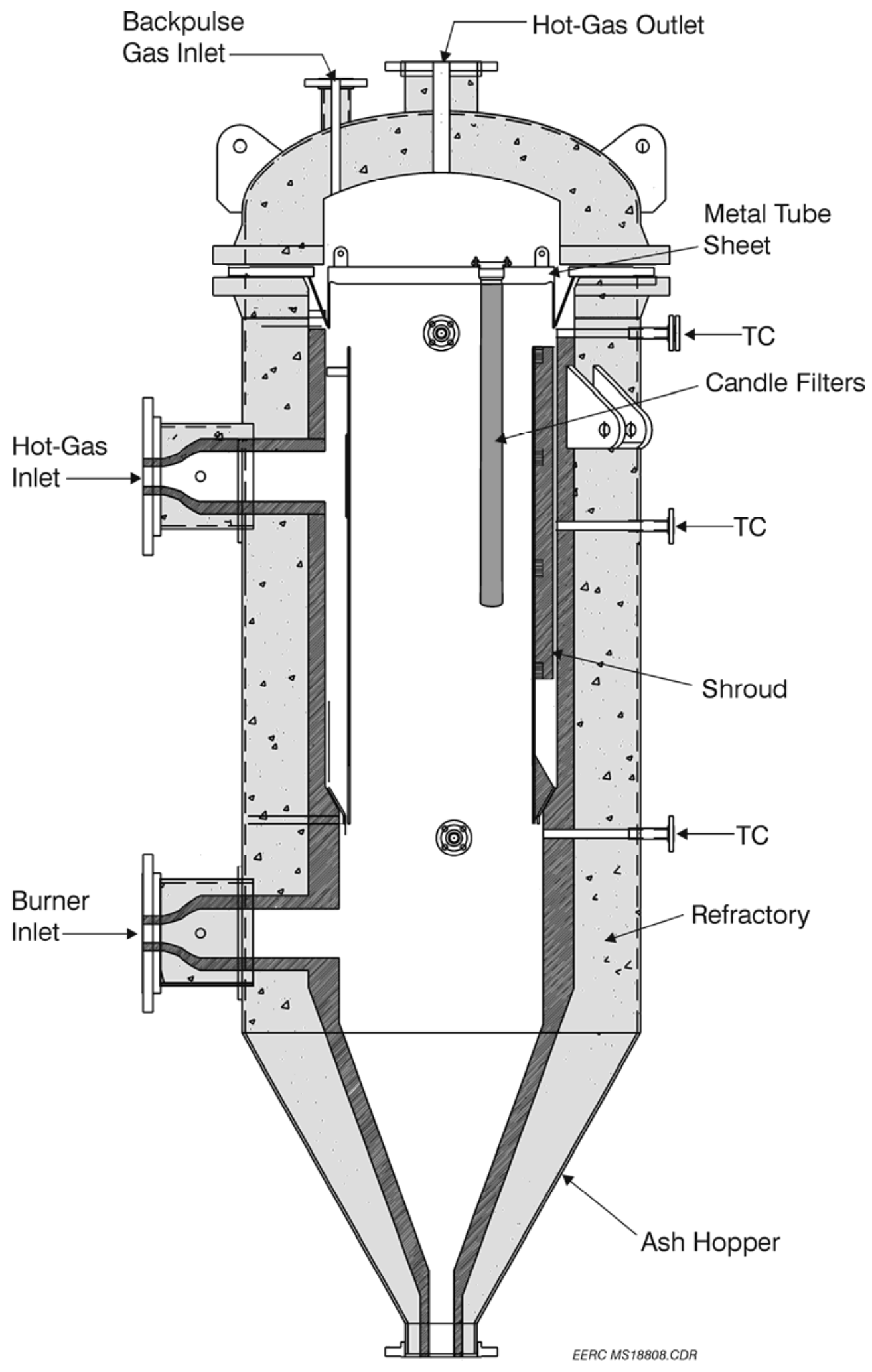

Figure 31. Schematic of the FV design with internal refractory, tube sheet, and shroud (TC is thermocouple). 
and candle filters having a 6.03-cm (2.375-in.) outer diameter (o.d.) with 10.16-cm (4-in.) centerline-to-centerline spacing. Current testing is focused on operation at lower temperatures, $260^{\circ}$ to $316^{\circ} \mathrm{C}\left(500^{\circ}-600^{\circ} \mathrm{F}\right)$, to also help facilitate warm-gas mercury control.

The total number of candles that can be mounted in the current geometry of the HGFV tube sheet is 19 . This enables filter face velocities as low as $1.27 \mathrm{~cm} / \mathrm{sec}(2.5 \mathrm{ft} / \mathrm{min})$ to be tested using 1-m candles, although most tests have been conducted using 12 or 13 candles providing a face velocity between 2.03 and $2.29 \mathrm{~cm} / \mathrm{sec}$ ( 4 and $4.5 \mathrm{ft} / \mathrm{min}$ ). The openings for the removed candles have been closed off. This program has mostly tested sintered metal (iron aluminide) and Vitropore silicon carbide ceramic candles from Pall Advanced Separation Systems Corporation. Current testing is focused on Pall iron aluminide filters with integrated fail-safe devices.

The ash letdown system consists of two sets of alternating high-temperature valves with a conical pressure vessel to act as a lock hopper. Additionally, a preheat natural gas burner attached to a lower inlet nozzle on the FV can be used to preheat the FV separately from the TRDU. The hot gas from the burner enters the vessel via a nozzle inlet separate from the dirty gas.

The high-pressure nitrogen backpulse system is capable of backpulsing up to four sets of four or five candle filters with ambient-temperature nitrogen in a time-controlled sequence. The pulse length and volume of nitrogen displaced into the FV is controlled by regulating the pressure (up to 56.2 bar) of the nitrogen reservoir and the solenoid valves used to control the timing of the gas pulse. Figure 30 also shows the FV location and process piping in the EERC gasifier tower. High-temperature valves allow the HGFV to be bypassed if desired; however, this feature is rarely utilized since bypassing of commercial filter systems will not be possible. Since all the filter tests are to be completed in the $425^{\circ}-650^{\circ} \mathrm{C}\left(800^{\circ}-1200^{\circ} \mathrm{F}\right)$ range, a length of heat exchanger was used to drop the gas temperature to the desired range. In addition, sample ports both up- and downstream of the FV have been utilized for obtaining particulate and hazardous air pollutant samples.

\section{Results}

The pilot-scale TRDU test started on September 22 with a program discussed and agreed upon by representatives of "Enemona" AS and the EERC. This program was based on the results from Tasks 1-3, and its objectives were to demonstrate acceptable hydrodynamic and gasification performance in the advanced high-temperature, high-pressure transport gasification unit under a variety of operating conditions.

The purpose of this 200-hour gasification test would allow steady-state heat and material balance information to be obtained, which would enable the syngas composition (heating value and carbon conversion) to be determined as a function of air-to-coal (oxygen-to-coal) and steamto-coal ratios.

Task 3 results with Blend " $\mathrm{C}$ " had moisture contents around 20 to $25 \mathrm{wt} \%$ with 35 to $40 \mathrm{wt} \%$ ash. The syngas from the adiabatic bench-scale gasification testing showed that the LHV of the syngas in oxygen-blown mode was sufficient to operate a gas turbine. The original test 
plan for the TRDU testing is shown in Table 23, and it was agreed that $2 / 3$ of the 50 tons of coal would be predried to match the 20 to $25 \mathrm{wt} \%$ moisture recommended by KBR, and that one-third would be kept around $35 \mathrm{wt} \%$ moisture for the remaining coal so as to avoid excessive coaldrying requirements.

The Task 5 test matrix was to start in combustion mode to get the transport reactor hot and then to start gasification testing on the dried feedstock before switching to the higher-moisture feedstock. This would allow the testing to verify if successful operation is even possible with the dried feedstock. If successful operation on the dried feedstock was not possible then it would not make sense to even try the higher-moisture feedstock because of the even higher heat load it would place on the gasifier. Initial operating data suggested that air-blown operation was not providing a syngas with much heating value, which was not entirely unexpected. The testing was then transitioned to oxygen-enriched gasification testing with the intent of finding the level of oxygen-enrichment necessary to achieve the minimum $4099 \mathrm{~kJ} / \mathrm{m}^{3}$ (110 Btu/scf) specified by GE. This resulted in the testing fairly quickly proceeding to full oxygen-blown operation on the air-dried fuel by the morning of September 24. Tables 24 and 25 show the fuel and the limestone analyses. These tables show that the fuel had approximately $50 \mathrm{wt} \%$ ash at the as-fed moisture of nominally $25 \mathrm{wt} \%$. This is considerably higher than the previously analyzed core sample which had approximately $37 \mathrm{wt} \%$ ash at a similar moisture content. The significantly higher than expected ash content would have a detrimental effect on the gasifier performance because of the even LHV in the fuel plus the extra heat load the higher ash concentrations would have when heating all of the bed material to the desired temperature. Tables 26 and 27 show the operating data obtained for the best-case air- and oxygen-blown tests on the TRDU. The oxygen-to-maf coal weight ratio was considerably higher (1.41 to 1.70$)$ than has typically been utilized for other low-rank coals ( 0.7 to 1.1 ), and in spite of the significantly high $\mathrm{O}_{2}$-to-maf coal ratio, the gasifier did not even get close to the desired gasifier operating temperature. Past testing has shown that increasing the coal feed rate generally increases the fuel gas heating but also generally results in somewhat lower carbon conversion for the fuel. The oxygen-blown test was conducted so as to present the absolute best conditions for maximizing syngas heating value by maximizing the TRDU coal feed rate and switching to full oxygen-blown operation (except for the air utilized to transport the coal into the gasifier) with minimal steam injection to maximize gasifier temperature. After 5 hours of near steady-state operation at full oxygen-blown conditions, it was apparent that even under the best possible operating conditions, the syngas heating value would not be sufficient to operate a gas turbine directly. During this testing, the bed material levels were increasing even while removing ash from the system as quickly as the ash removal hardware would allow. Table 26 also indicates that a very low cold gas efficiency was achieved with this feedstock partially because of the heat losses associated with near continuous removal of large amounts of hot ash from circulating bed material, primary cyclone dipleg, and FV and the lack of any heat recovery on the TRDU pilot-scale ash removal systems.

Table 28 shows the ash chemistry of various samples taken from the various streams in the transport reactor. These analyses show that the ash chemistry is very high in silica and alumina, consistent with the high levels of clay seen in the starting coal. In addition, the ash chemistry in each stream is very similar to the starting coal and limestone feed mixture being fed to the system. Figure 32, which is a plot of the PSD, shows that the dipleg PSD was slightly smaller 
Table 23. P83 Test Plan for Enomona Transport Reactor Integrated Gasification Test of Bulgarian Lignite

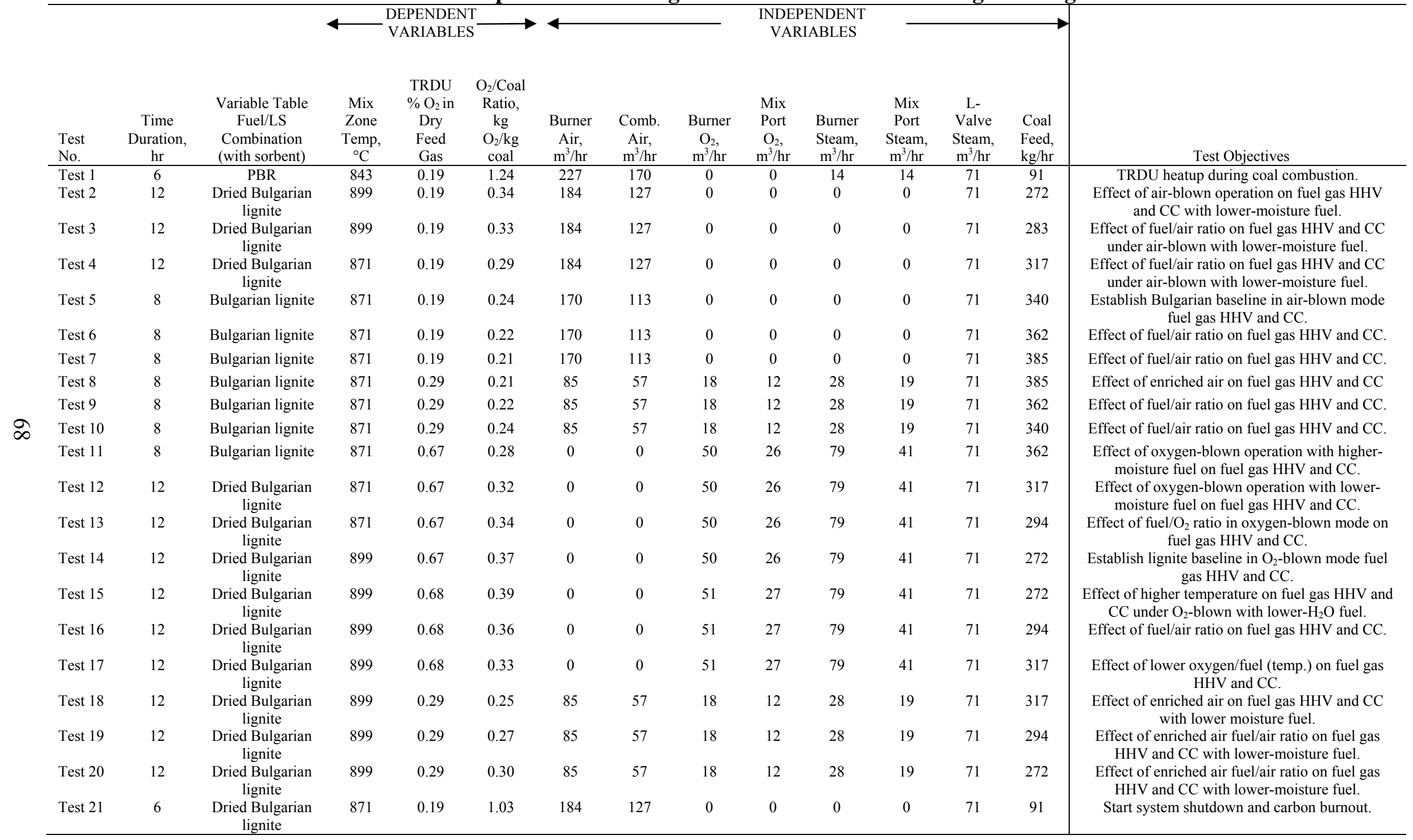


Table 24. Proximate, Ultimate, HHV, and XRF Analysis Results for LOM Lignite

\begin{tabular}{|c|c|c|}
\hline & $\begin{array}{c}-3.36 \mathrm{~mm}(-6 \mathrm{mesh}) \\
\text { Partially Dried } \\
\text { LOM Lignite }\end{array}$ & $\begin{array}{c}-3.36 \mathrm{~mm}(-6 \mathrm{mesh}) \\
\text { Moisture-Free } \\
\text { LOM Lignite }\end{array}$ \\
\hline \multicolumn{3}{|c|}{ Proximate Analysis, as run, wt\% } \\
\hline Moisture & 26.7 & NA \\
\hline Volatile Matter & 16.4 & 22.4 \\
\hline Fixed Carbon & 6.9 & 9.4 \\
\hline Ash & 50.0 & 68.2 \\
\hline \multicolumn{3}{|c|}{ Ultimate Analysis, MF, wt\% } \\
\hline Carbon & 19.58 & 26.73 \\
\hline Hydrogen & 4.43 & 1.99 \\
\hline Nitrogen & 0.39 & 0.53 \\
\hline Sulfur & 0.43 & 0.59 \\
\hline Oxygen & 25.18 & 1.94 \\
\hline Ash & 49.98 & 68.22 \\
\hline \multicolumn{3}{|c|}{ Ash Composition, $\%$ as oxides } \\
\hline Calcium, $\mathrm{CaO}$ & 2.7 & 2.7 \\
\hline Magnesium, $\mathrm{MgO}$ & 1.7 & 1.7 \\
\hline Sodium, $\mathrm{Na}_{2} \mathrm{O}$ & 0.4 & 0.4 \\
\hline Silica, $\mathrm{SiO}_{2}$ & 57.7 & 57.7 \\
\hline Aluminum, $\mathrm{Al}_{2} \mathrm{O}_{3}$ & 27.4 & 27.4 \\
\hline Ferric, $\mathrm{Fe}_{2} \mathrm{O}_{3}$ & 5.5 & 5.5 \\
\hline Titanium, $\mathrm{TiO}_{2}$ & 0.7 & 0.7 \\
\hline Phosphorus, $\mathrm{P}_{2} \mathrm{O}_{5}$ & 0.2 & 0.2 \\
\hline Potassium, $\mathrm{K}_{2} \mathrm{O}$ & 1.8 & 1.8 \\
\hline Sulfur, $\mathrm{SO}_{3}$ & 2.0 & 2.0 \\
\hline \multicolumn{3}{|l|}{ Higher Heating Value } \\
\hline $\mathrm{MF}, \mathrm{kJ} / \mathrm{kg}$ & & 6885 \\
\hline As Run, $\mathrm{kJ} / \mathrm{kg}$ & 5043 & \\
\hline
\end{tabular}

Table 25. XRF Analyses of Bulgarian Limestones

\begin{tabular}{lc}
\hline & $\begin{array}{c}-0.50 \mathrm{~mm}(-35 \text { mesh }) \\
\text { Bulgarian Limestone }\end{array}$ \\
\hline Sorbent Composition, \% as oxides & \\
Calcium, $\mathrm{CaO}$ & 76.3 \\
Magnesium, $\mathrm{MgO}$ & 1.8 \\
Sodium, $\mathrm{Na}_{2} \mathrm{O}$ & 0.0 \\
Silicon, $\mathrm{SiO}_{2}$ & 18.3 \\
Aluminum, $\mathrm{Al}_{2} \mathrm{O}_{3}$ & 2.6 \\
Ferric, $\mathrm{Fe}_{2} \mathrm{O}_{3}$ & 0.3 \\
Titanium, $\mathrm{TiO}_{2}$ & 0.2 \\
Phosphorus, $\mathrm{P}_{2} \mathrm{O}_{5}$ & 0.2 \\
Potassium, $\mathrm{K}_{2} \mathrm{O}$ & 0.3 \\
Sulfur, $\mathrm{SO}_{3}$ & 0.1 \\
LOI, as run & NA \\
\hline
\end{tabular}


Table 26. TRDU Operating Conditions for Oxygen-Blown Gasification Performance

\begin{tabular}{lcc}
\hline Test & Air-Dried LOM Lignite & Air-Dried LOM Lignite \\
\hline Oxidant & Air & $\mathrm{O}_{2}$ \\
\hline Gasifier Temp, ${ }^{\circ} \mathrm{C}$ & 736 & 778 \\
Coal/Sorbent Feed Rate, $\mathrm{kg} / \mathrm{hr}$ & 314.3 & 412.8 \\
Air Flow, $\mathrm{kg} / \mathrm{hr}$ & 506.2 & 76.3 \\
$\mathrm{O}_{2}$ Flow, $\mathrm{kg} / \mathrm{hr}$ & 0 & 104.1 \\
Steam Flow, $\mathrm{kg} / \mathrm{hr}$ & 82.1 & 112.0 \\
Steam: Coal Ratio, $\mathrm{kg} / \mathrm{kg}$ & 0.278 & 0.289 \\
$\mathrm{O}_{2} / \mathrm{maf}$ Coal Ratio, $\mathrm{kg} / \mathrm{kg}$ & 1.70 & 1.41 \\
Recirculation Rate, $\mathrm{kg} / \mathrm{hr}$ & 1780 & 3110 \\
TRDU Riser Velocity, m/s & 12.4 & 10.2 \\
Carbon Conversion, $\%$ & 90.8 & 89.9 \\
Cold Gas Efficiency, $\%$ & 9.2 & 15.9 \\
\hline
\end{tabular}

Table 27. Actual and Corrected TRDU Product Gas Compositions for Air- and OxygenBlown Steady-State Tests

\begin{tabular}{|c|c|c|}
\hline Test & $\begin{array}{l}\text { Partially Dried LOM } \\
\text { Lignite }\end{array}$ & $\begin{array}{c}\text { Partially Dried LOM } \\
\text { Lignite }\end{array}$ \\
\hline Oxidant & Air & $\mathrm{O}_{2}$ \\
\hline \multicolumn{3}{|l|}{ Product Gas Composition, vol\% } \\
\hline $\mathrm{H}_{2}$ & 0.3 & 2.5 \\
\hline $\mathrm{CO}$ & 1.0 & 3.4 \\
\hline $\mathrm{CH}_{4}$ & 0.2 & 1.3 \\
\hline $\mathrm{CO}_{2}$ & 10.7 & 25.2 \\
\hline $\mathrm{N}_{2}$ & 86.1 & 66.0 \\
\hline Total & 98.3 & 98.4 \\
\hline Heating Value, $\mathrm{kJ} / \mathrm{m}^{3}$ & 224 & 1192 \\
\hline$\% \mathrm{~N}_{2}$ in Dry Feed & 30.1 & 56.0 \\
\hline $\mathrm{N}_{2}$-Free Heating Value, $\mathrm{kJ} / \mathrm{m}^{3}$ & 335 & 2496 \\
\hline \multicolumn{3}{|c|}{ Product Gas, vol\% (adjusted for $131 \mathrm{kw}$ heat loss and all nitrogen purges) } \\
\hline $\mathrm{H}_{2}$ & 0.7 & 6.9 \\
\hline $\mathrm{CO}$ & 2.3 & 9.4 \\
\hline $\mathrm{CH}_{4}$ & 0.5 & 3.6 \\
\hline $\mathrm{CO}_{2}$ & 13.2 & 44.0 \\
\hline $\mathrm{N}_{2}$ & 83.3 & 36.1 \\
\hline Total & 100 & 100 \\
\hline Heating Value, $\mathrm{kJ} / \mathrm{m}^{3}$ & 559 & 3316 \\
\hline
\end{tabular}


Table 28. Analyses of the Collected Samples from TRDU Testing on Bulgarian Lignite

\begin{tabular}{lccccccc}
\hline & & & & & Air-Blown & $\mathrm{O}_{2}$-Blown \\
\hline & Coal & $\begin{array}{c}\text { Air-Blown } \\
\text { Lash }\end{array}$ & $\begin{array}{c}\mathrm{O}_{2} \text {-Blown } \\
\text { Lash }\end{array}$ & $\begin{array}{c}\text { Air-Blown } \\
\text { Dipleg }\end{array}$ & $\begin{array}{c}\mathrm{O}_{2} \text {-Blown } \\
\text { Dipleg }\end{array}$ & $\begin{array}{c}\text { Filter } \\
\text { Vessel }\end{array}$ & $\begin{array}{c}\text { Filter } \\
\text { Vessel }\end{array}$ \\
\hline $\mathrm{CaO}$ & 2.7 & 14.1 & 6.5 & 15.9 & 15.9 & 7 & 13.9 \\
$\mathrm{MgO}$ & 1.7 & 1.61 & 1.56 & 1.57 & 1.58 & 1.88 & 1.64 \\
$\mathrm{Na}_{2} \mathrm{O}$ & 0.4 & 0.38 & 0.36 & 0.34 & 0.32 & 0.34 & 0.35 \\
$\mathrm{SiO}_{2}$ & 57.7 & 53.2 & 57.2 & 51.9 & 52 & 54.3 & 53 \\
$\mathrm{Al}_{2} \mathrm{O}_{3}$ & 27.4 & 22.8 & 26.7 & 22.2 & 22.6 & 26.5 & 23.1 \\
$\mathrm{Fe}_{2} \mathrm{O}_{3}$ & 5.5 & 4.78 & 5.08 & 4.72 & 4.8 & 5.56 & 4.9 \\
$\mathrm{TiO}_{2}$ & 0.7 & 0.66 & 0.71 & 0.66 & 0.65 & 0.65 & 0.66 \\
$\mathrm{P}_{2} \mathrm{O}_{5}$ & 0.2 & 0.16 & 0.15 & 0.16 & 0.16 & 0.17 & 0.16 \\
$\mathrm{~K}_{2} \mathrm{O}$ & 1.8 & 1.56 & 1.75 & 1.52 & 1.53 & 1.64 & 1.53 \\
$\mathrm{SO}_{3}$ & 2 & 0.75 & 0 & 0.95 & 0.51 & 1.9 & 0.73 \\
\hline
\end{tabular}

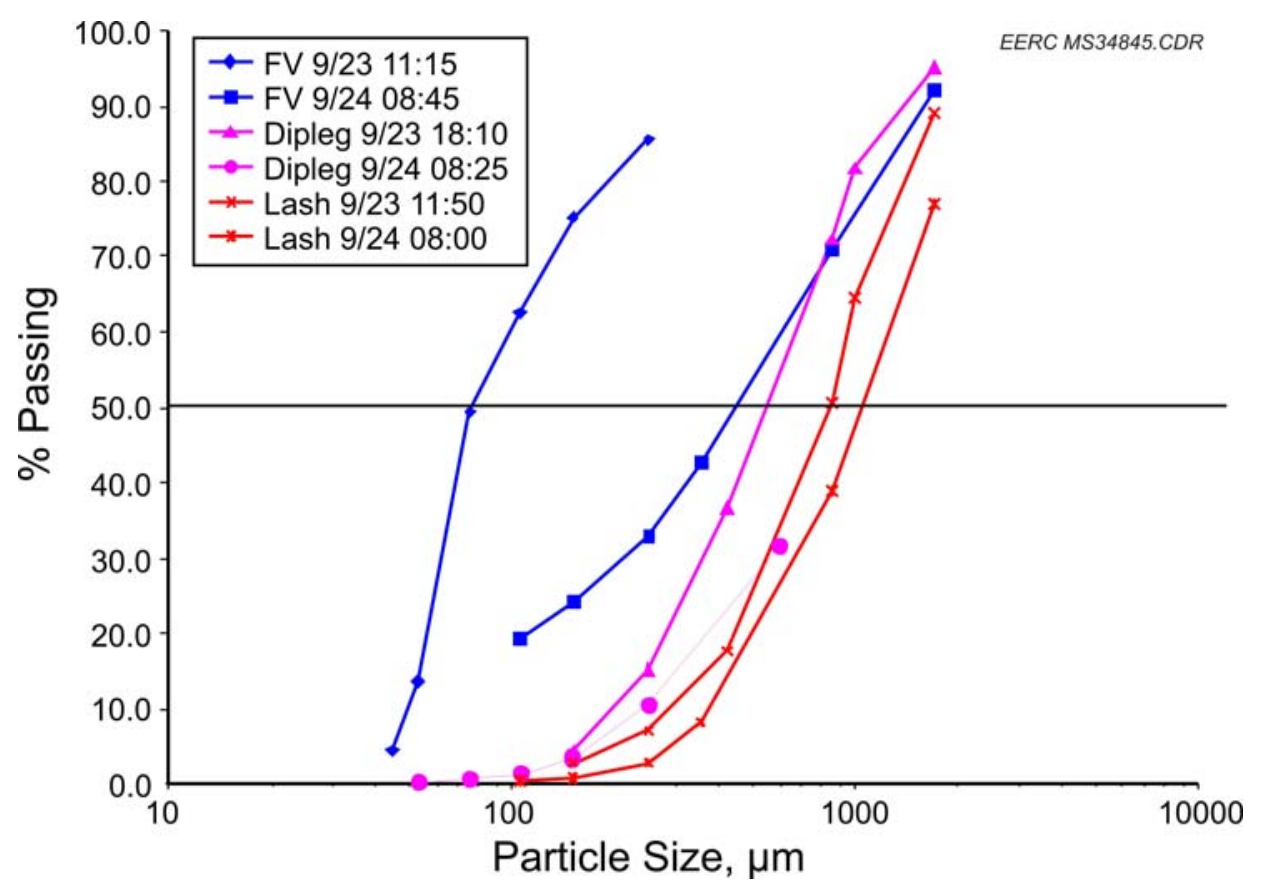

Figure 32. Plot of TRDU sample PSDs for selected Bulgarian lignite samples.

than the standpipe samples; however, the filter ash sample was considerably smaller under the air-blown lower coal feed rate testing. When the coal feed rate was maximized under the oxygenblown testing and the bed levels had increased to their maximum levels, the filter ash PSD had become much coarser as the recycle cyclones had become less efficient.

Since Bulgaria is joining the European Union and carbon dioxide capture and sequestration is likely to be required in future power plants, it was decided to examine whether precombustion 
removal of the carbon dioxide could increase syngas heating value to acceptable levels for combustion in a gas turbine. Posttest calculations indicate that air-blown operation cannot get to the necessary syngas heating value, even if all of the carbon dioxide were to be removed from the syngas before combustion in the turbine. However, calculations indicate that if approximately $50 \%$ of the carbon dioxide were removed from the oxygen-blown syngas prior to combustion in the gas turbine, a sufficient syngas heating value of $4583 \mathrm{~kJ} / \mathrm{m}^{3}(123 \mathrm{Btu} / \mathrm{scf})$ could be achieved. Removal of approximately $95 \%$ of the carbon dioxide would allow heating values as high as $7080 \mathrm{~kJ} / \mathrm{m}^{3}$ (190 Btu/scf) to be achieved. Additionally, if the proposed KBR commercial design were switched from air as the transport gas to pneumatically convey the coal into the gasifier to a recycled syngas stream, the total amount of nitrogen in the gasifier could be kept to less than $4 \%$ in oxygen-blown mode, and the syngas heating could approach the $4099 \mathrm{~kJ} / \mathrm{m}^{3}(110 \mathrm{Btu} / \mathrm{scf})$ minimum required by GE to run its $\mathrm{F}$ frame gas turbines. This modification would present some significant issues, such as possible venting of some syngas with each fill and vent cycle on the coal feed lock hoppers.

\section{Summary and Conclusions for Task 5}

The high moisture and ash content of this fuel resulted in the need to combust too much of the coal to leave enough of the coal heating value in the syngas heating value. The data presented above indicate that, given the low heating value of the fuel, too much of the fuel has to be partially oxidized to heat up the ash and vaporize the moisture to allow the generation of a syngas with sufficient heating value to operate a gas turbine. The heat balance with all of the ash could not reach the desired test temperature of $870^{\circ} \mathrm{C}$, only achieving a maximum temperature of $778^{\circ} \mathrm{C}$. The oxidation required to reach this temperature resulted in a product gas analysis with $\mathrm{CO}_{2}$ exceeding the sum of $\mathrm{H}_{2}$ and $\mathrm{CO}$ by a factor of 4 , whereas this factor would be expected to be on the order of one-forth based on the characteristic data for the KBR transport gasifier shown in Table 2. The product gas analysis would normally be expected to be close to that determined by equilibrium for the water-gas shift reaction, which was not observed under the high oxidation conditions involved in current tests. Also, operation at extremely high ash loadings interfered with the recycle and discharge of solids, resulting in buildup of ash and char in the reactor. If the resulting carbon buildup in the reactor had been successfully gasified by operating at a higher temperature, an alternative material and energy balance suggests that the calculated cold-gas efficiency of $16 \%$ in Table 26 would be increased by about $25 \%$, to a value between $40 \%$ and $50 \%$. Even under the very best of test conditions and heat balance assumptions, the corrected syngas value in a commercial plant would only reach approximately $3160 \mathrm{~kJ} / \mathrm{m}^{3}(\sim 85 \mathrm{Btu} / \mathrm{scf})$ well below what would be needed to operate a GE gas turbine. The only viable options to utilize IGCC with a transport gasifier and this particular fuel would be to remove at least $50 \%$ of the carbon dioxide from the syngas before combustion in a gas turbine or to supplement the fuel gas heating value with some natural gas. The low cold-gas efficiency of the gasifier also indicates that the overall thermal efficiency for this IGCC process will not be very high. Given the high risk associated with this option, the most prudent conversion process to consider probably would

be a circulating fluid-bed combustor in which all of the fuel heating value is released and recovered in the combustor heat exchangers. 


\section{Recommendations Based on Task 5 Results}

At this time, because of the low heating value of the Bulgarian lignite and the subsequent results obtained during testing of this fuel as a transport gasifier feedstock, it is recommended that circulating fluidized-bed combustion (CFBC) be pursued as the primary least risky alternate technology for the use of this fuel for energy production. CFBC is a technology that is the most tolerant of LHV fuels. With the use of a limestone bed, in-bed sulfur capture is possible. With a downstream dry scrubber, very high sulfur capture rates are more economically possible in combination with in-bed sulfur capture as a lower total calcium-to-sulfur ratio, compared to relying totally upon in-bed sulfur capture. Because of the lower temperature operation when compared to more conventional (typically suspension-fired) combustion technologies, $\mathrm{NO}_{\mathrm{x}}$ rates are inherently lower. Additionally, very low $\mathrm{NO}_{\mathrm{x}}$ rates can be achieved with the use of selective noncatalytic reduction (SNCR) by ammonia injection prior to the primary cyclone. A particulate control device, typically a baghouse, is used to control particulate emissions to an acceptable level.

\section{Task 4 - Pilot-Scale Combustion Testing in the CFBC}

\section{Objectives}

The Task 4 objective was to conduct a pilot-scale evaluation of CFBC as an option for future power generating capacity utilizing Bulgarian lignite. The EERC CFBC is very similar to CFBC systems available from several vendors and has been utilized in the past for testing a coal, with the operating data shared with several vendors. This allows the different vendors to supply proposals for a commercial CFB boiler based on the same set of data. The advantage of the pilotscale system over the bench-scale FBR is that heat balance data, including heat-transfer coefficients as well as material balance information, will be provided. This testing required approximately 25 tonnes of coal and approximately 3 tonnes of a calcium-based sorbent to be shipped to the EERC for testing. Given that slightly less than 20 tonnes of Bulgarian lignite remained from the pilot-scale transport gasifier testing, the test plan had to be somewhat abbreviated.

\section{Scope of Work}

Task 4 involves parametric testing at steady-state conditions, sampling, analysis, and reporting:

- Any required modification of the pilot-scale $\mathrm{CFBC}$, routine and specialized analyzer preparation, and accessory equipment maintenance and repair.

- Start the CFBC with $363 \mathrm{~kg}(800 \mathrm{lb})$ silica sand bed, a coal feed rate of approximately $272 \mathrm{~kg} / \mathrm{hr}(600 \mathrm{lb} / \mathrm{hr})$, and a limestone feed rate as required for a specified sulfur capture rate. Usually 12 to 24 hours is needed to allow the refractory and equipment to be stabilized. 
- Proceed with initial baseline testing at excess air $20 \%$, primary/secondary air split $60 / 40$, superficial velocity at $5.2 \mathrm{~m} / \mathrm{sec}(17 \mathrm{ft} / \mathrm{sec})$, and average combustion bed temperature of $843^{\circ} \mathrm{C}\left(1550^{\circ} \mathrm{F}\right)$. The limestone feed rate will be maintained to obtain as high a sulfur retention efficiency as possible, approaching $95 \%$, to assist in bed turnover for the next 24 hours.

- Proceed with the designated test periods. Typical test parameters include the following:

- Velocity: 4.6, 5.2, $5.8 \mathrm{~m} / \mathrm{sec}(15,17,19 \mathrm{ft} / \mathrm{sec})$

- Average combustion temperature $788,843,899^{\circ} \mathrm{C}\left(1450^{\circ}, 1550^{\circ}\right.$, and $\left.1650^{\circ} \mathrm{F}\right)$

- S capture efficiency $70 \%, 80 \%, 90 \%$ by varying $\mathrm{Ca} / \mathrm{S}$ ratio by changing the limestone feed rate.

Bed materials, cyclone ash, and baghouse ash were sampled during these tests for subsequent ash chemistry analysis and PSD characterization. Bed agglomeration were monitored by visual observation and bed material PSD check. During the testing period, standard gaseous emissions were continuously monitored, including $\mathrm{CO}_{2}, \mathrm{CO}, \mathrm{O}_{2}, \mathrm{SO}_{2}$, and $\mathrm{NO}_{\mathrm{x}}$. Special requests or requirements of the client were implemented as possible within budget and time constraints. The total testing time was limited to available fuel supply or 5 days, whichever was shorter.

\section{Test Duration}

A 100-hour test was completed using the EERC's 1-MWth pilot-scale CFBC system.

\section{Fuel and Sorbent Sizing}

The fuels and sorbent was supplied and shipped to the EERC. Sizing and drying of the fuel and sorbent were performed at the EERC in accordance to specifications developed and agreed upon.

\section{Operating Conditions}

The pilot system was operated at the average bed temperature, required $\mathrm{Ca} / \mathrm{S}$ ratio, superficial gas velocities, and excess air levels determined prior to testing. The EERC pilot plant is designed to operate over a wide range of conditions, and it is expected to be able to meet the typical temperature, velocity, primary air/secondary air (PA/SA) ratio, bed $\mathrm{dP}$, and fuel and limestone size as recommended by major CFB manufacturers. The EERC has two different elevations where overfire air can be added. Previously, testing using the ports at the third level has resulted in poor operability of the unit and poor performance results. The second level of secondary air ports was designed to most closely simulate vendor design and is the recommended location of secondary air addition for the proposed tests. Solids recycle will be done from both stages of the cyclone during these tests to more closely simulate the collection efficiency and recirculation rates of a full-scale system. 


\section{Measurement and Sampling}

During the tests, all flows, temperatures, pressures, and gas emissions $\left(\mathrm{O}_{2}, \mathrm{CO}, \mathrm{CO}_{2}, \mathrm{SO}_{2}\right.$, and $\mathrm{NO}_{\mathrm{x}}$ ) were monitored. Readings were acquired by the data acquisitions system once every minute and averaged for the test period.

Samples of coal, limestone, bed drain, loop seal, and fly ash were taken for designated test periods. Composites for each test period were analyzed as deemed appropriate and according to the plant test program.

\section{Data Evaluation}

The EERC performed its standard data analysis as has been done for fuels and sorbents tested previously. A preliminary report was supplied at the conclusion of testing as soon as possible. The final report discussed:

- A facility description and configuration for each run.

- A narrative, chronological summary of events during the week of testing.

- Heat and material balances for each test condition.

- A comparative evaluation on utilization of ash alkali and sorbent.

- A comparative evaluation on attrition characteristics of limestone and coal ash based on flow rates and size distribution of various feed, waste stream, and loop seal material.

- Functional relationships between bed temperature, residence time, and $\mathrm{Ca} / \mathrm{S}$ ratio based on $\mathrm{SO}_{2}, \mathrm{NO}_{\mathrm{x}}$, and $\mathrm{CO}$ emissions and combustion efficiency and carbon burnout.

- A qualitative comparison with other fuels tested previously by the EERC.

- A summary of results and conclusions.

- Photographs, descriptions, and analyses of any deposits formed as the result of burning this fuel.

\section{Description of the CFBC System}

EERC's $3165-\mathrm{MJ} / \mathrm{hr}(3,000,000-\mathrm{Btu} / \mathrm{hr}) \mathrm{CFBC}$ is used for test-firing coal and alternate fuels.

\section{The CFBC}

A cross-sectional view and a flow schematic of the CFBC system is shown in Figures 33 and 34. The overall system is divided up into the following subsystems. 


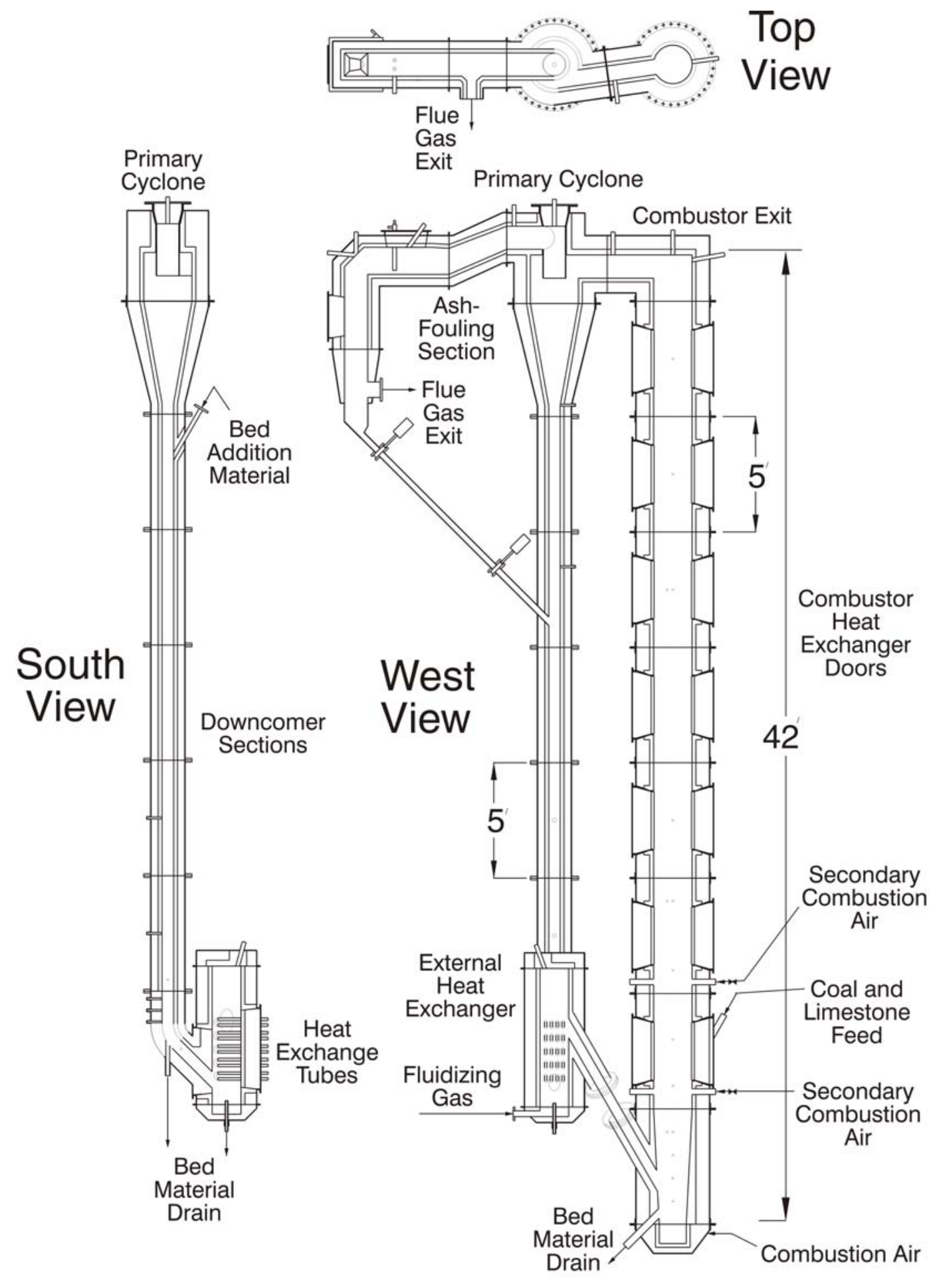

EERC DH08200.CDR

Figure 33. Cross-sectional view of the EERC CFBC. 


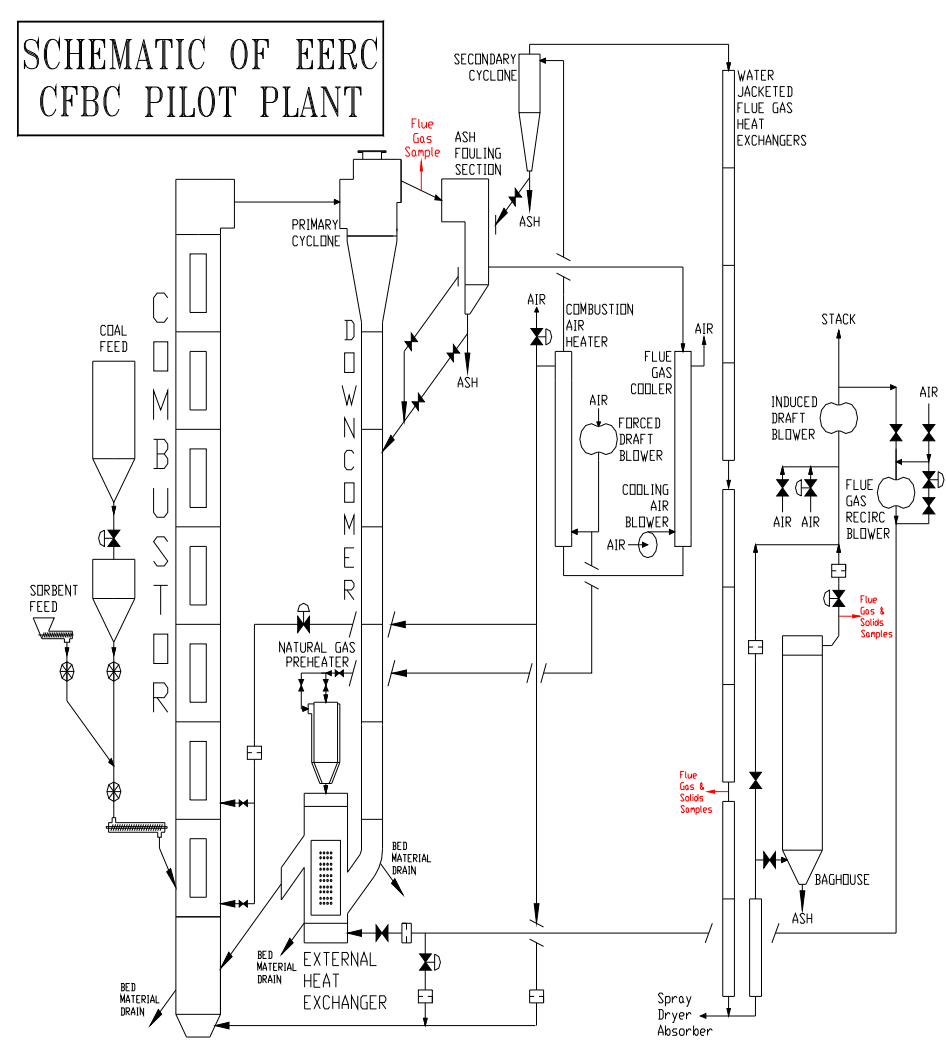

Figure 34. Schematic of the EERC CFBC.

- Combustion air system

- Flue gas system

- Flue gas recirculation system

- Ash-fouling section

- Fuel and sorbent system

- Combustor

- Solids recirculation system

- Natural gas-fired preheater

- Combustor heat exchange system

- External heat exchange system

- Flue gas cooling water system

A forced-draft blower supplies combustion air and secondary air to the combustor. The combustion air heat exchanger is a shell-and-tube heat exchanger that uses hot flue gas to preheat the combustion air before it enters the combustor. Total combustion air flow is controlled by the amount of flue gas diverted through the combustion air bypass valve located directly after the combustion air heat exchanger. The secondary combustion air control valve determines the ratio of combustion air that enters the test furnace above the distributor plate to the amount of combustion air introduced into the combustor plenum below the distributor plate. The secondary combustion air can be introduced through manifolds at two different levels, located $1.75 \mathrm{~m}$ 
(5' 9") and $3.2 \mathrm{~m}\left(10^{\prime} 6^{\prime \prime}\right)$ above the distributor plate in Sections 2 and 3, respectively, of the combustor. Four 7.6-cm (3-in.) manual gate valves at each level are used to select where overfire air is introduced into the combustor.

Flue gas exits the top of the combustor, then flows through a refractory-lined primary cyclone with an inside diameter of $64 \mathrm{~cm}$ (25 in.), the ash-fouling section, an air-cooled flue gas cooler, the combustion air heater, a 46-cm (18-in.) stainless steel secondary cyclone, the ten water-jacketed flue gas heat exchangers (modified for this testing with a hot-water recirculation system), and through either the flue gas bypass or the baghouse. Temperatures and pressures are monitored throughout the flue gas system.

Flue gas is drawn through the induced-draft (ID) blower where it finally enters a stack for release to the atmosphere. Flue gas flow is controlled by the amount of air allowed into the ID blower through the ID fan bypass valve. The ID fan bypass valve is computer-controlled and continually adjusted to maintain a static pressure of -2 in. $\mathrm{WC}$ at the inlet of the primary cyclone.

The flue gas recirculation blower is used normally to supply fluidizing air to the external heat exchanger, as was the case for this testing. It has the additional capability of supplying flue gas to the external heat exchanger (EHX) and also to the combustor if desired for flue gas recirculation testing. Manual gate valves located upstream of the blower allow either air or flue gas to enter the blower.

Primary and secondary combustion air, flue gas recirculation, and flue gas flow rates are measured using orifice plates. Instrumentation is interfaced with the data acquisition/control system to record and display the flow rates. Orifice differential and static pressures are also monitored with Magnehelic ${ }^{\circledR}$ pressure gauges.

The ash-fouling section is located at the exit of the 64-cm (25-in.) primary cyclone. Two vertically oriented air-cooled stainless steel probes maintained at $538^{\circ} \mathrm{C}\left(1000^{\circ} \mathrm{F}\right)$ are present in the ash-fouling section to detect potential ash deposition or slagging. Additionally, a horizontally oriented removable air-cooled probe was installed for this testing. This probe was also controlled to an average metal temperature of $538^{\circ} \mathrm{C}\left(1000^{\circ} \mathrm{F}\right)$. A hopper attached to the bottom of the ashfouling section is connected to the downcomer via a drain leg containing two pneumatically actuated gate valves for ash recirculation. Three pneumatically actuated gate valves are used to allow the solids collected downstream by the secondary cyclone to be either routed back into the downcomer or to a collection barrel located on the ground floor. The length of time that any of these five pneumatic valves is open or closed is controlled with the data acquisition/control system.

The fuel storage hopper has a capacity of about $1360 \mathrm{~kg}(3000 \mathrm{lb})$, which is transferred to a permanent feeder in approximately $270-\mathrm{kg}(600-\mathrm{lb})$ increments. A gate valve is used to recharge the fuel feed hopper. The fuel feed hopper is suspended from a load cell; approximate fuel feed rates are calculated from the weight loss of the hopper over time. At the bottom of the weigh hopper, a rotary valve with an electronic speed controller is used to control the fuel feed rate. 
The combustor is a series of refractory-lined sections bolted together. Each section has $5 \mathrm{~cm}$ ( 2 in.) of hard, abrasion-resistant refractory used in combination with $18 \mathrm{~cm}$ (7 in.) of insulating refractory. The bottom plenum section has the primary combustion air entrance and a bed material drain. The first combustor section (Section 1) has the solids recirculation return from the EHX. A removable stainless steel nozzle distributor plate is installed between the plenum and first combustor section. The next seven sections (Sections 2-8) each have two doorways on opposite sides for the installation of either blank refractory doors or heat exchange panels. At this time, twelve of the possible fourteen heat exchanger panels are installed in the combustor, two each in Sections 2, 3, 4, 7, and 8, and one each in Sections 5 and 6. Section 2 has the entrance for gravity feed of fuel and sorbent and the first set of secondary combustion air ports. Section 3 has the second set of four secondary combustion air ports. Section 9, the combustor exit, connects to the primary refractory-lined cyclone. Thermocouple and pressure taps are present in all of the combustor sections. All pressure taps are continuously purged with air to keep them open for accurate pressure measurements.

The refractory-lined components of the solids circulation system include the primary cyclone, the downcomer, and the EHX. Solids that are captured by the primary cyclone drop into the downcomer and travel downward into the EHX. Thermocouples monitor the temperature at the entrance and exit of the primary cyclone. The EHX has a plenum section into which either air or flue gas can be introduced. A removable stainless steel distributor plate is installed between the plenum and the main body of the EHX. The natural gas-fired preheater, described later, is attached to the top section of the EHX. Sixteen U-shaped stainless steel water-cooled heat exchanger tubes are installed in a removable refractory-lined door in the EHX. Thermocouple and pressure taps are distributed along the sections of the downcomer and in the EHX.

The preheater combustion chamber is constructed with inner and outer stainless steel shells. The natural gas-fired burner is bolted to the top of the preheater and fires downward. To maintain an acceptable operational temperature on the inside surface of the preheater, air is circulated through a baffled cooling jacket. Cooling air enters at the top of the preheater and flows downward, where it combines with the combustion gases at the bottom of the preheater transition cone. Preheater combustion air and the cooling jacket air are supplied by the forceddraft (FD) blower. A butterfly valve in the 10.2-cm (4-inch) supply line from the FD blower and a gate valve between the preheater and the EHX isolate the system when it is not being used. There are butterfly valves in the combustion air and cooling air lines for control purposes. There are also orifice plates in each line with magnehelics to monitor the flow rates. The flow of natural gas to the main and pilot burners is controlled with flowmeters located in the control room. A flame safety system is located in the control room to shut off the flow of natural gas to the preheater if 1) a flame is not present in the preheater, 2) combustion air is not being supplied to the preheater or cooling jacket, or 3) the combustion air pressure is greater than the natural gas pressure supplied to the preheater.

The rate of water flow to the combustor heat exchangers (CHX) is measured individually for each door by flowmeters and is controlled by globe valves installed above the flowmeters in the CHX panel boards. Total flow is measured with an in-line turbine flowmeter, which includes a bypass to allow for maintenance or repair during operations. An air system is connected to the 
inlet manifolds of each of the heat exchange panels. Air is used to cool the heat exchanger panels during operation prior to the introduction of water.

Sixteen heat exchange coils are available for water cooling in the external heat exchanger door. Each U-shaped heat exchanger is constructed out of $2.5-\mathrm{cm}(1-\mathrm{in}$.) stainless steel pipe with $1-\mathrm{cm}(1 / 2-\mathrm{in}$.) stainless steel tubing at each end. Each of the eight circuits has a flowmeter and a flow control valve mounted in a panel board to monitor and control the flow of water. Total flow is measured with an in-line turbine flowmeter, installed with a bypass to allow for maintenance or repair during operation. Flowmeters control the flow to either single- or dual-circuit sets of cooling coils with a thermocouple located at the exit of each circuit to measure the water exit temperature.

To eliminate or reduce the impact of any mercury loss as a result of flue gas coming in contact with cold metal surfaces for this testing, the flue gas water-cooling system upstream of the baghouse has been modified from its original configuration. Previously, water cooling was achieved with a once-through system using municipal water entering the heat exchangers at an average temperature of $4^{\circ}-15^{\circ} \mathrm{C}\left(40^{\circ}-60^{\circ} \mathrm{F}\right)$, depending upon the time of year. The system was converted to a hot-water-cooling system for the eight existing water-jacketed flue gas heat exchangers and the two newly installed water-jacketed flue gas heat exchangers. Water flow is supplied from an existing water pump connected to a water storage tank located on the fifth floor. Three manual control valves were installed for flue gas heat exchangers $1-3,4-6$, and 7-10 to control the water flow rate to these three sets of heat exchangers. The water temperature was controlled by adding cold makeup water to the recirculation water storage tank. Two existing flowmeters were available for metering the makeup water flow rate. A bypass from the pump to the tank is also available if required. For testing, an inlet temperature of $88^{\circ} \mathrm{C}\left(190^{\circ} \mathrm{F}\right)$ or higher to the heat exchangers and an exit temperature approaching $96^{\circ} \mathrm{C}\left(205^{\circ} \mathrm{F}\right)$ was maintained to ensure no mercury condensation in the heat exchangers. Each set of heat exchangers was equipped with a relief valve that opens if the temperature exceeds $100^{\circ} \mathrm{C}\left(212^{\circ} \mathrm{F}\right)$.

\section{Fabric Filter (FF) Baghouse}

The CFBC baghouse is a pulse-jet-style baghouse. It has a single compartment $(76 \times$ $94 \mathrm{~cm}[30 \times 37 \mathrm{in.]}$ ) capable of either online or off-line cleaning. The fabric type selected is a $744-\mathrm{g} / \mathrm{m}^{2}\left(22-\mathrm{oz} / \mathrm{yd}^{2}\right)$ woven-glass bag with a polytetrafluoroethylene membrane. It offers superior cleanability compared to other fabrics more commonly used, helping to reduce recovery

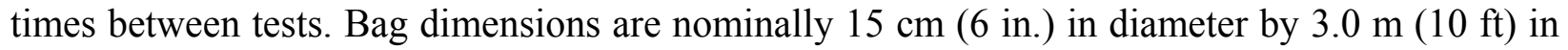
length, with each filter bag secured to the tube sheet using a snap band sewn into the top cuff. Stainless steel (304 SS) wire cages with 20 vertical wires and 15 -cm (6-in.) ring spacing provide bag support. The CFBC baghouse accommodates sixteen $15-\mathrm{cm}$ (6-in.) bags resulting in a total filtration area of $14.6 \mathrm{~m}^{2}\left(157.1 \mathrm{ft}^{2}\right)$.

\section{Niro Inc. Production Minor ${ }^{\mathrm{TM}}$ Spray Dryer, Model I}

The spray dryer absorber (SDA), previously integrated with the EERC pilot-scale particulate test combustor (PTC), can be combined with the pilot-scale CFBC for higher sulfur removal in the CFBC system. A portion of total combustion flue gas from the $\mathrm{CFBC}$ is diverted 
through a slipstream piping run of approximately $18 \mathrm{~m}(60 \mathrm{ft})$ into the PTC SDA-FF system. The flue gas flow rate through the PTC SDA-FF system is measured by the annubar of the PTC and controlled at about $2.83 \mathrm{~m}^{3} / \mathrm{min}(100 \mathrm{scfm})$.

A schematic of the unit is presented in Figure 35. The drying chamber is $1.2 \mathrm{~m}(3.9 \mathrm{ft})$ in diameter with a $0.75-\mathrm{m}(2.5-\mathrm{ft})$ cylindrical height and a $60^{\circ}$ conical bottom. The inner shell is constructed of 2-mm stainless steel, type AISI 316, with a 220-grit finish. A Niro Inc. Type FS-1 rotary atomizer, capable of speeds ranging from 10,500 to $30,000 \mathrm{rpm}$, is used for atomizing lime slurry. An air disperser, supplied with the rotary atomizer, is used to introduce the proper heated $149^{\circ} \mathrm{C}\left(300^{\circ} \mathrm{F}\right)$ air flow pattern throughout the chamber.

Electric heating is provided for the piping from the gas split point to the inlet of the SDA during the testing period, in order to maintain the gas inlet temperature of about $149^{\circ} \mathrm{C}\left(300^{\circ} \mathrm{F}\right)$. An SDA inlet gas temperature of $149^{\circ} \mathrm{C}\left(300^{\circ} \mathrm{F}\right)$ is a typical operational parameter used in a utility plant. The outlet gas temperature of the SDA (dry-bulb) is controlled at $79^{\circ} \pm 3^{\circ} \mathrm{C}\left(175^{\circ} \pm\right.$ $5^{\circ} \mathrm{F}$ ). This is also a typical operating parameter as encountered in a utility plant. The outlet gas temperature cannot be operated below the dew point of moisture in order to prevent any moisture condensation in the SDA downstream sections. A dry-bulb thermocouple is employed to monitor the flue gas, as previous experience indicated that a wet-bulb thermocouple can easily become plugged.

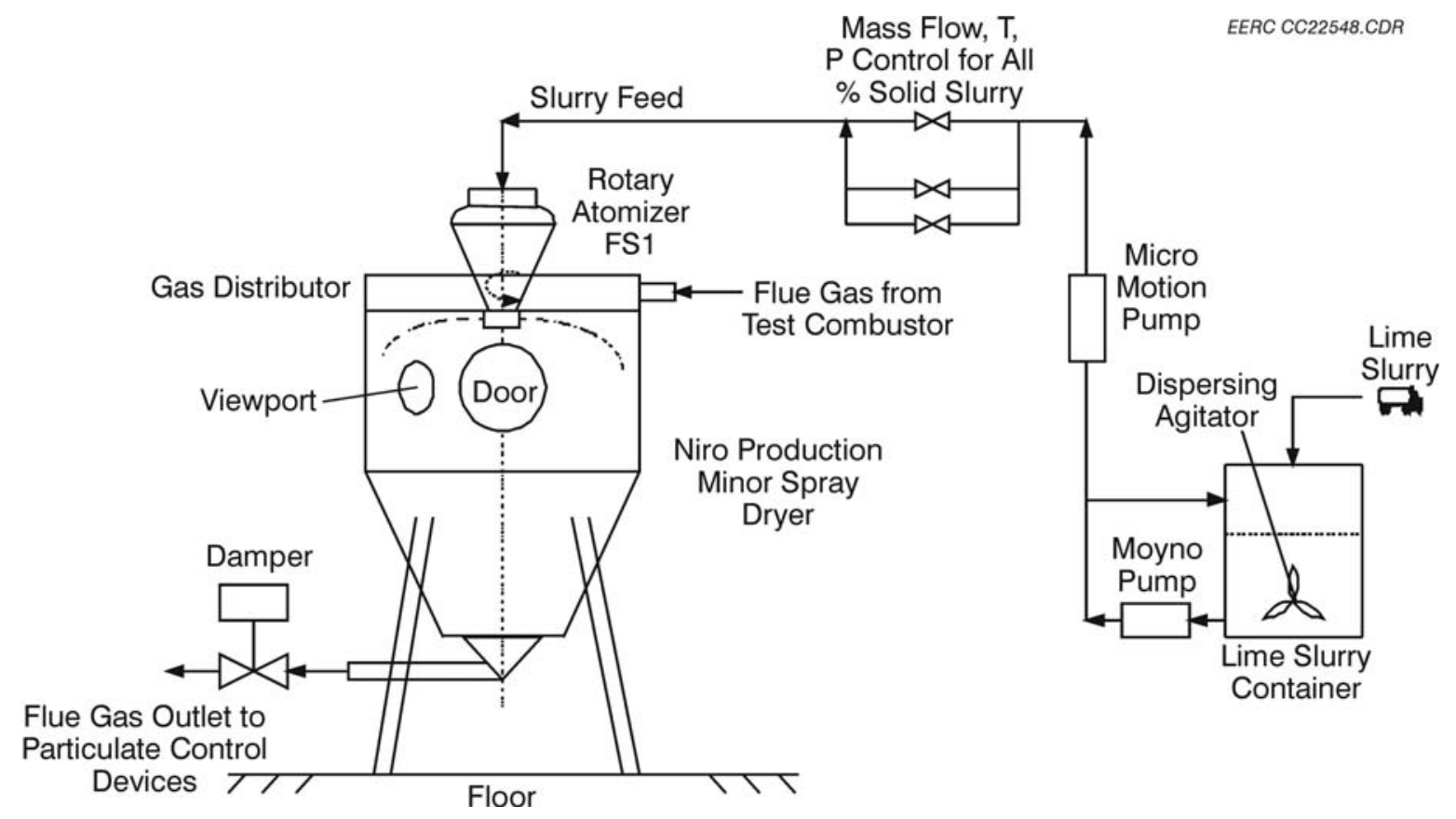

Figure 35. Schematic (not drawn to scale) of the Niro Inc. Production Minor Spray Dryer, Model I. 


\section{CFBC Testing of Bulgarian Lignite}

After limited testing with the TRDU gasification system, it was decided that CFBC might be a better candidate for a conversion technology for using the high-ash Bulgarian lignite. A pilot-scale test was scheduled for the earliest available time slot based upon that decision. This CFBC pilot-scale test run was conducted with the Bulgarian lignite to primarily investigate its combustion characteristics, inherent sulfur capture, and sulfur capture as a function of operating conditions. Control of sulfur emissions was additionally investigated using a spray dryer system. Nitrous oxide $\left(\mathrm{NO}_{\mathrm{x})}\right.$ emission values with and without SNCR using ammonia injection for $\mathrm{NO}_{\mathrm{x}}$ were obtained. Fouling tendencies of the coal were investigated; flue gas emissions as a function of operating conditions and trace element distribution for a selected test period were determined.

\section{Test Summary and Background}

Some modifications were required to prepare the EERC CFB system for this test. Provisions were made to inject ammonia to investigate $\mathrm{NO}_{\mathrm{x}}$ reduction. Piping was installed to allow a slipstream of flue gas to a dry scrubber system for investigating sulfur removal downstream of the combustor. The coal was air-dried so that it would feed in the existing fuel feed system. A water injection system was set up to inject water through one of the lower secondary air ports to allow assessment of combustion simulating the coal being fed into the combustor at an as-received moisture content.

The planned test matrix is shown in Table 29. This was an aggressive test matrix to ideally gain as much information as possible with the remaining coal available. It also served the purpose of being a guide as testing progressed, and it was recognized that some of the more extreme tests, such as the high temperature or high velocity, might not be achievable with this fuel. As testing proceeded, it became apparent that some of these proposed test periods would not be possible to achieve because of the combination of the low heating value of the coal and the EERC CFBC coal feed limitations. The actual coal feed rates required ended up being significantly higher than were calculated for this test.

A preliminary coal feed test had been conducted with a portion of the coal remaining from the previous gasification testing. That fuel did have some limestone blended in it and was sized at minus $3.2 \mathrm{~mm}$ (1/8 inch). A curve was developed for the coal feed rotary valve used to control

coal feed rate. The feed system has removable storage hoppers for transporting the coal (approximately $1360 \mathrm{~kg}$ of coal per hopper), an intermediate coal weigh hopper for measuring the feed rate, a coal feed rotary for controlling the feed rate, another rotary valve to help isolate the feed system from the operational combustion pressure, and an auger to transport the coal over to where it feeds into the combustor with a pneumatic assist. The coal enters into the combustor about $1.52 \mathrm{~m}$ ( 5 feet) above the distributor plate. There is some minimal positive pressure at the point of entry proportional to the bed material depth in the combustor. The upper limit established for the maximum coal feed rate was slightly more than $409 \mathrm{~kg} / \mathrm{hr}(900 \mathrm{lb} / \mathrm{hr})$. It was felt that the projected coal feed rate would be a sufficient rate for the proposed testing. It was recognized that significant modifications of the existing system would be required to allow a 
Table 29. Proposed Test Matrix

\begin{tabular}{lccccccc}
\hline Test & $\begin{array}{c}\text { Temp., } \\
{ }^{\circ} \mathrm{C}\end{array}$ & $\begin{array}{c}\text { Velocity, } \\
\text { m/sec }\end{array}$ & $\begin{array}{c}\text { Excess } \\
\text { Air, } \%\end{array}$ & $\begin{array}{c}\text { Sulfur } \\
\text { Capture }\end{array}$ & $\begin{array}{c}\text { PA/SA, } \\
\text { Location }\end{array}$ & $\begin{array}{c}\text { Spray } \\
\text { Dryer }\end{array}$ & $\begin{array}{c}\text { Ammonia } \\
\text { Injection }\end{array}$ \\
\hline 1 & 843 & 4.9 & 20 & Inherent & $60 / 40$ at 2 & no & no \\
2 & 843 & 4.9 & 20 & Inherent & $60 / 40$ at 2 & yes & yes \\
3 & 843 & 4.9 & 20 & 90 & $60 / 40$ at 3 & no & no \\
4 & 843 & 4.9 & 20 & 90 & $70 / 30$ at 2 & no & no \\
5 & 843 & 4.9 & 20 & 90 & $50 / 50$ at 2 & no & no \\
6 & 843 & 4.9 & 20 & 90 & $60 / 40$ at 2 & no & no \\
7 & 843 & 4.9 & 20 & 90 & $60 / 40$ at 2 & yes & yes \\
8 & 899 & 4.9 & 20 & 90 & $60 / 40$ at 2 & no & no \\
9 & 843 & 5.5 & 20 & 90 & $60 / 40$ at 2 & no & no \\
10 & 843 & 5.5 & 20 & 90 & $60 / 40$ at 2 & no & no \\
11 & 788 & 4.9 & 20 & 90 & $60 / 40$ at 2 & no & no \\
12 & 843 & 4.3 & 20 & 90 & $60 / 40$ at 2 & no & no \\
13 & 843 & 4.9 & 20 & 95 & $60 / 40$ at 2 & no & no \\
14 & 843 & 4.9 & 20 & 95 & $60 / 40$ at 2 & no & yes \\
15 & 843 & 4.9 & 20 & 70 & $60 / 40$ at 2 & no & no \\
\hline
\end{tabular}

higher feed rate. This coal had been air-dried to eliminate the surface moisture which leads to the coal adhering to the feeder surfaces. This would either reduce the maximum feed rate possible or result in the coal feed system plugging up. There is a series of air purges and pulses throughout the coal feed system to minimize or eliminate plugging.

\section{Coal and Limestone Properties}

The coal and limestone used for this test was shipped from Bulgaria in super sacks. Because of high surface moisture in the fuel, it was air dried before being crushed to a top size of $6.4 \mathrm{~mm}(-1 / 4 \mathrm{inch})$. Samples were collected throughout the week of testing, and a sample from each day was analyzed. The limestone was crushed to a $1000 \mu \mathrm{m}\left(-16\right.$ mesh) with a $\mathrm{d}_{50}$ of $450 \mu \mathrm{m}$, and a single composite sample was analyzed. The results of the coal and limestone analyses are shown in Tables 30 and 31, respectively. Figure 36 shows the size distribution of the Bulgarian coal and limestone for each sample. The coal particle size for Tests 10 through 12 was smaller and premixed with limestone because it had been prepared for use in the transport reactor. The analysis for Test 12 was adjusted to reflect the addition of water to the reactor, to simulate the burning of a high-moisture coal.

\section{Operational Performance}

A typical start-up was initiated Sunday, October 12, 2008. The fans were started up, $364 \mathrm{~kg}(800 \mathrm{lb})$ of silica sand added to the system, and heatup was initiated with natural gas. After about 5 hours of firing on natural gas, a subbituminous coal was used for approximately 4 hours for final heatup of the system to the specified operating temperature before switching to the Bulgarian lignite. The use of subbituminous coal for heatup allowed the conservation of the Bulgarian lignite for testing. After almost 5 hours of operation with the Bulgarian lignite, a coal 
Table 30. Coal Analyses

\begin{tabular}{lccccc}
\hline & Tests $1-5$ & Tests 6-8 & Test 9 & Tests 10-11 & Test 12 \\
\hline Proximate Analysis, as-received, $\mathrm{wt}^{\circ} \%$ & & & & \\
Moisture & 25.40 & 27.20 & 26.10 & 21.40 & 40.00 \\
Volatile Matter & 17.64 & 17.77 & 18.40 & 19.68 & 15.02 \\
Fixed Carbon & 6.24 & 7.08 & 7.36 & 7.02 & 5.36 \\
Ash & 50.72 & 47.95 & 48.13 & 51.90 & 39.62 \\
Ultimate Analysis, as-received, $\mathrm{wt} \%$ & & & & \\
Carbon & 15.29 & 14.80 & 16.40 & 15.81 & 12.07 \\
Hydrogen & 1.91 & 1.88 & 2.07 & 1.90 & 1.45 \\
Nitrogen & 0.35 & 0.37 & 0.38 & 0.35 & 0.27 \\
Sulfur & 0.44 & 0.46 & 0.43 & 0.45 & 0.34 \\
Oxygen & 5.88 & 7.33 & 6.49 & 8.19 & 6.26 \\
Ash & 50.72 & 47.95 & 48.13 & 51.90 & 39.61 \\
Moisture & 25.40 & 27.20 & 26.10 & 21.40 & 40.00 \\
Ash Composition, $\%$ as oxides & & & & \\
Calcium, $\mathrm{CaO}_{\text {Magnesium, } \mathrm{MgO}}$ & 2.80 & 3.00 & 2.80 & 4.60 & 4.60 \\
Sodium, $\mathrm{Na}_{2} \mathrm{O}$ & 1.65 & 1.67 & 1.68 & 1.65 & 1.65 \\
Silica, $\mathrm{SiO}{ }_{2}$ & 0.35 & 0.35 & 0.31 & 0.38 & 0.38 \\
Aluminum, $\mathrm{Al}_{2} \mathrm{O}_{3}$ & 57.60 & 57.00 & 57.20 & 56.40 & 56.40 \\
Ferric, $\mathrm{Fe}_{2} \mathrm{O}_{3}$ & 27.50 & 27.60 & 28.20 & 26.70 & 26.70 \\
Titanium, $\mathrm{TiO}_{2}$ & 5.39 & 5.47 & 5.43 & 5.31 & 5.31 \\
Phosphorus, $\mathrm{P}_{2} \mathrm{O}_{5}$ & 0.68 & 0.69 & 0.67 & 0.70 & 0.70 \\
Potassium, $\mathrm{K}_{2} \mathrm{O}$ & 0.16 & 0.15 & 0.15 & 0.15 & 0.15 \\
Sulfur, $\mathrm{SO}_{3}$ & 1.72 & 1.79 & 1.70 & 1.73 & 1.73 \\
HHV & 2.11 & 2.27 & 1.88 & 2.44 & 2.44 \\
moisture-free, $\mathrm{kJ} / \mathrm{kg}$ & 5861 & 6358 & 7455 & 6984 & 6984 \\
as-received, $\mathrm{kJ} / \mathrm{kg}$ & 4374 & 4627 & 5506 & 5492 & 4190 \\
\hline
\end{tabular}

Table 31. Limestone Analysis

\begin{tabular}{lr}
\hline \multicolumn{2}{l}{ Ash Composition, \% as oxides } \\
\hline Calcium, $\mathrm{CaO}$ & 46.00 \\
Magnesium, $\mathrm{MgO}$ & 1.12 \\
Sodium, $\mathrm{Na}_{2} \mathrm{O}$ & 0.00 \\
Silica, $\mathrm{SiO}_{2}$ & 14.31 \\
Aluminum, $\mathrm{Al}_{2} \mathrm{O}_{3}$ & 1.98 \\
Ferric, $\mathrm{Fe}_{2} \mathrm{O}_{3}$ & 0.03 \\
Titanium, $\mathrm{TiO}_{2}$ & 0.11 \\
Phosphorus, $\mathrm{P}_{2} \mathrm{O}_{5}$ & 0.00 \\
Potassium, $\mathrm{K}_{2} \mathrm{O}$ & 0.22 \\
Sulfur, $\mathrm{SO}_{3}$ & 0.08 \\
\hline
\end{tabular}




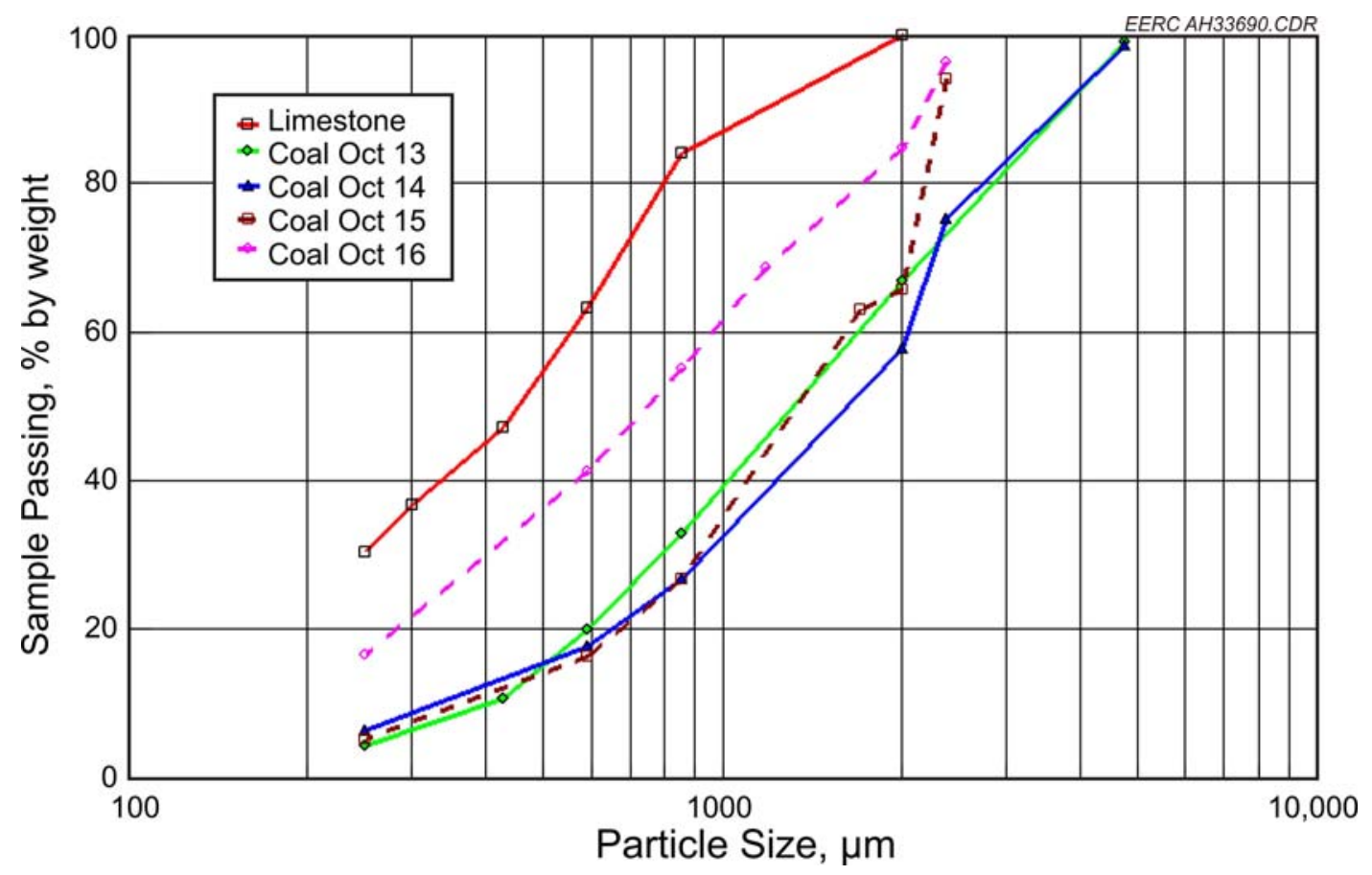

Figure 36. Size distribution of the Bulgarian coal and limestone for each sample.

plug in the feed system occurred. It is suspected to have initiated in the transport auger. This occurred before operational temperatures had stabilized sufficiently to begin the first test period. Some adjustments were made in the coal feed purges to reduce the potential for any additional coal feed plugs.

The auger plugged on three more occasions, 18:55 on October 14, 12:46 on October 15, and $02: 18$ on October 16. There was no particular correlation noted as to when or what would cause the coal auger to plug. A plug is cleared out by isolating the coal feed system from the combustor with a gate valve, running the auger in reverse to clean out the plug, and then cleaning out the coal between the two rotary valves if required. In two instances, the coal had additionally packed into the area between the two rotary valves, requiring this area to be cleaned cleaned out before the lower rotary seal valve would properly function. After a plug was cleared, the system would again continue to function without any apparent effects for several hours. There was also one storage hopper where the coal would not transfer to the weight hopper after the first initial charge. It was removed, replaced with a new hopper, and inspected. It appeared that there was some clay material present in the coal that had "balled up" to prevent the coal from flowing. This small amount of material was removed, and the remaining coal was loaded back into another storage hopper and successfully used later in the run.

Because of the low heating value of this coal, significantly higher feed rates are required when compared with other coals. Additionally, since this is a high-ash coal, there are accumulations of significant amounts of bed material in the combustor that require frequent draining. Inspection of the bed material drained showed some rather large bed material particles present. There was some concern about too much of this material accumulating and promoting 
poor fluidization in the combustor. Based upon these observations it was decided early in the testing to look at reducing the coal feed size from $-6.35 \mathrm{~mm}(1 / 4 \mathrm{inch})$ down to $-3.18 \mathrm{~mm}$ (1/8 inch). This is accomplished by installing a smaller screen in the coal crusher. Size analysis did not show any apparent reduction in size after going to the smaller screen, and there was no apparent effect in combustor performance with the smaller-sized coal, so this size was maintained for the remaining coal prepared for this test. For the last three test periods, the unused coal-limestone mixture was used from the earlier TRDU testing to allow as much operation as possible. This again did not have any significant effect on combustor performance.

Test Period 1, for the evaluation of the inherent sulfur capture with this coal, took place over the time period of 14:30 to 19:30 on October 13, 2008. The amount of inherent sulfur capture, $19 \%$, is fairly low as a result of the low percentage of available alkaline materials in the mineral matter of this coal.

Test Period 2 was with ammonia injection investigating SNCR of nitrous oxides $\left(\mathrm{NO}_{\mathrm{x}}\right)$ with no limestone injection. It was conducted from 22:40 on October 13, 2008, to 01:40 on October 14, 2008. Ammonia injection was at the top of the primary cyclone through an existing sight port. This port had been previously used with good success. There was a $44 \%$ reduction of $\mathrm{NO}_{\mathrm{x}}$ emissions achieved at the highest flow rate available with this combination of regulator and flowmeter. The predicted $\mathrm{NO}_{\mathrm{x}}$ emissions, based upon the coal analysis, was much higher than the actual $\mathrm{NO}_{\mathrm{x}}$ emissions obtained during testing. The predicted $\mathrm{NO}_{\mathrm{x}}$ emission rate was used to set the initial ammonia injection rate. It was planned to adjust as required to get as low a level as possible. As a result of this, the actual injection ratio was 2.2 instead of 1.0. A check of the flue gas stream for ammonia slip using Dräger tubes did not detect any excess ammonia. It is possible that excess ammonia was reacting with the sulfur dioxide to produce ammonium sulfate, although there was not a significant reduction in sulfur dioxide emissions after starting ammonia injection. The original test matrix called for flow to the spray dryer during this period; difficulties with the spray dryer system resulted in that being delayed until the next day. It is possible that the temperature at the injection point was not sufficient for a good reaction to occur, there was not enough residence time for good reduction, or there was a combination of these two factors. Some further optimization would be required to determine the maximum $\mathrm{NO}_{\mathrm{x}}$ reduction that could be obtained by injecting farther back in the system for increased residence time or finding a higher-temperature location for injection.

Test Periods 3, 4, and 5 examined the effect of altering the primary air location and changing the primary/secondary combustion air spilt from 60/40 (Test 3 at the upper level of secondary combustion air injection) to $70 / 30$ (Test 4 at the lower of secondary combustion air addition) and 50/50 (Test 5 at the lower of secondary combustion air addition). The original test matrix called for limestone addition during these tests, but the sulfur capture was not of primary concern at this point. These tests were all conducted on October 14, from 05:30 to 06:25, 06:50 to $07: 20$, and $07: 30$ to $09: 10$. No apparent trends were noted regarding sulfur dioxide or nitrous oxide emissions. There did, however, appear to be some trends for carbon monoxide (CO) emission levels. They were higher when switching to the higher secondary air injection point and when going to a lower percentage of primary air. Lower carbon monoxide emissions were obtained for a higher percentage of primary air, which is consistent with previous testing with the EERC CFBC system. Some variances in the average bed temperature might have contributed to 
the differences in the CO levels. Normally, it would be expected that as the combustion temperature decreased, there would be a corresponding increase in $\mathrm{CO}$ levels.

Two test periods, 6 and 7, were conducted by sending a portion of the flue gas stream to a spray dryer system, demonstrating that significant sulfur dioxide removal is possible with a system of this type. Test 6 corresponds to Test 2 in the original test matrix. With a spray dryer system, lower sulfur dioxide emissions at lower total calcium-to-sulfur ratios are possible compared to just using limestone in the combustor for sulfur capture. Test Period 6 had a high sulfur dioxide flue gas steam going into the spray dryer. A $10 \%$ by weight lime-water solution was used for this testing. The feed rate for Test 6 was $8.5 \mathrm{~kg} / \mathrm{hr}(18.8 \mathrm{lb} / \mathrm{hr})$. At a calcium-tosulfur ratio of approximately 2.4 , the sulfur dioxide emissions were reduced from $3550 \mathrm{mg} / \mathrm{Nm}^{3}$ at $6 \% \mathrm{O}_{2}(1356 \mathrm{ppm})$ down to $31 \mathrm{mg} / \mathrm{Nm}^{3}$ at $6 \% \mathrm{O}_{2}(12 \mathrm{ppm})$.

Limestone feed to the CFBC was initiated prior to Test Period 7 so that the sulfur dioxide level into the spray dryer was significantly lower, measured at $855 \mathrm{mg} / \mathrm{Nm}^{3}$ at $6 \% \mathrm{O}_{2}(317 \mathrm{ppm})$, corresponding to $82 \%$ sulfur retention by the limestone in the combustor at an added calcium-tosulfur ratio of 3.6. The slurry injection rate into the spry dryer was reduced to approximately $4.4 \mathrm{~kg} / \mathrm{hr}(9.6 \mathrm{lb} / \mathrm{hr})$. Sulfur dioxide emissions were reduced down to $78 \mathrm{mg} / \mathrm{Nm}^{3}$ at $6 \% \mathrm{O}_{2}$ $(29 \mathrm{ppm})$ at a calcium-to-sulfur ratio of 4.6. These tests verified that very low sulfur dioxide emissions are possible with the use of a spray dryer system in either scenario of a high sulfur dioxide input or a decreased sulfur dioxide emission level input when using limestone in the combustor. It appears that as the sulfur dioxide level decreases, the driving force for the reaction with the lime slurry also decreases. Thus based upon these results, it would be more efficient to capture the majority of the sulfur in the spray dryer instead of the combustor.

Trace metal testing was initiated during Test Period 8 (Test 6 on the original matrix). This test period was with limestone addition at a baseline condition to assess sulfur capture for comparison to testing with just inherent sulfur capture. This test would be typical of normal operation in a CFBC system. There was $78.6 \%$ sulfur capture at an added calcium-to-sulfur ratio of 3.66 resulting in $21.5 \%$ calcium utilization. This is somewhat lower than typical. This could be due to a large amount of bed material that has to be drained because of the high ash content and feed rate with this coal.

Test Period 9 was the second test with ammonia injection, the difference being that there was limestone addition for this test period. This test corresponds to Test 14 on the original matrix. The $\mathrm{NO}_{\mathrm{x}}$ emissions were reduced by $30 \%$ for this test, with no ammonia slip measured by Dräger tube sampling. The reduction in sulfur dioxide emissions for the test period suggests that a large portion of the ammonia was reacting with the $\mathrm{SO}_{2}$. This occurs when more ammonia is injected than is required for complete $\mathrm{NO}_{\mathrm{x}}$ reduction. Based upon the results at that time and the prerun calculations for the ammonia injection rate, it was thought that we were near a stoichiometric ratio of ammonia and $\mathrm{NO}_{\mathrm{x}}$. Postrun calculations, however, revealed a ratio of 4.9 to 1 for ammonia to $\mathrm{NO}_{\mathrm{x}}$. It is likely that the ammonia injection was not in an optimal location in terms of sufficiently high enough temperature or long enough gas residence time, even though this location has been successfully used for some short-duration testing with two other coals. 
It was determined that the high-temperature test, Test 8 on the original test plan, could not be achieved with the low heating value of this coal, so it was eliminated. The high velocity test (Test 9 or the original test plan) was eliminated as well.

The remaining test periods all used coal left over from TRDU testing preblended with 7\% limestone. Test Period 10 was intended to be a low-velocity test (Test 12 on the proposed test matrix). The velocity was slightly lower, and the average combustor temperature did increase. We were able to achieve a higher bed temperature, mostly from the fact that we ran a sustained period without any coal plugs. After a coal plug, the combustor temperature drops off, and the combustor refractory takes a while to heat up again to an equilibrium state of operation. The combination of lower velocity and higher temperature resulted in poorer sulfur capture. This continued on into Test Period 11 with even a higher limestone feed rate. While sulfur retention was higher, the limestone calcium utilization was the lowest obtained for all of the tests.

The final test period, Test 12, used water injection near the coal feed point to simulate coal feed at an as-received condition without any drying (Test 10 on the proposed test matrix). The higher flue gas velocity is from the contribution of more water present being converted to a vapor state. While maintaining relatively constant coal feed and sorbent feed rates, the average bed temperature dropped off from $841^{\circ} \mathrm{C}\left(1545^{\circ} \mathrm{F}\right)$ down to $819^{\circ} \mathrm{C}\left(1506^{\circ} \mathrm{F}\right)$. This does demonstrate that this coal could be combusted without drying, but there is a thermodynamic penalty for this, and there would likely be handling issues with feeding a coal with moisture this high.

\section{Summary of Results}

Upon completion of the run, data for each of the steady-state periods were averaged. A summary of the process data for each test period is shown in Table 32. The test numbers correspond to those in the discussion of operability. The average temperatures in the combustor, EHX, and downcomer are shown in Table 33. The temperatures are averaged over each combustor or downcomer section, with the lowest numbered sections at the bottom of the combustor and downcomer.

\section{PSDs and Analyses}

Figure 37 shows the PSDs for each of the ash streams leaving the system. The bed material is only slightly larger than the downcomer material. For most of this test, little or none of the secondary cyclone ash was recirculated back to the combustor because of the very high ash content of this coal. The extra bed material was not needed in the bed, and the secondary cyclone ash had already been cooled by going through the combustion air heat exchanger and would need to be reheated in the combustor, which would result in further decreasing the system thermal efficiency. When coals are fired with a lower ash content, some or all of the secondary cyclone ash is recycled back into the combustor via the downcomer, resulting in a much greater size difference between these two ash streams. The secondary cyclone ash size is fairly consistent, with the exception of the sample collected during Test 11 . One possible explanation for this size difference is the large quantity of limestone fed during this test period compared to other tests. 
Table 32. Summary of Process Data

\begin{tabular}{|c|c|c|c|c|c|c|c|c|c|c|c|c|}
\hline Test No: & 1 & 2 & 3 & 4 & 5 & 6 & 7 & 8 & 9 & 10 & 11 & 12 \\
\hline Fuel Feed Rate, kg/hr & 402 & 384 & 362 & 368 & 376 & 380 & 360 & 360 & 351 & 365 & 353 & 450 \\
\hline Sorbent Feed Rate, $\mathrm{kg} / \mathrm{hr}$ & 0 & 0 & 0 & 0 & 0 & 0 & 23 & 25 & 6 & 30 & 49 & 40 \\
\hline Combustor Pressure Drop, $\mathrm{kPa}$ & 13.83 & 13.92 & 15.84 & 14.35 & 14.20 & 12.50 & 12.50 & 11.96 & 13.00 & 14.92 & 16.12 & 15.10 \\
\hline \multicolumn{13}{|l|}{ Combustion Air: } \\
\hline EHX Flow, $\mathrm{m}^{3} / \mathrm{min}$ & 1.10 & 1.13 & 1.13 & 1.10 & 1.10 & 1.08 & 1.08 & 1.05 & 1.08 & 1.05 & 1.05 & 1.05 \\
\hline Primary Air, $\mathrm{m}^{3} / \mathrm{min}$ & 6.77 & 6.77 & 6.37 & 8.27 & 5.49 & 6.74 & 6.49 & 6.46 & 6.40 & 6.06 & 6.09 & 6.00 \\
\hline Secondary Air, $\mathrm{m}^{3} / \mathrm{min}$ & 4.62 & 4.96 & 5.04 & 3.60 & 6.15 & 4.79 & 4.76 & 4.42 & 4.25 & 4.19 & 4.11 & 4.39 \\
\hline Feed Assist Air, $\mathrm{m}^{3} / \mathrm{min}$ & 0.25 & 0.23 & 0.23 & 0.20 & 0.20 & 0.17 & 0.23 & 0.14 & 0.23 & 0.23 & 0.23 & 0.25 \\
\hline DC Aeration Air, $\mathrm{m}^{3} / \mathrm{min}$ & 0.99 & 0.99 & 0.99 & 0.76 & 0.82 & 0.82 & 0.99 & 0.91 & 0.82 & 0.82 & 0.82 & 0.82 \\
\hline Purge Air, $\mathrm{m}^{3} / \mathrm{min}$ & 0.45 & 0.45 & 0.45 & 0.45 & 0.45 & 0.45 & 0.45 & 0.45 & 0.45 & 0.45 & 0.45 & 0.45 \\
\hline Total Air, $\mathrm{m}^{3} / \mathrm{min}$ & 14.16 & 14.53 & 14.22 & 14.39 & 14.24 & 14.05 & 13.99 & 13.42 & 13.23 & 12.80 & 12.74 & 12.97 \\
\hline $\mathrm{PA} / \mathrm{SA}, \%$ & 55.60 & 54.40 & 52.80 & 65.10 & 46.40 & 55.60 & 54.00 & 56.00 & 56.50 & 55.50 & 55.90 & 54.40 \\
\hline Excess Air, \% & 26.50 & 25.90 & 27.40 & 30.20 & 25.90 & 25.30 & 31.30 & 31.20 & 34.80 & 26.30 & 29.20 & 25.60 \\
\hline $\mathrm{FG} \mathrm{SGV,} \mathrm{m/sec}$ & 5.61 & 5.70 & 5.46 & 5.52 & 5.55 & 5.67 & 5.36 & 5.27 & 4.97 & 4.94 & 5.06 & 5.79 \\
\hline EHX SGV, m/sec & 0.45 & 0.45 & 0.45 & 0.44 & 0.45 & 0.45 & 0.44 & 0.44 & 0.46 & 0.45 & 0.45 & 0.45 \\
\hline Bagfouse Air/Cloth & 2.65 & 2.51 & 2.40 & 2.48 & 2.46 & 2.39 & 2.38 & 2.35 & 2.60 & 2.42 & 2.47 & 2.14 \\
\hline \multicolumn{13}{|l|}{ Flue Gas (Baghouse Outlet): } \\
\hline Flow Rate, $\mathrm{m}^{3} / \mathrm{min}$ & 15.97 & 15.75 & 15.97 & 15.69 & 15.18 & 13.00 & 12.86 & 15.01 & 15.41 & 14.95 & 14.92 & 16.77 \\
\hline Oxygen, $\%$ & 4.8 & 4.7 & 6.0 & 5.5 & 5.0 & 4.6 & 5.11 & 5.34 & 5.59 & 4.38 & 4.73 & 4.29 \\
\hline $\mathrm{SO}_{2}, \mathrm{ppm}$ & 1355 & 1347 & 1251 & 1239 & 1346 & 1356 & 317 & 325 & 195 & 624 & 263 & 256 \\
\hline $\mathrm{CO}, \%$ & 0.0051 & 0.0091 & 0.0110 & 0.0039 & 0.0118 & 0.0038 & 0.0039 & 0.0048 & 0.0054 & 0.0047 & 0.0048 & 0.0091 \\
\hline $\mathrm{NO}_{\mathrm{x}}, \mathrm{ppm}$ & 139 & 78 & 134 & 107 & 110 & 107 & 116 & 114 & 80 & 126 & 155 & 106 \\
\hline $\mathrm{CO}_{2}, \%$ & 15.6 & 15.7 & 14.8 & 15.2 & 15.3 & 15.5 & 15.5 & 15.4 & 15.3 & 16.0 & 16.1 & 16.0 \\
\hline $\mathrm{O}_{2}$, Cyclone Exit, $\%$ & 4.4 & 4.3 & 4.5 & 4.9 & 4.3 & 4.3 & 5.0 & 5.0 & 5.4 & 4.2 & 4.2 & 3.6 \\
\hline \multicolumn{13}{|l|}{ Spray Dryer Outlet: } \\
\hline Flue Gas Flow, $\mathrm{m}^{3} / \mathrm{min}$ & & & & & & 2.74 & 3.17 & & & & & \\
\hline $\mathrm{O}_{2}, \%$ & & & & & & 0.25 & 0.25 & & & & & \\
\hline $\mathrm{CO}_{2}, \%$ & & & & & & 0.45 & 0.45 & & & & & \\
\hline $\mathrm{CO}, \mathrm{ppm}$ & & & & & & 0.68 & 0.74 & & & & & \\
\hline $\mathrm{SO}_{2}, \mathrm{ppm}$ & & & & & & 2.89 & 3.37 & & & & & \\
\hline
\end{tabular}


Table 33. Air and Gas Temperatures, ${ }^{\circ} \mathrm{C}$

\begin{tabular}{|c|c|c|c|c|c|c|c|c|c|c|c|c|}
\hline Test No: & 1 & 2 & 3 & 4 & 5 & 6 & 7 & 8 & 9 & 10 & 11 & 12 \\
\hline \multicolumn{13}{|l|}{ Combustor Temperatures: } \\
\hline Plenum & 217 & 207 & 201 & 208 & 197 & 204 & 212 & 189 & 194 & 200 & 203 & 210 \\
\hline Section 1 & 857 & 848 & 813 & 837 & 839 & 854 & 831 & 836 & 857 & 876 & 878 & 835 \\
\hline Section 2 & 856 & 844 & 807 & 833 & 834 & 850 & 826 & 829 & 848 & 867 & 869 & 827 \\
\hline Section 3 & 824 & 812 & 786 & 796 & 806 & 818 & 801 & 794 & 810 & 827 & 830 & 796 \\
\hline Section 4 & 844 & 831 & 809 & 814 & 826 & 837 & 818 & 814 & 827 & 844 & 847 & 811 \\
\hline Section 5 & 820 & 807 & 789 & 790 & 801 & 811 & 795 & 784 & 798 & 814 & 818 & 787 \\
\hline Section 6 & 846 & 832 & 817 & 814 & 825 & 836 & 818 & 808 & 821 & 840 & 843 & 809 \\
\hline Section 7 & 846 & 832 & 820 & 816 & 826 & 836 & 818 & 808 & 821 & 840 & 842 & 809 \\
\hline Section 8 & 903 & 886 & 875 & 868 & 881 & 890 & 866 & 871 & 881 & 899 & 899 & 859 \\
\hline Section 9 & 878 & 850 & 846 & 841 & 853 & 867 & 836 & 845 & 847 & 867 & 866 & 830 \\
\hline Average & 849 & 837 & 811 & 823 & 829 & 843 & 822 & 821 & 837 & 855 & 857 & 819 \\
\hline \multicolumn{13}{|l|}{ EHX Temperatures: } \\
\hline Plenum & 39 & 34 & 39 & 43 & 43 & 43 & 48 & 34 & 29 & 33 & 36 & 33 \\
\hline $0.5^{\prime}$ above Distributor Plate & 788 & 742 & 736 & 754 & 762 & 802 & 772 & 802 & 832 & 846 & 851 & 826 \\
\hline 1.5' above Distributor Plate & 797 & 743 & 740 & 758 & 765 & 861 & 775 & 807 & 836 & 849 & 856 & 831 \\
\hline 2.7' above Distributor Plate & 792 & 740 & 739 & 758 & 765 & 804 & 772 & 813 & 841 & 852 & 861 & 836 \\
\hline 3.8' above Distributor Plate & 751 & 709 & 701 & 719 & 726 & 771 & 749 & 754 & 783 & 787 & 787 & 763 \\
\hline 5.3' above Distributor Plate & 702 & 675 & 663 & 678 & 687 & 732 & 725 & 686 & 722 & 719 & 713 & 693 \\
\hline Average & 766 & 722 & 716 & 733 & 741 & 783 & 758 & 772 & 803 & 811 & 813 & 789 \\
\hline \multicolumn{13}{|l|}{ Downcomer Temperatures: } \\
\hline Section 3 & 870 & 856 & 839 & 843 & 850 & 870 & 836 & 842 & 859 & 876 & 878 & 849 \\
\hline Section 4 & 861 & 792 & 772 & 779 & 783 & 808 & 783 & 774 & 800 & 819 & 827 & 801 \\
\hline Section 6 & 841 & 823 & 799 & 808 & 816 & 831 & 807 & 795 & 811 & 832 & 836 & 805 \\
\hline Section 8 & 896 & 877 & 860 & 861 & 869 & 880 & 849 & 850 & 858 & 879 & 881 & 846 \\
\hline Ambient & 22 & 17 & 21 & 23 & 24 & 26 & 31 & 20 & 18 & 19 & 22 & 17 \\
\hline
\end{tabular}




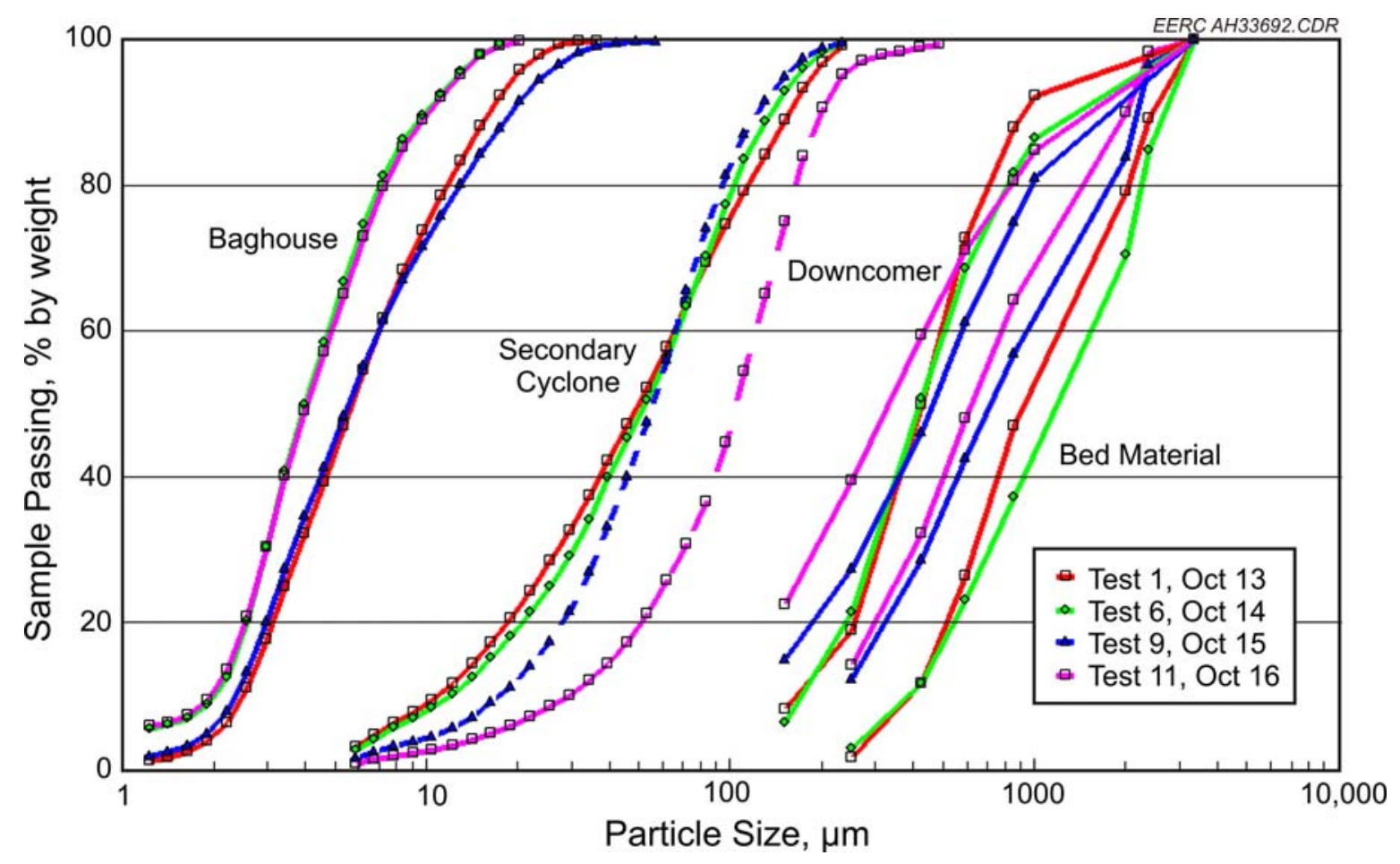

Figure 37. PSDs for each of the ash streams leaving the system.

The XRF analysis (XRFA) of the secondary cyclone ash for Test 11 showed twice as much $\mathrm{CaO}$ as Test 9 and four times as much as Tests 1 and 6 (which had no limestone feed). The XRFA data are shown in Table 34.

\section{Ash Balance}

The ash balance for each test period is presented in Table 35. Ash inputs into the system included calculated quantities of coal ash and limestone ash, based on their respective analyses and feed rates. The limestone-derived ash was further broken down into estimates of sorbent which was either calcined or had undergone sulfation. The output was composed of measured quantities of bottom ash (drained from the combustor bed), fly ash removed from the secondary cyclone, and fly ash removed from the baghouse.

The ratios of fly ash to bottom ash, as well as the percent closures, are included in Table 35 . The total closure ranging from $66 \%$ to $122 \%$ was reasonably good because of the high coal feed rate and large quantities of ash removed from the system. The bottom ash/total ash split was much lower than is typically seen for this unit, because of the almost continuous removal of solids from the secondary cyclone for most of the test periods. 
Table 34. XRFA of Ash Samples

\begin{tabular}{|c|c|c|c|c|c|c|c|c|}
\hline & $\begin{array}{c}\text { Test } 1 \\
\text { Bed }\end{array}$ & $\begin{array}{c}\text { Test } 6 \\
\text { Bed }\end{array}$ & $\begin{array}{c}\text { Test } 9 \\
\text { Bed }\end{array}$ & $\begin{array}{c}\text { Test } 11 \\
\text { Bed }\end{array}$ & Test 1 & Test 6 & Test 9 & Test 11 \\
\hline & Material & Material & Material & Material & Downcomer & Downcomer & Downcomer & Downcomer \\
\hline $\mathrm{SiO}_{2}$ & 68 & 60.9 & 56.8 & 52.2 & 62.6 & 59.8 & 56.5 & 55.3 \\
\hline $\mathrm{Al}_{2} \mathrm{O}_{3}$ & 21.9 & 27.5 & 25.6 & 22.6 & 25.8 & 28.1 & 24.8 & 25.9 \\
\hline $\mathrm{Fe}_{2} \mathrm{O}_{3}$ & 4.19 & 5.12 & 5.08 & 4.82 & 4.93 & 5.25 & 4.92 & 5.15 \\
\hline $\mathrm{TiO}_{2}$ & 0.58 & 0.72 & 0.7 & 0.65 & 0.64 & 0.67 & 0.65 & 0.66 \\
\hline $\mathrm{P}_{2} \mathrm{O}_{5}$ & 0.16 & 0.15 & 0.15 & 0.16 & 0.15 & 0.15 & 0.15 & 0.15 \\
\hline $\mathrm{CaO}$ & 1.8 & 1.9 & 7.1 & 14.8 & 2.3 & 2.3 & 7.4 & 7.7 \\
\hline $\mathrm{MgO}$ & 1.27 & 1.51 & 1.53 & 1.55 & 1.49 & 1.57 & 1.52 & 1.59 \\
\hline $\mathrm{Na}_{2} \mathrm{O}$ & 0.6 & 0.42 & 0.36 & 0.41 & 0.36 & 0.37 & 0.39 & 0.33 \\
\hline $\mathrm{K}_{2} \mathrm{O}$ & 1.52 & 1.81 & 1.68 & 1.58 & 1.7 & 1.79 & 1.64 & 1.67 \\
\hline \multirow[t]{3}{*}{$\mathrm{SO}_{3}$} & 0 & 0 & 1 & 1.28 & 0 & 0 & 1.95 & 1.54 \\
\hline & Test 1 & Test 6 & Test 9 & Test 11 & Test 1 & Test 6 & Test 9 & Test 11 \\
\hline & Cyclone & Cyclone & Cyclone & Cyclone & Baghouse & Baghouse & Baghouse & Baghouse \\
\hline$\overline{\mathrm{SiO}_{2}}$ & 57.9 & 58 & 54.7 & 51.7 & 55.2 & 53.9 & 52.4 & 49.8 \\
\hline $\mathrm{Al}_{2} \mathrm{O}_{3}$ & 28.3 & 28 & 27.1 & 24.3 & 26.5 & 26.6 & 25.3 & 23.8 \\
\hline $\mathrm{Fe}_{2} \mathrm{O}_{3}$ & 5.71 & 5.8 & 5.72 & 5.51 & 6.44 & 6.82 & 6.36 & 6.55 \\
\hline $\mathrm{TiO}_{2}$ & 0.67 & 0.67 & 0.65 & 0.65 & 0.76 & 0.8 & 0.72 & 0.72 \\
\hline $\mathrm{P}_{2} \mathrm{O}_{5}$ & 0.16 & 0.15 & 0.15 & 0.16 & 0.17 & 0.16 & 0.16 & 0.17 \\
\hline $\mathrm{CaO}$ & 3.3 & 3.3 & 6 & 11.1 & 5.6 & 6.2 & 8.6 & 12.3 \\
\hline $\mathrm{MgO}$ & 1.73 & 1.72 & 1.77 & 1.77 & 2.08 & 2.2 & 2.12 & 2.19 \\
\hline $\mathrm{Na}_{2} \mathrm{O}$ & 0.34 & 0.38 & 0.31 & 0.32 & 0.37 & 0.3 & 0.28 & 0.24 \\
\hline $\mathrm{K}_{2} \mathrm{O}$ & 1.75 & 1.74 & 1.68 & 1.55 & 1.59 & 1.47 & 1.39 & 1.21 \\
\hline $\mathrm{SO}_{3}$ & 0.27 & 0.25 & 1.89 & 2.96 & 1.32 & 1.49 & 2.59 & 3.03 \\
\hline
\end{tabular}

\section{Combustion Efficiency}

Combustion efficiency is based on the unburned carbon in each of the ash streams removed from the system. For these tests, combustion efficiency ranged from 98.2 to $99.2 \%$, as shown in Table 36. The highest percentage of unburned carbon was measured in the baghouse ash, at around 1\%; however, the baghouse ash made up a small percentage of the total ash removed. The unburned carbon in the bed material and secondary cyclone ash was about $0.4 \%$.

\section{Boiler Efficiency}

Boiler efficiencies for each test period were calculated for each test period using a modified version of ASME PTC 4.1. The modifications to the PTC 4.1 are those recommended in EPRI's “Atmospheric Fluidized-Bed Combustion Performance Guidelines." The basic modification made to the PTC 4.1 is a method to account for the heat losses and gains associated with calcinations and sulfation of the limestone. 
Table 35. Ash Balance

\begin{tabular}{|c|c|c|c|c|c|c|c|c|c|c|c|c|}
\hline Test No: & 1 & 2 & 3 & 4 & 5 & 6 & 7 & 8 & 9 & 10 & 11 & 12 \\
\hline \multicolumn{13}{|l|}{ Input, $\mathrm{kg} / \mathrm{hr}$} \\
\hline Ash & 203.8 & 194.4 & 183.6 & 186.6 & 190.5 & 181.8 & 172.7 & 172.5 & 169.0 & 175.5 & 182.8 & 198.0 \\
\hline \multicolumn{13}{|l|}{ Sorbent* } \\
\hline $\mathrm{CaO}$ & 0 & 0 & 0 & 0 & 0 & 0 & 8.9 & 9.9 & 2.1 & 12.7 & 21.0 & 16.6 \\
\hline $\mathrm{CaSO}_{4}$ & 0 & 0 & 0 & 0 & 0 & 0 & 3.9 & 38.0 & 2.2 & 3.0 & 4.2 & 4.1 \\
\hline Inerts & 0 & 0 & 0 & 0 & 0 & 0 & 4.1 & 4.5 & 1.4 & 5.4 & 8.6 & 7.3 \\
\hline Total Solids In & 203.8 & 194.4 & 183.6 & 186.6 & 190.5 & 181.8 & 189.6 & 224.9 & 174.6 & 196.6 & 216.6 & 226.0 \\
\hline \multicolumn{13}{|l|}{ Output, kg/hr } \\
\hline Bed Material Drained & 52.2 & 72.1 & 88.0 & 88.0 & 87.5 & 102.1 & 140.2 & 99.8 & 103.0 & 105.2 & 60.8 & 110.7 \\
\hline Cyclone Material & 86.2 & 66.7 & 53.1 & 87.5 & 80.7 & 61.2 & 77.1 & 67.1 & 38.1 & 59.9 & 72.1 & 62.1 \\
\hline Baghouse Ash & 13.6 & 18.1 & 14.1 & 14.1 & 14.1 & 14.1 & 14.1 & 14.1 & 14.1 & 10.9 & 10.9 & 10.9 \\
\hline Total Solids Out & 152.0 & 156.9 & 155.1 & 189.6 & 182.3 & 177.4 & 231.3 & 181.0 & 155.1 & 176.0 & 143.8 & 183.7 \\
\hline Closure, $\%$ & 74.5 & 80.7 & 84.5 & 101.6 & 95.7 & 97.5 & 122.0 & 94.9 & 89.0 & 89.5 & 66.3 & 81.3 \\
\hline Bottom Ash/Total Ash, \% & 34.3 & 46.0 & 56.7 & 46.4 & 48.0 & 57.5 & 60.6 & 55.1 & 66.4 & 59.8 & 42.3 & 60.2 \\
\hline
\end{tabular}

* The $\mathrm{CaO}$ and $\mathrm{CaSO}_{4}$ mass inputs are included to express sorbent equivalent mass inputs. 
Table 36. Combustion Efficiency

\begin{tabular}{|c|c|c|c|c|c|c|c|c|c|c|c|c|}
\hline Test No: & 1 & 2 & 3 & 4 & 5 & 6 & 7 & 8 & 9 & 10 & 11 & 12 \\
\hline \multicolumn{13}{|l|}{ Input } \\
\hline Fuel Feed Rate, $\mathrm{kg} / \mathrm{hr}$ & 401.9 & 383.3 & 362.0 & 367.9 & 375.6 & 379.2 & 360.2 & 359.7 & 351.1 & 364.7 & 352.4 & 449.5 \\
\hline Fuel Carbon, $\%$ & 15.3 & 15.3 & 15.3 & 15.3 & 15.3 & 14.8 & 14.8 & 14.8 & 16.4 & 16.4 & 15.8 & 12.1 \\
\hline Carbon Feed Rate, $\mathrm{kg} / \mathrm{hr}$ & 61.5 & 58.6 & 55.3 & 56.2 & 57.4 & 56.1 & 53.3 & 53.3 & 57.6 & 59.8 & 55.7 & 54.3 \\
\hline Total, kg/hr & 61.5 & 58.6 & 55.3 & 56.2 & 57.4 & 56.1 & 53.3 & 53.3 & 57.6 & 59.8 & 55.7 & 54.3 \\
\hline \multicolumn{13}{|l|}{ Output } \\
\hline Bottom Ash Discharge Rate, $\mathrm{kg} / \mathrm{hr}$ & 52.2 & 72.1 & 88.0 & 88.0 & 87.5 & 102.1 & 140.2 & 99.8 & 103.0 & 105.2 & 60.8 & 110.7 \\
\hline Unburned Carbon, \% & 0.3 & 0.3 & 0.3 & 0.3 & 0.3 & 0.4 & 0.4 & 0.4 & 0.4 & 0.4 & 0.8 & 0.8 \\
\hline Bottom Ash Carbon Discharge Rate, $\mathrm{kg} / \mathrm{hr}$ & 0.1 & 0.2 & 0.2 & 0.2 & 0.2 & 0.4 & 0.5 & 0.4 & 0.4 & 0.4 & 0.5 & 0.9 \\
\hline Cyclone Ash Discharge Rate, $\mathrm{kg} / \mathrm{hr}$ & 86.2 & 66.7 & 53.1 & 87.5 & 80.7 & 61.2 & 77.1 & 67.1 & 38.1 & 59.9 & 72.1 & 62.1 \\
\hline Unburned Carbon, \% & 0.4 & 0.4 & 0.4 & 0.4 & 0.4 & 0.4 & 0.4 & 0.4 & 0.4 & 0.4 & 0.9 & 0.9 \\
\hline Cyclone Ash Carbon Discharge Rate, $\mathrm{kg} / \mathrm{hr}$ & 0.3 & 0.2 & 0.2 & 0.3 & 0.3 & 0.2 & 0.3 & 0.3 & 0.1 & 0.2 & 0.6 & 0.5 \\
\hline Baghouse Discharge Rate, $\mathrm{kg} / \mathrm{hr}$ & 13.6 & 18.1 & 14.1 & 14.1 & 14.1 & 14.1 & 14.1 & 14.1 & 14.1 & 10.9 & 10.9 & 10.9 \\
\hline Unburned Carbon, $\%$ & 1.1 & 1.1 & 1.1 & 1.1 & 1.1 & 0.8 & 0.8 & 0.8 & 0.9 & 0.9 & 0.8 & 0.7 \\
\hline Baghouse Carbon Discharge Rate, $\mathrm{kg} / \mathrm{hr}$ & 0.1 & 0.2 & 0.1 & 0.1 & 0.1 & 0.1 & 0.1 & 0.1 & 0.1 & 0.1 & 0.1 & 0.1 \\
\hline Total, kg/hr & 0.6 & 0.6 & 0.6 & 0.7 & 0.7 & 0.8 & 1.0 & 0.8 & 0.7 & 0.5 & 0.6 & 0.9 \\
\hline Combustion Efficiency, \% & 99.0 & 98.92 & 98.95 & 98.95 & 98.81 & 98.66 & 98.18 & 98.56 & 98.84 & 99.15 & 98.98 & 98.27 \\
\hline
\end{tabular}


Table 37 summarizes the boiler efficiencies for the Bulgarian tests. In performing these calculations, boiler radiation and convective losses were assumed to be $0.4 \%$. Although these losses were much higher in our pilot plant, $0.4 \%$ was chosen as a number that would represent a full-scale system. An exit gas temperature of $149^{\circ} \mathrm{C}\left(300^{\circ} \mathrm{F}\right)$ was used in these calculations. Thegreatest boiler loss by far for this fuel was the moisture in the fuel, accounting for $11 \%$ to $16 \%$ of the total loss. Boiler efficiency increased for Tests 7 through 12, with limestone addition. Solids removal accounted for a large percentage of boiler efficiency loss ranging from $3.0 \%$ to $9.1 \%$. Overall boiler efficiency ranged from $58 \%$ to $73 \%$, with an average of $68 \%$. This is considerably lower than what is typically seen in the EERC CFB, even for lignite fuels. Drying the fuel and extracting as much heat as possible from ash removal systems would improve boiler efficiency at full scale. This fuel had the lowest boiler efficiencies measured when compared to operation of all other fuels tested on the EERC CFBC system at similar test conditions. Prior to this, the lowest boiler efficiency of $77.6 \%$ was measured for an Asian lignite; the highest boiler efficiency recorded on the EERC CFB was $89.5 \%$ for a low-sulfur subbituminous coal tested.

\section{Pressure and Temperature Profiles}

The pressure profiles - pressure distribution across the height of the furnace - are shown in Figure 38. The difference in total differential pressure (at 0 meters or feet above the distributor plate) varies as a function of drain rate of bed material from the combustor. The pressure profiles are fairly consistent, except for Test 5, which was run at a primary-to-secondary air split of 50:50. The lower velocity in the lower portion of the combustor resulted in more material fluidized at the bottom of the furnace.

The temperature profiles for each test are shown in Figure 39. The drop in temperature at about $2.1 \mathrm{~m}$ ( $7 \mathrm{feet}$ ) above the distributor plate shows where the cold coal enters the combustor. Variation in temperature is caused by the use of cooling coils in the external heat exchanger during some, but not all, tests, and by changes in the primary-to-secondary air ratio.

\section{Thermal Performance}

Table 38 is an overall energy balance for this testing. The conduction and radiation losses are forced here to obtain 100\% closure. Based upon surface temperature measurements obtained for this testing, it would be reasonable for conduction and radiation losses to average around $316 \mathrm{MJ} / \mathrm{hr}(300,000 \mathrm{Btu} / \mathrm{hr})$, compared to the values between 241 and 755 currently calculated by difference. In most instances, this rate would not vary by more than plus or minus $79 \mathrm{MJ} / \mathrm{hr}$ $(75,000 \mathrm{Btu} / \mathrm{hr})$ depending upon such factors as the combustor and external heat exchanger operating temperatures, ambient air temperature, and the amount of heat-transfer surface used in the combustor and EHX. The heat-transfer surface not only cools the bed material but has an effect on refractory temperature. For the first six tests and up through Test 7, when limestone

feed was started, at least two heat-transfer tubes in the EHX were used to control bed 
Table 37. Boiler Efficiency

\begin{tabular}{|c|c|c|c|c|c|c|c|c|c|c|c|c|}
\hline Test No: & 1 & 2 & 3 & 4 & 5 & 6 & 7 & 8 & 9 & 10 & 11 & 12 \\
\hline $\begin{array}{l}\text { Assumed Flue Gas Exit } \\
\text { Temp, }{ }^{\circ} \mathrm{C}\end{array}$ & 149 & 149 & 149 & 149 & 149 & 149 & 149 & 149 & 149 & 149 & 149 & 149 \\
\hline \multicolumn{13}{|l|}{ Losses, $\mathrm{kJ} / \mathrm{hr}$} \\
\hline Dry Gas & 151,567 & 144,099 & 136,770 & 141,732 & 140,892 & 135,621 & 135,245 & 133,210 & 146,601 & 143,679 & 131,680 & 131,680 \\
\hline $\begin{array}{l}\text { Water in Fuel } \\
\text { Combustion of Fuel }\end{array}$ & 282,907 & 269,815 & 254,808 & 258,958 & 264,387 & 285,859 & 271,497 & 271,155 & 253,955 & 263,713 & 208,933 & 498,382 \\
\hline Hydrogen & 21,249 & 20,265 & 19,139 & 19,450 & 19,858 & 19,735 & 18,743 & 18,720 & 20,141 & 20,915 & 18,572 & 18,091 \\
\hline Unburned Carbon & 19,846 & 20,832 & 19,049 & 23,230 & 22,366 & 24,739 & 31,711 & 25,175 & 21,929 & 16,662 & 18,535 & 30,754 \\
\hline $\begin{array}{l}\text { Sorbent Calcination } \\
\text { Radiation and }\end{array}$ & 0 & 0 & 0 & 0 & 0 & 0 & 40,729 & 44,609 & 11,556 & 54,114 & 88,058 & 71,099 \\
\hline Convection* & 7,037 & 6,711 & 6,337 & 6,441 & 6,576 & 7,024 & 6,671 & 6,662 & 7,737 & 8,035 & 7,745 & 7,541 \\
\hline Solids & 78,932 & 91,544 & 97,704 & 109,767 & 107,700 & 115,622 & 151,449 & 114,096 & 109,597 & 100,546 & 58,780 & 101,625 \\
\hline Sorbent Sulfation & 0 & 0 & 0 & 0 & 0 & 0 & $(16,811)$ & $(17,228)$ & $(9036)$ & $(12,945)$ & $(18,294)$ & $(16,823)$ \\
\hline Total & 561,536 & 553,267 & 533,807 & 559,578 & 561,778 & 588,598 & 639,235 & 596,400 & 583,580 & 594,719 & 514,009 & 842,349 \\
\hline \multicolumn{13}{|l|}{ Losses, $\%$} \\
\hline Dry Gas & 8.6 & 8.6 & 8.6 & 8.8 & 8.6 & 7.7 & 8.1 & 8.0 & 7.6 & 7.2 & 6.8 & 7.0 \\
\hline $\begin{array}{l}\text { Water in Fuel } \\
\text { Combustion of Fuel }\end{array}$ & 16.1 & 16.1 & 16.1 & 16.1 & 16.1 & 16.3 & 16.3 & 16.3 & 13.1 & 13.1 & 10.8 & 26.4 \\
\hline Hydrogen & 1.2 & 1.2 & 1.2 & 1.2 & 1.2 & 1.1 & 1.1 & 1.1 & 1.0 & 1.0 & 1.0 & 1.0 \\
\hline Unburned Carbon & 1.1 & 1.2 & 1.2 & 1.4 & 1.4 & 1.4 & 1.9 & 1.5 & 1.1 & 0.8 & 1.0 & 1.6 \\
\hline $\begin{array}{l}\text { Sorbent Calcination } \\
\text { Radiation and }\end{array}$ & 0.0 & 0.0 & 0.0 & 0.0 & 0.0 & 0.0 & 2.4 & 2.7 & 0.6 & 2.7 & 4.5 & 3.8 \\
\hline Convection* & 0.4 & 0.4 & 0.4 & 0.4 & 0.4 & 0.4 & 0.4 & 0.4 & 0.4 & 0.4 & 0.4 & 0.4 \\
\hline Solids & 4.5 & 5.5 & 6.2 & 6.8 & 6.6 & 6.6 & 9.1 & 6.8 & 5.7 & 5.0 & 3.0 & 5.4 \\
\hline Sorbent Sulfation & 0.0 & 0.0 & 0.0 & 0.0 & 0.0 & 0.0 & -1.0 & -1.0 & -0.5 & -0.6 & -0.9 & -0.9 \\
\hline Total & 31.9 & 33.0 & 33.7 & 34.8 & 34.2 & 33.5 & 38.3 & 35.8 & 29.1 & 29.6 & 26.5 & 44.7 \\
\hline Boiler Efficiency, \% & 68.1 & 67 & 66.3 & 65.2 & 65.8 & 66.5 & 61.7 & 64.2 & 70.9 & 70.4 & 73.5 & 55.3 \\
\hline
\end{tabular}

* Assumes $0.4 \%$ radiative and convective losses. 


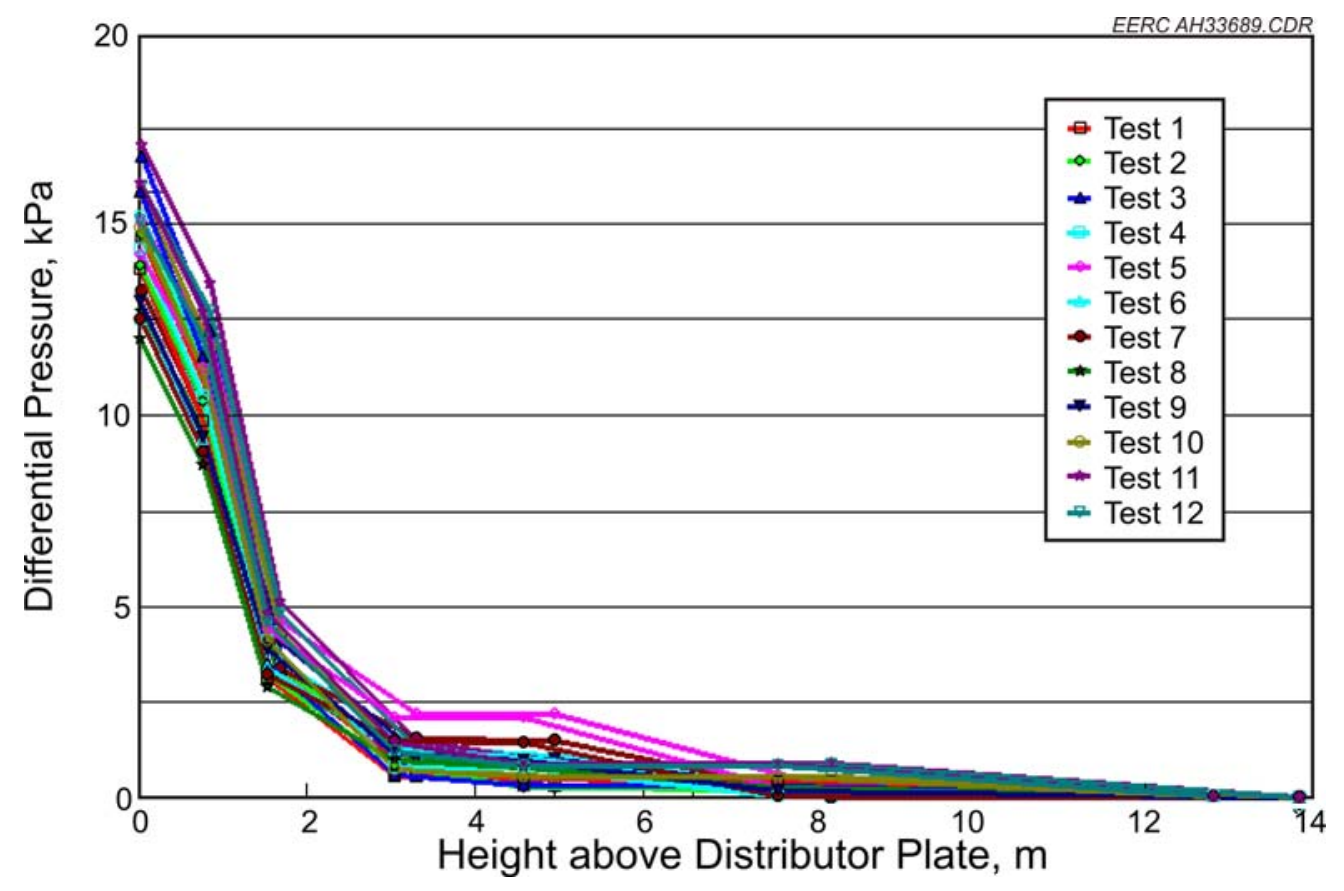

Figure 38. Pressure profiles - pressure distribution across the height of the furnace.

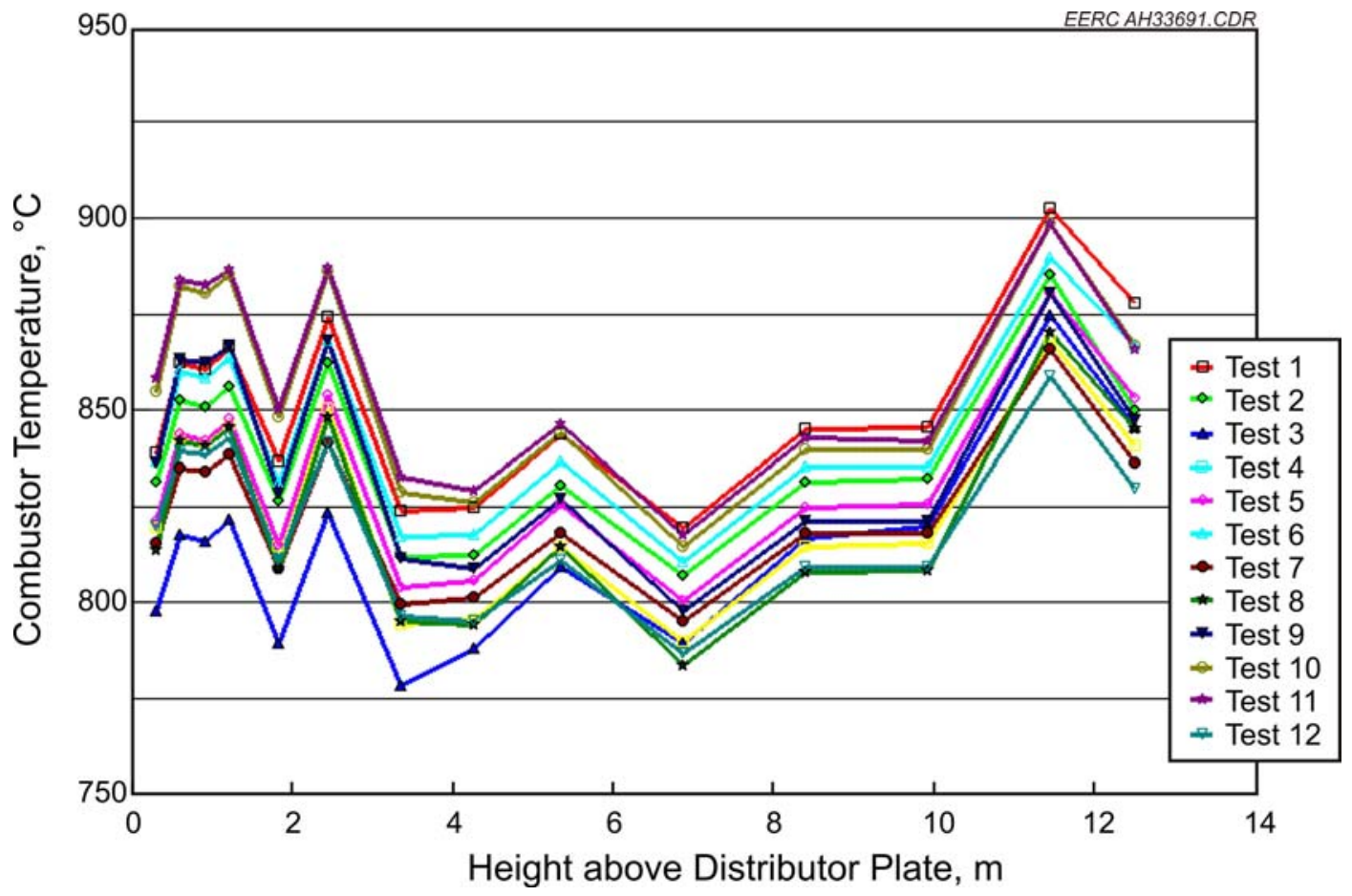

Figure 39. Temperature profiles for each test. 
Table 38. Energy Balance

\begin{tabular}{|c|c|c|c|c|c|c|c|c|c|c|c|c|}
\hline Test No: & 1 & 2 & 3 & 4 & 5 & 6 & 7 & 8 & 9 & 10 & 11 & 12 \\
\hline \multicolumn{13}{|l|}{ Input, $\mathrm{MJ} / \mathrm{hr}$} \\
\hline Fuel & 1782 & 1700 & 1605 & 1631 & 1666 & 1779 & 1690 & 1688 & 1955 & 2021 & 1953 & 1926 \\
\hline Primary Air & 53 & 52 & 46 & 62 & 38 & 48 & 47 & 44 & 45 & 44 & 44 & 47 \\
\hline Secondary Air & 36 & 38 & 37 & 27 & 43 & 34 & 35 & 30 & 30 & 30 & 30 & 34 \\
\hline EHX Air & 1 & 1 & 1 & 1 & 1 & 1 & 1 & 1 & 1 & 1 & 1 & 1 \\
\hline Sorbent Sulfation & 0 & 0 & 0 & 0 & 0 & 0 & 17 & 17 & 9 & 12 & 18 & 17 \\
\hline Total & 1873 & 1791 & 1689 & 1721 & 1748 & 1863 & 1790 & 1780 & 2041 & 2109 & 2047 & 2025 \\
\hline \multicolumn{13}{|l|}{ Input, \% } \\
\hline Fuel & 95.2 & 94.9 & 95.0 & 94.8 & 95.3 & 95.5 & 94.4 & 94.8 & 95.8 & 95.9 & 95.4 & 95.1 \\
\hline Primary Air & 2.8 & 2.9 & 2.7 & 3.6 & 2.2 & 2.6 & 2.6 & 2.5 & 2.2 & 2.1 & 2.2 & 2.3 \\
\hline Secol & 1.9 & 2.1 & 2.2 & 1.6 & 2.4 & 1.8 & 1.9 & 1.7 & 1.5 & 1.4 & 1.5 & 1.7 \\
\hline EHX & 0.1 & 0.1 & 0.1 & 0.1 & 0.1 & 0.1 & 0.1 & 0.1 & 0.0 & 0.0 & 0.0 & 0.1 \\
\hline Sorben & 0.0 & 0.0 & 0.0 & 0.0 & 0.0 & 0.0 & 0.9 & 1.0 & 0.4 & 0.6 & 0.9 & 0.8 \\
\hline Total & 100 & 100 & 100 & 100 & 100 & 100 & 100 & 100 & 100 & 100 & 100 & 100 \\
\hline \multicolumn{13}{|l|}{ Output, MJ/hr } \\
\hline Flue Gas (sensible) & 1320 & 1244 & 1139 & 1193 & 1195 & 1176 & 1137 & 1134 & 1285 & 1283 & 1126 & 1183 \\
\hline $\operatorname{Ash}($ & 79 & 92 & 98 & 110 & 108 & 116 & 151 & 114 & 110 & 101 & 59 & 102 \\
\hline $\operatorname{Ash}($ & 20 & 21 & 19 & 23 & 22 & 25 & 32 & 25 & 22 & 17 & 19 & 31 \\
\hline Comb & 0 & 0 & 0 & 0 & 0 & 0 & 0 & 0 & 0 & 0 & 0 & 0 \\
\hline EHX & 103 & 194 & 125 & 130 & 133 & 146 & 134 & 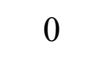 & 0 & 0 & 0 & 0 \\
\hline $\begin{array}{l}\text { Sorbent } \\
\text { Conduct }\end{array}$ & 0 & 0 & 0 & 0 & 0 & 0 & 41 & 45 & 12 & 54 & 88 & 71 \\
\hline Radiat & 352 & 241 & 30 & 265 & 289 & 401 & 29 & 46 & 612 & 659 & 755 & 638 \\
\hline Total & 1873 & 1791 & 1689 & 1721 & 1748 & 1863 & 1790 & 1780 & 2041 & 2114 & 2047 & 2025 \\
\hline \multicolumn{13}{|l|}{ Output, \% } \\
\hline Flue Gas (s & 70.5 & 69.5 & 67.4 & 69.3 & 68.4 & 63.1 & 63.5 & 63.7 & 63.0 & 60.7 & 55.0 & 58.4 \\
\hline Ash (sensibl & 4.2 & 5.1 & 5.8 & 6.4 & 6.2 & 6.2 & 8.5 & 6.4 & 5.4 & 4.8 & 2.9 & 5.0 \\
\hline Ash & 1.1 & 1.2 & 11 & & 1. & 1. & 18 & 1 & 1 & 0 . & 0.9 & 1.5 \\
\hline Comb & 0.0 & 0.0 & 0. & 0.0 & 0.0 & 0 . & 0. & 0.0 & 0 . & 0.0 & 0.0 & 0.0 \\
\hline EHX & 5.5 & 10.8 & 7.4 & 7.6 & 7.6 & 7.8 & 7.5 & 0.0 & 0.0 & 0.0 & 0.0 & 0.0 \\
\hline $\begin{array}{l}\text { Sorbent Calcination } \\
\text { Conduction and }\end{array}$ & 0.0 & 0.0 & 0.0 & 0.0 & 0.0 & 0.0 & 2.3 & 2.5 & 0.6 & 2.6 & 4.3 & 3.5 \\
\hline $\begin{array}{l}\text { Conduction } \\
\text { Radiation }^{1}\end{array}$ & 18.8 & 13.4 & 18.2 & 15.4 & 16.5 & 21.5 & 16.5 & 26.0 & 30.0 & 31.2 & 36.9 & 31.5 \\
\hline Total & 100 & 100 & 100 & 100 & 100 & 100 & 100 & 100 & 100 & 100 & 100 & 100 \\
\hline Closure, $\%$ & 100 & 100 & 100 & 100 & 100 & 100 & 100 & 100 & 100 & 100 & 100 & 100 \\
\hline
\end{tabular}

${ }^{1}$ Conduction and radiation losses were adjusted to force closure to $100 \%$.

temperature. For the test periods without any limestone feed, the conduction and radiation losses are fairly typical of those obtained for other tests. The heat losses through the refractory walls likely increased somewhat for the last five tests without any heat exchange, as the bed material temperature did increase in the EHX. The amount of heat input for the fuel for the last four test periods is somewhat suspect, as it did significantly increase because of HHVs being measured for the coal sampled for those test periods. It is suspected that the actual heating values for the coal for these test periods is actually lower than reported. 


\section{Environmental Performance}

Average flue gas emissions for each steady-state test period are presented in Table 39 and discussed in the following sections.

\section{$\mathrm{SO}_{2}$ Emissions}

Uncontrolled $\mathrm{SO}_{2}$ emissions, corrected to $6 \%$ oxygen, were about $3580 \mathrm{mg} / \mathrm{Nm}^{3}$ (1250 ppm). The inherent sulfur retention on ash ranged from $18.4 \%$ to $24.8 \%$. There did not appear to be a significant effect of secondary air location or primary/secondary air ratio on $\mathrm{SO}_{2}$ emissions.

With the addition of limestone at a calcium-to-sulfur ratio $(\mathrm{Ca} / \mathrm{S})$ of about $4, \mathrm{SO}_{2}$ emissions were reduced to about 300 , or $82 \%$ sulfur retention. The target level of sulfur retention was $90 \%$; variations in the sulfur content in the actual fuel analyses resulted in slightly lower sulfur capture values.

The addition of ammonia during Test 9 appeared to have an effect on $\mathrm{SO}_{2}$ emissions as well, reducing $\mathrm{SO}_{2}$ to $190 \mathrm{ppm}\left(\right.$ at $6 \% \mathrm{O}_{2}$ ), or $87 \%$ retention. Tests $10-12$ used a coal/limestone mixture that had been prepared for the gasifier test. During Test 10, the additional limestone feed was reduced to determine how much sulfur capture was possible with just the premixed limestone. It appears that the smaller particle size of the premixed limestone was less effective at sulfur capture than the limestone fed separately; Test 10 had only $60 \%$ sulfur capture, or $563 \mathrm{pm}$ (at $6 \% \mathrm{O}_{2}$ ) with a $\mathrm{Ca} / \mathrm{S}$ of 5.1 . The limestone feed rate was increased for Tests 11 and 12, achieving about $85 \%$ retention at a $\mathrm{Ca} / \mathrm{S}$ of 8.2 and 6.1 , respectively. The difference in $\mathrm{Ca} / \mathrm{S}$ required to achieve essentially the same level of sulfur capture in these tests is a function of temperature; Test 11 had an average temperature of $855^{\circ} \mathrm{C}\left(1571^{\circ} \mathrm{F}\right)$, while the water injection during Test 12 (simulating a higher-moisture fuel) dropped the average bed temperature to $819^{\circ} \mathrm{C}\left(1506^{\circ} \mathrm{F}\right)$. Previous tests on the EERC CFB have demonstrated that sulfur capture performance is dependent on temperature, and for lower rank coals, optimum sulfur capture generally occurs at less than $815^{\circ} \mathrm{C}\left(1500^{\circ} \mathrm{F}\right)$.

\section{$\mathrm{NO}_{x}$ Emissions}

$\mathrm{NO}_{\mathrm{x}}$ emissions (corrected to $6 \% \mathrm{O}_{2}$ ) under normal operating conditions ranged from 201 to $240 \mathrm{mg} / \mathrm{Nm}^{3}$ (98 to $143 \mathrm{ppm}$ ). There was a distinct increase in $\mathrm{NO}_{\mathrm{x}}$ emissions with increasing temperature, as shown in Figure 40. Two other factors influenced $\mathrm{NO}_{\mathrm{x}}$ emissions. Moving the secondary air injection port from Level 2 to Level 3 increased $\mathrm{NO}_{\mathrm{x}}$ from around $225 \mathrm{mg} / \mathrm{Nm}^{3}$ $(110 \mathrm{ppm})$ to $275 \mathrm{mg} / \mathrm{Nm}^{3}$ (134 ppm). Ammonia injection during Tests 2 and 9 reduced $\mathrm{NO}_{\mathrm{x}}$ emissions from about $225 \mathrm{mg} / \mathrm{Nm}^{3}$ (115 ppm) down to $148 \mathrm{mg} / \mathrm{Nm}^{3}$ (72 ppm) and $160 \mathrm{mg} / \mathrm{Nm}^{3}$ (78 ppm).

\section{CO Emissions}

$\mathrm{CO}$ emissions were less than $138 \mathrm{mg} / \mathrm{Nm}^{3}(110 \mathrm{ppm})$, corrected to $6 \% \mathrm{O}_{2}$ for all test periods, with the majority of tests having $\mathrm{CO}$ emissions around $55 \mathrm{mg} / \mathrm{Nm}^{3}$ (45 ppm). 
Table 39. Flue Gas Emissions

\begin{tabular}{|c|c|c|c|c|c|c|c|c|c|c|c|c|}
\hline Test No: & Test 1 & Test 2 & Test 3 & Test 4 & Test 5 & Test 6 & Test 7 & Test 8 & Test 9 & Test 10 & Test 11 & Test 12 \\
\hline \multicolumn{13}{|l|}{ Combustor Outlet } \\
\hline $\mathrm{O}_{2}, \%$ & 4.4 & 4.3 & 4.5 & 4.9 & 4.3 & 4.3 & 5.0 & 5.0 & 5.4 & 4.2 & 4.2 & 3.6 \\
\hline EA & 26.5 & 25.9 & 27.4 & 30.2 & 25.9 & 25.3 & 31.3 & 31.2 & 34.8 & 25.0 & 25.3 & 19.9 \\
\hline \multicolumn{13}{|l|}{ Baghouse Outlet } \\
\hline $\mathrm{O}_{2}, \%$ & 4.8 & 4.7 & 6.0 & 5.5 & 5.0 & 4.6 & 5.1 & 5.3 & 5.6 & 4.4 & 4.7 & 4.3 \\
\hline EA & 29.6 & 29.0 & 40.5 & 35.2 & 31.0 & 28.1 & 32.2 & 34.3 & 36.5 & 26.3 & 29.2 & 25.6 \\
\hline CO Content, ppm & 51 & 91 & 110 & 39 & 118 & 38 & 39 & 48 & 54 & 47 & 48 & 91 \\
\hline CO Content, ${ }^{1} \mathrm{ppm}$ & 47 & 84 & 110 & 38 & 110 & 35 & 37 & 46 & 53 & 42 & 44 & 82 \\
\hline $\mathrm{CO}$ Emission, $\mathrm{mg} / \mathrm{Nm}^{3}$ at $6 \% \mathrm{O}_{2}$ & 59.0 & 104.9 & 137.7 & 47.1 & 138.1 & 43.5 & 46.0 & 57.5 & 65.7 & 53.0 & 55.3 & 102.1 \\
\hline $\mathrm{CO}_{2}$ Content, $\%$ & 15.6 & 15.7 & 14.8 & 15.2 & 15.3 & 15.5 & 15.5 & 15.4 & 15.3 & 16.0 & 16.1 & 16.0 \\
\hline $\mathrm{CO}_{2}$ Content, ${ }^{1} \%$ & 14.4 & 14.4 & 14.8 & 14.6 & 14.3 & 14.2 & 14.6 & 14.8 & 14.9 & 14.5 & 14.8 & 14.4 \\
\hline $\mathrm{NO}_{\mathrm{x}}$ Content, ppm & 139 & 78 & 134 & 107 & 110 & 107 & 116 & 114 & 80 & 126 & 155 & 106 \\
\hline $\mathrm{NO}_{\mathrm{x}}$ Content, ${ }^{1} \mathrm{ppm}$ & 129 & 72 & 134 & 103 & 103 & 98 & 110 & 109 & 78 & 114 & 143 & 95 \\
\hline $\mathrm{NO}_{\mathrm{x}}$ Emission, $\mathrm{mg} / \mathrm{Nm}^{3}$ at $6 \% \mathrm{O}_{2}$ & 264.3 & 147.7 & 275.5 & 212.1 & 211.5 & 201.3 & 224.9 & 224.2 & 159.9 & 233.5 & 293.5 & 195.4 \\
\hline $\mathrm{SO}_{2}$ Content, ppm & 1355 & 1347 & 1251 & 1239 & 1346 & 1356 & 317 & 325 & 195 & 624 & 263 & 256 \\
\hline $\mathrm{SO}_{2}$ Content, ${ }^{1} \mathrm{ppm}$ & 1255 & 1242 & 1253 & 1196 & 1260 & 1243 & 299 & 311 & 190 & 563 & 242 & 230 \\
\hline $\mathrm{SO}_{2}$ Emission, $\mathrm{mg} / \mathrm{Nm}^{3}$ at $6 \% \mathrm{O}_{2}$ & 3585 & 3548 & 3579 & 3417 & 3601 & 3550 & 855 & 889 & 542 & 1609 & 693 & 657 \\
\hline $\mathrm{SO}_{2}$ Retention, ${ }^{2} \%$ & 19.3 & 20.2 & 21.8 & 24.1 & 18.4 & 24.8 & 82.4 & 81.9 & 87.0 & 63.5 & 84.6 & 84.9 \\
\hline $\mathrm{Ca} / \mathrm{S}$ ratio $\left(\mathrm{ls}^{3}\right.$ only $)$ & 0.0 & 0.0 & 0.0 & 0.0 & 0.0 & 0.0 & 3.6 & 4.0 & 1.1 & 4.9 & 8.2 & 6.8 \\
\hline $\mathrm{Ca} / \mathrm{S}$ ratio (total) & 1.8 & 1.8 & 1.8 & 1.8 & 1.8 & 1.8 & 5.4 & 5.8 & 2.9 & 7.9 & 11.2 & 9.9 \\
\hline Ca Utilization ( $1 \mathrm{~s}^{3}$ only) & NA & NA & NA & NA & NA & NA & 22.7 & 20.6 & 77.0 & 13.1 & 10.3 & 12.5 \\
\hline Ca Utilization (total) & NA & NA & NA & NA & NA & NA & 15.2 & 14.2 & 29.8 & 8.0 & 7.5 & 8.6 \\
\hline Alkali-to-Sulfur & 2.1 & 2.1 & 2.1 & 2.1 & 2.1 & 2.0 & 5.6 & 6.0 & 3.1 & 8.1 & 11.4 & 10.1 \\
\hline Alkali Utilization & NA & NA & NA & NA & NA & NA & 14.7 & 13.8 & 27.9 & 7.8 & 7.4 & 8.4 \\
\hline Avg. Comb. Temp., ${ }^{\circ} \mathrm{C}$ & 420 & 395 & 391 & 401 & 406 & 428 & 411 & 428 & 445 & 452 & 455 & 441 \\
\hline Moisture in FG, vol\% & 21.6 & 21.6 & 21.6 & 21.6 & 21.6 & 22.2 & 22.3 & 22.3 & 22.8 & 22.7 & 19.6 & 26.0 \\
\hline Fuel Carbon, \% & 15.3 & 15.3 & 15.3 & 15.3 & 15.3 & 14.8 & 14.8 & 14.8 & 16.4 & 15.8 & 15.8 & 12.1 \\
\hline Fuel Sulfur, \% & 0.4 & 0.4 & 0.4 & 0.4 & 0.4 & 0.5 & 0.5 & 0.5 & 0.4 & 0.5 & 0.5 & 0.3 \\
\hline
\end{tabular}

${ }^{1}$ Corrected to $6 \% \mathrm{O}_{2}$.

${ }^{2}$ Limestone. 


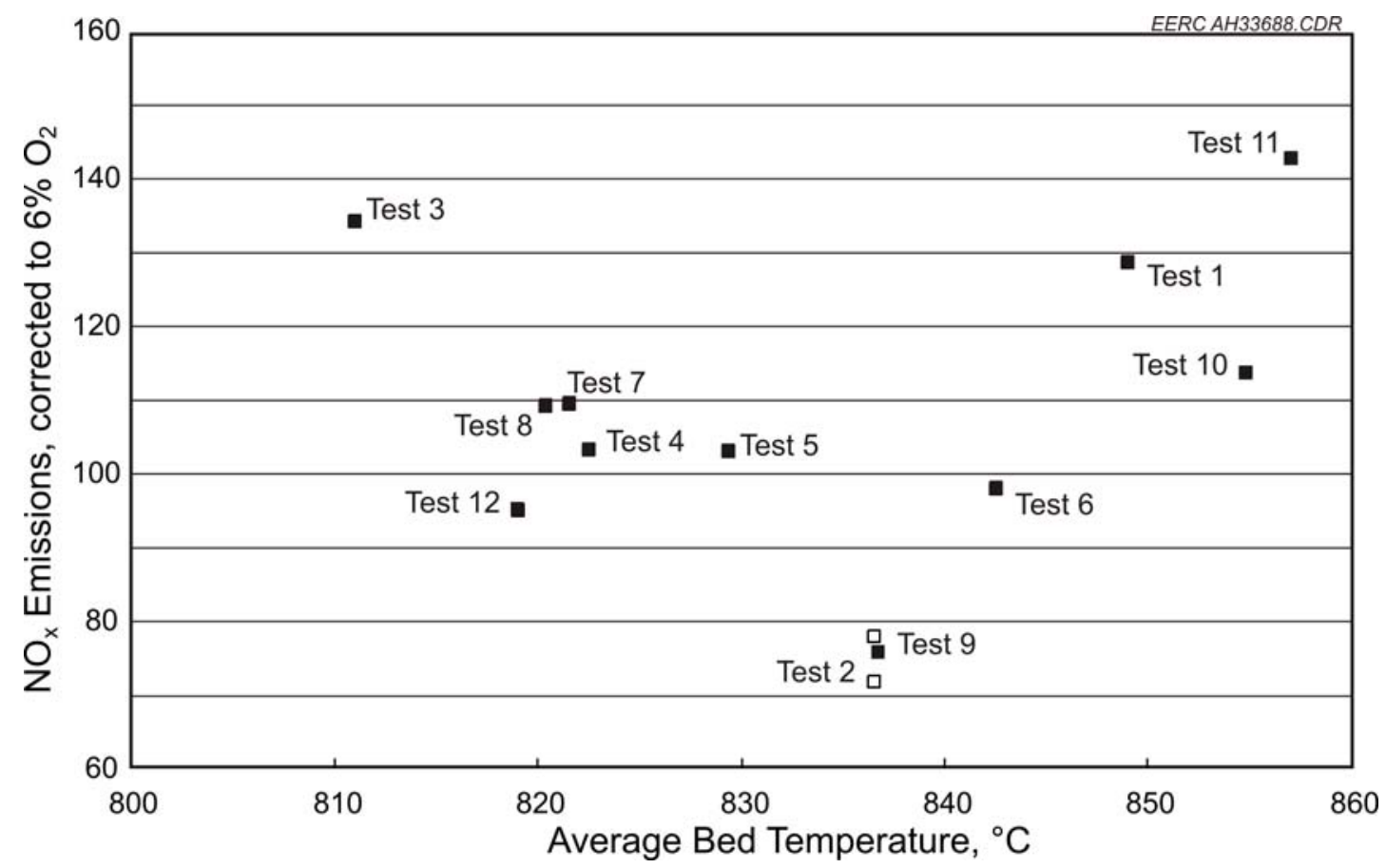

Figure $40 . \mathrm{NO}_{\mathrm{x}}$ emissions as a function of temperature.

\section{Spray Dryer Operation}

The spray dryer was in operation on October 14, during Tests 6 and 7. Approximately $2.83 \mathrm{~m}^{3} / \mathrm{min}(100 \mathrm{scfm})$ of flue gas flow $(18 \%$ of the total gas produced by the CFB) was to bediverted to the spray dryer. Test 6 did not include limestone feed to the combustor, so the $\mathrm{SO}_{2}$ emissions going to the spray dryer were very high, $3572 \mathrm{ng} / \mathrm{Nm}^{3}(1250 \mathrm{ppm})$, corrected to $6 \%$ $\mathrm{O}_{2}$. Test 7 had limestone feed, and the inlet $\mathrm{SO}_{2}$ concentration was $835 \mathrm{ng} / \mathrm{Nm}^{3}$ (292 ppm). The $\mathrm{SO}_{2}$ emissions exiting the spray dryer for Tests 6 and 7 were $34 \mathrm{ng} / \mathrm{Nm}^{3}$ (12 ppm) and $83 \mathrm{ng} / \mathrm{Nm}^{3}$ (29 ppm), respectively. It appears that as the sulfur dioxide level decreases, the driving force for the reaction with the lime slurry also decreases. The results of the spray dryer operation are shown in Table 40.

\section{Agglomeration and Fouling}

The agglomeration and fouling potential with this coal is very low. There was no evidence of any bed material agglomeration at all with this coal. This should allow operation with this coal at higher temperatures than what was achieved in this testing without agglomeration concerns. The ash-fouling probes were removed for inspection at the end of this test and showed only a light dusting for a deposit. It does not appear that any type of soot blowing would be required for operation with this coal. 
Table 40. Spray Dryer Data

\begin{tabular}{lcc}
\hline & Test 6 & Test 7 \\
\hline Flue Gas Flow, $\mathrm{m}^{3} / \mathrm{min}$ & 2.75 & 3.17 \\
$\mathrm{O}_{2}$ Content, $\%$ & 8.8 & 8.8 \\
Inlet $\mathrm{SO}_{2}$ Content, $\mathrm{ng} / \mathrm{Nm}^{3}$ & 2905 & 679 \\
Inlet $\mathrm{SO}_{2}$ Content, $\mathrm{ppm}$ & 1017 & 238 \\
Inlet $\mathrm{SO}_{2}$ Content, $\mathrm{ng} / \mathrm{Nm}^{3}$, corrected to $6 \% \mathrm{O}_{2}$ & 3572 & 835 \\
Inlet $\mathrm{SO}_{2}$ Content, $\mathrm{ppm}$, corrected to $6 \% \mathrm{O}_{2}$ & 1250 & 292 \\
Exit $\mathrm{SO}_{2}$ Content, $\mathrm{ng} / \mathrm{Nm}^{3}$ & 34 & 83 \\
Exit $\mathrm{SO}_{2}$ Content, ppm & 12 & 29 \\
Exit $\mathrm{SO}_{2}$ Content, $\mathrm{ng} / \mathrm{Nm}^{3}$, corrected to $6 \% \mathrm{O}_{2}$ & 42 & 102 \\
\hline Exit $\mathrm{SO}_{2}$ Content, $\mathrm{ppm}$, corrected to $6 \% \mathrm{O}_{2}$ & 15 & 36 \\
\hline
\end{tabular}

\section{Trace Element and Volatile Organic Compound Emissions}

During Tests 8 and 9, respectively, U.S. Environmental Protection Agency (EPA) Method 23 and 29 were performed to measure volatile organic compound (VOC) emissions and trace element emissions. Table 41 summarizes the results of the VOC sampling. Only three compounds were slightly above the detectable limits of this testing. They were fluoranthene $\left(0.182 \mu \mathrm{g} / \mathrm{m}^{3}\right)$, phenanthrene $\left(0.659 \mu \mathrm{g} / \mathrm{m}^{3}\right)$, and pyrene $\left(0.063 \mu \mathrm{g} / \mathrm{m}^{3}\right)$. Benzo(b)fluoranthene was detected at a low level, but the blank indicated that some contamination was present, so that this compound is not believed to be present in the gas stream.

Table 41. Summary of Results of VOC Testing

\begin{tabular}{ll}
\hline $\begin{array}{l}\text { Dust Loading, } \mu \mathrm{g} / \mathrm{m}^{3} \\
\text { Particulate }\end{array}$ & 15,103 \\
VOCs, $\mu \mathrm{g} / \mathrm{m}^{3}$ & \\
Acenaphthene & 0 \\
Acenaphthylene & 0 \\
Anthracene & 0 \\
Benzo(a)anthracene & 0 \\
Benzo(a)pyrene & 0 \\
Benzo(b)fluoranthene & 0.035 \\
Benzo(e)pyrene & 0 \\
Benzo(g,h,i)perylene & 0 \\
Benzo(k)fluoranthene & 0 \\
Chrysene & 0 \\
Dibenz(a,h)anthracene & 0 \\
Fluoranthene & 0.182 \\
Fluorene & 0 \\
Indeno(1,2,3-cd)pyrene & 0 \\
Perylene & 0 \\
\hline
\end{tabular}


Table 42 summarizes the results for the Method 29 trace element sampling. Table 43 shows trace element analysis of the coal, combustor bed material, downcomer, secondary cyclone, and baghouse ash for Test 9, from the same period of time for which the Method 29 sampling took place. The combustor bed material, downcomer material, and secondary cyclone material did not vary significantly from the coal ash. By this time in the run, because of the high

Table 42. Method 29 Results

\begin{tabular}{lc}
\hline $\begin{array}{l}\text { Dust Loading, } \mu \mathrm{g} / \mathrm{m}^{3} \\
\text { Particulate }\end{array}$ & 687.0 \\
Trace Elements, $\mu \mathrm{g} / \mathrm{m}^{3}$ & \\
$\mathrm{Sb}$ & 0.55 \\
$\mathrm{As}$ & 4.74 \\
$\mathrm{Ba}$ & 2.54 \\
$\mathrm{Be}$ & 0.77 \\
$\mathrm{Cd}$ & 0.52 \\
$\mathrm{Cr}$ & 5.2 \\
$\mathrm{~Pb}$ & 2.57 \\
$\mathrm{Mn}$ & 4.93 \\
$\mathrm{Ni}$ & 6.93 \\
$\mathrm{Se}$ & 3.22 \\
$\mathrm{U}$ & 0.08 \\
$\mathrm{Hg}$ & 43.56 \\
\hline
\end{tabular}

Table 43. Trace Elements Analysis of CFBC Samples

\begin{tabular}{|c|c|c|c|c|c|}
\hline & Coal & $\begin{array}{c}\text { Bed } \\
\text { Material }\end{array}$ & Downcomer & $\begin{array}{c}\text { Sec. } \\
\text { Cyclone }\end{array}$ & Baghouse \\
\hline \multicolumn{6}{|c|}{ Concentration, $\mu \mathrm{g} / \mathrm{g}$} \\
\hline Antimony & 1.4 & 1.6 & 1.8 & 2.0 & 3.7 \\
\hline Arsenic & 21.8 & 20.6 & 26.4 & 39.5 & 160 \\
\hline Barium & 316 & 352 & 400 & 434 & 484 \\
\hline Beryllium & 1.98 & 2.26 & 2.68 & 2.86 & 4.52 \\
\hline Cadmium & 0.33 & 0.39 & 0.62 & 0.82 & 0.70 \\
\hline Chlorine & 34 & 11 & 7 & 23 & 130 \\
\hline Chromium & 89.1 & 140 & 135 & 124 & 194 \\
\hline Fluorine & 598 & 246 & 243 & 231 & 1900 \\
\hline Lead & 17.8 & 22.4 & 26.4 & 26.1 & 20.8 \\
\hline Manganese & 120 & 260 & 210 & 290 & 350 \\
\hline Mercury & 0.179 & 0.0189 & 0.0314 & 0.0774 & 2.45 \\
\hline Nickel & 34.5 & 53.6 & 50.1 & 59.1 & 107 \\
\hline Selenium & 3.23 & 0.28 & 0.24 & 2.83 & 23.6 \\
\hline Silver & 0.27 & 0.23 & 0.26 & 0.28 & 0.31 \\
\hline Uranium & 2.84 & 2.90 & 3.37 & 4.21 & 8.77 \\
\hline
\end{tabular}


ash loading of this coal, most of the silica sand bed material had been turned over, resulting in a bed of mostly coal ash. There was enrichment in concentration of a few of the elements in the baghouse ash including arsenic, fluorine, mercury, selenium, and uranium. The amount of baghouse ash generated is insignificant compared to the combustor bed material drained. These data indicate that the baghouse was effective at controlling the trace metal emissions with only $\mathrm{Hg}, \mathrm{Cl}$, and $\mathrm{Fl}$ passing through the baghouse to any large extent.

\section{Conclusions for Task 4}

While it was demonstrated that this fuel does have sufficient heating value to sustain combustion, it will be challenging to economically extract sufficient energy for the generation of steam for electrical generation. The boiler efficiency for the dried coal was $73.5 \%$ for $85 \%$ sulfur capture (21.4\% moisture) compared to $55.3 \%$ for $85 \%$ sulfur capture ( $40 \%$ moisture), while the maximum obtained with the EERC CFBC system was $89.5 \%$ at $90 \%$ sulfur capture using a lowsulfur subbituminous coal. Improved boiler efficiencies for this coal will be possible operating a system more specifically designed for this coal and feeding at as low a moisture content as possible. For comparison purposes, the JEA CFBC reported a $91.6 \%$ boiler efficiency testing with an Illinois No. 6 coal. They also reported an average heat rate of $10,040 \mathrm{~kJ} / \mathrm{kWh}$ $(9516 \mathrm{Btu} / \mathrm{kWh})$ over a 2-year period.

To maximize energy input into the combustor per unit area, it will be beneficial to operate at as high a superficial flue gas velocity as possible, $5.5 \mathrm{~m} / \mathrm{sec}(18 \mathrm{ft} / \mathrm{sec})$ or higher. What maximum temperatures and velocities are considered economically possible would likely be vendor-specific. Cleaning and drying should be seriously considered for this coal. There were significant amounts of clay in the coal that might be potentially easier to separate out than with most lignite fuels. A reduction in the ash content could dramatically improve the heating content of this fuel. This coal should be dried as much as possible before being fed into the combustor. Consider the possibility of using any low-quality waste heat sources from the plant to dry the coal. Bed material agglomeration and any fouling potential do not appear to be a concern with this coal. $\mathrm{NO}_{\mathrm{x}}$ emissions can be at least partially reduced by SNCR for this coal. Higher $\mathrm{NO}_{\mathrm{x}}$ reduction could be possible than obtained with this testing by selecting a higher temperature region for ammonia injection if available. For very low sulfur emissions, it will be more economical to use a spray dryer system in combination with limestone fed into the bed. Heat exchangers to extract as much energy as possible from the hot bed material drained will additionally increase overall system efficiency.

\section{$\mathrm{CO}_{2}$ Capture Issues}

Since it is likely that the Bulgarian Lignite Power Project is likely to have to capture and sequester carbon dioxide in order for the project to proceed under European Union protocols, DOE has asked that a cost comparison for capturing carbon dioxide from both the IGCC and the CFBC power systems be added as a part of this study. 


\section{Background}

In systems designed for high $\mathrm{CO}_{2}$ capture, raw product gas leaving different types of gasifiers may variously be quenched, cooled in a heat recovery boiler, and filtered or scrubbed to remove particulates and tar/oil condensates before being sent to the shift converter where steam and $\mathrm{CO}$ react to form $\mathrm{H}_{2}$ and $\mathrm{CO}_{2}$. After shift conversion, the different syngas compositions produced from low-rank coals in the gasifier types listed in Table 2 would contain from 41 to $44 \mathrm{vol} \% \mathrm{CO}_{2}, 48$ to $58 \mathrm{vol} \% \mathrm{H}_{2}$, and 0 to $10 \mathrm{vol} \% \mathrm{CH}_{4}$ (dry basis, assuming nearly complete shift conversion). The methane in the syngas limits carbon capture since it cannot be removed by shift conversion and subsequent $\mathrm{CO}_{2}$ capture. In Table 2, the carbon in methane as a percent of total carbon decreases with increasing gasifier exit temperature: from $7 \%$ to $18 \%$ for fixed-bed gasifiers in the range of $260^{\circ}$ to $649^{\circ} \mathrm{C}\left(500^{\circ}-1200^{\circ} \mathrm{F}\right)$, to $5 \%-12 \%$ for fluidized-bed and transport gasifiers in the range of $816^{\circ}-1038^{\circ} \mathrm{C}\left(1500^{\circ}-1900^{\circ} \mathrm{F}\right)$, and to essentially $0 \%$ for entrained-flow gasifiers in the range of $1038^{\circ}-1649^{\circ} \mathrm{C}\left(1900^{\circ}-3000^{\circ} \mathrm{F}\right)$. Entrained-flow reactors, where applicable, offer the best opportunity for meeting DOE's goal of $90 \%$ carbon capture without separately reforming methane. As discussed previously, slurry-fed entrained-flow gasifiers have limited application for low-rank coals. The transport gasifier with its high circulation velocity has the second lowest methane yield, and it is particularly well suited to lowrank coals. Also, the transport gasifier should, in principle, have flexibility for minimizing $\mathrm{CH}_{4}$ by adjusting the residence time of the coal feed ahead of the gas-solids disengager. The methane produced in fix-bed or fluidized-bed gasifiers could also be converted to $\mathrm{CO}$ and $\mathrm{H}_{2}$ by reforming or partial oxidation and recycled back to the shift converter. A further consideration in choosing a gasifier design for optimum $\mathrm{CO}_{2}$ capture is that higher pressures allow physical absorption processes such as Selexol (discussed later) to recover $\mathrm{CO}_{2}$ more efficiently by regenerating the absorbing solution at an intermediate pressure (e.g., 3-4 atm, [50 psig]) rather than at lower pressure, thereby providing considerable savings in downstream compression cost and auxiliary power consumption (50).

Acid gas removal processes are used to remove $\mathrm{H}_{2} \mathrm{~S}, \mathrm{CO}_{2}$, and $\mathrm{COS}$ from syngas, where $\mathrm{H}_{2} \mathrm{~S} / \mathrm{CO}_{2}$ selectivity and the ability to remove $\mathrm{CO}_{2}$ and $\mathrm{COS}$ to low levels are important performance and cost factors. The discussion here will focus on $\mathrm{CO}_{2}$ capture technologies, which are categorized by type in Figure 41 (51). Physical absorption processes that capture $\mathrm{CO}_{2}$ in solvents at elevated pressure based on Henry's law and then flash off the $\mathrm{CO}_{2}$ at a lower pressure represent the state of the art for IGCC power plants. Chemical processes that chemically absorb $\mathrm{CO}_{2}$ in aqueous amines and recover $\mathrm{CO}_{2}$ by steam stripping impose a much higher energy penalty than physical absorption processes, but new combinations of amines are lowering this penalty, and this class of processes is currently considered the best available control technology for removing $\mathrm{CO}_{2}$ from flue gas at low pressures and concentrations. A number of other technologies, both commercial and developmental, can be considered for particular applications, including systems using mixtures of chemical and physical solvents, solid adsorbents, membranes, cryogenics, and other methods.

The Rectisol and Selexol processes are the leading physical absorption processes currently used in gasification systems. The Rectisol process removes both $\mathrm{CO}_{2}$ and $\mathrm{H}_{2} \mathrm{~S}$ in methanol at $-70^{\circ} \mathrm{C}\left(-94^{\circ} \mathrm{F}\right)$, requiring significant gas cooling and reheating. The two-stage version of the 


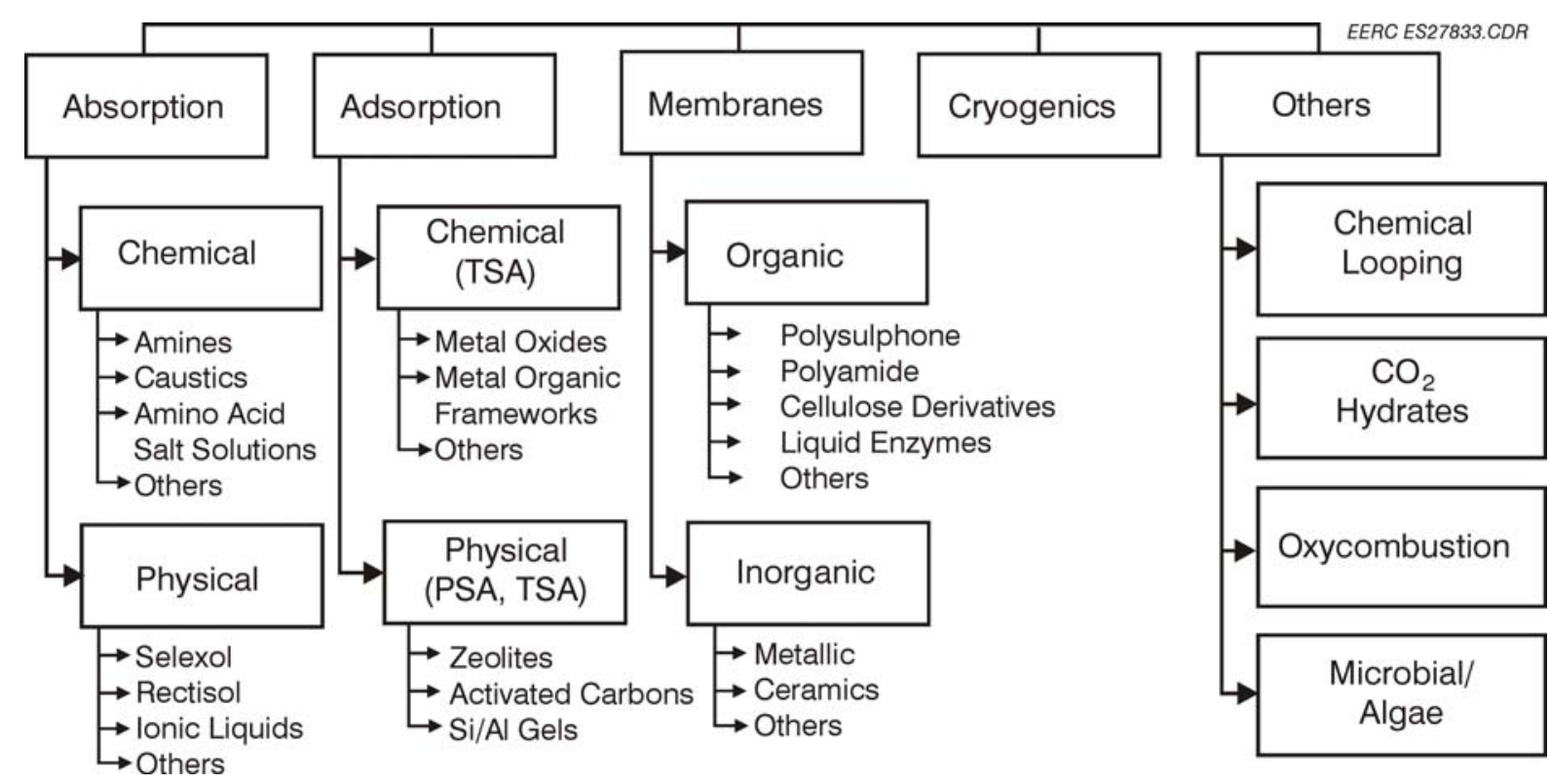

Figure 41. $\mathrm{CO}_{2}$ separation technologies (51).

Selexol ${ }^{\mathrm{TM}}$ process, which selectively removes $\mathrm{H}_{2} \mathrm{~S}$ and $\mathrm{CO}_{2}$ in two separate product streams by physical solution in dimethyl ether of polyethylene glycol at near-ambient temperatures, is the preferred process for gasification systems designed for $\mathrm{CO}_{2}$ capture $(52,53)$. In the first stage of the Selexol process, $\mathrm{H}_{2} \mathrm{~S}$ is preferentially removed from the syngas steam by solvent previously saturated with $\mathrm{CO}_{2}$, and an $\mathrm{H}_{2} \mathrm{~S}$-rich gas is stripped by indirect heating and being sent to a Claus sulfur recovery unit. The sweet syngas leaving the first stage is cooled and sent to the secondstage absorber where $97 \%$ of the remaining $\mathrm{CO}_{2}$ is removed. $\mathrm{CO}_{2}$ is recovered from the solvent by reducing pressure.

Amine absorption processes remove acid gases $\left(\mathrm{H}_{2} \mathrm{~S}\right.$ and $\left.\mathrm{CO}_{2}\right)$ by virtue of a loose chemical bond between the acid gas component and the amine. Three main types of amines are used commercially: primary amines, e.g., monoethanolamine (MEA); secondary amines, e.g., diethanolamine (DEA); and tertiary amines, e.g., methyl diethanol amine (MDEA). MEA forms the most stable bond with acid gases, followed in turn by DEA and MDEA. All of these amines have been used extensively by the natural gas industry, but MDEA has become more popular because it is the less corrosive and is less degraded by COS than either of the other amines. MDEA fits the requirements of the natural gas industry because it has a high selectivity for $\mathrm{H}_{2} \mathrm{~S}$. The reaction rate of MDEA with $\mathrm{CO}_{2}$ is about 2300 times slower than that of $\mathrm{CO}_{2}$ with MEA (53). MEA-based solvents are being used to recover $\mathrm{CO}_{2}$ from flue gas for use in the food industry and have been used to recover $\mathrm{CO}_{2}$ from natural gas for EOR (54). MEA processes can recover $85 \%$ to $95 \%$ of the $\mathrm{CO}_{2}$ in flue gas at purities over $99 \%$. The drawback of the MEA process for recovering $\mathrm{CO}_{2}$ is that it has a high auxiliary power requirement for gas and solvent circulation and a very high energy requirement for steam stripping: as high as $5.23 \mathrm{~kJ} /$ tones (4.5 million Btu/ton) of $\mathrm{CO}_{2}$ was recovered (54). A large number of amine formulations have been developed to meet different requirements using various mixtures of amines along with proprietary additives, focusing recently on formulations that optimize removal of $\mathrm{CO}_{2}$ from 
combustion flue gas at coal-fired power plants (53-55). The goal is to enhance the capacity and reactivity of the amine solution to absorb $\mathrm{CO}_{2}$ and to reduce the steam requirement for stripping the $\mathrm{CO}_{2}$ and regenerating the amine solution. Recent advances have included the commercial development of sterically hindered amines (amines that have a large hydrocarbon group attached to the nitrogen group). These amines are capable of high solvent loadings and can be tailored to enhance selectivity for specific acid gas components. Mitsubishi Heavy Industries has developed a process with selectivity for $\mathrm{CO}_{2}$, and the ExxonMobil FLEXSORB SE process has a high selectivity for $\mathrm{H}_{2} \mathrm{~S}(53,54)$. The primary application for enhanced amine processes in power systems will continue to be in the recovery of $\mathrm{CO}_{2}$ from flue gas, including new or retrofitted power plants firing coal. However, amine processes may become more cost-competitive for both pc-fired and IGCC plants if their energy requirements can be substantially reduced.

After most of the $\mathrm{CO}_{2}$ and $\mathrm{H}_{2} \mathrm{~S}$ are removed from syngas using absorption processes, the remaining $\mathrm{H}_{2}$-rich stream can be further purified using commercially available pressure swing adsorption (PSA) or related technologies. In the future, large quantities of high-purity hydrogen may be needed for fuel cell systems. Dry PSA systems sequentially raise and lower the pressure in a bed of activated carbon or other sorbent material to preferentially capture and release the impurities to be separated. Related technologies that cycle other system parameters to remove adsorbed impurities include temperature swing adsorption (TSA), electrical swing adsorption, and adsorption followed by liquid washing or chromatographic displacement with a carrier gas. A conceptually related experimental technique is based on forming $\mathrm{CO}_{2}$ hydrates at high pressure and below-ambient temperatures and recovering the $\mathrm{CO}_{2}$ by heating and lowering pressure. Another promising new technique involves metal-organic frameworks, also known as MOFs. MOFs are engineered nanoscale hybrid organic-inorganic structures which capture $\mathrm{CO}_{2}$ at ambient temperature and $31.6 \mathrm{~atm}$ (465 psi) (56). $\mathrm{CO}_{2}$ is released by reducing the pressure.

New technologies are being investigated for capturing $\mathrm{CO}_{2}$ at higher temperatures to improve the efficiency and reduce the cost of IGCC systems. The temperature selected for removing mercury, which is currently limited to about $260^{\circ} \mathrm{C}\left(500^{\circ} \mathrm{F}\right)$ using treated carbon sorbents, determines the maximum temperature of a hot-gas-cleaning system for removing particulate, $\mathrm{H}_{2} \mathrm{~S}$, and $\mathrm{CO}_{2}$. At $260^{\circ} \mathrm{C}\left(500^{\circ} \mathrm{F}\right), \mathrm{CO}_{2}$ can be captured using either a membrane or a regenerable sorbent. Sorbents that are being investigated for capture and thermal release of $\mathrm{CO}_{2}$ include lime, hydrotalcite, and lithium silicate. A number of gas separation membranes are being developed to selectively fractionate gases either to produce a high-purity product (usually in a number of stages) or to remove products (e.g., $\mathrm{CO}_{2}$ ) from membrane-enhanced reactors used for partial oxidation, reforming, or water-gas shift conversion. Membrane technologies are also being developed to separate oxygen from air as a lower-cost alternative to cryogenic distillation. A variety of membrane materials are being investigated for a range of temperatures and pressures, including polymers, ceramics, metal alloys, and nanoporous materials. The extensive work in this area (57-61) has been reviewed by others and will not be discussed here in any detail.

Cryogenic methods are commercially available for liquefying $\mathrm{CO}_{2}$ at temperatures below its $31^{\circ} \mathrm{C}\left(88^{\circ} \mathrm{F}\right)$ critical point. Different processes operate either at high pressures up to 75 atm (1100 psig) near the critical temperature or at lower pressures of 17-24 atm (250-350 psig) and lower temperatures down to $-12^{\circ} \mathrm{C}\left(10^{\circ} \mathrm{F}\right)(54)$. 
A number of advanced processes utilize different chemical looping methods to capture $\mathrm{CO}_{2}$ as a carbonate during gasification or combustion and subsequently recover $\mathrm{CO}_{2}$ by externally calcining and recycling the adsorbent (e.g., lime) back to the gasifier or combustor. These types of processes can also transfer heat and/or oxygen to the gasifier to produce mediumheating value gas without an air separation unit. The $\mathrm{CO}_{2}$ Acceptor process developed in the 1970s fits into this class of technologies. Companies that are currently pursuing these technologies include Alstom Power, the Zeca Corporation, and GE Global Research.

\section{IGCC Design and Cost for a Changing Marketplace Requiring Carbon Capture}

Because of the relatively low cost of energy from coal, there has been little past incentive for utilities to build IGCC plants for the sake of improving efficiency. Capital cost and reliability have been the most important considerations, whereas utilities still perceive IGCC as unproven technology. The two IGCC demonstration plants operating in the United States have been able to reach $70 \%$ to $80 \%$ availability over several years, and the gasifiers at the Eastman Chemicals plant have been onstream 97.97\% over a 3-year period (62). These plants use slurry-fed entrained-flow gasifiers (GE at Tampa and Eastman and E-Gas at Wabash), which are not preferred designs for low-rank coal as currently offered. Fluidized-bed gasifiers (HTW, U-Gas, and KRW), the slagging fixed-bed gasifier (BGL), and the transport gasifier (KBR) all represent potentially lower-cost options for low-rank coals that have not been adequately factored into the available cost studies. The still-scheduled 560-MWe IGCC demonstration using Mississippi lignite in the KBR transport gasifier and further tests on lignite at the Wilsonville PSDF are milestones that can be expected to favorably change cost comparisons for low-rank coals.

Table 44 presents a summary of IGCC performance and cost with and without carbon capture for bituminous and low-rank coals, along with a pc-fired ultrasupercritical (USC) steam plant burning bituminous coal. The values given represent costs in 2003 or earlier and do not reflect the cost volatility seen with the runup in cost resulting from the boom in energy construction stemming from high oil and gas prices and the current commodities de-escalation seen with the current worldwide recession. However, the percentage differences are substantially applicable today. Without carbon capture and sequestration (CCS), currently offered IGCC systems for bituminous coal have been generally evaluated to represent COEs higher than those for a pc-fired plant (EPRI, [50,63]) by an average of $11 \%$ in Table 44, comparing IGCC using three different entrained-flow gasifiers with a USC plant [50]). For low-rank coals, the margin between IGCC and pc firing has been characterized as somewhat less favorable than for bituminous coal $(18,50,63,64)$, although the adjusted COE for PRB coal in an E-Gas system shown in Table 44 is essentially the same as that for bituminous coal because of the lower price for minemouth PRB coal; it also matches the COE estimated for the KBR gasifier (15). The adjusted COE for lignite is about 20\% higher than that for either bituminous coal or PRB coal. These comparisons between low-rank and bituminous coals in IGCC systems do not address the question of the relative cost of IGCC versus pc firing for low-rank coals. In Table 44, the capital costs for low-rank coal in either E-Gas or KRB IGCC plants are $\$ 300$ to $\$ 500 / \mathrm{kW}$ higher than the capital cost of a USC plant for bituminous coal, which is consistent with a study by Great River Energy directly comparing IGCC and pc-fired plants for North Dakota lignite (17). The higher efficiency of IGCC compared to conventional pc firing cannot make up for this difference 
Table 44. Summary of IGCC Performance and Cost with and Without Carbon Capture

\begin{tabular}{|c|c|c|c|c|c|c|c|c|c|}
\hline \multirow[t]{3}{*}{ Technology } & \multicolumn{3}{|c|}{$\begin{array}{l}\text { Heat Rate, Heating } \\
\text { Value/kWh }\end{array}$} & \multicolumn{3}{|c|}{ Total Plant Cost, $\$ / \mathrm{kW}$} & \multicolumn{3}{|c|}{ COE, \$/MWh } \\
\hline & & & $\%$ & & & $\%$ & & & $\%$ \\
\hline & Without & With & Change & Without & With & Change & Without & With & Change \\
\hline \multicolumn{10}{|c|}{ Bituminous Coal, Best Available Technology, EPRI (17) } \\
\hline GE/Quench & 9,450 & 11,550 & 22 & 1,270 & 1,620 & 28 & 46 & 57 & 24 \\
\hline E-Gas & 8,550 & 11,050 & 29 & 1,300 & 1,850 & 42 & 46 & 62 & 35 \\
\hline Shell & 8,370 & 10,345 & 24 & 1,470 & 2,020 & 37 & 49 & 65 & 33 \\
\hline Avg. & 8,790 & 10,982 & 25 & 1,347 & 1,830 & 36 & 47 & 61 & 30 \\
\hline \multicolumn{7}{|c|}{ Low-Rank Coals, Best Available Technology, EPRI (17) } & \multicolumn{3}{|c|}{ Estimates Based on Ratios ${ }^{1}$} \\
\hline E-Gas PRB & 9,747 & & $\begin{array}{l}14 \text { vs. } \\
\text { bit. coal }\end{array}$ & 1,551 & & $\begin{array}{l}19 \text { vs. } \\
\text { bit. } \\
\text { Coal }\end{array}$ & 44 & 60 & 36 \\
\hline $\begin{array}{l}\text { E-Gas } \\
\text { Lignite }\end{array}$ & 10,431 & & $\begin{array}{l}22 \text { vs. } \\
\text { bit. coal }\end{array}$ & 1,738 & & $\begin{array}{l}34 \text { vs. } \\
\text { bit. coal }\end{array}$ & 53 & 69 & 30 \\
\hline \multicolumn{10}{|c|}{ Bituminous Coal, Best Available Technology, EPRI (50) } \\
\hline GE/Quench & 9,300 & 11,300 & 22 & 1,300 & 1,650 & 27 & 50 & 63 & 25 \\
\hline E-Gas & 8,630 & 11,000 & 27 & 1,250 & 1,800 & 44 & 47 & 66 & 40 \\
\hline Shell & 8,400 & 10,400 & 24 & 1,500 & 2,050 & 37 & 53 & 71 & 33 \\
\hline Avg. & 8,777 & 10,900 & 24 & 1,350 & 1,833 & 36 & 50 & 67 & 33 \\
\hline PC USC & 8,650 & 11,300 & 31 & 1,235 & 2,150 & 74 & 45 & 76 & 69 \\
\hline \multicolumn{10}{|c|}{$\begin{array}{l}\text { PRB Subbituminous Coal, KBR Transport Gasifier, Amine Capture of } \mathrm{CO}_{2} \text { from Syngas, Southern Co., } \\
2003 \text { dollars }(14,66)\end{array}$} \\
\hline KBR & 8,270 & 13,700 & 66 & 1,507 & 2,850 & 89 & 45 & 82 & 84 \\
\hline
\end{tabular}

in capital cost at current fuel prices. Also, pc-fired USC plants offer efficiencies comparable to current generation IGCC. We are, therefore, faced with the reality that there will be a limited market for currently offered IGCC systems for any coal, including low-rank coals, apart from the very real prospect of having to control carbon emissions.

When CCS is required, it is generally agreed that IGCC systems with state-of-the-art $\mathrm{CO}_{2}$ capture, currently represented by the Selexol process, will be significantly less costly than pcfired plants equipped with amine scrubbers $(18,50,63-65)$. In Table 44, the capital cost of IGCC for bituminous coal increases by an average of $36 \%$, heat rate by about $25 \%$, and COE by about $33 \%$ with the addition of $\mathrm{CO}_{2}$ capture using the best available technology. The comparable increases for a pc-fired USC plant equipped with amine scrubbing are a $74 \%$ increase in capital cost, $31 \%$ in heat rate, and $69 \%$ in COE. The 33\% increase in COE for IGCC and $69 \%$ for pcfired USC are in general agreement with other assessments published by DOE and EPRI. However, the total costs of CCS, including pipeline transport and sequestration, are estimated to be somewhat higher, at $40 \%-50 \%$ for IGCC and $80 \%-90 \%$ for pc-fired plants $(18,64)$. No detailed IGCC studies with and without $\mathrm{CO}_{2}$ capture have yet been completed for low-rank coals on a basis that fits a preferred technology with the properties of low-rank coals. Direct transfer of 
results of cost studies for bituminous coal to low-rank coals may not give an adequate picture since most of the cost studies have been based on entrained-flow gasifiers that experience reduced efficiency and capacity on high-moisture coals (GE and E-Gas) or have a high capital cost associated with large syngas coolers (Shell). The one study in Table 44 comparing the use of PRB coal in the KBR transport gasifier with and without $\mathrm{CO}_{2}$ capture was based on amine scrubbing of syngas, which is not state-of-the-art capture technology for IGCC and, predictably, showed a very large $84 \%$ increase in $\mathrm{COE}$ for $\mathrm{CO}_{2}$ capture $(14,66)$.

Building a carbon capture-ready IGCC plant that can later be used to implement capture and sequestration technologies requires that suitable design options be considered up-front (63). Conversion to carbon capture will result in some reduction in efficiency and generating capacity. Oversizing major systems may be needed, including coal preparation and handling, the air separation unit, and the gasification block. The design of the shift conversion block will depend on the future level of $\mathrm{CO}_{2}$ capture envisioned: a single-stage shift reactor is suitable for $60 \%$ capture, whereas a multistage system is needed to reach $90 \%$ capture. Thought should be given to later modifications of the acid gas-cleaning process; e.g., can a single-stage Selexol process for capturing $\mathrm{H}_{2} \mathrm{~S}$ be modified to a two-stage process producing separate streams of $\mathrm{H}_{2} \mathrm{~S}$ and $\mathrm{CO}_{2}$ ? A high design pressure in the gasifier facilitates $\mathrm{CO}_{2}$ capture in physical absorption processes such as Selexol and minimizes requirements for compressing the captured $\mathrm{CO}_{2}$. And, the gas turbine should be capable of operating on hydrogen-rich gas while supplying compressed air to the air separation unit across the range of ambient temperature.

Changes in design are being worked on to reduce cost, make gasification technologies more suitable for capturing $\mathrm{CO}_{2}$, and extend their application to a wider range of fuels, including low-rank coals (63). A significant cost savings could be realized from the commercial development of a membrane air separation unit $(67,68)$. As previously stated, $\mathrm{CO}_{2}$ capture is facilitated by designing for high pressure and a low methane yield. New methods for preparing high-solids-content slurry feed from high-moisture coals for GE and E-Gas gasifiers involve hydrothermal drying to densify the coal particles followed by separation of excess water. Quench cooling for entrained-flow gasifiers reduces the high cost of radiant syngas coolers and provides moisture needed for downstream shift conversion. ConocoPhillips has proposed an entrained slagging transport reactor (ESTR) as a modification of E-Gas technology to achieve higher efficiency, reduced oxygen consumption, and ability to use a wider range of coals at lower cost by feeding a higher proportion of slurry to a taller second stage and by operating at higher pressures up to $68 \mathrm{~atm}(1000 \mathrm{psig})(63,69)$. Both of these modifications will result in a higher methane yield. However, by suitably controlling slurry feed to the second stage, the ESTR design can limit methane production while still offer increased throughput for low-rank coals and savings from economy of scale from a larger high-pressure reactor. The intermediate methane yield from the KRB gasifier can be reduced by adjusting the coal feed location to allow less time for pyrolysis before the char is separated from the raw product gas and recycled back for partial combustion. For low-rank coals, all of these possible design modifications need to be performed with attention to the fouling, slagging, and corrosion properties of the ash.

The focus of this paper has been on gasification of low-rank coals with carbon capture and sequestration. This is technically possible today at a significant, but not unreasonable, added cost. It will be realized when a national policy is adopted to limit carbon emission to the 
atmosphere. There are many possible variations on this theme concerned with using hydrogen for fuel cells, petrochemicals, or fertilizer and using syngas for the synthesis of methanol, dimethylether, or Fischer-Tropsch liquid fuels. The immense coal resources of the world can and will be used to power electric generation and transportation with the control of carbon emissions. Gasification and IGCC technologies are key to making that possible.

\section{$\mathrm{CO}_{2}$ CAPTURE COSTS FOR BURNING BULGARIAN LIGNITE}

There were two potential platforms considered when performing an economic analysis for using Bulgarian lignite. The first scenario chosen was if the coal were to be fired in a CFB, thus creating flue gas that would be best treated by what is considered as a postcombustion carbon capture technology. Several postcombustion strategies are under development, but the current state of the art is considered to be a solvent scrubbing system. Within the solvent systems there are several solvents that are in various development stages. The most mature option is the use of MEA, which is currently considered to be the best available control technology because of its experience in the gastreating industry. Therefore, the technology chosen for evaluation for this scenario was the Fluor Daniels Econamine process. The second scenario involved the gasification of the fuel to produce a syngas which would be most easily separated with a precombustion capture technology. Only two primary technologies are currently offered commercially for this type of application: Selexol and Rectisol. Both technologies have been demonstrated at full scale and are operational. The technology of choice for this situation is Selexol, due to its more favorable costs and energy penalties as compared to the Rectisol system. The following sections describe the results of the analysis.

\section{Postcombustion $\mathrm{CO}_{2}$ Capture Results}

\section{Solvent Scrubbing Background}

Amine-based $\mathrm{CO}_{2}$ absorption has been studied in the past and identified as one of the most suitable means for removing $\mathrm{CO}_{2}$ from combustion-based power plants for the following reasons:

- The systems are effective for dilute $\mathrm{CO}_{2}$ streams, such as are typically found in North Dakota lignite-fired facilities.

- The technology is proven and commercially available.

- The units are operated at temperature and pressures similar to other pollution control devices currently employed at power plants.

- A current worldwide effort is being undertaken to improve amine systems because of their potential role for wide-scale $\mathrm{CO}_{2}$ capture; therefore, future benefits from technology advances are anticipated. 
Amine-based absorption/stripping has been around for several decades as a commercial technology for $\mathrm{CO}_{2}$ removal from natural gas and hydrogen. The amine process was first patented by R.R. Bottom in 1930 for acidic gas treatment. Throughout the years, the amine-based gas treatment process has remained relatively unchanged. The concept of removing or capturing $\mathrm{CO}_{2}$ from flue gas streams started back in the $1970 \mathrm{~s}$ as a possible economical source of $\mathrm{CO}_{2}$, mainly for EOR operations (70). Today, about $80 \%$ of $\mathrm{CO}_{2}$ production is used for EOR applications, most of which is obtained from natural $\mathrm{CO}_{2}$ domes (71). $\mathrm{CO}_{2}$ is also produced for several other industrial applications, including carbonation of brine, dry ice production, urea production, and in beverages.

Several commercial $\mathrm{CO}_{2}$ plants were constructed in the late 1970s and early 1980s in the United States $(72,73)$. Although some of these plants are still in operation today, all of them are much smaller than a typical power plant in terms of tonnage of $\mathrm{CO}_{2}$ handled or produced. Once the $\mathrm{CO}_{2}$ is captured, it has to be securely stored (sequestered) to prevent it from entering the atmosphere, unless an alternate use is identified for the captured $\mathrm{CO}_{2}$. Very little experience exists with the sequestration of $\mathrm{CO}_{2}$, other than in EOR applications. The first commercial $\mathrm{CO}_{2}$ sequestration technology started in 1996 in response to a Norwegian carbon tax. The facility, Statoil, has been storing approximately one million tonnes of $\mathrm{CO}_{2}$ per year from the Sleipner West gas field into a sandstone aquifer 1000 meters beneath the North Sea $(74,75)$. Statoil's operations have been monitored closely by the research community in order to enhance the understanding of geological sequestration.

Commercial providers of MEA technology include ABB-Lummus Global and Fluor Daniel Econamine $\mathrm{FG}^{\mathrm{SM}}$. ABB-Lummus uses a 15\%-20\% MEA solution for its commercial facilities. Fluor Daniel uses a 30\% MEA solution and incorporates additives to control corrosion and oxidative and thermal degradation. It has more than 20 commercial plants ranging in size from 4.5 to 363 tonnes $\mathrm{CO}_{2} /$ day. Facilities use MEA-based solvents to capture $\mathrm{CO}_{2}$ from coal-, fuel oil-, and natural gas-derived flue gas streams for use in the food industry and, in the past, for enhanced oil recovery (EOR). These plants have had capacities in the range of 90.9 to 1000 tonnes/day, which is significantly less than the 5000 tonnes/day produced by a 500-MW coal-fired plant.

A diagram of a system employing an MEA process for $\mathrm{CO}_{2}$ capture is presented in Figure 42. In gas turbine combined-cycle systems, as shown in Figure 5, flue gas from the heat recovery steam generator (HRSG) is cooled to about $43.3^{\circ} \mathrm{C}$ with circulating cooling water. Additional cooling is not required in systems employing flue gas desulfurization (FGD). The flue gas is partially compressed to $1.2 \mathrm{~atm}$ by a centrifugal blower to overcome the gas-path pressure drop. The flue gas enters the absorber base, flowing upward countercurrent to the lean MEA solution. $\mathrm{CO}_{2}$ is removed from the flue gas in the packed-bed absorber column through direct contact with MEA. The $\mathrm{CO}_{2}$-depleted flue gas is exhausted to the atmosphere. The $\mathrm{CO}_{2}$-rich solution is heated in a heat exchanger and sent to the stripper unit where low-pressure steam from the steam turbine crossover provides the thermal energy to liberate the $\mathrm{CO}_{2}$. The $\mathrm{CO}_{2}$ vapor is condensed, cooled, and sent to a multistaged compressor where the $\mathrm{CO}_{2}$ is compressed to a pressure of over $81.6 \mathrm{~atm}$. The $\mathrm{CO}_{2}$-laden stream is dehydrated using glycol or molecular sieve processes. After drying, the $\mathrm{CO}_{2}$ is ready for transport and sequestration. 


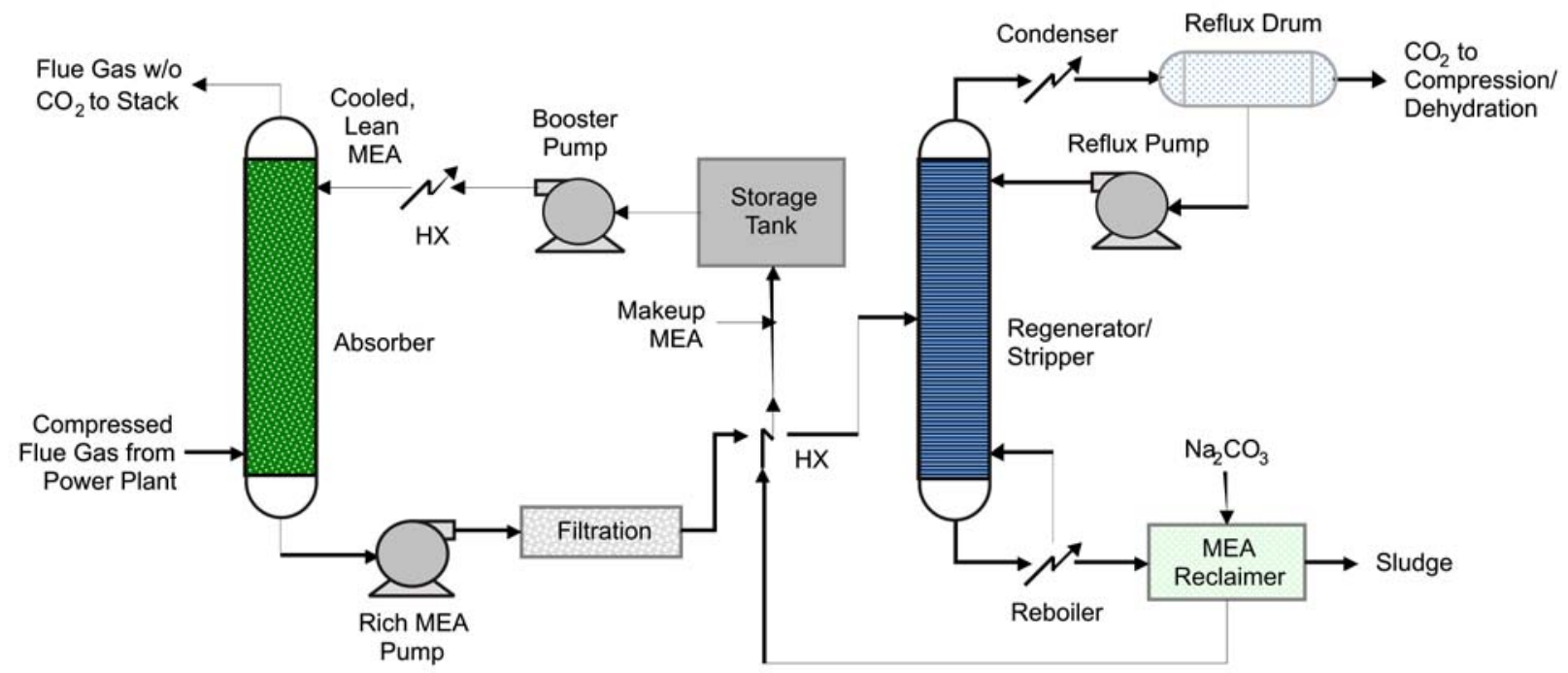

Figure 42. Schematic of an MEA absorption system for capturing $\mathrm{CO}_{2}$ from flue gas.

The major advantages of MEA amines are the high capacity for $\mathrm{CO}_{2}$ and high rate of absorption; limitations for MEA include high heat of absorption and corrosion issues. The MEA process can achieve recoveries of $85 \%$ to $95 \%$, with $\mathrm{CO}_{2}$ purities over 99 vol\%. However, the MEA process also requires a significant amount of power to operate pumps and blowers for gas and solvent circulation. The largest parasitic load to the power cycle is associated with the steam used for solvent regeneration. Energy consumption as steam can be as high as 4187 to $5234 \mathrm{~J} /$ tonne $\mathrm{CO}_{2}$ recovered. Additional issues with the process are equipment corrosion, solvent degradation caused by the presence of dissolved $\mathrm{O}_{2}$ and other impurities or reaction with $\mathrm{SO}_{2}$, $\mathrm{SO}_{3}$, and $\mathrm{NO}_{\mathrm{x}}$ to produce nonregenerable, heat-stable salts. This requires $\mathrm{SO}_{2}$ levels to be below $10 \mathrm{ppm}, \mathrm{NO}_{2}$ levels to be below $20 \mathrm{ppm}$, and $\mathrm{NO}_{\mathrm{x}}$ to be below $400 \mathrm{ppm}$. Solvent degradation and loss also occur during regeneration. Improving MEA solvent performance is conducted by blending amines or promoting with potassium carbonate.

\section{Other Commercial Solvents}

Additional commercial and developing technologies are available to capture carbon utilizing chemical sorbents other than MEA:

1. Sterically hindered KS family of amines (Mitsubishi Heavy Industries)

2. Activated Hot Potassium Carbonate (Eickmeyer \& Associates [Catacarb ${ }^{\circledR}$ ], UOP $\left[\right.$ Benfield $\left.{ }^{\mathrm{TM}}\right]$ ) 


\section{Sterically Hindered KS Family of Amines}

Recent advances in chemical solvents have included the commercial introduction of KS-2 and KS-3 amines. Their molecular structure is tailored to enhance reactivity toward a specific gas component, in this instance $\mathrm{CO}_{2}$. The process requires $1 \mathrm{~mol}$ of hindered amine to react with $1 \mathrm{~mol} \mathrm{CO}_{2}$ (compared with 2 mol MEA). Studies have shown $90 \%$ less solvent degradation, $20 \%$ lower regeneration energy, $15 \%$ less power, $40 \%$ lower solvent recirculation rates due to higher net absorption capacity, lower regeneration temperature, less corrosion in the presence of dissolved oxygen, and lower chemical additive cost. Two commercial plants are available, capturing $\sim 191$ and 300 tonnes $\mathrm{CO}_{2}$ daily. Although the solvent cost is higher than that of MEA, advantages over MEA include improved capacity is through changes in molecular structure or configuration, more resistance to degradation, lower energy requirements for regeneration, higher net $\mathrm{CO}_{2}$ loading, less corrosion in the presence of dissolved $\mathrm{O}_{2}$, and smaller quantities of chemical additives (such as corrosion inhibitors) are needed.

\section{Activated Hot Potassium Carbonate (AHPC)}

This commercially available process features an aqueous solution of $\mathrm{K}_{2} \mathrm{CO}_{3}$ and an activator that chemically absorbs $\mathrm{CO}_{2}$ in an absorber at a relatively high temperature. Solvent regeneration is accomplished through pressure reduction and heating. Less detailed information is available about the Catacarb ${ }^{\circledR}$ process, but papers discussing the Benfield ${ }^{\mathrm{TM}}$ process indicate that recent process improvements include a new activator that reduces $\mathrm{CO}_{2}$ slip by half and a $10 \%$ increase in capacity (which equals a $10 \%$ reduction in regeneration heat and solution pumping requirements), high-efficiency random packing in the towers, and a reduction in regeneration steam requirements over designs from 10 years ago. However, to achieve a high $\mathrm{CO}_{2}$ removal efficiency in the Benfield ${ }^{\mathrm{TM}}$ process, the solvent stream must be split before entering the absorber and a portion cooled to increase $\mathrm{CO}_{2}$ solubility. The $\mathrm{CO}_{2}$ partial pressure should be at least $200-350 \mathrm{kPa}(29-51 \mathrm{psi})$ for both processes.

\section{Solvents under Development}

Other chemical absorption systems are being developed to improve the cost-effectiveness of $\mathrm{CO}_{2}$ capture through higher $\mathrm{CO}_{2}$ absorption capacity, faster $\mathrm{CO}_{2}$ absorption rates (to achieve lower solvent circulation rates and smaller equipment), reduced solvent degradation, less corrosiveness, and lower regeneration energy requirements. Development efforts for these technologies range from bench- to pilot-scale:

1. $\mathrm{ECO}_{2}{ }^{\mathrm{TM}}$ Process (Powerspan, National Energy Technology Laboratory [NETL])

2. Chilled Ammonia Process (Nexant)

3. Postcombustion capture process (E.ON, Alstom Power)

4. Cansolv $\mathrm{CO}_{2}$ Capture Process (Cansolv)

5. Potassium carbonate/piperazine complex (University of Texas at Austin)

6. Absorption using PSR solvents (University of Regina, Saskatchewan)

7. Amino acid salt solutions (University of Twente [Netherlands], TNO Environment, Energy, and Process Innovation; Norwegian University of Science and Technology)

8. Vortex contactor for amine scrubbing (INEEL, Pacific Gas \& Electric Company) 
9. Regenerative carbonate process (Alstom Power)

10. Enzymatic sorbents (Carbozyme, Inc., CO2Source)

\section{$\mathrm{ECO}_{2}{ }^{\mathrm{TM}}$ (Aqua [Aqueous] Ammonia) Process}

This pilot-scale process uses ammonia scrubbing for $\mathrm{CO}_{2}$ capture, Figure 43. A higher $\mathrm{CO}_{2}$ loading ( $\mathrm{kg} \mathrm{CO}_{2}$ absorbed per $\mathrm{kg}$ sorbent) is possible compared to using MEA. The process utilizes absorption and regeneration equipment similar to that of MEA absorption; however, the ammonia method requires less energy to release $\mathrm{CO}_{2}$ and regenerate the sorbent and shows minimal sorbent degradation by other flue gas constituents. The $\mathrm{ECO}_{2}$ process is integrated after the ECO process (Figure 44), which provides $\mathrm{NO}_{\mathrm{x}}, \mathrm{SO}_{\mathrm{x}}$, and particulate control. Ammonia and water react with $\mathrm{CO}_{2}$ to form ammonium carbonate and ammonium bicarbonate. When heated, the ammonium carbonate dissociates, releasing $\mathrm{CO}_{2}$. The ammonia solution is recycled following regeneration. Bench-scale testing showed $90 \% \mathrm{CO}_{2}$ removal with ammonium carbonate solutions. Parametric testing will define absorption rates, ammonia vapor management, and absorptive capacity. Pilot testing is planned for FirstEnergy's R.E. Burger Plant on a 1-MW slipstream (18.2 tonne/day), scheduled to begin in 2008. The technology was also selected by Basin Electric for a 125-MW demonstration. Benefits over MEA include a lower heat of regeneration, a higher net $\mathrm{CO}_{2}$ transfer capacity, no stripping steam required, and a multipollutant control (also reacts with $\mathrm{SO}_{2}$ and $\mathrm{NO}_{x}$ [to form ammonium sulfate and ammonium nitrate, respectively], claimed to remove $\mathrm{HCl}$ and $\mathrm{HF}$ as well). Disadvantages include the ammonium bicarbonate which decomposes at $60^{\circ} \mathrm{C}\left(140^{\circ} \mathrm{F}\right)$, so temperatures in the absorber must be well below this level to prevent ammonia entering the flue gas exhaust; ammonia is more volatile than MEA, requiring measures for capture and recycle in the stripping column; and

$$
\begin{aligned}
& \text { - } 2 \mathrm{NH}_{3}+\mathrm{CO}_{2} \longrightarrow \mathrm{NH}_{2} \mathrm{COONH}_{4} \\
& \text { - } \mathrm{NH}_{2} \mathrm{COONH}_{4}+\mathrm{CO}_{2}+2 \mathrm{H}_{2} \mathrm{O} \longrightarrow 2 \mathrm{NH}_{4} \mathrm{HCO}_{3} \\
& \text { - } \mathrm{NH}_{2} \mathrm{COONH}_{4}+\mathrm{H}_{2} \mathrm{O} \longrightarrow \mathrm{NH}_{4} \mathrm{HCO}_{3}+\mathrm{NH}_{3} \\
& \text { - } \mathrm{NH}_{3}+\mathrm{H}_{2} \mathrm{O}+\mathrm{CO}_{2} \longrightarrow \mathrm{NH}_{4} \mathrm{HCO}_{3} \\
& \text { - } 2 \mathrm{NH}_{3}+\mathrm{H}_{2} \mathrm{O}+\mathrm{CO}_{2} \longrightarrow\left(\mathrm{NH}_{4}\right)_{2} \mathrm{CO}_{3} \\
& \text { - }\left(\mathrm{NH}_{4}\right)_{2} \mathrm{CO}_{3}+\mathrm{CO}_{2}+\mathrm{H}_{2} \mathrm{O} \longrightarrow 2 \mathrm{NH}_{4} \mathrm{HCO}_{3} \\
& \text { - } 2 \mathrm{NH}_{4} \mathrm{HCO}_{3}(\mathrm{aq}) \longrightarrow\left(\mathrm{NH}_{4}\right)_{2} \mathrm{CO}_{3}(\mathrm{aq})+\mathrm{CO}_{2}(\mathrm{~g})+\mathrm{H}_{2} \mathrm{O} \\
& \text { - } \mathrm{NH}_{4} \mathrm{HCO}_{3}(\mathrm{aq}) \longrightarrow \mathrm{NH}_{3}(\mathrm{aq})+\mathrm{CO}_{2}(\mathrm{~g})+\mathrm{H}_{2} \mathrm{O} \\
& \text { - }\left(\mathrm{NH}_{4}\right)_{2} \mathrm{CO}_{3}(\mathrm{aq}) \longrightarrow 2 \mathrm{NH}_{3}(\mathrm{aq})+\mathrm{CO}_{2}(\mathrm{~g})+\mathrm{H}_{2} \mathrm{O}
\end{aligned}
$$

Figure 43. Ammonia process chemistry during absorption (top) and regeneration (bottom). 


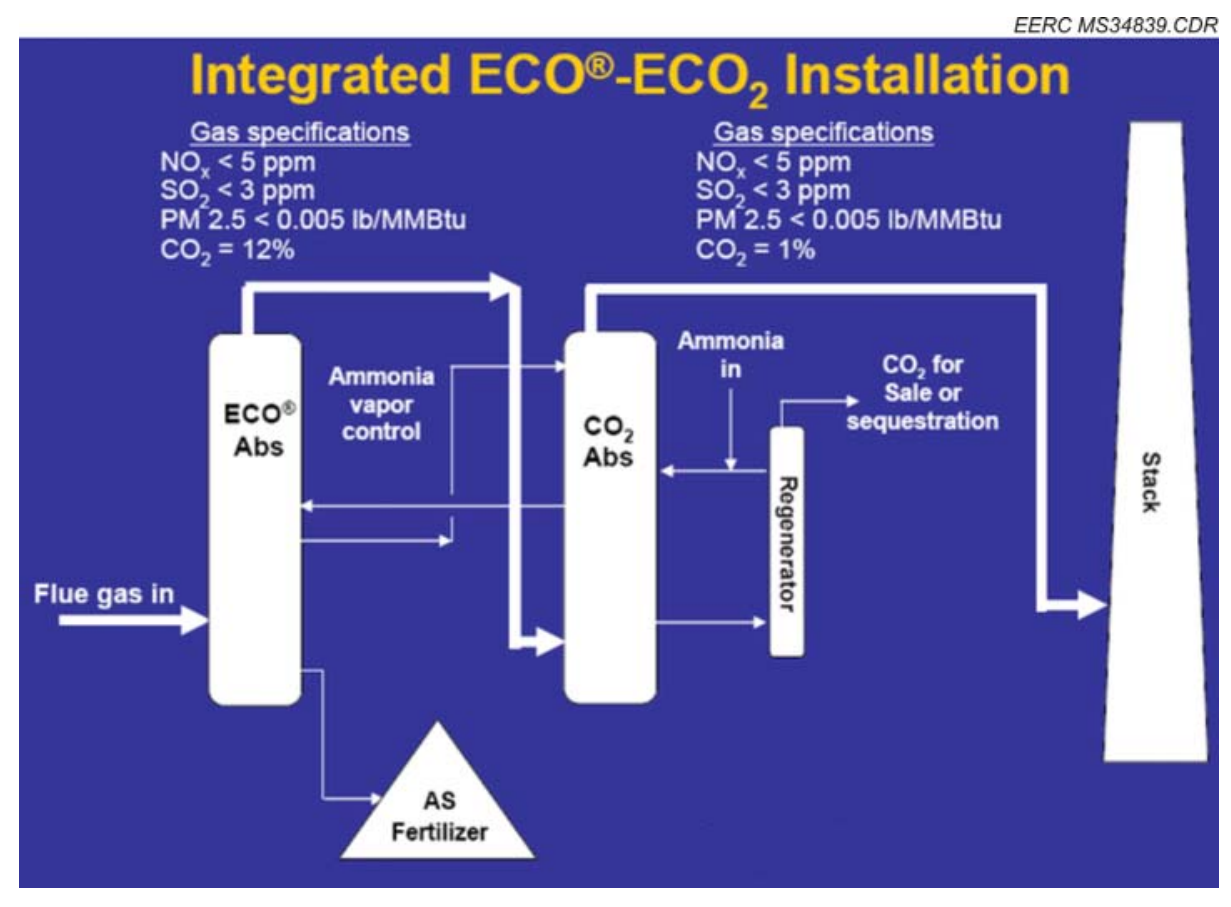

Figure 44. Powerspan $\mathrm{ECO}$ and $\mathrm{ECO}_{2}$ integration.

ammonia is consumed through the irreversible formation of ammonium sulfates and nitrates, as well as the removal of $\mathrm{HCl}$ and $\mathrm{HF}$.

\section{Chilled Ammonia Process (CAP)}

Nexant is also developing an ammonia process for postcombustion $\mathrm{CO}_{2}$ capture. CAP is under development based on the chemistry of the $\mathrm{NH}_{3}-\mathrm{CO}_{2}-\mathrm{H}_{2} \mathrm{O}$ system and the ability ofammoniated solution to absorb $\mathrm{CO}_{2}$ at low temperature and to release the $\mathrm{CO}_{2}$ at elevated pressure. This will decrease the size and power requirements of the compressor, lowering system cost and raising efficiency. The use of ammoniated salts at low temperature practically eliminates ammonia emission to the atmosphere. Nexant is a subcontractor to Alstom in building a 5-MW demonstration plant in Wisconsin, a skid-mounted unit for Statoil in Norway, and also a 30-MW demonstration plant for American Electric Power (AEP) to capture $\mathrm{CO}_{2}$ from an existing coal-fired power plant.

\section{Postcombustion Capture Process}

German utility E.ON is to test a new postcombustion capture process that can be used to remove up to $90 \%$ of the carbon dioxide from power plant flue gases, at its Karlshamn power plant in Sweden, in conjunction with French power generation specialist Alstom. The companies have agreed to develop the technology, currently being worked on by Alstom, at Karlshamn to a stage where it can be used in the actual environment of a power plant. The pilot plant at Karlshamn is to start trial operation in early 2008. The method to be used in Sweden is based on new technology that involves using ammonia to capture $\mathrm{CO}_{2}$. The key advantage is that this 
cleaning process uses less energy than other $\mathrm{CO}_{2}$ removal processes, so its impact on the overall efficiency of the power plant is relatively low, E.ON said.

\section{Cansolv $\mathrm{CO}_{2}$ Capture Process}

Cansolv is developing carbon capture technology from its core platform $\mathrm{SO}_{2}$ scrubbing process, selective amine scrubbing in an oxidative environment. Figures 45 and 46 show the process flow and technology integration, respectively. The Cansolv absorbents are designed to exhibit fast kinetics (similar to $1^{\circ}$ amines), very low degradation (similar to $3^{\circ}$ amines), high resistance against oxidation and free radical attack, and the lowest possible regeneration energy (similar to formulated amines). Breakthroughs in operating costs have thus been observed by meeting these standards. R\&D in 2000-2004 focused on developing high-performance solvents for $\mathrm{NO}_{\mathrm{x}}, \mathrm{Hg}$, and $\mathrm{CO}_{2}$ absorption. Commercialization efforts in 2005-2007 focused on heat integrating and optimizing $\mathrm{CO}_{2}-\mathrm{SO}_{2}$ and $\mathrm{SO}_{2}-\mathrm{NO}_{\mathrm{x}}$-mercury processes. A commercial plant case study is located at NSC (Japan). Although the solvent cost is higher than that of MEA, advantages over MEA include improved capacity through changes in molecular structure or configuration, more resistance to degradation, lower energy requirements for regeneration, higher net $\mathrm{CO}_{2}$ loading, less corrosion in the presence of dissolved $\mathrm{O}_{2}$, and smaller quantities of chemical additives (such as corrosion inhibitors) needed.

\section{Potassium Carbonate/Piperazine Complex}

This pilot-scale process permits the use of waste heat because the regeneration temperature is lower: $55^{\circ} \mathrm{C}\left(131^{\circ} \mathrm{F}\right)$ compared to $120^{\circ} \mathrm{C}\left(248^{\circ} \mathrm{F}\right)$ for MEA regeneration. This process features a circulated solvent that chemically absorbs $\mathrm{CO}_{2}$ in an absorber and is regenerated in a stripper with the application of heat (low-pressure steam). The solvent, potassium carbonate, is promoted with piperazine, a cyclic diamine. It exhibits foaming tendencies that must be addressed; however, the solvent also has a greater $\mathrm{CO}_{2}$ capacity, faster absorption rate, lower regeneration temperature, lower-cost, and minimal degradation compared to MEA.

\section{Absorption Using PSR Solvents}

These solvents are proprietary designer solvents formulated for optimized separation of $\mathrm{CO}_{2}$ from any gas stream. Operating in a similar manner to amine scrubbing, the process uses a proprietary, multi-ingredient designer solvent formulated for optimized separation of $\mathrm{CO}_{2}$ from any gas stream. Flexible formulation can be optimized to meet the needs of specific tasks. Relative to MEA, the solvents exhibit $20 \%$ to $80 \%$ higher working capacity, $5^{\circ}$ to $10^{\circ} \mathrm{C}$ lower regeneration temperature, $15 \%$ to $45 \%$ lower energy requirements, $70 \%$ to $90 \%$ lower solvent degradation rates, and $30 \%$ to $60 \%$ lower corrosion rates. Efforts are currently pilot-scale. Determining the correct combination and proportion of ingredients to optimize $\mathrm{CO}_{2}$ removal for a given stream has yet to be determined. There are also possible scaleup and cost issues. 


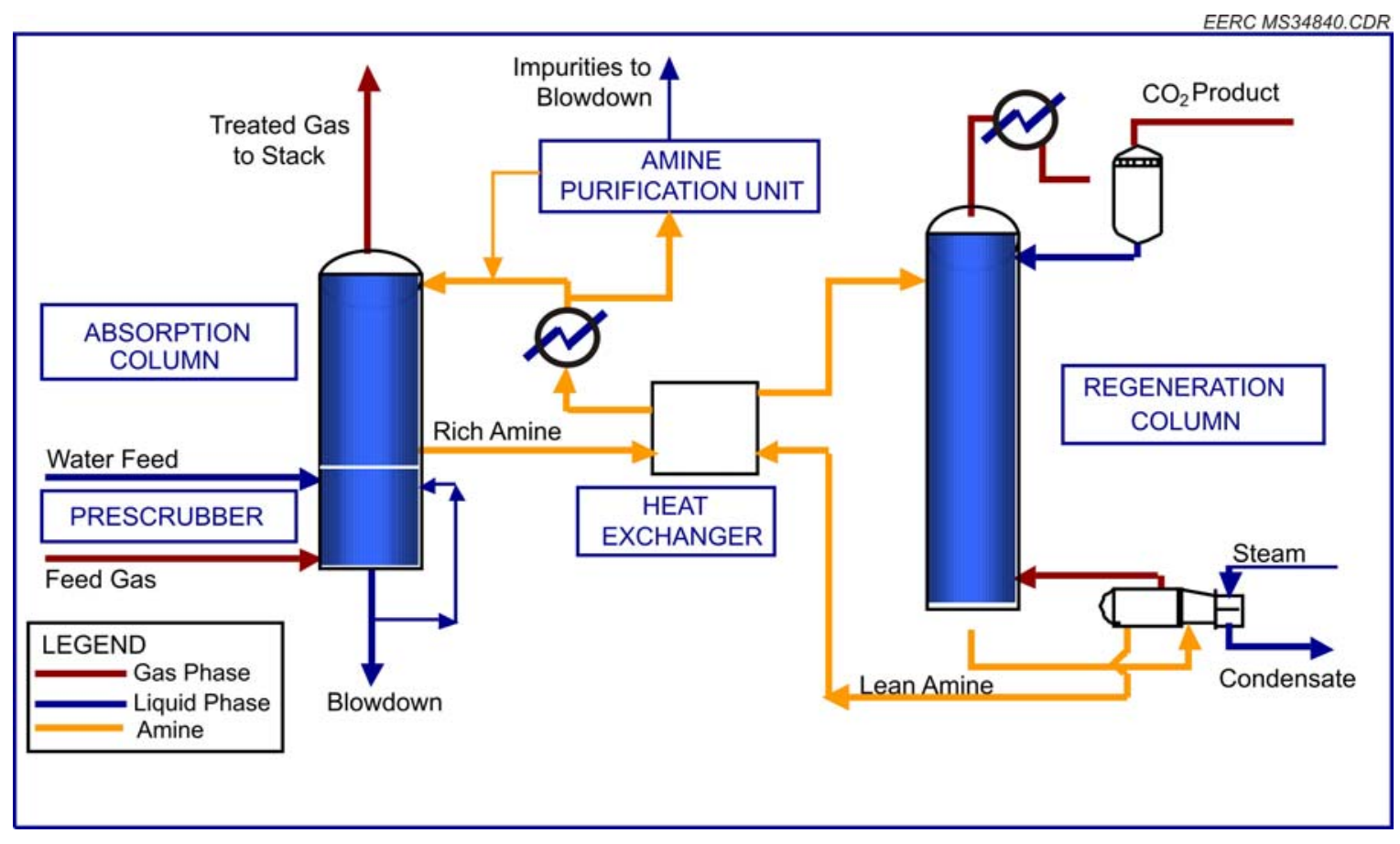

Figure 45. Cansolv $\mathrm{CO}_{2}$ capture flow sheet.

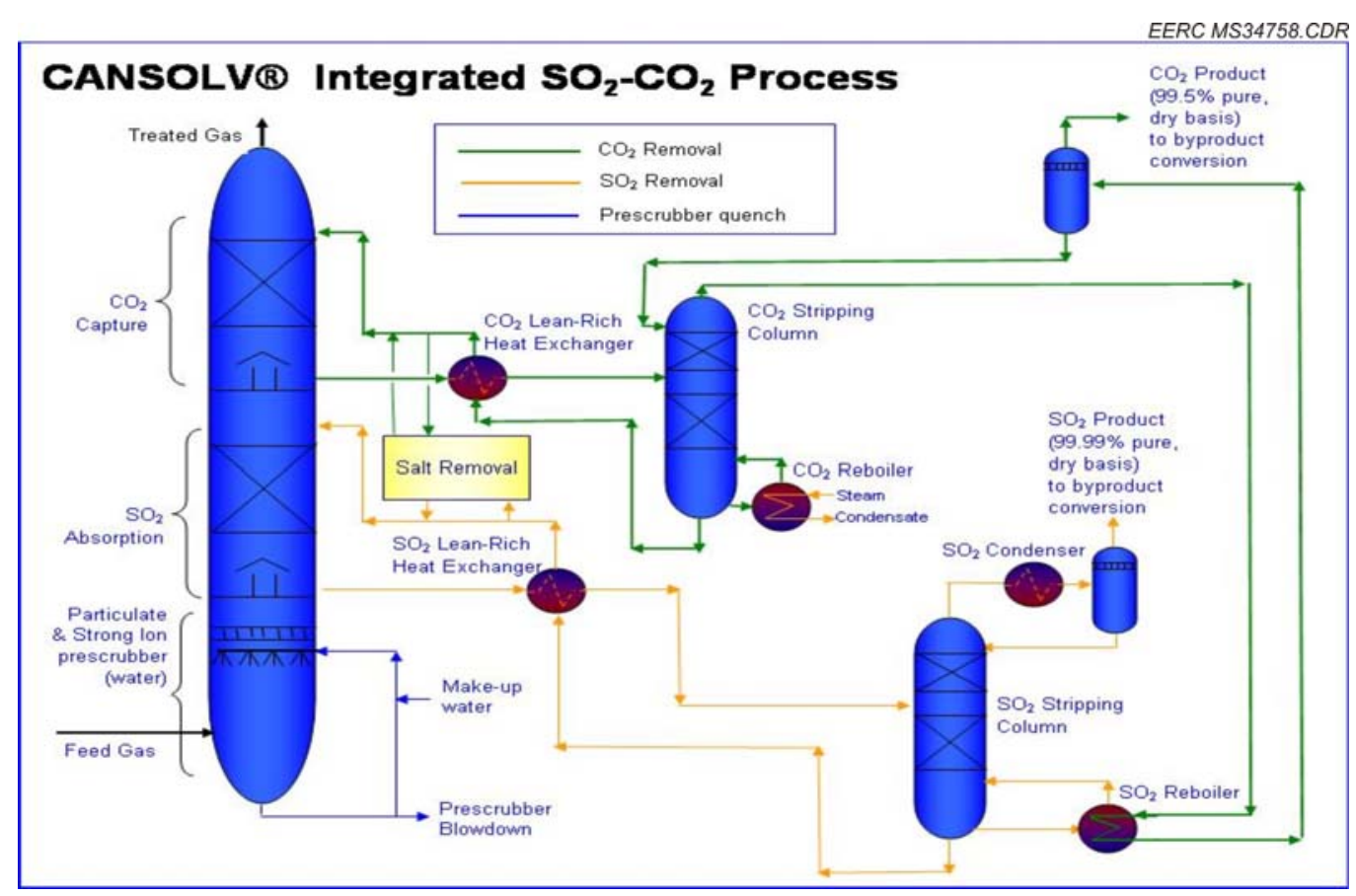

Figure 46. Cansolv sulfur and carbon removal process. 


\section{Amino Acid Salt Solutions}

Amino acid salt solutions would be used in membrane gas-liquid contactors in place of more conventional gas-treating solvents such as amines. Development is currently in the early laboratory-scale stages. The solutions are stable in the presence of $\mathrm{O}_{2}$, nonvolatile, and can be used with relatively inexpensive polyolefin microporous membranes. Further development is needed to identify the least-expensive, most efficient solution.

\section{Vortex Contactor for Amine Scrubbing}

In this pilot-scale process, separation is performed by forcing the $\mathrm{CO}_{2}$-containing gas and solvent (DEA was tested) into a turbulent rotational flow field. Liquid is separated from $\mathrm{CO}_{2}$ free gas and the solvent regenerated and recycled. The power plant flue gas would require pressurization, possibly to greater than $12.5 \mathrm{~atm}$. Benefits include low capital cost, a simple compact system, high-efficiency mass transfer, reduced solvent regeneration requirements, parallel design permits flexibility for turndown and scale-up, low maintenance, and a system complementary to chemical and physical absorbents.

\section{Regenerative Carbonate Process}

In this early laboratory-scale process, combustion occurs in a circulating moving-bed boiler that is temperature-controlled to $1090^{\circ} \mathrm{C}$. Flue gas from the combustor enters the decarbonator where $\mathrm{CO}_{2}$ is captured by an exothermic reaction with lime. The calcium carbonate is regenerated in a calciner, which releases the $\mathrm{CO}_{2}$. Nearly pure $\mathrm{CO}_{2}$ is upgraded by condensation of steam followed by compression/liquefaction. The main energy penalty or parasitic loss is for compression/liquefaction of $\mathrm{CO}_{2}$, but there is no thermodynamic efficiency loss for $\mathrm{CO}_{2}$ capture.

\section{Enzymatic Sorbents}

This laboratory-scale, enzyme-based system achieves $\mathrm{CO}_{2}$ capture and release by mimicking mammalian respiratory mechanisms. Carbozyme's process uses spiral-wound membranes, and $\mathrm{CO}_{2}$ Source's process uses a packed bed. Advantages include fast kinetics (i.e., smaller system size and cost), relatively resistant to $\mathrm{SO}_{\mathrm{x}}$ and $\mathrm{NO}_{\mathrm{x}}$, and a $\mathrm{pH}$ swing-based operation that offers the potential to produce $\mathrm{CO}_{2}$ above atmospheric pressure. Disadvantages are a $37.8^{\circ} \mathrm{C}$-operating limit and exothermic $\mathrm{CO}_{2}$ sorption reaction requiring flue gas cooling, entrained particulates in the flue gas from coal boilers which may block membrane channels or form sludge in packed bed, and possible sensitivity to acid gases.

\section{Postcombustion Capture Model Results}

In order to determine the costs associated with capturing $\mathrm{CO}_{2}$ from a Bulgarian lignite plant, a process model known as the Integrated Environmental Control Model (IECM) was used. The IECM is a tool for calculating the performance, emissions, and cost of a fossil-fueled power plant. The model was developed by Carnegie Mellon University with support from NETL. The amine-scrubbing portion is one module within the model that can be used to predict the mass, 
energy, and cost of an amine-based $\mathrm{CO}_{2}$ removal system. IECM was built using two process simulators: ASPEN Plus and ProTreat. These two process simulators were used to derive the performance equations used in the model. ProTreat ${ }^{\mathrm{TM}}$ is a true mass- and heat-transfer rate-based engineering software tool that was developed by optimized gas treating. It simulates processes used to remove $\mathrm{H}_{2} \mathrm{~S}, \mathrm{CO}_{2}$, and mercaptans from a variety gases by absorption into thermally regenerable aqueous solutions containing one or more amines (ProTreat 2002). ASPEN Plus is a widely used process simulator that is primarily used during the design and optimization of steady-state process plants.

The coal analysis that was used for the model was taken from the coal core samples used during the bench scale testing. The model was set up to maintain a constant net output of $\sim 400 \mathrm{MWe}$ while employing an MEA solvent scrubbing system for $\mathrm{CO}_{2}$ capture, a fabric filter, and a wet scrubber. The IECM was then run for five different $\mathrm{CO}_{2}$ capture rates $(10 \%, 25 \%, 50 \%, 75 \%$, and 90\%). The results are summarized in Table 45. The cost to capture a ton of $\mathrm{CO}_{2}$ is essentially unchanged for $\mathrm{CO}_{2}$ capture rates of $25 \%$ to $90 \%$ on a per ton basis. The cost for this range of capture was $\$ 49$ to $\$ 53 /$ ton of $\mathrm{CO}_{2}$ captured for the capture rates of $90 \%$ to $25 \%$, respectively. Although the cost per ton was relatively stable, the total cost and power requirement increased rapidly as the capture percentage increased. The lowest total cost of $\$ 25$ million annually would be required to capture $10 \%$ of the $\mathrm{CO}_{2}$. As much as $\$ 284$ million annually would be needed to capture $90 \%$ of the $\mathrm{CO}_{2}$. The power requirement ranged from 18 to $259 \mathrm{MW}$ for $10 \%$ to $90 \%$ $\mathrm{CO}_{2}$ capture, respectively. These costs represent the cost for the $\mathrm{CO}_{2}$ capture plant only; in order to maintain a net output of $400 \mathrm{MW}$, the gross output of the plant had to be increased significantly, which raised the overall cost of the plant. The total plant cost ranged from a low of $\$ 269$ million annually at 10\% capture to a high of $\$ 525$ million annually for $90 \%$ capture. These results can be seen graphically in Figure 47.

Figure 48 shows the breakdown of the gross MW output for the potential combustion plant. It can be seen that the amount of auxiliary power required to capture the $\mathrm{CO}_{2}$ is increased greatly from a capture rate of $10 \%$ to $90 \%$ which affects the overall plant size. At a $10 \%$ capture rate the required gross output is $470 \mathrm{MWg}$, while at the $90 \%$ capture rate, $740 \mathrm{MWg}$ plant would be required. The costs and energy penalty associated with capturing the $\mathrm{CO}_{2}$ are high, but several technologies are under development to significantly reduce the cost of postcombustion capture. When looking at the cost breakdown of the MEA process shown in Figure 49, it can be seen that several areas need improvement. The largest area of expense is shown to be the energy use which consists of $47 \%$ of the total costs. Several solvents under development are claiming a 50\% energy reduction over that of MEA. Other advanced solvents are able to increase the reaction kinetics and $\mathrm{CO}_{2}$ loading ratio's which will allow for smaller capital equipment, further reducing capital cost which accounts for $16 \%$ of the annual cost. If the technology claims can be proven at commercial scale, the potential costs would be approximately $33 \%$ or more less than that of the MEA process. The current processes currently under development were briefly described above. 
Table 45. A Summary of the $\mathrm{CO}_{2}$ Capture Modeling for a Bulgarian Lignite-Fired Combustions System

\begin{tabular}{|c|c|c|c|c|c|c|c|c|c|c|}
\hline Capture \% & \multicolumn{2}{|r|}{10} & \multicolumn{2}{|c|}{25} & \multicolumn{2}{|r|}{50} & \multicolumn{2}{|r|}{75} & \multicolumn{2}{|c|}{90} \\
\hline Gross Electrical Output (MWg) & \multicolumn{2}{|r|}{470} & \multicolumn{2}{|c|}{505} & \multicolumn{2}{|r|}{575} & \multicolumn{2}{|r|}{670} & \multicolumn{2}{|c|}{740} \\
\hline Boiler Use** & \multicolumn{2}{|r|}{27} & \multicolumn{2}{|c|}{30} & \multicolumn{2}{|r|}{34} & \multicolumn{2}{|r|}{39} & \multicolumn{2}{|c|}{43} \\
\hline Amine Scrubber Use (MW) & \multicolumn{2}{|r|}{18} & \multicolumn{2}{|c|}{49} & \multicolumn{2}{|r|}{112} & \multicolumn{2}{|r|}{195} & \multicolumn{2}{|c|}{259} \\
\hline Wet FGD Use (MW) & \multicolumn{2}{|r|}{21} & \multicolumn{2}{|c|}{22} & \multicolumn{2}{|r|}{25} & \multicolumn{2}{|r|}{30} & \multicolumn{2}{|c|}{33} \\
\hline Fabric Filter & \multicolumn{2}{|c|}{2.80} & \multicolumn{2}{|c|}{3.01} & \multicolumn{2}{|c|}{3.43} & \multicolumn{2}{|c|}{4.00} & \multicolumn{2}{|c|}{4.42} \\
\hline Total Aux. Load & \multicolumn{2}{|r|}{69} & \multicolumn{2}{|c|}{104} & & 174 & & 268 & & 339 \\
\hline Net Electrical Output & & 401 & & 01 & & 401 & & 402 & & 401 \\
\hline Coal Usage, Mtons/yr & & 4.32 & & 64 & & 5.29 & & 6.16 & & 5.80 \\
\hline Total $\mathrm{CO}_{2}$ Produced, Mtons/yr & & 4.08 & & .38 & & 4.98 & & 5.81 & & 5.41 \\
\hline $\mathrm{CO}_{2}$ Captured, Mtons/yr & & 0.41 & & .09 & & 2.49 & & 4.36 & & 5.77 \\
\hline $\mathrm{CO}_{2}$ Emitted, Mtons/yr & & 3.67 & & .28 & & 2.49 & & 1.45 & & .64 \\
\hline $\mathrm{CO}_{2}$ Capture Cost Component & $\$ M / y r$ & $\$ /$ ton $\mathrm{CO}_{2}{ }^{*}$ & $\$ M / y r$ & $\$ /$ ton $\mathrm{CO}_{2}{ }^{*}$ & $\$ M / y r$ & $\$ /$ ton $\mathrm{CO}_{2}{ }^{*}$ & $\$ M / y r$ & $\$ /$ ton $\mathrm{CO}_{2}{ }^{*}$ & $\$ M / y r$ & $\$ /$ ton $\mathrm{CO}_{2}{ }^{*}$ \\
\hline Annual Fixed Cost & 2.15 & 5.28 & 3.29 & 3.01 & 6.08 & 2.44 & 9.48 & 2.18 & 12 & 2.09 \\
\hline Annual Variable Cost & 15 & 37 & 40 & 37 & 90 & 36 & 154 & 35 & 202 & 35 \\
\hline Total Annual O\&M Cost & 17 & 42 & 43 & 40 & 96 & 38 & 164 & 38 & 214 & 37 \\
\hline Annualized Capital Cost & 8 & 19 & 15 & 14 & 32 & 13 & 54 & 12 & 70 & 12 \\
\hline $\mathrm{CO}_{2}$ Capture Plant Levelized Cost & 25 & 62 & 58 & 53 & 128 & 51 & 217 & 50 & 284 & 49 \\
\hline Base Plant Capital Cost (\$M) & & 708 & & 48 & & 826 & & 929 & & .003 \\
\hline $\mathrm{CO}_{2}$ Capture Plant Capital Cost (\$M) & & 53 & & 02 & & 219 & & 363 & & 472 \\
\hline Total Plant Capital (M) & & 931 & & 033 & & 1243 & & 1506 & & 701 \\
\hline Base Plant Levelized Cost, \$M/yr & & 178 & & 74 & & 165 & & 155 & & 148 \\
\hline Total Plant Levelized Cost, $\$ \mathrm{M} / \mathrm{yr}$ & & 269 & & 02 & & 370 & & 459 & & 525 \\
\hline
\end{tabular}

2007 US\$/ton $\mathrm{CO}_{2}$ captured. 


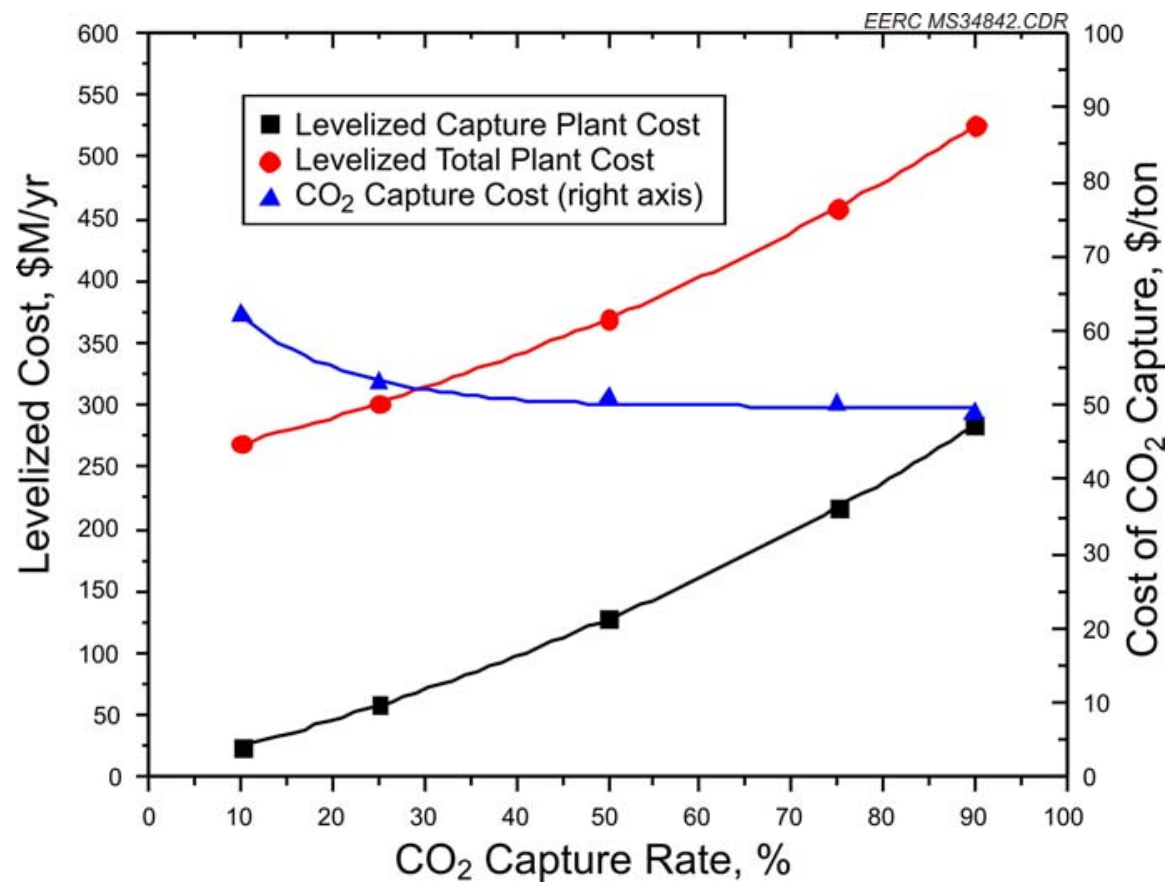

Figure 47. A summary of the $\mathrm{CO}_{2}$ capture costs for implementation on a Bulgarian lignite-fired combustion system.

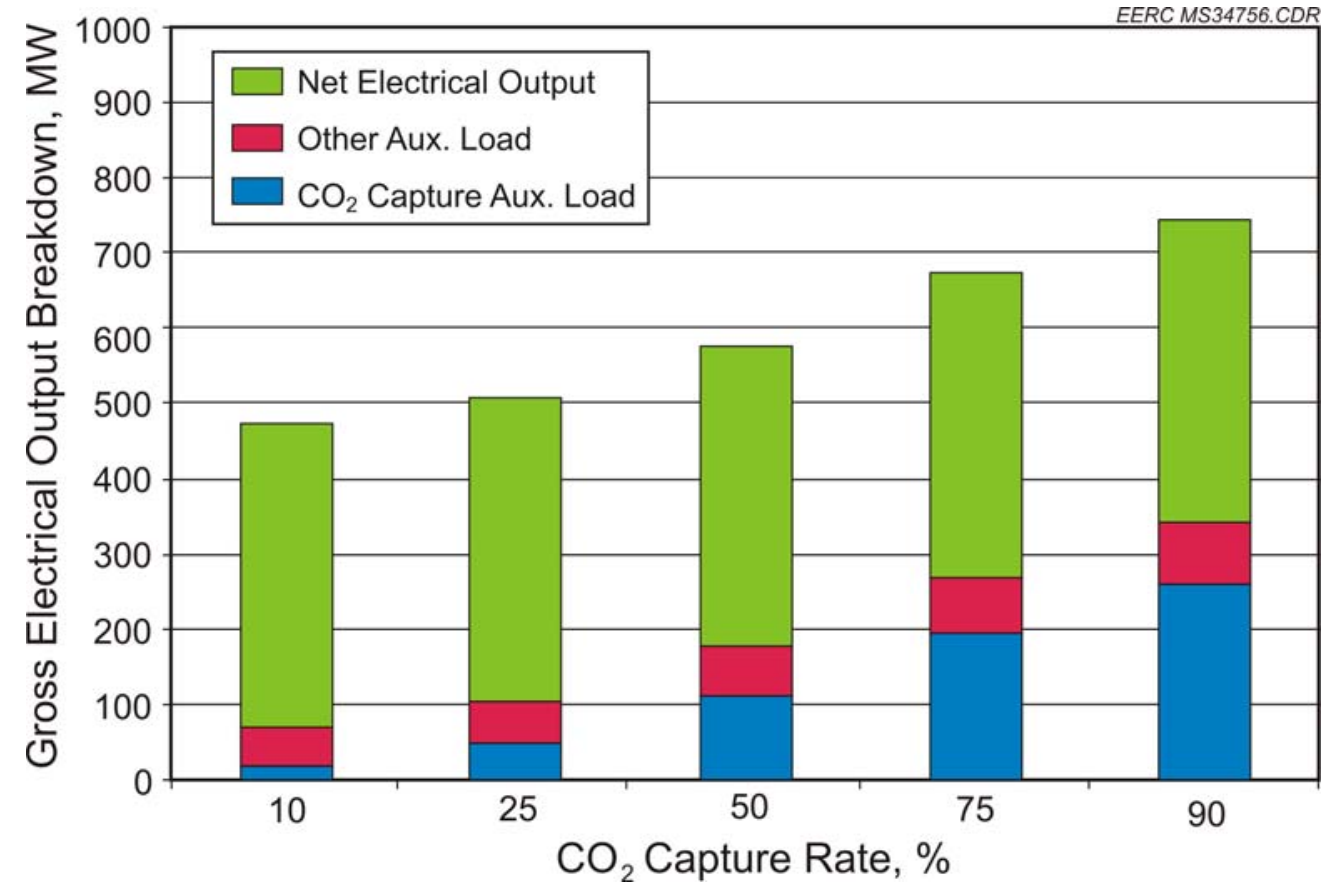

Figure 48. A summary of the plant size required to maintain a $400-\mathrm{MWe}$ output while increasing the $\mathrm{CO}_{2}$ capture rate. 


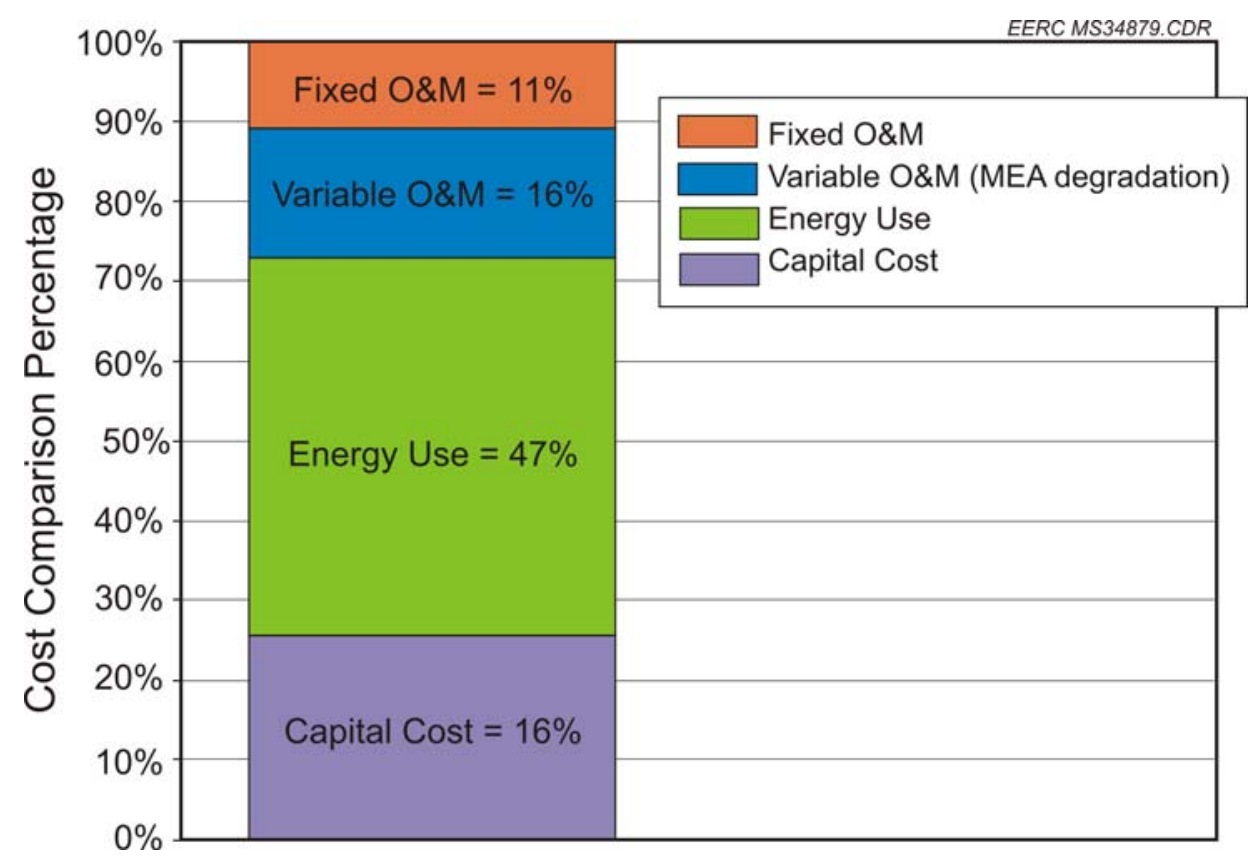

Figure 49. Component breakdown for the costs associated with an $\mathrm{MEA} \mathrm{CO}_{2}$ capture system.

\section{Precombustion $\mathrm{CO}_{2}$ Capture Costs}

\section{Precombustion Technology Background}

Three physical absorbents are commercially available, primarily to remove $\mathrm{CO}_{2}$ from gasification fuel or synthesis gas:

1. SelexolTM

2. Rectisol ${ }^{\mathbb{B}}$

3. Purisol $^{\circledR}$

\section{Selexol}

This technology is a liquid physical solvent developed over 30 years ago for application to gasification systems and currently owned by UOP. It removes $\mathrm{H}_{2} \mathrm{~S}, \mathrm{CO}_{2}$, and mercaptans and is for both hydrocarbon and water dew point control. With respect to potential future requirements for high $(>90 \%) \mathrm{CO}_{2}$ recovery during gasification, the double-stage Selexol process, in which desulfurization and $\mathrm{CO}_{2}$ separation are separated, is favored. The double-stage or -absorber Selexol unit preferentially removes $\mathrm{H}_{2} \mathrm{~S}$ in one product stream and then removes $\mathrm{CO}_{2}$ as a second product stream. The Selexol solvent is a mixture of dimethyl ethers of polyethylene glycol and has the formulation of $\mathrm{CH}_{3}\left(\mathrm{CH}_{2} \mathrm{CH}_{2} \mathrm{O}\right)_{n} \mathrm{CH}_{3}$, where $\mathrm{n}$ is between 3 and 9. A true physical solvent, it does not react chemically with the absorbed gases. It has also high selectivity for sulfur compounds over $\mathrm{CO}_{2}$, producing a highly enriched feed to the Claus unit as well as maximum $\mathrm{CO}_{2}$ for any downstream process. The glycol is regenerated by air stripping. Advantages include no heat required for regeneration, acid gases delivered at higher pressures 
than amine processes, a higher capacity to absorb gases than amines, removal of $\mathrm{H}_{2} \mathrm{~S}$ and organic sulfur compounds, no salt formation with $\mathrm{HCN}$, and simultaneous dehydration of the gas stream. Disadvantages include coabsorbed hydrocarbons (resulting in reduced product revenue and often requiring recycle compression), refrigeration for the lean solution (adding complexity and cost), and high pressure requirements for optimal economics.

Figures 50 and 51 provide flow diagrams of the Selexol process and its position for capture, respectively. The synthesis gas enters the first absorber unit at approximately $48 \mathrm{~atm}$ (705 psia) and $39.4^{\circ} \mathrm{C}\left(103^{\circ} \mathrm{F}\right)$. In this absorber, $\mathrm{H}_{2} \mathrm{~S}$ is removed from the fuel gas stream by "loading" the lean Selexol solvent with $\mathrm{CO}_{2}$. The $\mathrm{CO}_{2}$-saturated solvent preferentially removes $\mathrm{H}_{2} \mathrm{~S}$. The rich solution is regenerated in a stripper by heating. The stripper acid gas stream, consisting of $34 \% \mathrm{H}_{2} \mathrm{~S}$ and $58 \% \mathrm{CO}_{2}$ and water, is then sent to a Claus sulfur removal unit. Following processing in the Claus unit, cleaned fuel gas from the first absorber is cooled and routed to the second absorber unit. In this absorber, the fuel gas is contacted with lean solvent. The solvent removes approximately $97 \%$ of the $\mathrm{CO}_{2}$ from the fuel gas stream. The fuel gas from the second absorber is warmed and humidified in the fuel gas saturator, reheated and expanded, and then sent to the burner of the combustion turbine. $\mathrm{CO}_{2}$ is flashed from the rich solution and is then ready for dehydration and compression to pipeline-ready conditions.

\section{Rectisol}

This technology uses refrigerated methanol at $-70^{\circ} \mathrm{C}\left(-94^{\circ} \mathrm{F}\right)$ as a physical absorption solvent for gasification systems, requiring significant syngas cooling and reheating. Figure 52 provides the absorption coefficients of several gases in methanol. All impurities and trace contaminants, such as $\mathrm{CO}_{2}$ and $\mathrm{H}_{2} \mathrm{~S}$, are removed in one single absorption process, generating an ultrapure product gas: e.g., total sulfur $<0.1 \mathrm{ppmv}, \mathrm{CO}_{2}<2 \mathrm{ppmv}$. Nitrogen stripping is used to separate the $\mathrm{CO}_{2}$ from the methanol. Refrigeration costs hurt the economics compared to glycol systems. Advantages include low utility consumption; inexpensive, easily available solvent; and flexibility in process configuration. High system pressure and high sour gas concentrations are particularly favorable.

\section{Purisol $^{\circledR}$}

This technology is applied to the gas produced from partial oxidation of heavy oils or coal gasification, primarily for sulfur recovery. N-methyl-2-pyrrolidone absorbs $\mathrm{CS}_{2}, \mathrm{H}_{2} \mathrm{~S}, \mathrm{COS}$, $\mathrm{NCN}, \mathrm{NH}_{3}$ and $\mathrm{CO}_{2}$ at low temperatures $\left(10^{\circ} \mathrm{C}\right.$ to ambient). The gaseous components are desorbed by reducing the pressure and reboiling the solvent. The $\mathrm{H}_{2} \mathrm{~S}$ is reabsorbed in the hot upper section of the reabsorber. Benefits include a low solvent circulation rate (because of high solubility) and no corrosion problems. However, there is potential for contamination of the $\mathrm{CO}_{2}$ stream by small quantities of coabsorbed components such as $\mathrm{HCN}$ and $\mathrm{NH}_{3}$. 


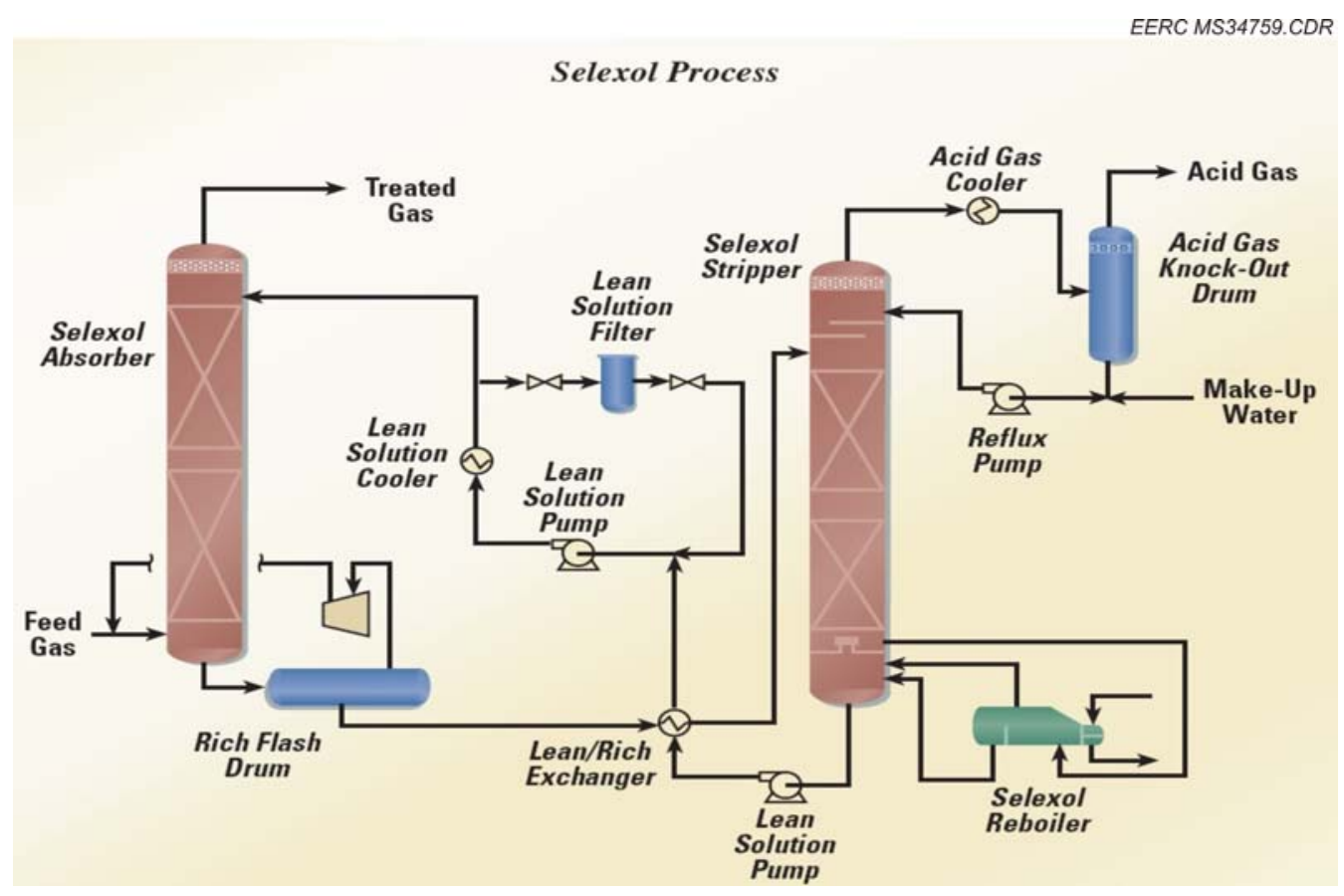

Figure 50. Selexol ${ }^{\mathrm{TM}}$ process schematic.

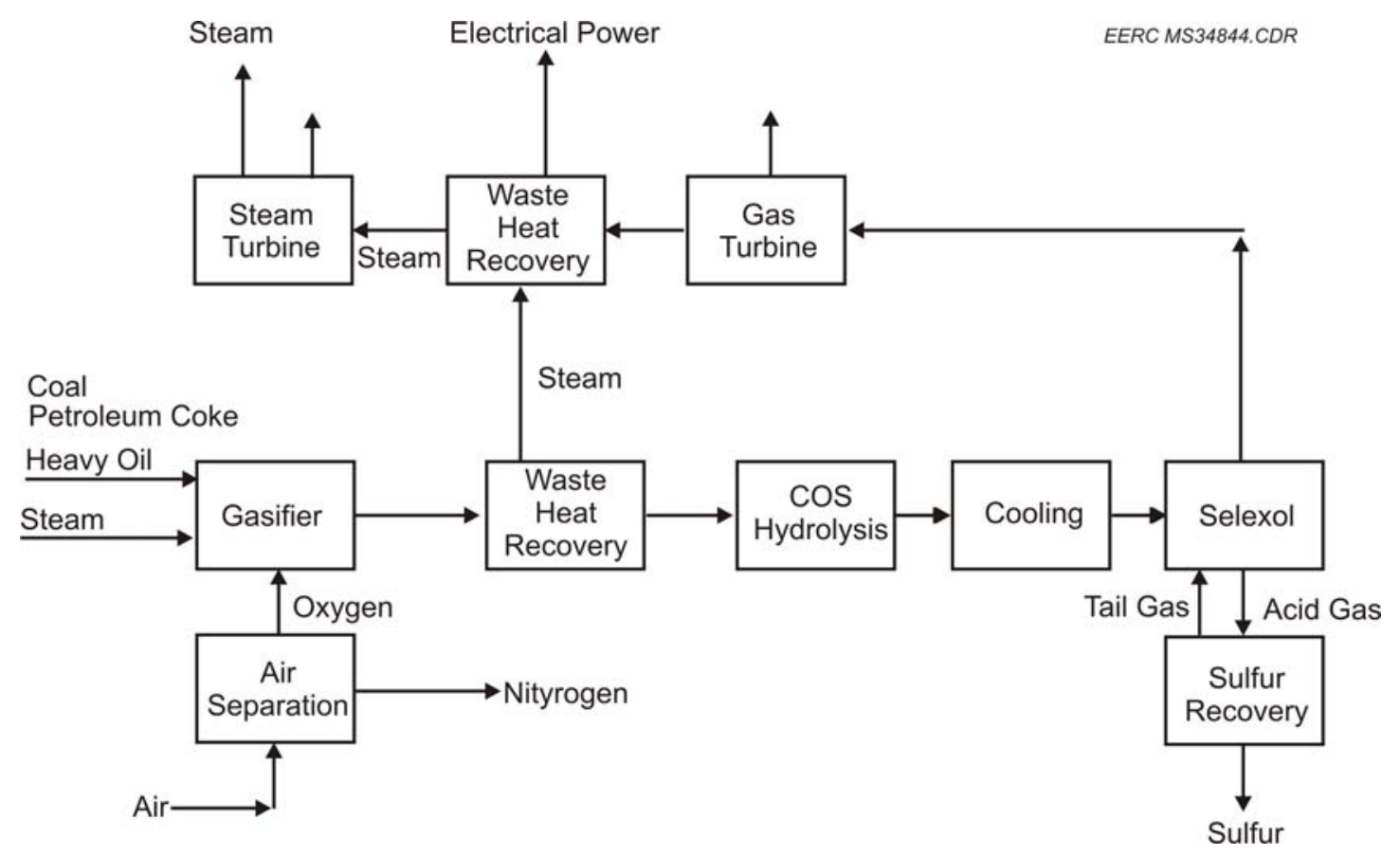

Figure 51. IGCC with Selexol ${ }^{\mathrm{TM}}$. 


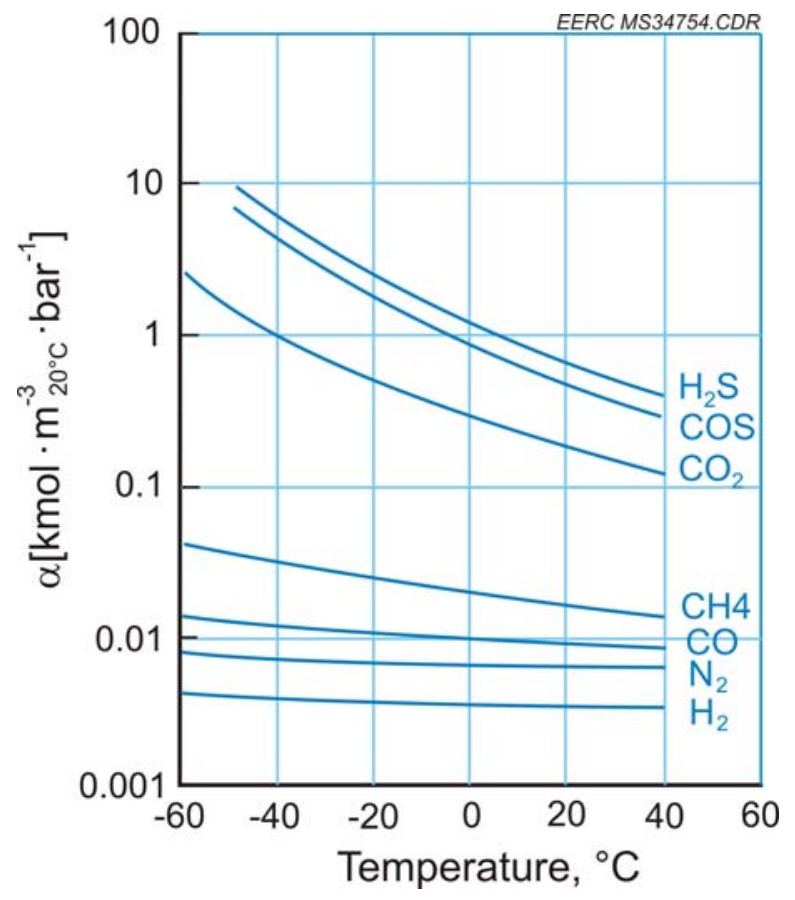

Figure 52. Absorption coefficients in methanol.

\section{Precombustion Analysis Results}

Given the short time frame and the infancy of the IGCC technology, the amount of modeling that was able to be done was very limited. The IECM does have a process module that predicts the costs of an IGCC plant equipped with the Selexol process. This module however is very limited in the parameters that can be changed. The fuel input to the model was unable to be changed to match the analysis of the Bulgarian lignite, so a model default based on North Dakota lignite had to be used. The fuel properties for the North Dakota lignite compared to the Bulgarian lignite analysis can be seen in Table 46. The process module is based on a GE gasifier, with a gross generating capacity that varies dependent on the level of $\mathrm{CO}_{2}$ capture the Selexol system is designed for: the more $\mathrm{CO}_{2}$ that is captured, the more the electrical generating capacity is reduced. The majority of the auxiliary power is consumed by the air compression unit and the air separation unit. Several other auxiliary loads also impact the net generation. Figure 53 shows the breakdown of the energy uses of the IGCC plant with respect to the amount of $\mathrm{CO}_{2}$ captured. Figure 54 shows a more simplistic look at the effects of energy uses attributed to $\mathrm{CO}_{2}$ capture rate. The trend shows that the lower the capture rate, the higher the net electricity of the plant can be, ranging from 582 to $469 \mathrm{MWe}$ at a capture rate of $50 \%$ to $95 \%$, respectively.

The cost to capture the $\mathrm{CO}_{2}$ did not range significantly over the $50 \%$ to $95 \%$ capture rates analyzed, ranging from 137.4 to $173.5 \$ \mathrm{M} / \mathrm{yr}$ (50\% to $95 \%$ capture rates). When comparing the capture costs in terms of $\$$ ton of $\mathrm{CO}_{2}$ captured, it would seem to make sense to capture at a 
Table 46. North Dakota Lignite Default Properties Used in the IECM Model Simulations

\begin{tabular}{lcc}
\hline Property & ND Lignite & Bulgarian Lignite \\
\hline Heating Value & 6020 & 4039 \\
Carbon & 35.04 & 25.48 \\
Hydrogen & 2.68 & 2.56 \\
Oxygen & 11.31 & 10.02 \\
Chlorine & 0.09 & 0.06 \\
Sulfur & 1.16 & 0.94 \\
Nitrogen & 0.77 & 0.59 \\
Ash & 15.92 & 37.49 \\
Moisture & 33.03 & 22.9 \\
Cost & 15.28 & 15.00 \\
\hline
\end{tabular}

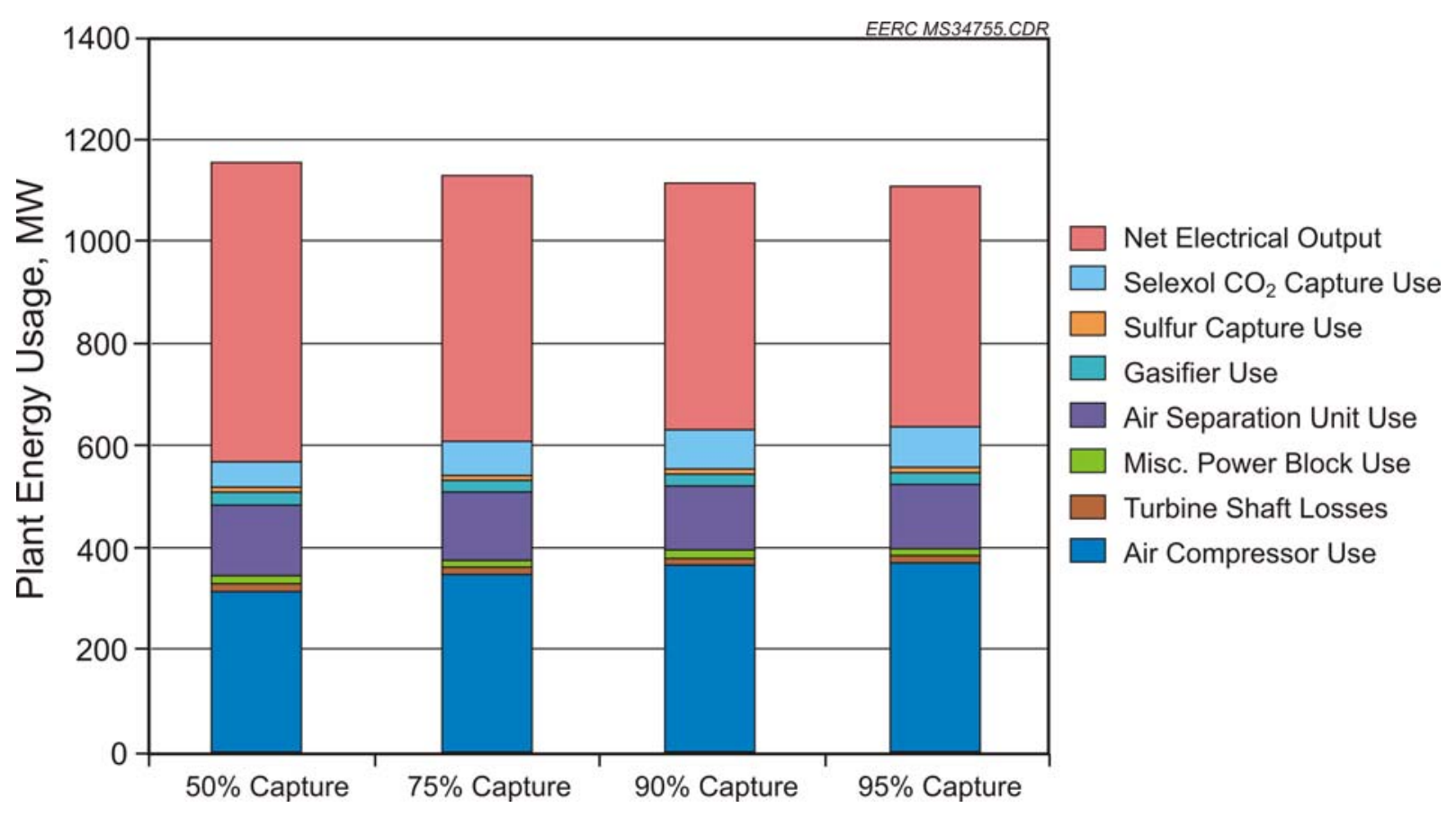

Figure 53. The breakdown of the IGCC + capture plant energy output and requirements. 


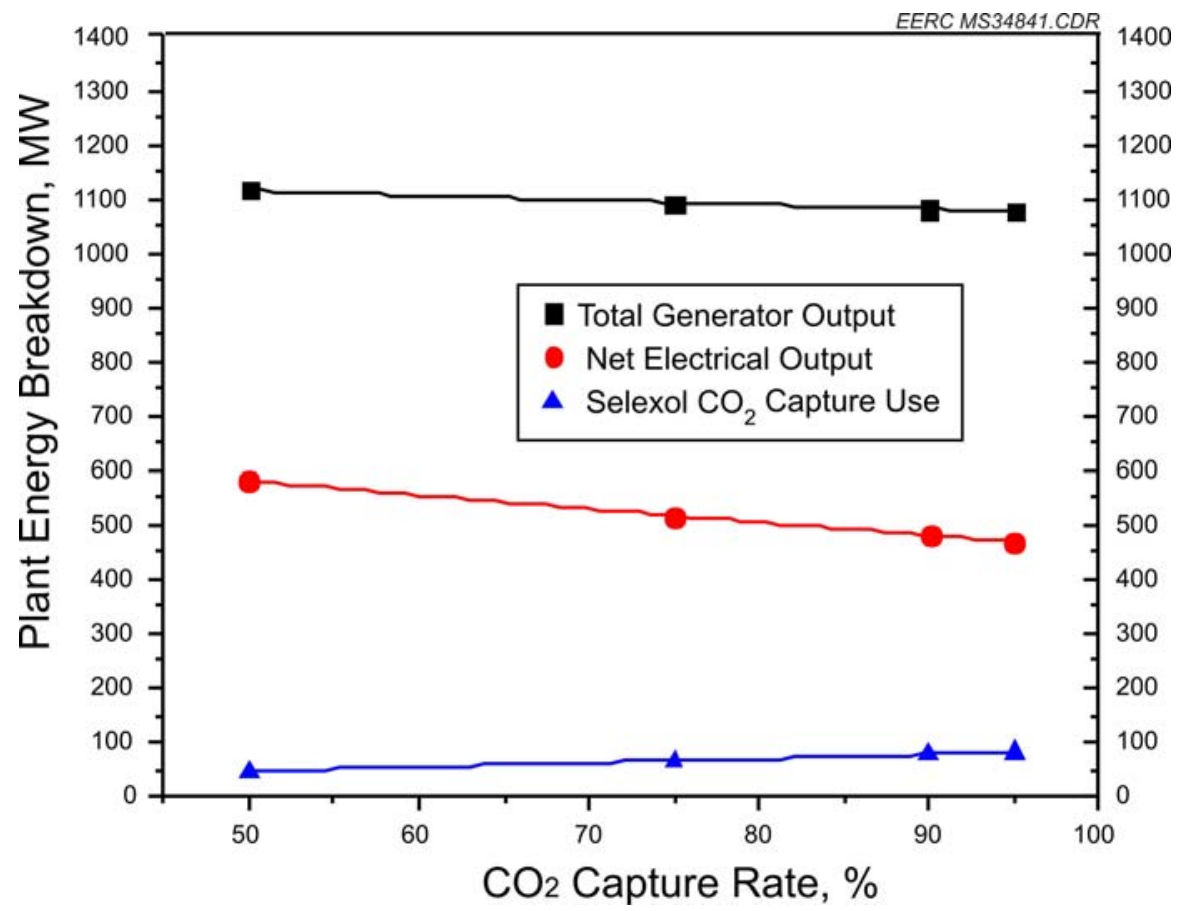

Figure 54. The breakdown of the IGCC + capture plant energy output and requirements.

higher rate of $90 \%$ to $95 \%$. The cost ranged from 32.2 to $44.3 \$$ ton at capture rates of $95 \%$ to $50 \%$, respectively. This is due to the cost being spread out over more captured $\mathrm{CO}_{2}$. A summary and comparison of the costs can be seen in Figure 55. For a more detail description of the costs, refer to Table 47.

\section{Summary of $\mathrm{CO}_{2}$ Control Options for IGCC versus CFBC Power Plant Systems}

Several options are being developed for the capture of $\mathrm{CO}_{2}$ from either flue gas or gasification syngas. The two technologies that are considered commercially available are MEA absorption for a combustion system and the Selexol process for a gasification system. The results from the modeling cannot be directly compared because of the issues surrounded by the lack of input in the IGCC IECM model. The most comparable case was at $90 \%$ capture from the MEA system and $95 \%$ capture from the Selexol process. If we can assume the differences in the fuel properties have no impact, it appears that the cost to capture the $\mathrm{CO}_{2}$ from the IGCC + Selexol system is slightly cheaper at $174 \$ \mathrm{M} /$ year (32.15\$/ton at $95 \%$ capture) compared to the MEA system at a cost of $284 \$ \mathrm{M} / \mathrm{yr}$ ( $49 \$ /$ ton at $90 \%$ capture). The total plant costs, however, were very similar, showing essentially no difference in cost given the error of the economic analysis with a total cost of $554 \$ \mathrm{M} / \mathrm{yr}$ for the IGCC + Selexol system and $525 \$ \mathrm{M} / \mathrm{yr}$ for the combustion system + MEA absorption. 


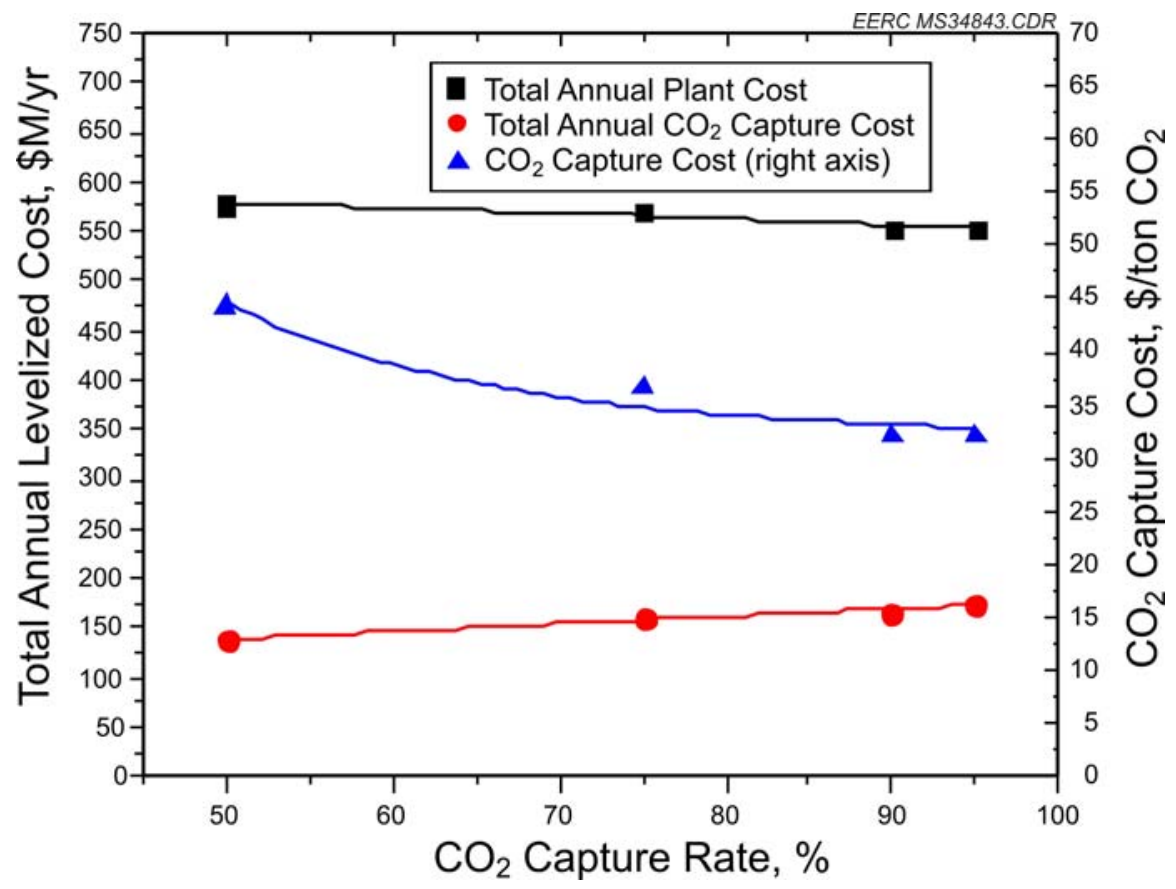

Figure 55. IGCC $+\mathrm{CO}_{2}$ capture plant cost summary.

\section{CONCLUSIONS REGARDING UTILIZATION OF BULGARIAN LIGNITE IN ADVANCED POWER SYSTEMS}

- Gasification tests were run at the EERC in the 100-400 kg/hr TRDU on a 50-tonne sample of lignite supplied by the BLPP. The quality of the test sample was inferior to any coal previously tested in this unit, containing $50 \%$ ash at $26.7 \%$ moisture and having a HHV of $5043 \mathrm{~kJ} / \mathrm{kg}$ after partial drying in preparation for testing. The interpretation of results from these gasification tests was limited by difficulties experienced in operating the TRDU on this low-quality coal. These difficulties included excessive heat losses from the high ash removal rates in addition to the pilot plant system physical limitations on the coal feed system, limiting the maximum feed rate to approximately $1000 \mathrm{lb} / \mathrm{hr}$ and on the ash removal systems not being able to keep up with the building bed material in the system even with almost continuous ash removal.

- The tentative conclusion reached on the basis of tests in the TRDU is that oxygen-blown gasification of this high-ash Bulgarian lignite sample using the KBR transport gasifier technology would provide not provide a syngas suitable for directly firing a gas turbine. After correcting for test conditions specific to the pilot-scale TRDU, including an unavoidably high heat loss and nitrogen dilution by transport air, the best-case heating value for oxygen-blown operation was estimated to be $3316 \mathrm{~kJ} / \mathrm{m}^{3}$ for a commercial KBR transport gasifier. This heating value is about $80 \%$ of the minimum required for firing a gas turbine. Removing $50 \%$ of the carbon dioxide from the syngas would increase the heating value to $4583 \mathrm{~kJ} / \mathrm{m}^{3}$, i.e., to about $110 \%$ of the minimum requirement, and $95 \%$ removal would 
Table 47. Total Cost of an IGCC Plant Equipped with a Selexol Unit for $\mathrm{CO}_{2}$ Capture Based on the IECM

\begin{tabular}{|c|c|c|c|c|}
\hline Parameter & $\begin{array}{c}50 \% \\
\text { Capture }\end{array}$ & $\begin{array}{c}75 \% \\
\text { Capture }\end{array}$ & $\begin{array}{c}90 \% \\
\text { Capture }\end{array}$ & $\begin{array}{c}95 \% \\
\text { Capture }\end{array}$ \\
\hline \multicolumn{5}{|l|}{ Fixed O\&M (\$M/yr) } \\
\hline Air Separation Unit & 12.87 & 12.46 & 12.23 & 12.16 \\
\hline Gasifier Area & 35.3 & 33.85 & 33.04 & 32.78 \\
\hline Sulfur Control & 5.668 & 5.549 & 5.482 & 5.454 \\
\hline $\mathrm{CO}_{2}$ Capture & 20.99 & 21.87 & 19.46 & 19.86 \\
\hline Power Block & 7.905 & 7.871 & 7.852 & 7.846 \\
\hline Subtotal & 82.73 & 81.6 & 78.07 & 78.1 \\
\hline \multicolumn{5}{|c|}{ Variable O\&M (\$M/yr) } \\
\hline Air Separation Unit & 96.65 & 95.22 & 94.48 & 94.25 \\
\hline Gasifier Area & 111.5 & 106.6 & 103.8 & 102.9 \\
\hline Sulfur Control & 4.683 & 4.86 & 4.967 & 5.003 \\
\hline $\mathrm{CO}_{2}$ Capture & 30.88 & 54.46 & 68.58 & 73.69 \\
\hline Power Block & -134.3 & -148.1 & -156.9 & -160.3 \\
\hline Subtotal & 109.4 & 113 & 115 & 115.6 \\
\hline Total O\&M (\$M/yr) & 192.1 & 194.6 & 193 & 193.7 \\
\hline \multicolumn{5}{|c|}{ Capital Required (\$M) } \\
\hline Air Separation Unit & 501.2 & 480.6 & 469.2 & 465.5 \\
\hline Gasifier Area & 972.4 & 929.4 & 905.4 & 897.7 \\
\hline Sulfur Control & 147.1 & 140.7 & 137.2 & 135.7 \\
\hline $\mathrm{CO}_{2}$ Capture & 577.9 & 582.2 & 531.5 & 540.5 \\
\hline Power Block & 401.2 & 397.6 & 395.6 & 394.8 \\
\hline Total & 2600 & 2531 & 2439 & 2434 \\
\hline \multicolumn{5}{|c|}{ Annualized Capital (\$M/yr) } \\
\hline Air Separation Unit & 74.18 & 71.13 & 69.43 & 68.89 \\
\hline Gasifier Area & 143.9 & 137.5 & 134 & 132.9 \\
\hline Sulfur Control & 21.77 & 20.83 & 20.3 & 20.08 \\
\hline $\mathrm{CO}_{2}$ Capture & 85.52 & 86.17 & 78.65 & 79.98 \\
\hline Power Block & 59.38 & 58.85 & 58.54 & 58.44 \\
\hline Subtotal & 384.8 & 374.5 & 360.9 & 360.2 \\
\hline \multicolumn{5}{|c|}{ Capital Required (\$/kW-net) } \\
\hline Air Separation Unit & 861.7 & 928.5 & 974.5 & 992 \\
\hline Gasifier Area & 1672 & 1795 & 1881 & 1913 \\
\hline Sulfur Control & 252.9 & 271.9 & 284.9 & 289.1 \\
\hline $\mathrm{CO}_{2}$ Capture & 993.5 & 1125 & 1104 & 1152 \\
\hline Power Block & 689.8 & 768.2 & 821.6 & 841.6 \\
\hline Total & 4470 & 4889 & 5065 & 5188 \\
\hline
\end{tabular}


Table 47. Total Cost of an IGCC Plant Equipped with a Selexol Unit for $\mathrm{CO}_{2}$ Capture Based on the IECM (continued)

\begin{tabular}{lcccc}
\hline Parameter & $\begin{array}{c}\mathbf{5 0 \%} \\
\text { Capture }\end{array}$ & $\begin{array}{c}\mathbf{7 5 \%} \\
\text { Capture }\end{array}$ & $\begin{array}{c}\mathbf{9 0 \%} \\
\text { Capture }\end{array}$ & $\begin{array}{c}\mathbf{9 5 \%} \\
\text { Capture }\end{array}$ \\
\hline Total Levelized Annual Cost $\mathbf{( \$ M / y r )}$ & & & \\
\hline Air Separation Unit & 183.7 & 178.8 & 176.1 & 175.3 \\
Gasifier Area & 290.7 & 278 & 270.9 & 268.6 \\
Sulfur Control & 32.12 & 31.24 & 30.75 & 30.53 \\
$\mathrm{CO}_{2}$ Capture & 137.4 & 162.5 & 166.7 & 173.5 \\
Power Block & -67.07 & -81.41 & -90.5 & -94.01 \\
Total & $\mathbf{5 7 6 . 9}$ & $\mathbf{5 6 9 . 1}$ & $\mathbf{5 5 3 . 9}$ & $\mathbf{5 5 3 . 9}$ \\
\hline
\end{tabular}

provide a heating value of $7080 \mathrm{~kJ} / \mathrm{m}^{3}$. Supplemental firing of natural gas would also allow the IGCC technology to be utilized without having to remove $\mathrm{CO}_{2}$. If removal of all nitrogen from the input gas streams such as the coal transport air were achieved, a heating value very close to that needed to fire a gas turbine would be achieved; however, some operational issues associated with recycle syngas or carbon dioxide as the transport gas would also have to be resolved.

- Low cold-gas efficiencies on the order of $20 \%$ calculated for oxygen-blown tests resulted in part from specific difficulties experienced in trying to operate the pilot-scale TRDU on this very high-ash lignite. These low levels of efficiency are not believed to be representative of what could be achieved in a commercial KBR transport gasifier. The specific difficulties in question include the inability to reach a desired operating temperature of $870^{\circ} \mathrm{C}$ (the maximum temperature achieved was $778^{\circ} \mathrm{C}$ ), failure to satisfactorily recycle and discharge solids owing to the extremely high ash loading, and a resulting buildup of ash and char in the reactor that was not factored into the material balance based on the measured filter ash and bed drain. If the carbon buildup in the reactor had been successfully gasified by operating at a higher temperature, an alternative material and energy balance suggests that the calculated cold-gas efficiency would be increased by about $25 \%$, to a value between $40 \%$ and $50 \%$. This value would still be lower than that of any lignite previously tested. Firing the hot or warm syngas in the gas turbine would significantly increase the cycle efficiency since the higher fuel gas moisture content would add extra mass flow through the gas turbine.

- The coal core samples supplied by BLPP for initial characterization and preliminary gasification tests in the EERC's 2-kg/hr bench-scale CFBR were of much better quality than the coal supplied for tests in the TRDU. The partially dried composite core sample used in the CFBR tests contained $37.5 \%$ ash at $22.9 \%$ moisture and had a higher heating value of $9387 \mathrm{~kJ} / \mathrm{kg}$, which was nearly twice the heating value of coal used in the TRDU. The heating value of gas produced by oxygen-blown gasification in the CFBR was as high as $6893 \mathrm{~kJ} / \mathrm{m}^{3}$, which would be entirely satisfactory for firing a gas turbine before removal of $\mathrm{CO}_{2}$. Because of the external heating associated with the CFBR, no conclusions regarding operability or efficiency can be reached based on the results obtained in the bench-scale CFBR, but previous experience suggests that the gasification of this higher-quality lignite might be more commercially viable. 
- Because of the lower quality of the lignite supplied for testing in the TRDU and the unfavorable results obtained, it was decided with the concurrence of the BLPP that tests should be performed in the EERC's CFBC to evaluate an alternative technology for use of this fuel. This decision was supported by the previous recommendation made in 1995 in the evaluation of advanced coal technologies for the Bulgarian power industry performed by the EERC in cooperation with the Bulgarian energy firms Energoproekt and TOTEMA (see summary in Appendix A and Reference 75). One of the important conclusions in the earlier study was that: "CFBC offers the lowest risk and greatest flexibility for burning low-quality, highash, high-sulfur lignite with good turndown capability, high levels of sulfur and $\mathrm{NO}_{\mathrm{x}}$ control, and high sorbent utilization." This study relied on input from a large number of technology vendors. Kellogg, in its 1995 evaluation of Maritsa lignite, concluded that operating its transport reactor technology as a pressurized fluidized-bed combustor would be preferred over operating it as a gasifier. These previous recommendations did not take into consideration the current need for carbon capture.

- It was demonstrated that this fuel does have sufficient heating value to sustain combustion, even without coal drying; however, it will be challenging to economically extract sufficient energy for the generation of steam for electrical generation. The boiler efficiency for the dried coal was $73.5 \%$ at $85 \%$ sulfur capture (21.4\% moisture) compared to $55.3 \%$ at $85 \%$ sulfur capture (40\% moisture). Improved boiler efficiencies for this coal will be possible operating a system more specifically designed to maximize heat extraction from the ash streams for this high ash fuel. Drying of the coal to approximately $25 \%$ moisture probably would be recommended either power system.

- Fuel moisture also has a large impact on fuel feedability. Pressurized gasifiers generally like drier fuels than systems operating at ambient pressures. The commercially recommended feedstock moisture for a pressurized transport reactor gasifier is $25 \%$ moisture. Maximum moisture content for a CFB system would be approximately $40 \%$ moisture, as has been demonstrated on the Alstom CFB operating on Mississippi lignite.

- A separate ash-cleaning study to determine how much a nonwetting ash-cleaning system such as air jigging might remove is suggested especially if the cleaning technique can also incorporate some coal drying by utilizing a heat air stream. As discussed previously, every $\mathrm{kg}$ of fuel moisture removed results in a significantly higher improvement in a cycle efficiency than a comparable weight of ash removed. In all likelihood, the removal or blending of coals just for the purpose of ash reduction is probably not worth the cost.

- To incorporate carbon capture into the current study, DOE requested that a preliminary economic evaluation be performed on the alternatives of 1) precombustion separation of $\mathrm{CO}_{2}$ in an IGCC using the KBR transport gasifier and 2) postcombustion $\mathrm{CO}_{2}$ capture using a CFBC. It appears that the capture of $\mathrm{CO}_{2}$ from the high-pressure IGCC precombustion system would be less costly than from the low-pressure postcombustion CFBC system by a factor of 1.5, although the cost difference is not directly comparable because of the model input was limited to a coal similar to a North Dakota lignite as a worst case and to the fact that a slurry-fed GE gasifier was modeled. Use of a more appropriate gasifier would improve 
the economics, while the use of a coal quality similar to the Bulgarian LOM lignite would reduce the cost advantage.

- While the decision to pursue precombustion removal of carbon dioxide has been technically proven with the Rectisol and Selexol processes, GE and Siemens have not sold any gas turbine systems running on the high-hydrogen syngas. However, they have successfully demonstrated a gas turbine on syngases containing up to $95 \%$ hydrogen. The technological hurdles should not be too difficult given this experience in the gas turbine industry.

- Other possible conversion systems for the Bulgarian LOM lignite include pulverized coal combustion, pyrolysis of the feedstock, or oxyfuel combustion. Pulverized coal combustion probably would not be a good technology for the LOM lignite because of its high ash leading to high fouling rates in the combustor in addition to the low boiler efficiencies that would occur with a high-moisture, high-ash fuel. In addition, the tendency of the fuel to ball up when processed would preclude pulverization. Pyrolysis also would not be a good technology for the LOM lignite because of its high ash and relatively low volatile matter to fixed carbon and ash ratios would result in very large heat loads to generate a very small amount of pyrolysis products. The only alternate technology that might make some sense especially in the context of $\mathrm{CO}_{2}$ capture and sequestration would be oxyfuel firing in a CFB; however, this is currently being demonstrated in a small Alstom pilot plant, and commercial demonstration has not been contemplated yet.

- The high carbon in the gasifier ash and the unreacted limestone preclude the use of the ash as a cement filler. The CFB ash could possibly be utilized to mitigate acid runoff in the mine if it is an issue. Most likely, the ash will be returned to the mine, as none of the trace metal analyses suggests any problems with soil contamination.

- Mercury control will soon be required in the United States; however, when the issue would be addressed for plants in Bulgaria is hard to say. When it is finally required, it will be possible with treated activated carbon injection into the baghouse or electrostatic precipitator for a CFB system or with the possible removal in the wet scrubber if the $\mathrm{Hg}$ is in an oxidized form. Activated carbon beds for $\mathrm{Hg}$ control in pressurized gasification systems have been demonstrated for many years at Tennessee Eastman.

\section{REFERENCES}

1. Energy Information Administration. International Energy Outlook 2006; DOE/EIA0484(2006), June 2006.

2. Alfsen, G.C. An Overview of Hydrogen Production from Coal Gasification. Prepared for the U.S. Department of Energy, Morgantown Energy Technology Center, Dec 1984.

3. Sondreal, E.A. Review of Catalytic Gasification; EERC Internal Report, March 2005. 
4. Exxon Research and Engineering Company. Exxon Catalytic Coal Gasification Process Predevelopment Program; Final Project Report; Work Performed under DOE Contract No. EX-76-C-01-2369; 1978.

5. Electric Power Research Institute. Coal Gasification Guidebook: Status Applications and Technologies; Final Report; Prepared by SFA Pacific, Inc., EPRI TR-102034; Dec 1993.

6. Jacobsen, J.P. Char Reaction Kinetics in a Transport Gasifier. Master's Thesis, University of North Dakota, May 2001.

7. Mann, M.D.; Knutson, R.Z.; Erjavec, J.; Jacobsen, J.P. Modeling Reaction Kinetics of Steam Gasification for a Transport Gasifier. Fuel 200483.

8. Hossain, M.M. ASPEN/SP Computer Model of Great Plains Coal Gasifiers. Master's Thesis, University of North Dakota, 1995.

9. Carpenter, B.C. Optimization of Great Plains Coal Gasification Using ASPEN/SPP. Master's Thesis, University of North Dakota, 1993.

10. Electric Power Research Institute. Low-Rank Coal-Water Slurries for Gasification; Final Report; Prepared by the Energy \& Environmental Research Center, W.G. Willson Project Manager, EPRI AP-4262, Nov 1985.

11. U.S. Department of Energy. Tampa Electric Integrated Gasification Combined Cycle Project; Project Performance Summary, DOE/FE-0469, June 2004.

12. Shellhorse, V. The BGL Slagging Gasifier - Fuel Flexibility. Presented at the Gasification Technology Conference, San Francisco, CA, Oct 2005.

13. Miller, W.R.; Lang, R.A. Great Plains Coal Gasification Plant Public Design Report; $\mathrm{DOE} / \mathrm{CH} / 10088-1874,1985$.

14. Gronhovd, G.H.; Harak, A.E.; Fegley, M.M.; Severson, D.E. Slagging Fixed-Bed Gasification of North Dakota Lignite at Pressures to 400 psig; Bureau of Mines RI 7408, 1970.

15. Tam, S.; Nizamoff, A.; Kramer, S.; Olson, S.; Lau. F; Roberts, M.; Stopek, D.; Zabransky, R.; Hoffmann, J.; Shuster, E.; Zhan, N. Gasification Plant Cost and Performance Optimization; Task 3 Final Report; U.S. Department of Energy Contract No. DE-AC2699T40342, May 2005.

16. Rogers; L.H.; Bonsu, A.K.; Eiland, J.D.; Gardner, B.F., Powell; L.H., Booras, G.S.; Breault, R.W.; Salazar, S. Power from PRB - Four Conceptual IGCC Plant Designs Using the Transport Gasifier. Presented at the 22nd International Pittsburgh Coal Conference, Pittsburgh, PA, Sept 12-15, 2005. 
17. Smith, P.V. KBR Transport Gasifier. Presented at the Gasification Technology Conference, San Francisco, CA, Oct 2005.

18. Holt, N. A Summary of Recent IGCC Studies of $\mathrm{CO}_{2}$ Capture for Sequestration. Gasification Technologies Conference. Presented at the Gasification Technology Conference, San Francisco, CA, Oct 2003.

19. U.S. Department of Energy. The Wabash River Coal Gasification Repowering Project - An Update; Clean Coal Technology, Technical Report No. 20, Sept 2000.

20. Excelsior Energy, Inc. The Masaba Energy Project. Presented at the Gasification Technology Conference, San Francisco, CA, Oct 2005.

21. Anderson, C.M.; Willson, W.G.; Irwin, W. Opportunities for Coal-Water Fuels. Presented at 44th Annual Meeting of the Petroleum Society, Calgary, Alberta, Canada, May 1993.

22. U.S. Department of Energy National Energy Technology Laboratory. Texaco Gasifier IGCC Base Cases; National Energy Technology Laboratory Process Engineering Division, PEDIGCC-98-001, Sept 1998, Revised June 2000, www.netl.doe.gov/ technologies/ coalpower/gasification/system/texac3y.pdf.

23. Sondreal, E.A.; Daly, D.J. Energy Policy and Technologies: Analysis and Recommendations; Beaver, F.W.; Jones, M.L.; Mathsen, D.V.; Willson, W.G., Contributors; Groenewold, G.H., Eds.; Energy \& Environmental Research Center: Grand Forks, ND, March 1991.

24. Zygarlicke, C.J.; Nowok, J.W.; McCollor, D.P.; Galbreath, K.C.; Kiel, J.H.A.; Visser, H.J.M. Coal Ash Behavior in Reducing Environments (CABRE) II; Final Report for Combined Years 1 and 2 (April 8, 1996 - Dec 31, 1998) for U.S. Department of Energy Cooperative Agreement No. DE-FC21-93MC30098; EERC Publication 99-EERC-02-09; Energy \& Environmental Research Center: Grand Forks, ND, Feb 1999.

25. Notestein, J.E. Commercial Gasifier for IGCC Applications; DOE Study Report; DOE/METC No. 91/6118, June 1990.

26. Willson, W.G.; Hendrikson, J.G.; Mann, M.D.; Galegher, S.J.; Gallagher, J.R.; Mayer, G.G.; Thomas, W.C.; Winton, S.L.; Nelson, D.F. Use of Treated Gasification Wastewater in a Pilot Cooling Tower, Phase I; Final Report of Period Ending Jan 31, 1984; DOE/FE/60181-1602, 1984.

27. Hauserman, W.B.; Willson, W.G. Mechanical Problems in the Design of a Fixed-Bed Slagging Gasifier. In Proceedings of the Technical Economics Synfuels and Coal Energy Symposium; ASME 7th Annual Energy-Sources Technology Conference; Houston, TX, 1984. 
28. Sander, H.J.; Daradimos, G.; Hirschfelder, H. Operating Results of the BGL Gasifier at Schwarze Pumpe. Presented at the Gasification Technology Conference, San Francisco, CA, Oct 2003.

29. Picard, L. Development Status of BGL Gasification. Presented at the International Freiberg Conference on IGCC Technologies, June 2005.

30. Lau, F.; Rabovitser, J.; Byran, B.; Stopek, D. Biomass Gasification Co-Firing Project in Kentucky. Presented at the 18th International Pittsburgh Coal Conference, Sydney, Australia, Dec 2001.

31. Gasification Technologies Council Database. www.gasification.org/resource/database/ search.aspx (accessed 2006).

32. Van Sickels, M.J. Kellogg's KRW IGCC Power Generation Process. In Proceedings of the 14th Biennial Symposium on the Technology and Utilization of Low-Rank Coal Fuels; Organized by the University of North Dakota EERC, May 1987; p 4C2-3.

33. U.S. Department of Energy. Piñon Pine IGCC Power Project: A U.S. Department of Energy Assessment; DOE/NETL-2003/1183, Dec 2002.

34. Femmer, U.; Lambertz, J.; Scharf, H.J.; Schrader, L.; Teggers, H. Progress in Rheinbraun's Hydrogasification and High-Temperature Winkler Processes. In Proceedings of the 13th Biennial Lignite Symposium; DOE/METC-86, Feb 1986.

35. Renzenbrink, W.; Wischnewski, R.; Engelhard, J.; Mittelstadt, A. High-Temperature Winkler (HTW) Gasification. Presented at the Gasification Technology Conference, 1998.

36. Swanson, M.L.; Hajicek, D.R. Advanced High-Temperature, High-Pressure Transport Reactor Gasification. Presented at the 20th Annual International Pittsburgh Coal Conference, Pittsburgh, PA, Sept 15-19, 2003.

37. Wallace, F.; Guan, X.; Leonard, R.; Nelson, M.; Vimalchand, P.; Peng, W.W.; Smithe, P.V.; Breqult, R.W. Operation of the Transport Gasifier at the PSDF. Presented at the 31st International Technical Conference on Coal Utilization \& Fuels Systems; Clearwater, FL, May 21-25, 2006.

38. Swanson, M.L.; Hajicek, D.R.; Collings, M.E.; Henderson, A.K.; Breault, R. Gasification of Lignite in a Transport Reactor. Presented at the 23rd Annual International Pittsburgh Coal Conference, Pittsburgh, PA, Sept 25-28, 2006.

39. Swanson, M.L.; Zygarlicke, D.J.; Henderson, A.K.; Musich, M.A.; Moore, M.R. Gasifying Switchgrass Lignin for Biopower Applications. In Proceedings of the 30th International Technical Conference on Coal Utilization \& Fuels Systems; Clearwater, FL, April 17-21, 2005; pp 189-199. 
40. Swanson, M.L.; Hajicek, D.R.; Collings, M.E.; Henderson, A.K. Gasification of Low-Rank Coals in a Transport Reactor. In Proceedings of Western Fuels Symposium: 19th International Conference on Lignite, Brown, and Subbituminous Coals; Billings, MT, Oct 12-14, 2004.

41. Swanson, M.L.; Hajicek, D.R.; Collings, M.E.; Henderson, A.K. Gasification of Low-Rank Coals in a Transport Reactor. Presented at the 21st Annual International Pittsburgh Coal Conference, Osaka, Japan, Sept 13-17, 2004.

42. Swanson, M.L. Gasification of Industrial By-Products and Wastes in a Fluid-Bed Gasifier. Presented at the 28th International Conference on Coal Utilization \& Fuel Cells, Clearwater, FL, March 9-13, 2003.

43. Swanson, M.L.; Hajicek, D.R. Lignite Gasification in an Advanced Transport Reactor Gasifier. In Proceedings of the 18th International Low-Rank Fuels Symposium; Billings, MT, June 24-26, 2003.

44. Breault, R.; Swanson, M; Hajicek, D.; Henderson, A. Gasification of Mississippi Lignite Coal in the Transport Gasifier. Presented at the 31st International Technical Conference on Coal Utilization \& Fuels Systems, Clearwater, FL, May 21-25, 2006.

45. Longanbach, J.R. Transport Gasifier Operations at the Power Systems Development Facility. Presented at the 29th International Technical Conference on Coal Utilization \& Fuels Systems, Clearwater, FL, May 2004.

46. Peng, W.W.; Nelson, M.; Leonard, R.; Liu, G.; Vimalchand, P.; Dahlin, R.S. High-Sodium Lignite Gasification with the PSDF Transport Gasifier. Presented at the 22nd International Pittsburgh Coal Conference, Pittsburgh, PA, Sept 12-15, 2005.

47. Nelson, J.M.; Davies, O.L.; Davis, B.; Guan, X; Leonard, R.; Liu, G.; Peng, W.; Romans, D.; Vimalchand, P.; Smith, P.V.; Longanbach, J. Low-Rank Coal Gasification Studies at the PSDF. Presented at the 18th International Low-Rank Fuels Symposium, Billings, MT, June 24-26, 2003.

48. Guenther, C.; Syamlal, M.; Longanbach, J.; Smith, P.V. Two-Fluid Model of an IndustrialScale Transport Gasifier. AIChE 2003 Annual Meeting, San Francisco, CA, Nov 16-21, 2003.

49. Swaine, D.J. Trace Elements in Coal; Butterworth \& Co. Ltd, 1990.

50. Davis, B.M.; Smith, P.V.; Longanbach, J.R. Operation of the PSDF Transport Reactor. Presented at the 19th International Pittsburgh Coal Conference, Pittsburgh, PA, Sept 23-27, 2002.

51. Holt, N. Gasification Process Selection - Trade-Offs and Ironies. Presented at the Gasification Technology Conference, Washington, DC, 2004. 
52. Massoud, R.A.; Chen, S.; Lu, Y. Assessment of Carbon Capture Options for Power Plants. Presented at the 4th Annual Conference on Carbon Capture and Sequestration, Alexandria, VA, May 2005.

53. U.S. Department of Energy. Evaluation of Fossil Fuel Power Plants with $\mathrm{CO}_{2}$ Recovery; Final Report; Prepared by Parsons under DOE Contract No. DE-AM26-99FT40465, Feb 2002.

54. Korens, N.; Simbeck, D.R.; Wilhelm; D.J. Process Screening Analysis of Alternative Gas Treating and Sulfur Removal for Gasification; Prepared for U.S. Department of Energy National Energy Technology Laboratory by SFA Pacific, Inc., Task Order No. 73965600100, Dec 2002.

55. Jensen, M.D.; Musich, M.S.; Ruby, J.D. Carbon Separation and Capture; Plains $\mathrm{CO}_{2}$ Reduction Partnership Topical Report No. 11 for the U.S. Department of Energy; Energy \& Environmental Research Center: Grand Forks, ND, Jun 2005.

56. Osborne, J.B. Cost and Performance Breakthroughs in Regenerable $\mathrm{SO}_{2}$ Scrubbing and $\mathrm{CO}_{2}$ Capture. Presented at the Plains $\mathrm{CO}_{2}$ Reduction (PCOR) Partnership Meeting, Oct 2005.

57. Yaghi, O.M. Porous Crystals for Carbon Dioxide Storage. Presented at the 5th Annual Conference on Carbon Capture and Sequestration, Alexandria, VA, May 2006; Paper 193.

58. Carapellucci, R.; Milazzo, A. Membrane Systems for $\mathrm{CO}_{2}$ Capture and Their Integration with Gas Turbine Plants. In Proceedings of the I MECH E Part A Journal of Power and Energy 2003, $217(5), 505-517$.

59. Hägg, M.; Lindbråthen, A. $\mathrm{CO}_{2}$ Capture from Natural Gas Fired Power Plants by Using Membrane Technology. Ind. Eng. Chem. Res. 2005, 44 (20), 7668-7675.

60. Middleton, P.; Solgaard-Andersen, H.; Rostrup-Nielsen, H.T. Hydrogen Production with $\mathrm{CO}_{2}$ Capture Using Membrane Reactors; $\mathrm{CO}_{2}$ Capture Project Report; Available online at www.co2captureproject.org/reports/reports.htm (accessed 2006).

61. Tsapatsis, M. A New Concept for the Fabrication of Hydrogen Selective Silica Membranes; Annual Report (August 1, 2004 - July 31, 2005) for the U.S. Department of Energy Award Number DE-FG26-04NT42119; University of Minnesota Department of Chemical Engineering and Materials Science: Minneapolis, MN, Oct 2005.

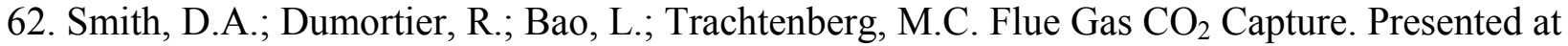
the 5th Annual Conference on Carbon Capture and Sequestration, Alexandria, VA, May 2006; Paper 39.

63. Maurstad, O. An Overview of Coal-Based Integrated Gasification Combined Cycle Technology; Massachusetts Institute of Technology, MIT LFEE 2005-002 WP, Sept 2005. 
64. Holt, N. IGCC and Gasification for a Changing Marketplace. Presented at the Gasification Technology Conference, Washington, DC, 2006.

65. Chen, C.; Rubin, E.S.; Berkenpas, M. $\mathrm{CO}_{2}$ Control Technology Effects on IGCC Plant Performance and Cost. Presented at the 23rd Annual International Pittsburgh Coal Conference, Pittsburgh, PA, Sept 25-28, 2006.

66. Rubin, E.S.; Rao, A.B.; Chen, C. Comparative Assessments of Fossil Fuel Power Plants with $\mathrm{CO}_{2}$ Capture and Storage. In Proceedings of 7th International Conference on Greenhouse Gas Control Technologies; Elsevier, 2005; Volume I, pp 285-293.

67. Bonsu, A.K.; Eiland, J.D.; Gardner, B.F.; Powell; C.A.; Rogers; L.H.; Booras, G.S.; Breault, R.W.; Salazar, S. Impact of $\mathrm{CO}_{2}$ Capture on Transport Gasifier IGCC Power Plant. Presented at the 31st International Technical Conference on Coal Utilization \& Fuels Systems, Clearwater, FL, May 21-25, 2006.

68. Armstrong, P. Method for Predicting Performance of an Ion Transport Membrane UnitOperation. Air Products and Chemicals, Inc., 2002, www.netl.doe.gov/ technologies/coalpower/gasification/projects/gas-sep/O2/o2-40343.html.

69. U.S. Department of Energy National Energy Technology Laboratory. Development of Ion Transport Membrane (ITM) Oxygen Technology for Integration in IGCC and Other Advanced Power Generation Systems. Project Facts, May 2006.

70. Amick, P. ConocoPhillips Gasification 2004, Presented at the Gasification Technology Conference, Washington, DC, 2004.

71. Chapel, D.; Ernst, J.; Martz, C. Recovery of $\mathrm{CO}_{2}$ from Flue Gases: Commercial Trends. Presented at the Canadian Society of Chemical Engineers Annual Meeting, Saskatoon, SK, October, 4-6, 1999, Paper No. 340.

72. Kaplan, L.J. Cost-Saving Process Recovers $\mathrm{CO}_{2}$ from Power Plant Flue Gas. Chem. Eng. 1982, 80 (24), 30-31.

73. Pauley, C.R.; Simiskey, P.L.; Haigh, S. N-Ren Recovers $\mathrm{CO}_{2}$ from Flue Gas Economically. Oil Gas J. 1984, 82 (20), 87-92.

74. U.S. Department of Energy. Carbon Sequestration: Research and Development; U.S. Department of Energy Office of Science, Office of Fossil Energy: Washington, DC, 1999.

75. Statoil. $\mathrm{CO}_{2}$ Storage $1000 \mathrm{~m}$ Down. www.statoil.com/STATOILCOM/SVG00990. nsf/web/SLEIpneren?opendocument (accessed Aug 2006).

76. University of North Dakota Energy \& Environmental Research Center. Bulgarian Clean Coal Utilization Technology Options Handbook; 95-EERC-09-01, Sept 1995, 181 p. 
APPENDIX A

\section{SUMMARY INFORMATION FROM THE BULGARIAN CLEAN COAL UTILIZATION TECHNOLOGY OPTIONS HANDBOOK}




\section{SUMMARY INFORMATION FROM THE BULGARIAN CLEAN COAL UTILIZATION TECHNOLOGY OPTIONS HANDBOOK}

Selected information from this 1995 study report is summarized below as background for further assessment of advanced technologies for lignite-based power production in Bulgaria.

\section{OVERVIEW}

With the support of the U.S. Department of Energy, the Energy \& Environmental Research Center (EERC) in close cooperation with the Bulgarian energy firms Energoproekt and TOTEMA performed an extensive evaluation of clean coal technologies for the Bulgarian power industry in 1995 (1. EERC. Bulgarian Clean Coal Utilization Technology Options Handbook, Final Report No. 95-EERC-09-01, September 1995). This study identified technology options for coal beneficiation, fuel switching, plant rehabilitation, emission controls, repowering, and advanced power systems - including integrated gasification combined cycle (IGCC) and pressurized fluidized-bed combustion (PFBC). Specific recommendations were made for the coal-fired power generation complexes at Bobov Dol, Sofia, and Maritsa East, but the study had broad application to Bulgaria's lignite-based power generation and domestic solid fuel (briquette) production. The central goal was to facilitate the transfer of U.S. technologies to meet Bulgaria's need for power generation, domestic solid fuel, and reduced emissions at minimum cost. The study identified opportunities for integrating near-term options into the long-term development of Bulgaria's lignite resources.

As a part of this study, material and energy balances were calculated to determine the sensitivity of PFBC and gasifier performance to changes in coal moisture, ash, and sulfur contents.

\section{THE FUTURE OF ADVANCED POWER SYSTEMS IN BULGARIA}

The future contribution of advanced coal-fired power technologies to the Bulgarian power industry was considered in the context of using turbine combined-cycle systems fired with imported natural gas to meet near-term requirements for low-emissions generating capacity obtainable at a relatively low capital cost. Later addition of coal gasifiers would be considered for converting to an IGCC system when the capital and operating costs favor such conversion. PFBC was also included in the current evaluation.

The objective of the current evaluation was to identify the unique process requirements involved in gasifying Bulgarian coals, particularly Maritsa East lignites characterized by very high levels of moisture, ash, and sulfur. Very little test data were available on the gasification, by any method, of this extremely low quality coal. Problems can be envisioned in every type of commercial gasifier, including entrained-flow, fluidized-bed, and fixed-bed designs. The potential problems carry forward from the gasifier into sulfur recovery and particulate removal, whether they involve hot-gas- or cold-gas-cleaning methods. 
The approach in this evaluation was first to lay out a matrix of the potentially applicable methods and the anticipated problems and then to survey vendors to assess the capabilities of currently available commercial equipment to address these problems.

Certain gasification technologies were identified to be most suitable for Bulgarian lignites containing high levels of moisture, ash, and sulfur. However, the optimum choices for lowquality lignite were recognized to be subject to change as developments progressed on advanced gasifiers, gas separation and cleaning methods, and gas turbines. Considering the projected adequacy of Bulgaria's installed electrical generating capacity, after it has been rehabilitated to acceptable levels of availability, the time horizon for a baseload lignite-fired advanced power system was not expected to occur until these technical improvements have been fully developed and demonstrated to present an acceptable level of risk. However, guidance received from Bulgarian sources indicated that advanced technologies could possibly be considered sooner for 1) cogeneration at the Maritsa East 1 Station supplying steam to the briquetting factory and

2) installation of natural gas-fired peaking turbines that would later be converted to IGCC operation.

\section{VENDOR CONTACTS}

To enhance the usefulness of this Technology Options Handbook, the EERC solicited relevant information from U.S. equipment vendors and energy firms that supplied goods or services in each of the major topical areas. Each vendor was contacted by phone to determine the company's level of interest. If a company expressed interest in participating in this study, the company was sent a letter detailing the current energy situation in Bulgaria. These letters also outlined specific data that would be useful in their assessment. The information received back from vendors was then incorporated into the appropriate section of this report. Table A-1 lists the vendors contacted in each of the topical areas and whether they responded with information. 
$\underline{\text { Table A-1. Bulgarian Clean Coal Utilization Project - Vendor Information }}$

Information

Not Interested Received

\section{PFBC-CFBC}

Deutsche Babcock Riley International, Inc.

Combustion Power Company

ABB-CE

Foster Wheeler Energy Corporation

Pyropower Corporation

Tampella Power

\section{GASIFICATION}

DESTEC Engineering, Inc.

Texaco

Institute of Gas Technology

Lurgi Corporation

Uhde GmbH

ABB Combustion Engineering, Inc.

Shell International Petroleum Company

MW Kellogg Company

Dakota Gasification Co.

\section{COAL SUPPLY}

ARCO Coal Company

Caballo Rojo, Inc.

Westmoreland Resources, Inc.

Cyprus Coal Company

Kennecott Energy Company

\section{ARCHITECT \& ENGINEERING FIRMS}

Overseas Bechtel, Inc., Corporation

Knox Broom

Morrison Knudsen Corporation

Stone \& Webster Engineering Corporation

Applied Power Associates, Inc.

Bibb and Associates, Inc.

Black \& Veatch

Burns \& McDonnell

Gilbert/Commonwealth, Inc.

HDR, Inc.

ICF Kaiser Engineers

Parsons Brinckerhoff, Inc. 
Table A-1. Bulgarian Clean Coal Utilization Project - Vendor Information (continued)

Information

Not Interested Received

ARCHITECT \& ENGINEERING FIRMS (continued)

Parsons Main, Inc.

Raytheon Engineers \& Constructors, Inc.

Sargent \& Lundy

STV/Sanders \& Thomas

Tippett \& Gee, Inc.

\section{ENVIRONMENTAL CONTROL SYSTEMS}

ABB Environmental Systems, Inc.

ABB Combustion Engineering, Inc.

Burns \& McDonnell

Raytheon Engineers \& Constructors, Inc.

Pure Air

ENVIRONMENTAL SYSTEMS

Wheelabrator Air Pollution Control

Environmental Elements Corporation

Black \& Veatch

Stone \& Webster Engineering Corporation

Sargent \& Lundy Engineers

GE Environmental Services, Inc.

Research Cottrell

Babcock \& Wilcox Company

\section{UPGRADE COAL-HANDLING SYSTEM}

CLI Corporation

Brechbuhler Scales, Inc.

FMC Corporation

T.J. Gundlach Machine Company

Heyl \& Patterson, Inc.

Interstate Equipment Corporation

McNally Wellman

Montague Systems, Inc.

Pennsylvania Crusher Corporation

Roberts \& Schaefer Company

TAMS Consultants, Inc.

Continued... 
Table A-1. Bulgarian Clean Coal Utilization Project - Vendor Information (continued)

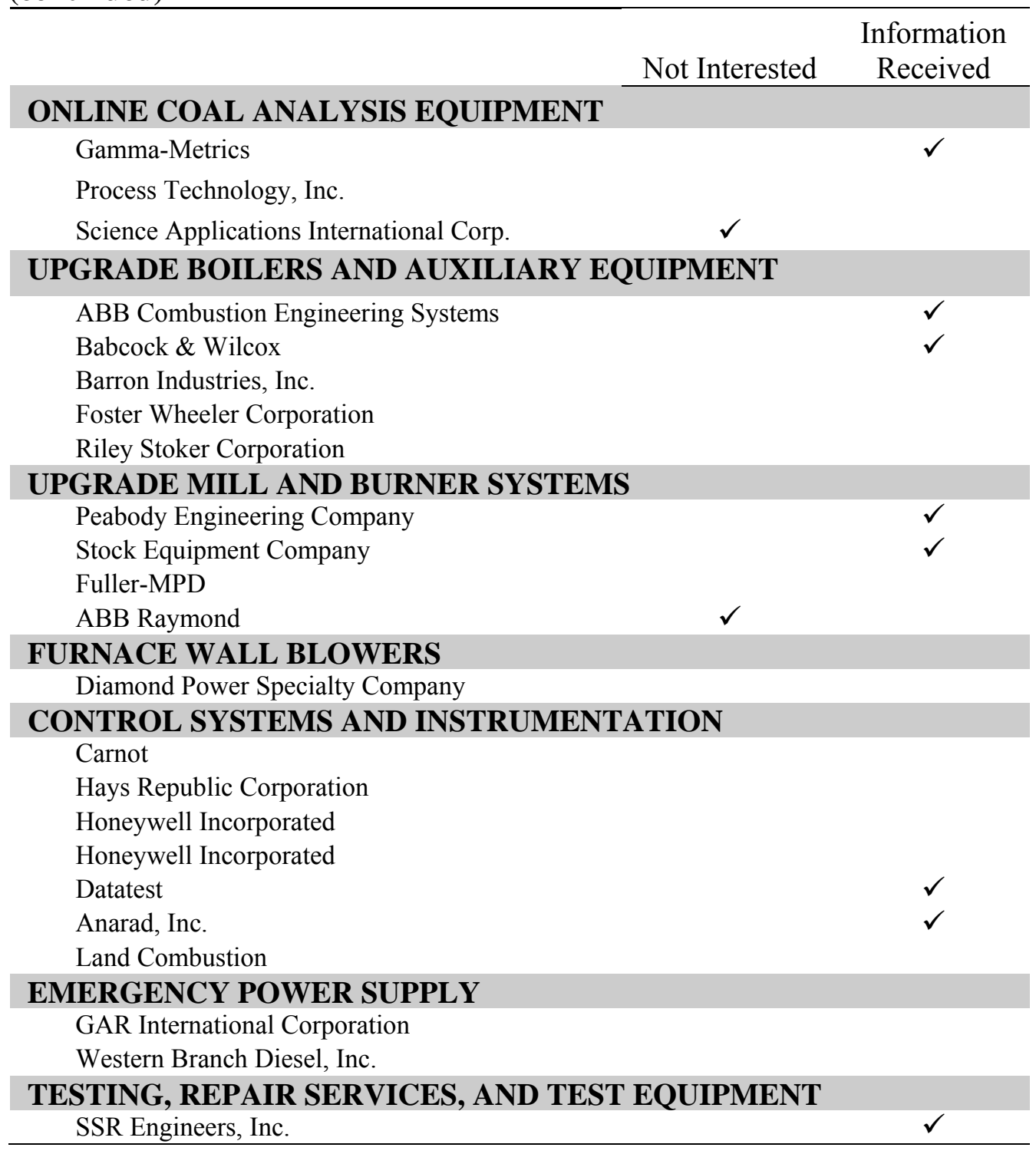




\section{SUMMARY OF BULGARIAN POWER PLANTS}

Five major coal-fired power complexes exist in Bulgaria, with a total gross capacity of 4840 MW (1995). Based on information provided by Energoproekt and TOTEMA, and by a study report by Bechtel, (Overseas Bechtel, Inc. "Volume 1: Power Complex Rehabilitation in Bulgaria," final report; Committee of Energy: Bulgaria, TDA\#91-735B-02, 1993), the current status and needs of the power plants in Bulgaria were identified. Information on the size and fuel supply of these facilities is summarized below.

Power Plant Name: Gross Plant Capacity: Current Fuel Source:

Power Plant Name: Gross Plant Capacity: Current Fuel Source:

Power Plant Name: Gross Plant Capacity: Current Fuel Source:

Power Plant Name: Gross Plant Capacity: Current Fuel Source:

Power Plant Name: Gross Plant Capacity: Current Fuel Source:

Power Plant Name: Gross Plant Capacity: Current Fuel Source:

Power Plant Name: Gross Plant Capacity: Current Fuel Source:
Bobov Dol $630 \mathrm{MW}$

Bobov Dol, subbituminous, 50\% moisture- and ash-free (maf) volatile matter, 8800-11,700 kJ/kg (3783-5030 Btu/lb) LHV, 38\%-46\% ash, $16 \%-19 \%$ moisture, $1.6 \%$ sulfur

\section{Varna}

$1260 \mathrm{MW}$

Ukranian anthracite, dry ball mills with subsequent fuel storage $29,300 \mathrm{~kJ} / \mathrm{kg}(12,597 \mathrm{Btu} / \mathrm{lb}) \mathrm{LHV}, 12 \%-16 \%$ ash, 6\%-8\% moisture, $<0.5 \%$ sulfur, $12 \%-14 \%$ volatile matter, ash fusion temperature of $1200^{\circ} \mathrm{C}\left(2192^{\circ} \mathrm{F}\right)$

Maritsa East 1 (briquette factory)

$500 \mathrm{MW}$

Lignite, Troyanovo 1

Maritsa East 2, older units (1-4)

600-MW design, derated to $520 \mathrm{MW}$

Lignite, Troyanovo 2, 5530-6710 kJ/kg (2377-2882 Btu/lb), 12\%$23 \%$ ash, $52 \%-58 \%$ moisture, $1.7 \%-2.3 \%$ sulfur

Maritsa East 2, newer units (5-8)

$840 \mathrm{MW}$

Lignite, Troyanovo 2, 5530-6710 kJ/kg (2377-2882 Btu/lb), 12\%$23 \%$ ash, $52 \%-58 \%$ moisture, $1.7 \%-2.3 \%$ sulfur

Maritsa East 3

840 MW

Lignite, Troyanovo 3, $5945 \mathrm{~kJ} / \mathrm{kg}$ (2556 Btu/lb) LHV, 15\% ash, 56\% moisture, $1.6 \%-2.4 \%$ sulfur

Maritsa 3

$170 \mathrm{MW}$

Lignite, Mambas 


\section{QUALITY OF COAL RESOURCES}

In Bulgaria, the 1995 estimate of proven reserves included $30 \mathrm{MM}$ tons of higherrank coal (mainly bituminous), which accounted for less than 1\% of annual production. Low-rank coal (LRC) reserves totaled $3700 \mathrm{MM}$ tons, of which two-thirds were available for surface mining. Half of the Bulgarian LRC reserves and three-quarters of the 35.3 million tons of LRC (mainly lignite) produced in 1988 are accounted for by the Maritsa East lignite deposit. The Maritsa East lignite bed, varying from 3 to $25 \mathrm{~m}$ in thickness, is high in moisture $(49 \%-57 \%)$, ash $(30 \%-45 \%)$, and sulfur $(2.8 \%-4.1 \%$ dry) and has a low heating value (LHV) $(5-7 \mathrm{MJ} / \mathrm{kg})$. The characteristics of the Maritsa lignite deposits are shown in Tables A-1 and A-2 below. In addition to the properties of the coal, the reduction levels of the major pollutants required to meet current and proposed standards are listed. Other mines of interest are those that serve the Bobov Dol and the Sofia Stations. The properties of the coals from these mines are also presented in the following tables. 
Table A-2. Design Coal Analysis for Bulgarian Maritsa East 1 and 2 Lignite

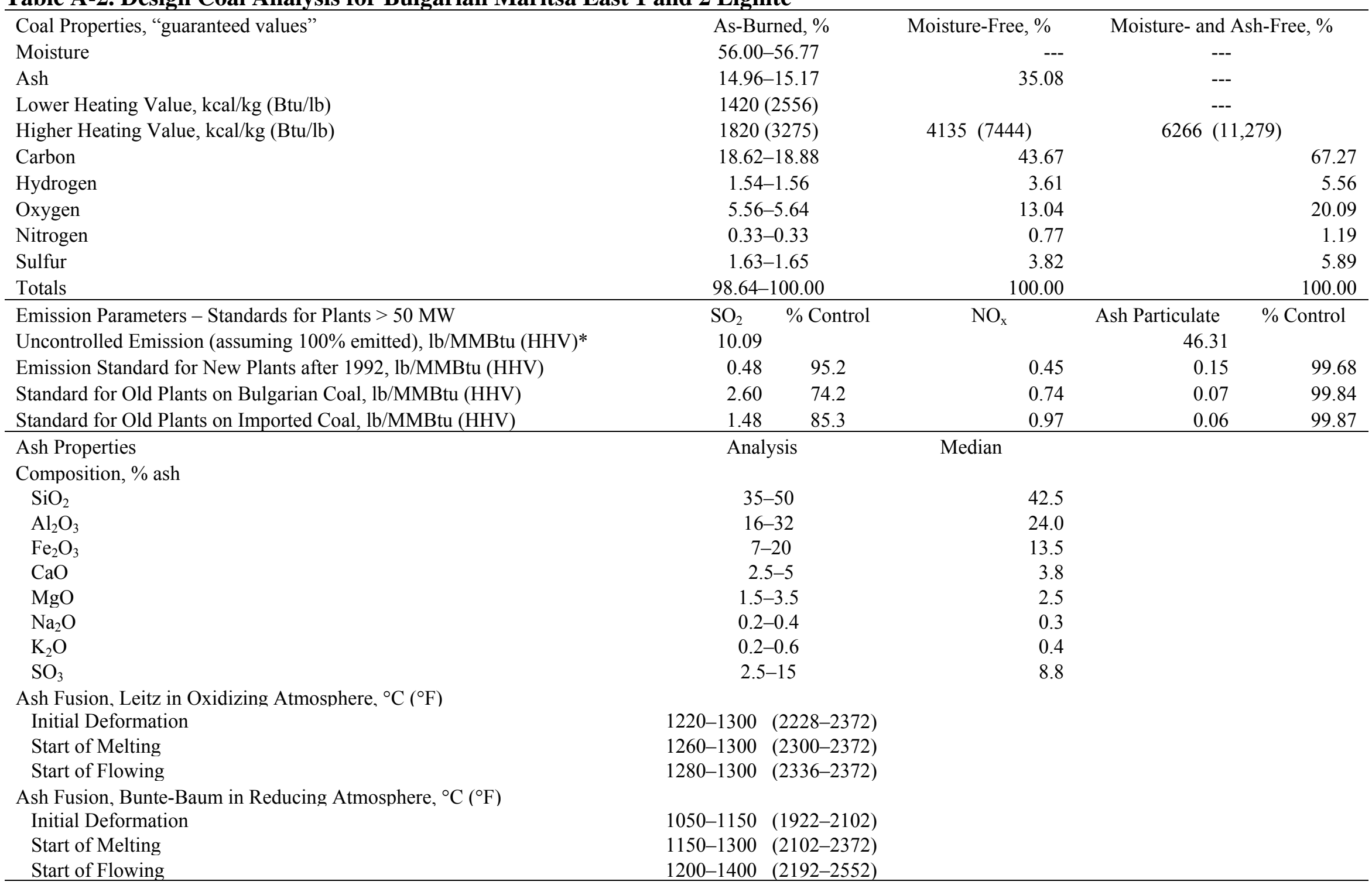

* High heating value. 
Table A-3. Design Coal Analysis for Bulgarian Maritsa East 3 Lignite

Coal Properties, guaranteed values

Moisture

Ash

Lower Heating Value, $\mathrm{kcal} / \mathrm{kg}$ (Btu/lb)

Higher Heating Value, $\mathrm{kcal} / \mathrm{kg}(\mathrm{Btu} / \mathrm{lb})$

Carbon

Hydrogen

Oxygen

Nitrogen

Sulfur

Totals

Emission Parameters - Standards for Plants $>50 \mathrm{MW}$

Uncontrolled Emission (assuming 100\% emitted), lb/MMBtu (HHV)*

Emission Standard for New Plants after 1992, lb/MMBtu (HHV)

Standard for Old Plants on Bulgarian Coal, lb/MMBtu (HHV)

Standard for Old Plants on Imported Coal, lb/MMBtu (HHV)

Composition, \% Ash

$\mathrm{SiO}_{2}$

$\mathrm{Al}_{2} \mathrm{O}_{3}$

$\mathrm{Fe}_{2} \mathrm{O}_{3}$

$\mathrm{CaO}$

$\mathrm{MgO}$

$\mathrm{Na}_{2} \mathrm{O}$

$\mathrm{K}_{2} \mathrm{O}$

$\mathrm{CO}_{3}$

Ash Fusion, Leitz in Oxidizing Atmosphere, ${ }^{\circ} \mathrm{C}\left({ }^{\circ} \mathrm{F}\right)$

Initial Deformation

Start of Melting

Start of Flowing

Ash Fusion, Bunte-Baum in Reducing Atmosphere, ${ }^{\circ} \mathrm{C}\left({ }^{\circ} \mathrm{F}\right)$

Initial Deformation

Start of Melting

Start of Flowing

* High heating value.
** Not available.

\begin{tabular}{|c|c|c|c|}
\hline As-Burned, \% & Moisture-Free, $\%$ & \multicolumn{2}{|c|}{ Moisture- and Ash-Free } \\
\hline $38.00-38.42$ & - & \multicolumn{2}{|c|}{-} \\
\hline $31.00-31.34$ & 50.90 & \multirow{2}{*}{\multicolumn{2}{|c|}{-}} \\
\hline $1565(2817)$ & & & \\
\hline $1870(3366)$ & $3016(5429)$ & \multicolumn{2}{|c|}{$6032(10,857)$} \\
\hline 20.70-20.93 & 33.99 & \multicolumn{2}{|c|}{69.23} \\
\hline $1.70-1.72$ & 2.79 & \multicolumn{2}{|c|}{5.69} \\
\hline $3.30-3.34$ & 5.42 & \multicolumn{2}{|c|}{11.04} \\
\hline $0.50-0.51$ & 0.82 & \multicolumn{2}{|c|}{1.67} \\
\hline $3.70-3.74$ & 6.08 & \multicolumn{2}{|c|}{12.37} \\
\hline $98.90-100.00$ & 100.00 & \multicolumn{2}{|c|}{100.00} \\
\hline$\%$ Control & $\mathrm{NO}_{\mathrm{x}}$ & $\begin{array}{c}\text { Ash Particulate } \\
93.13\end{array}$ & $\%$ Control \\
\hline 97.8 & 0.45 & 0.15 & 99.84 \\
\hline 88.3 & 0.74 & 0.07 & 99.92 \\
\hline 93.3 & 0.97 & 0.06 & 99.94 \\
\hline Analysis & Median & & \\
\hline $35-40$ & 37.5 & & \\
\hline $8-20$ & 14.0 & & \\
\hline $10-18$ & 14.0 & & \\
\hline $22-30$ & 26.0 & & \\
\hline $1-3$ & 2.0 & & \\
\hline $\mathrm{NA}^{* *}$ & NA & & \\
\hline NA & NA & & \\
\hline $15-35$ & 25.0 & & \\
\hline
\end{tabular}

1130-1180 (2066-2156)

1240-1290 (2264-2354)

1330-1400 (2426-2552)

NA

NA

NA 
Table A-4. Design Coal Analysis for Bobov Dol Coal Mines

Coal Properties, guaranteed values

Moisture

Ash

Lower Heating Value, $\mathrm{kcal} / \mathrm{kg}$ (Btu/lb)

Higher Heating Value, kcal/kg (Btu/lb

Carbon

Hydrogen

Oxygen

Nitrogen

Sulfur

Totals

Emission Parameters - Standards for Plants $>50 \mathrm{MW}$

Uncontrolled Emission (assuming 100\% emitted), lb/MMBtu (HHV)*

Emission Standard for New Plants after 1992, lb/MMBtu (HHV)

Standard for Old Plants on Bulgarian Coal, lb/MMBtu (HHV)

Standard for Old Plants on Imported Coal, lb/MMBtu (HHV)

Ash Properties

Composition, \% Ash

$\mathrm{SiO}_{2}$

$\mathrm{Al}_{2} \mathrm{O}_{3}$

$\mathrm{CaO}$

$\mathrm{MgO}$

$\mathrm{Na}_{2} \mathrm{O}$

$\mathrm{K}_{2} \mathrm{O}$

$\mathrm{SO}_{3}$

\begin{tabular}{|c|c|c|c|}
\hline As-Burned, $\%$ & Moisture-Free, $\%$ & \multicolumn{2}{|c|}{ Moisture- and Ash-Free, $\%$} \\
\hline $16.00-16.53$ & - & \multicolumn{2}{|c|}{-} \\
\hline $40.30-41.63$ & 49.88 & \multicolumn{2}{|c|}{-} \\
\hline $2712(4882)$ & & & \\
\hline $2917(5250)$ & $3472(6250)$ & \multicolumn{2}{|c|}{$6675(12,014)$} \\
\hline $29.60-30.58$ & 36.63 & \multicolumn{2}{|c|}{73.09} \\
\hline $2.20-2.27$ & 2.72 & \multicolumn{2}{|c|}{5.43} \\
\hline $5.90-6.10$ & 7.30 & \multicolumn{2}{|c|}{14.57} \\
\hline $1.10-1.14$ & 1.36 & \multicolumn{2}{|c|}{2.72} \\
\hline $1.70-1.76$ & 2.10 & \multicolumn{2}{|c|}{4.20} \\
\hline $96.80-100.00$ & 100.00 & \multicolumn{2}{|c|}{100.00} \\
\hline$\%$ Control & $\mathrm{NO}_{\mathrm{x}}$ & $\begin{array}{c}\text { Ash Particulat } \\
79.30\end{array}$ & $\%$ Contro \\
\hline 92.8 & 0.45 & 0.15 & 99.81 \\
\hline 61.2 & 0.74 & 0.07 & 99.91 \\
\hline 77.8 & 0.97 & 0.06 & 99.93 \\
\hline
\end{tabular}

Ash Fusion, Leitz in Oxidizing Atmosphere, ${ }^{\circ} \mathrm{C}\left({ }^{\circ} \mathrm{F}\right)$

Initial Deformation

Start of Melting Start of Flowing

Ash Fusion, Bunte-Baum in Reducing Atmosphere, ${ }^{\circ} \mathrm{C}\left({ }^{\circ} \mathrm{F}\right)$

Initial Deformation

Analysis

Median

$50-60 \quad 55.0$

$23-30 \quad 26.5$

$9-18 \quad 13.5$

$1-3 \quad 2.0$

$1-4.5 \quad 2.8$

NA** NA

NA NA

$\begin{array}{ll}0.8-3.5 & 2.2\end{array}$

Start of Melting

Start of Flowing

110-1400 (2012-2552)

* High heating value.

1400-1800

NA
NA
NA
$(1742-2102)$
$(2012-2552)$
$(2552-3272)$

** Not available. 
Table A-5. Design Coal Analysis for Sofia Coal Mines

\begin{tabular}{|c|c|c|c|c|c|}
\hline Coal Properties, guaranteed values & \multicolumn{2}{|c|}{ As-Burned, \% } & Moisture-Free, $\%$ & \multicolumn{2}{|c|}{ Moisture- and Ash-Free, $\%$} \\
\hline Moisture & \multicolumn{2}{|c|}{$49.00-51.09$} & - & \multicolumn{2}{|c|}{-} \\
\hline Ash & \multicolumn{2}{|c|}{$18.40-19.19$} & 39.23 & \multicolumn{2}{|c|}{-} \\
\hline Lower Heating Value, kcal/kg (Btu/lb) & \multicolumn{2}{|c|}{$1431(2576)$} & & \\
\hline Higher Heating Value, kcal/kg (Btu/lb) & \multicolumn{2}{|c|}{1789 (3219) } & $3507(6312)$ & \multicolumn{2}{|c|}{$5486(9875.2)$} \\
\hline Carbon & \multicolumn{2}{|c|}{$18.20-18.98$} & 38.81 & \multicolumn{2}{|c|}{63.86} \\
\hline Hydrogen & \multicolumn{2}{|c|}{$1.50-1.56$} & 3.20 & \multicolumn{2}{|c|}{5.26} \\
\hline Oxygen & \multicolumn{2}{|c|}{$7.10-7.40$} & 15.14 & \multicolumn{2}{|c|}{24.91} \\
\hline Nitrogen & \multicolumn{2}{|c|}{$0.40-0.42$} & 0.85 & \multicolumn{2}{|c|}{1.40} \\
\hline Sulfur & \multicolumn{2}{|c|}{$1.30-1.36$} & 2.77 & \multicolumn{2}{|c|}{4.56} \\
\hline Totals & \multicolumn{2}{|c|}{$95.90-100.00$} & 100.00 & \multicolumn{2}{|c|}{100.00} \\
\hline Emission Parameters - Standards for Plants $>50 \mathrm{MW}$ & $\mathrm{SO}_{2}$ & $\%$ Control & $\mathrm{NO}_{\mathrm{x}}$ & Ash Particulate & $\%$ Control \\
\hline Emission Standard for New Plants after 1992, lb/MMBtu (HHV) & $\hat{0.0 .48}$ & 94.3 & 0.45 & 0.15 & 99.75 \\
\hline Standard for Old Plants on Bulgarian Coal, lb/MMBtu (HHV) & 2.60 & 69.1 & 0.74 & 0.07 & 99.88 \\
\hline Standard for Old Plants on Imported Coal, lb/MMBtu (HHV) & 1.48 & 82.4 & 0.97 & 0.06 & 99.90 \\
\hline Ash Properties & \multicolumn{2}{|c|}{ Analysis } & Median & & \\
\hline \multicolumn{6}{|l|}{ Composition, \% Ash } \\
\hline $\mathrm{SiO}_{2}$ & \multicolumn{2}{|c|}{$15-35$} & 25.0 & & \\
\hline $\mathrm{Al}_{2} \mathrm{O}_{3}$ & \multicolumn{2}{|c|}{$8-12$} & 10.0 & & \\
\hline $\mathrm{Fe}_{2} \mathrm{O}_{3}$ & \multicolumn{2}{|c|}{$5-12$} & 8.5 & & \\
\hline $\mathrm{CaO}$ & \multicolumn{2}{|c|}{$15-60$} & 37.5 & & \\
\hline $\mathrm{MgO}$ & \multicolumn{2}{|c|}{$1-3$} & 2.0 & & \\
\hline $\mathrm{Na}_{2} \mathrm{O}$ & \multicolumn{2}{|c|}{$\mathrm{NA}^{* *}$} & NA & & \\
\hline $\mathrm{K}_{2} \mathrm{O}$ & & & NA & & \\
\hline $\mathrm{SO}_{3}$ & & & 15.0 & & \\
\hline Ash Fusion, Leitz in Oxidizing Atmosphere, ${ }^{\circ} \mathrm{C}\left({ }^{\circ} \mathrm{F}\right)$ & & & & & \\
\hline Initial Deformation & & & & & \\
\hline Start of Melting & & & & & \\
\hline Start of Flowing & & & & & \\
\hline Ash Fusion, Bunte-Baum in Reducing Atmosphere, ${ }^{\circ} \mathrm{C}\left({ }^{\circ} \mathrm{F}\right)$ & & & & & \\
\hline Initial Deformation & $1050-1200$ & $(1922-2192)$ & & & \\
\hline Start of Melting & $1100-1400$ & $(2012-2552)$ & & & \\
\hline Start of Flowing & $1400-1800$ & $(2552-3272)$ & & & \\
\hline
\end{tabular}

Start of Flowing

* High heating value.

** Not available. 


\section{TECHNOLOGIES RECOMMENDED FOR COGENERATION AT MARITSA EAST 1}

Three advanced technologies were identified as offering unique advantages for a Maritsa East 1 cogeneration unit:

- CFBC offers the lowest risk and greatest flexibility for burning low-quality, high-ash, high-sulfur lignite with good turndown capability, high levels of sulfur and $\mathrm{NO}_{\mathrm{x}}$ control, and high sorbent utilization.

- A PFBC combined-cycle system operating on Bulgarian lignite is predicted to generate more than half of its power in the gas turbine, owing to the low level of in-bed heat transfer and high mass flow associated with high moisture. A simple and relatively low-cost PFBC system could be designed to generate limited amounts of power from high-moisture lignite using only a gas turbine without the steam turbine, sending all steam production to the briquetting plant. Interest in this approach depends on the relative power and steam load requirements and the economics of the simplified system.

- The transport reactor developed by MW Kellogg Company (a pressurized, circulating, fast fluidized bed capable of operating in both combustion and gasification modes) is recommended for firing a gas turbine on Bulgarian lignite, with supplementary firing on natural gas. Supplemental firing would raise the turbine inlet temperature and provide a high incremental efficiency for the natural gas burned. Also, within somewhat narrow limits, the division of energy flow between power generation and steam for the briquetting plant could be adjusted by tempering with additional moisture in the transport combustor. The combination of tempering and supplemental firing represents a possibility for designing a system that would offer some flexibility to respond to both surge needs for electrical generation and changes in demand for steam at the briquetting plant.

\section{FLUIDIZED-BED COMBUSTION SYSTEMS}

Vendor information on CFBC and PFBC was supplied by ABB-CE, Foster Wheeler, Pyropower, and Tampella Power. In addition, Kellogg provided information on its transport reactor operating in a pressurized combustion mode.

\section{REPOWERING WITH CIRCULATING FLUIDIZED-BED COMBUSTION}

CFBC is a direct alternative to flue gas desulfurization (FGD) for new plants and a potential repowering technology option for older plants. In the study performed by Overseas Bechtel, Inc, it was determined that the boilers powering the Maritsa East 1 facility were past their useful life and needed replacement. Replacement with fluid-bed technology was a recommended approach. Fluid-bed retrofits have been demonstrated to be technically and economically effective methods of extending plant life and regaining or expanding the capacity 
of the original boiler. Additionally, CFBCs have been successfully operated on a wide variety of fuels, some of even poorer quality than that of the Maritsa lignites.

Vendor response indicated that a CFBC could be used to generate the electricity, steam, and hot water required to replace the Maritsa East 1 operating unit. A calcium-to-sulfur ratio of 3.0, equivalent of 0.6 pounds limestone per pound of coal, was recommended to meet the post$1995 \mathrm{SO}_{2}$ emission standard. $\mathrm{NO}_{\mathrm{x}}$ would be controlled within the 1995 limits with no special control devices because of the inherently low $\mathrm{NO}_{\mathrm{x}}$ emissions from CFBCs. Particulate control would need to be accomplished using a baghouse or ESP.

Based on the analysis of the Maritsa East 1 lignite and the experience of the EERC with similar fuels, it is believed that the $\mathrm{SO}_{2}$ emissions could be achieved at a calcium-to-sulfur ratio lower than 3.0. Since high limestone feed rates impact both the capital costs of feed- and ashhandling systems and operating costs for reagent and ash disposal, pilot-scale testing of the Maritsa fuel is recommended as the basis for performing a detailed cost estimate for a CFBC system. A relatively inexpensive pilot test could save millions of dollars in unnecessary capital and operating expense.

\section{IMPACTS OF COAL PROPERTIES ON THE PERFORMANCE AND COST OF CFBC}

Because of the action of the circulating solids, the CFBC typically operates with a high heat flux. The heat flux for full-load conditions ranges from about 25,000 to $35,000 \mathrm{Btu} / \mathrm{hr} \mathrm{ft}^{2}$. The heat flux increases with increasing temperature and velocity. Fuel type may indirectly affect heat flux to a small degree by its effects on recirculation rates and particle-size distributions

Lignitic coals are typically very reactive, and carbon burnout approaching $100 \%$ can be achieved for some coals. Factors affecting carbon burnout for the Maritsa lignite will be high ash and sulfur levels, which result in a high solids removal rate. Because the carbon content in the bed is typically around 3\%, high solid drain rates will result in higher unburned carbon losses. A variety of fluid-bed heat exchanger and bed removal systems are offered as options to CFBCs. These systems increase efficiency by providing an opportunity to burn off residual solids and capture the sensible heat in the bottom ash before discharge. A cost-benefit analysis of using such a system for Maritsa East 1 is warranted.

Coal properties affect both the design and operation of a CFBC system. For example, a system designed for high-moisture fuel would require a larger fuel feed system. Downstream heat recovery equipment would have to be larger for high-moisture Maritsa coal to account for the higher flue gas flow rates. During operation of a CFBC, high-moisture fuels generate greater mass flows through the system, resulting in a higher fraction of the energy being recovered in the downstream convective heat recovery unit. The amount of energy that ends up in the hot gas leaving the CFBC can vary from $40 \%$ for relatively dry bituminous coals to $65 \%$ for fuels with $40 \%$ moisture, with a further percentage increase at progressively higher moisture contents. This shift results in a reduction of boiler efficiency because of greater stack losses for the highmoisture coals. Other losses in boiler efficiency result from the conversion of fuel hydrogen to water, unrecoverable heat from the discharge of ash and spent sorbent, and the calcination of the 
raw sorbent. A boiler efficiency credit is given for the sulfation of the sorbent, as this process produces usable heat. The loss in efficiency for Maritsa East lignite as a result of its high ash content could be reduced by removing ash and sulfur and drying before combustion, but any beneficiation to improve coal quality would need to be evaluated for cost-effectiveness.

For FBC boilers firing LRC, the most important design and selection parameters to obtain low steam and power costs are the combustor bed temperature, coal heating value and cost, system availability, sulfur control costs, total capital investment, and exhaust gas temperature. All other cost factors and design parameters, even the capital cost of the FBC with its internal components, are secondary. Most of the FBC design parameters which have significant effects upon environmental performance have insignificant effects upon production costs, including bed design velocity, bed depth, bed pressure drop, combustor size, configuration, and excess air. The FBC velocity, bed depth, pressure drop, and excess air should be designed for optimization of the system's energy output, combustion efficiency, and sulfur retention (in approximately that order) rather than for any reduction of capital costs.

The prime fuel parameters of heating value, sulfur content, delivered cost, and required $\mathrm{Ca} / \mathrm{S}$ addition have major impacts on operating costs. For high-sulfur coals, such as that from the Maritsa mines, the optimization of solids recycle, bed temperature, and sorbent properties can be quite beneficial in reducing operating costs. The system design and $\mathrm{SO}_{2}$-sorbent selection should be optimized to lower the sulfur control costs (e.g., small limestone particle size, high calcium content per dollar cost, minimum bed drain rates, recycle of solids to the combustor). The FBC bed temperature should also be designed for optimum sorbent usage, which is typically near $1550^{\circ} \mathrm{F}\left(843^{\circ} \mathrm{C}\right)$.

\section{PRESSURIZED FLUIDIZED-BED COMBUSTION}

Repowering with PFBC was recommended as a possible solution for aging units at the Maritsa East 1 power station, which was built during a period between 1958 and 1963. The current station consists of six natural circulation-drum steam boilers with four extraction turbines. These units provide process steam for an adjacent briquetting plant and hot water for the centralized heating systems of a local town, greenhouse, and the power and briquetting plants. A total of $200 \mathrm{MW}$ of electricity, 990,000 lb/hour of steam, and $160 \mathrm{MMBtu} / \mathrm{hr}$ of hot water is produced from these boilers. There are also two double condensing units built for the sole purpose of producing electricity, with $150 \mathrm{MWe}$ each. The combined total electric generation is $500 \mathrm{MW}$. Studies performed by Overseas Bechtel, Inc., and the Bulgarian firms TOTEMA and Energoproekt have determined that these boilers will soon reach the end of their useful life. The boiler tube metal is nearly exhausted, and operating these boilers requires unjustifiably high operating expenses. The overall efficiency of the existing boilers is very low. Emissions of particulates, nitrogen oxides, and sulfur dioxide are all above the new limits. Based on these factors, rehabilitation of the existing boilers was ruled out. Replacement of the boilers with PFBC is a potential option for this plant.

The calculated effect of increasing coal moisture over a range of $5 \%$ to $64 \%$, including pasting water for slurry feed at higher moisture levels, was to increase the percentage of system 
power generated by the gas turbine from $27 \%$ to $59 \%$ while reducing in-bed heat transfer from $62 \%$ to $21 \%$ of coal LHV, and total steam generation both in-bed and in the HRSG from $75 \%$ to $38 \%$ of coal LHV. Generating efficiency (LHV) drops from $38.7 \%$ at $5 \%$ moisture to $34.5 \%$ at $64 \%$, indicating that higher stack losses due to excess moisture are only partially compensated by the beneficial shift in energy flow to the gas turbine. At high coal moisture, the generating efficiency based on gas turbine power alone approaches $20 \%$, while still providing $38 \%$ of the coal LHV as steam that can be used for heat or process applications. This result suggests that the use of high-moisture coal in a PFBC system operating with a gas turbine alone (no steam turbine) could be a low-capital-cost approach for IPP or combined heat and power (CHP) projects.

The calculated heat loss in the PFBC bed drain increases nearly linearly with coal ash content to about $2.2 \%$ of coal LHV at $40 \% \mathrm{db}$ ash content. The amount of in-bed heat transfer as a percentage of coal LHV was shown to be further reduced by high coal ash levels. Bed drain loss was only slightly affected by coal sulfur content $(0.3 \%$ loss at $6 \%$ coal sulfur and $3: 1 \mathrm{Ca}: \mathrm{S})$, because of the nearly neutral enthalpy balance for limestone addition under conditions of a high partial pressure of $\mathrm{CO}_{2}$, where the unreacted reagent remains in the form of calcium carbonate rather than calcium oxide. In a PFBC, nearly full benefit is obtained from the heating value in coal sulfur, whereas in IGCC, where hydrogen sulfide is removed, most of this heating value is either lost or recovered as low-grade heat. These calculations support the use of PFBC for East Central European coal, even at extremely high levels of moisture, ash, and sulfur. Operational and turndown capabilities at these high concentration levels will need to be evaluated with vendors of PFBC systems.

\section{THE KELLOGG TRANSPORT REACTOR PRESSURIZED COMBUSTION PROCESS}

Kellogg offers its transport reactor process that can be used in pressurized combustion combined-cycle (PCCC) power generation in the same manner as other PFBC technologies. Based upon Kellogg's preliminary calculations for Maritsa 1 East and Sofia lignites, the most effective conversion process would be PCCC compared to either of its gasification processes.

The transport reactor is a high-velocity reactor that processes pulverized solid fuel generally in the presence of calcium-based sorbent such as limestone which acts as a sulfur removal agent. The pulverized feeds and high velocity result in very rapid reaction rates requiring much smaller reactors than other fluid-bed systems. Typically, the velocity ranges from 20-40 fps, and high combustion efficiency is achieved by recycling a large flow of solids through the reactor. In combustion mode, the reactor operates in the $815^{\circ}-870^{\circ} \mathrm{C}$ $\left(1500^{\circ}-1600^{\circ} \mathrm{F}\right)$ temperature range where the sulfur sorbent is most effective. The relatively low operating temperature avoids ash slagging and permits effective use of the sulfur sorbent.

Kellogg has used the transport reactor concept in the design of many fluid-bed catalytic cracking (FCC) units, which are the workhorses of the modern petroleum refinery. The features of the transport gasifier and combustor are based upon Kellogg's extensive experience in design and operation of FCC units. A paper describing the development of the PCCC based upon this FCC experience is in the vendor appendix. 


\section{INTEGRATED GASIFICATION COMBINED-CYCLE SYSTEMS}

Gasification technologies recommended for Maritsa lignite included the following systems: 1) the Shell dry-ash entrained-flow gasifier; 2) fluidized bed gasifiers offered by IGT/Tampella (U-Gas), Uhde-GmbH (HTW), and Kellogg (the transport gasifier); and 3) the fixed-bed dry-ash Lurgi gasifier being used by the Dakota Gasification Company to produce synthetic natural gas (SNG) from North Dakota lignite. The British Gas Lurgi (BGL) slagging fixed-bed gasifier was not recommended by Lurgi for Maritsa lignite, although tests on North Dakota lignite in a 1-ton/hr pilot-scale gasifier at the EERC had been quite successful. The vendors contacted did not recommend the slurry-fed entrained-flow gasifiers, Texaco (now GE) or Destec (now ConocoPhilips), because of the high oxygen demand and energy penalty associated with high moisture and ash contents.

\section{MASS AND ENERGY CALCULATIONS FOR RECOMMENDED GASIFIERS}

Effects of coal moisture, ash, and sulfur calculated for the recommended gasifiers, including fixed-bed, fluidized-bed, and entrained-flow designs, are summarized below. Calculations were performed by varying the coal analysis in reference to a baseline analysis for Maritsa East lignite containing 57\% moisture, 35\% ash db (dry basis), and 5.9\% sulfur maf (moisture- and ash-free). Base-case operating conditions and product gas compositions for different gasifier designs were adapted from literature sources and EERC equilibrium calculations. Hydrogen, carbon, oxygen, nitrogen, sulfur, and ash were mass-balanced in all calculations.

\section{The Calculated Effects of Coal Moisture Content}

- For a dry-feed, oxygen-blown, entrained-flow gasifier (Shell), the calculated heating value of the raw product gas falls below $100 \mathrm{Btu} / \mathrm{scf}$ above $45 \%$ coal moisture. Oxygen demand is increased by about $50 \%$ as coal moisture increases from $5 \%$ to $45 \%$. Since it is far more economical to dry the coal using low-grade heat outside of the gasifier than to supply additional oxygen, the upper economic limit on coal moisture was estimated to be $5 \%$ to $10 \%$.

- In oxygen-blown fluidized-bed gasifiers (Kellogg, U-Gas and HTW), the sensitivity to coal moisture content is less than that for the entrained-flow case. For the oxygen-blown case, the calculated heating value of the raw gas falls below $100 \mathrm{Btu} / \mathrm{scf}$ at coal moisture contents above about $50 \%$. Oxygen demand is lower overall than for the entrained-flow case, and increases by only about $12 \%$ between $0 \%$ and $20 \%$ coal moisture. Drying to $20 \%$ coal moisture may represent an economic optimum. The steam requirement of the gasifier is theoretically reduced to zero at $25 \%$ coal moisture. In an air-blown fluidized-bed gasifier, coal moisture is limited to about $18 \%$ to achieve a minimum gas heating value of $100 \mathrm{Btu} / \mathrm{scf}$.

- The limiting effect of coal moisture in a Lurgi-type dry-ash fixed-bed gasifier is determined by the exit gas temperature, which drops below a practical lower limit of about $200^{\circ} \mathrm{C}$ at $36 \%$ 
coal moisture. The Dakota Gasification Great Plains Plant operating on U.S. North Dakota lignite was designed for a coal moisture content of $34 \%$. Over the entire range of coal moisture, the oxygen and steam requirements remain essentially unchanged, and the raw gas heating value is reduced only by the diluting effect of the moisture. The Lurgi gasifier requires a high stream rate regardless of coal moisture. The stable operating characteristics of a fixed-bed gasifier make it more forgiving of variations in coal quality and less sensitive to turndown. Applicability to lignite depends on the adequate strength of coal particles to support the moving bed, or for friable coal, on the feasibility of producing a strong briquette.

\section{The Calculated Effects of Coal Ash Content}

- Characteristic heat losses in ash or slag at $40 \%$ ash content are calculated to be $1.1 \%, 2.3 \%$, and $3.2 \%$ for fixed-bed, fluidized-bed, and entrained-flow gasifiers, respectively, reflecting differences in ash/slag discharge temperatures. These losses may be reduced if heat is recovered. However, the effect of ash content on the mass and energy balances also depends on the associated moisture content. For a dry-feed, oxygen-blown, entrained-flow gasifier (Shell) operating on lignite with $57 \%$ coal moisture, the raw gas heating value is reduced from 102 to $43 \mathrm{Btu} / \mathrm{scf}$ over the range of $0 \%$ to $40 \%$ ash, while oxygen requirement is increased by $31 \%$. This adverse impact of ash is attributed to the moisture associated with the added ash. By comparison, the effect of ash at $0 \%$ moisture is slight; the gas heating value is reduced from 291 to $279 \mathrm{Btu} / \mathrm{scf}$, and the oxygen requirement increases by only $7 \%$.

- An even greater adverse impact of high ash content may be experienced in a fluidized-bed gasifier if the carbon loss increases along with ash content as reported for Czech coals (Gavor, J.; Vanek, F.; Kadrnozka, J. "IGCC - One of the Possibilities of Czechoslovak Coal Resources Utilization," In Proceedings of the Energy and Environment: Transitions in Eastern Europe Conference; EERC publication, 1992, pp 565-579). Based on experimental data for five coals, the percentage of unburned carbon in the ash solids increased linearly with coal ash contents from $10 \%$ carbon in ash solids at $5 \%$ ash to $30 \%$ carbon in ash solids at $23 \%$ ash. Based on this linear correlation, the calculated heat loss in ash plus unconverted carbon (including the heating value in the lost carbon) was increased from zero to $44 \%$ of the coal heating value at coal ash contents between $0 \%$ and $35 \%$. Gavor reported $36 \%$ heat loss at $23 \%$ coal ash content for a different set of conditions. The gasification of high-ash coal would not be feasible under these circumstances. Compensating operational changes in gasification temperatures and recycle rates should be capable of offsetting these unacceptably high carbon losses.

\section{The Calculated Effects of Coal Sulfur Content}

- The concentration of $\mathrm{H}_{2} \mathrm{~S}$ in the moist raw product gas is calculated to increase from 0 to 32,000 ppmv between $0 \%$ and $10 \%$ sulfur (dry ash free basis) for a dry-feed, oxygen-blown, entrained-flow gasifier (Shell) operated on lignite dried to $10 \%$ moisture content. Comparable values would be calculated for other types of gasifiers. The heating value of the $\mathrm{H}_{2} \mathrm{~S}$, which is substantially lost in gas cleaning, ranges upward to about $8 \%$ of the raw gas heating value. Higher percentages of gas heating value would be lost at higher coal moisture contents and other conditions involving higher oxygen rates and lower gas heating values. 


\section{INFORMATION PROVIDED BY GASIFIER VENDORS}

The information presented below was either provided by the vendor for the Bulgarian study or was taken from reports published by the vendor.

\section{The Shell Gasifier System}

- The Shell gasification and cold-gas-cleaning system described by the vendor consists of a dryfeed, oxygen-blown, entrained-flow gasifier followed by a syngas cooler, wet scrubber, and coldacid gas absorption unit. This configuration was demonstrated on Texas lignite at a capacity of 400 short tons/day where it achieved a carbon conversion of $99.77 \%$, a cold-gas efficiency of $80.3 \%$ (HHV), and a total energy recovery (gas plus steam) of $95.7 \%$. Sulfur control of $99 \%$ can be achieved with conversion to salable sulfur. Hot-gas cleanup is estimated to improve efficiency by 1.3 percentage points. A $250-\mathrm{MW}$ IGCC plant based on Shell technology has been operated successfully by Demkolec in the Netherlands since 1994 on bituminous coal.

- The principal advantage of the Shell gasifier for Bulgarian lignite is the dry coal feed, which allows thermally dried coal to be fed without reabsorbing water in a slurry preparation step. This feature is shared by the Prenflow entrained-flow gasifier that will be used at a 335-MWe plant planned at Puertollano, Spain. With cold-gas cleaning, these technologies provide a medium-Btu gas that would permit conversion from natural gas to coal gas with reasonable modifications. The high gasifier exit temperature of $1371^{\circ} \mathrm{C}\left(2500^{\circ} \mathrm{F}\right)$ makes this technology less attractive for IGCC designs incorporating hot/warm gas sulfur removal because of the substantial gas cooling required.

- Shell provided material balances for Maritsa East lignite covering four areas: 1) coal milling and drying, 2) gasification, 3) wet scrubbing, and 4) gas and water treatment. The lignite is first pulverized and dried to $5 \%$ moisture and then fed to the gasifier at a $\mathrm{O}_{2} / \mathrm{C}$ mole ratio of 0.283 (lower than the 0.44 ratio calculated by the EERC for Maritsa East lignite or the 0.42 value given for Texas lignite in an EPRI reference (Simbeck, D.R.; Korens, N.; Biaska, F.E., Vejtasa, S.; Dickenson, R.L. "Coal Gasification Guidebook: Status, Applications, and Technologies," final report, EPRI, TR-102034, Dec. 1993). Raw product gas at 110 bar is cooled to $235^{\circ} \mathrm{C}$ in the syngas steam generator and then wet-scrubbed to $40^{\circ} \mathrm{C}$. The cold-gas efficiency is calculated to be $89.8 \%$ based on the coal lower heating value, or $73.1 \%$ based on coal higher heating value.

\section{The Tampella/U-Gas Gasification Process}

- The U-Gas gasification process was developed by IGT in the United States and licensed to Tampella Corporation in Finland for commercialization in U.S. and European markets. The UGas process feeds dried and crushed coal $(25 \%$ moisture sized to $1 / 4$ in. $\times 0)$ through a lock hopper to a PFB gasifier that incorporates a hot ash-agglomerating zone. Normal operating conditions are $871^{\circ} \mathrm{C}\left(1600^{\circ} \mathrm{F}\right)$ and $290 \mathrm{psig}(20 \mathrm{~atm})$. Operation has been demonstrated with both oxygen and air. No steam is required for lignite, owing to the moisture remaining in the dried lignite feed. Ash agglomerates are discharged in an essentially nonleachable vitrified form through a countercurrent heat exchanger where they are cooled to $469^{\circ} \mathrm{C}\left(1200^{\circ} \mathrm{F}\right)$ with 
increasing gas. The high-temperature agglomerating zone provides a higher carbon conversion (e.g., 95\%) with lower external char recycle than does conventional fluidized-bed gasification.

- IGT identified no special problems using Bulgarian lignites. Provisions for dry coal feed, char recycle, and ash discharge were deemed satisfactory. Hot-gas cleanup for particulates and sulfur have been investigated by IGT and Tampella, including limestone addition for in-bed sulfur removal. The raw gas heating value of $111 \mathrm{Btu} / \mathrm{scf}$ calculated by IGT for air-blown gasification of lignite dried to $25 \%$ was higher than that calculated by EERC for a generic fluidized-bed gasifier (92 Btu/scf). However, further EERC calculations for the conditions given by IGT confirmed that the higher value of gas heating value was attributable to higher carbon conversion (95\% to 90\%), higher air temperature, and lower exit temperatures for product gas and ash.

\section{The Kellogg Transport Reactor Gasification Process}

- Kellogg offers two gasification technologies: the KRW process and the new transport reactor process. The Kellogg response was limited to evaluation of the transport reactor process on the premise that its ability to retain almost all of the coal energy in the product gas (absent the use of a waterwall design) provides the best hope of gasifying run of mine lignite at $57 \%$ moisture content.

- The transport reactor design feeds highly crushed coal into a high-velocity fluidized bed operating at a velocity of 20 to $40 \mathrm{ft} / \mathrm{sec}(6.1$ to $12.2 \mathrm{~m} / \mathrm{sec})$. High carbon conversion is achieved by recycling solids back into the reactor and operating at a gasifier temperatures that matches the reactivity of the coal, between $927^{\circ}$ to $1038^{\circ} \mathrm{C}\left(1700^{\circ}\right.$ to $\left.1900^{\circ} \mathrm{F}\right)$. The transport reactor concept is adapted from the proven design used for fluidized-bed catalytic cracking units used in the petroleum industry. Development for coal conversion has been confirmed at a scale of 2.4 tons/day at the EERC, and construction was started in 1995 on a 38-ton/day pilot unit at the Wilsonville Power Systems Development Facility (PSDF). The PSDF as of 2009 has been successfully run on numerous coals including North Dakota lignite, and it has performed well on high ash/high moisture coals. The transport gasifier will be used by Southern Company in the construction of the 550 MW Kemper County IGCC plant scheduled to begin operation on Mississippi lignite in 2013.

- Kellogg's calculations for the transport reactor process indicate that oxygen-blown gasification of run-of-mine Maritza lignite would produce a raw product gas with a heating value of only $70 \mathrm{Btu} / \mathrm{scf}$ (confirmed by EERC calculations). Kellogg calculations for air-blown gasification at $10 \%$ and $20 \%$ moisture indicated heating values of 78 and $75 \mathrm{Btu} / \mathrm{scf}$, which are lower than the values calculated by EERC for a generic air-blown fluidized-bed gasifier. These calculations indicate that gasification of run-of-mine Maritsa lignite would not be practical. EERC calculations suggest that either oxygen-blown or air-blown gasification of dried lignite should be acceptable. The transport reactor design offers unique advantages in designing IGCC systems at minimum cost owing to its compact design and potential for achieving high conversions by recycling char and coal fines. 


\section{The High-Temperature Winkler (HTW) Process}

- Uhde $\mathrm{GmbH}$ together with Rheinbraun AG and Lurgi $\mathrm{GmbH}$ has developed the fluidized-bed HTW process in Germany for both 1) a 10-bar oxygen-blown bubbling-bed design generating synthesis gas for methanol production from 720 tons/day of dried brown coal and 2) a 25-bar design using either air or steam/oxygen as the gasification agent for IGCC applications. The IGCC design, which can be either a bubbling or a circulating bed, by 1995 had been operated at pilot plant scale for $9500 \mathrm{hr}$ at a throughput rate of 160 tons/day. An air-blown circulating fluidized-bed HTW gasifier design is being used for the 355-MW Kobra IGCC plant under construction in Hürth, Germany.

- Uhde provided a detailed discussion of HTW design parameters and calculated material and energy balances for Maritsa East and Sofia lignites. Lignite dried to nominally $12 \%$ moisture content is fed through a lock hopper system to the lower fluidized zone of the gasifier operation at $850^{\circ} \mathrm{C}$. Gasification agent (air or steam/oxygen) is admitted both to the lower zone and to the above-bed freeboard to gasify entrained carbon at approximately $940^{\circ} \mathrm{C}$. Entrained solids leaving in the raw product gas are separated in a cyclone and fed by gravity back into the gasifier. Ash is withdrawn from the bottom of the gasifier and fed to a moving-bed cooler. No particular problems were identified in using Bulgarian lignites in the HTW gasifier. Coal is crushed to a grain size by 4-mm maximum with fines retained in the coal feed. Beneficiation to reduce ash content is not recommended. Design measures are described for preventing ash and slag deposits in the gasifier system. High ash content is indicated to result in a lower cold efficiency, estimated to be $68 \%$ to $70 \%$ for Bulgarian lignites versus $76 \%$ for German Rhenish brown coal. A dry gas heating value of $129 \mathrm{Btu} / \mathrm{scf}$ is indicated for air-blown gasification of Rhenish brown coal, compared to $271 \mathrm{Btu} / \mathrm{scf}$ for oxygen gasification. Similar values were obtained in EERC calculations for Maritsa East lignite dried to $12 \%$ moisture.

- Both cold-gas and hot-gas cleaning systems were described for the HTW gasifier. The cold-gas case includes 1) gas cooling to $260^{\circ} \mathrm{C}$ in a high-pressure steam generator; 2) particulate filtration using ceramic candle filters; 3 ) wet scrubbing for removal of alkalies, chlorides, and other trace contaminants; 4) hydrolysis of $\mathrm{COS}$ and $\mathrm{H}_{2} \mathrm{~S} ; 5$ ) desulfurization using a selective process leaving $\mathrm{CO}_{2}$ in the gas stream; and 6) final humidification and pretreating. The proposed hot-gas cleaning system, which had not been commercially proven, incorporated 1) cooling to $650^{\circ} \mathrm{C}$, 2) particulate filtration, 3) treatment in a limestone/dolomite fixed bed for removal of alkalies and heavy metals, 4) metal-oxide desulfurization, and 5) final particulate filtration. The retention of $\mathrm{NH}_{3}$ in the treated gas (absent a water scrubber) is identified as a problem affecting $\mathrm{NO}_{\mathrm{x}}$ emissions. 